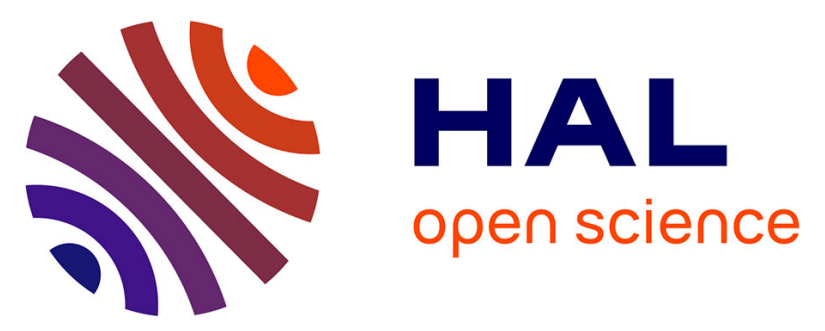

\title{
Nanostructured electrodes for electrocatalytic advanced oxidation processes: From materials preparation to mechanisms understanding and wastewater treatment applications
}

Xuedong Du, Mehmet Oturan, M. Zhou, Nacer Belkessa, P. Su, Jingju Cai, Clément Trellu, Emmanuel Mousset

\section{To cite this version:}

Xuedong Du, Mehmet Oturan, M. Zhou, Nacer Belkessa, P. Su, et al.. Nanostructured electrodes for electrocatalytic advanced oxidation processes: From materials preparation to mechanisms understanding and wastewater treatment applications. Applied Catalysis B: Environmental, 2021, 296, pp.120332. 10.1016/j.apcatb.2021.120332 . hal-03261468

\author{
HAL Id: hal-03261468 \\ https://hal.science/hal-03261468
}

Submitted on 18 Nov 2021

HAL is a multi-disciplinary open access archive for the deposit and dissemination of scientific research documents, whether they are published or not. The documents may come from teaching and research institutions in France or abroad, or from public or private research centers.
L'archive ouverte pluridisciplinaire HAL, est destinée au dépôt et à la diffusion de documents scientifiques de niveau recherche, publiés ou non, émanant des établissements d'enseignement et de recherche français ou étrangers, des laboratoires publics ou privés. 
Nanostructured electrodes for electrocatalytic advanced oxidation

processes: from materials preparation to mechanisms

understanding and wastewater treatment applications

Xuedong DU ${ }^{1}$, Mehmet A. OTURAN ${ }^{1,2, *}$, Minghua ZHOU ${ }^{1, *}$, Nacer BELKESSA ${ }^{3}$, Pei SU ${ }^{1}$, Jingju CAI ${ }^{1}$, Clément TRELLU ${ }^{2}$, Emmanuel MOUSSET $^{3, *}$

${ }^{1}$ Key Laboratory of Pollution Process and Environmental Criteria, Ministry of Education, College of Environmental Science and Engineering, Nankai University, Tianjin 300350, China

${ }^{2}$ Université Gustave Eiffel, Laboratoire Géomatériaux et Environnement (EA 4508), UPEM, 77454, Marne-la-Vallée, France

${ }^{3}$ Laboratoire Réactions et Génie des Procédés, Université de Lorraine, CNRS, LRGP, F-54000 Nancy, France

\section{ACCEPTED IN}

APPLIED CATALYSIS B: ENVIRONMENTAL JOURNAL

* Corresponding authors' Emails: mehmet.oturan@univ-eiffel.fr (Mehmet A. Oturan), zhoumh@nankai.edu.cn (Minghua Zhou), emmanuel.mousset@univ-lorraine.fr (Emmanuel Mousset) 


\section{Abstract}

2 The implementation of nanostructured materials in electrochemistry implied the enhancement

3 of conversion yield in fuel cell, in electrosynthesis of oxidants and electrolytic treatment for environmental protection, while it allowed reducing the detection limit in electroanalysis.

5 Nanostructured materials are becoming a hot topic of research, especially in electrochemical 6 treatment for environmental applications that is strongly related to the rise of graphene and 7 subsequent 2D materials that emerged in the last ten years. Nano-structuration allows bringing new properties of the materials such as number of active sites and conductivity improvement. It can therefore enhance the heterogeneous catalysis mechanism at electrode surface. This is primordial since it makes increase the rate of electrochemical reactions that can be the rate limiting steps in electrocatalytic treatment. Such advanced materials contribute to make advanced electrochemical processes as "greener" processes than the conventional ones. This paper aims to be a comprehensive, critical, and accessible review of general interest. The literature covers mainly the last ten years' period due to the recent topic, especially the last five years with the considerable increase of number of publications in this period. The contents particularly devote efforts to establish links between the nanostructured-based electrode properties and electrochemical treatment efficiency through the mechanisms involved. The perspectives about mechanisms understanding and electrodes stability improvement are especially discussed.

Keywords: Nanostructured electrodes; electrooxidation; Electro-Fenton; Oxygen reduction reaction, Oxygen evolution reaction, Wastewater treatment 
List of abbreviations................................................................................................................... 5

2. General electrocatalytic mechanisms

\section{Preparation and characterization of nanostructured-based electrodes 14}

3.1. Preparation methods

3.1.1. Cathode materials

3.1.1.1. Polymeric precursor method for metal oxide supported on carbon materials. 15

3.1.1.2. Hydrothermal functionalization for the heteroatoms-doped carbon

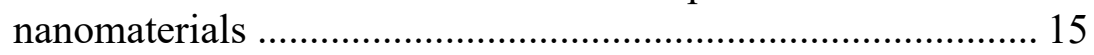

3.1.1.3. Plasma discharge treatment for nanostructured preparation ......................... 16

3.1.1.4. Electrochemical exfoliation synthesis of graphene followed by ink-coating

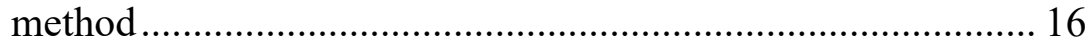

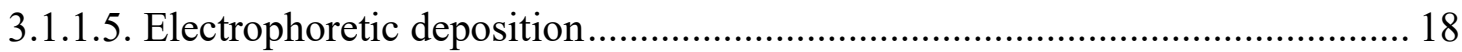

3.1.1.6. Microemulsion and co-precipitation to prepare bi metallic nanoparticles and mixed metal oxides nanostructures ........................................ 18

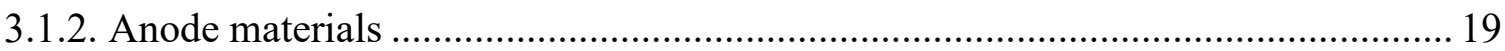

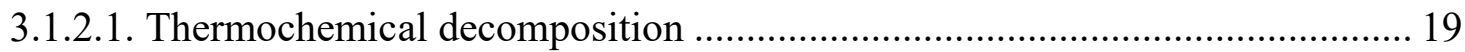

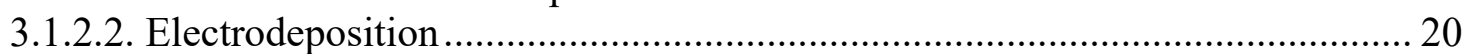

3.1.2.3. CVD

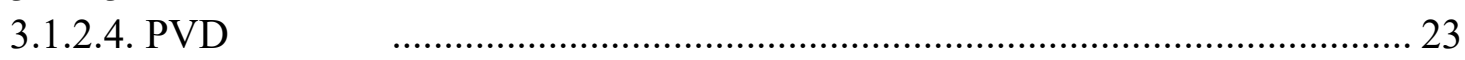

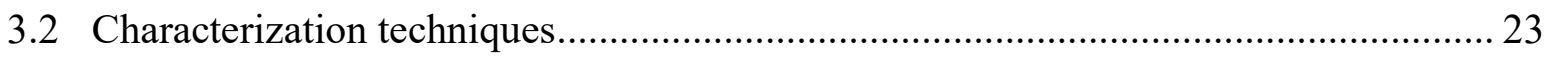

4. Nanostructured-based electrode properties ...............................................................30

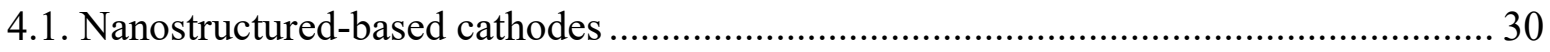

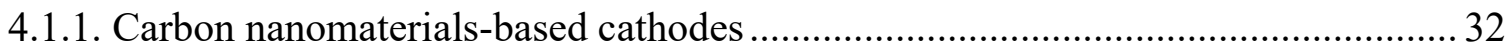

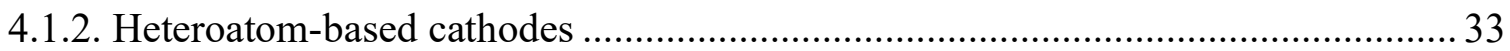

4.1.3. Metal- and metal-oxide based cathodes ............................................................... 34

4.1.4. Mixed metal / metal oxide and carbon-based cathodes ......................................... 35

4.1.5. General requirement for cathode characteristics and operating conditions ............ 36

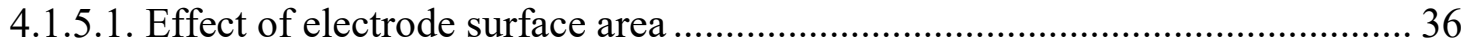

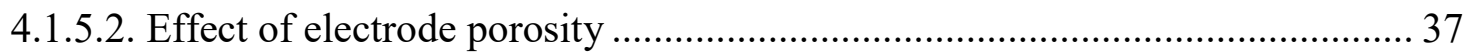

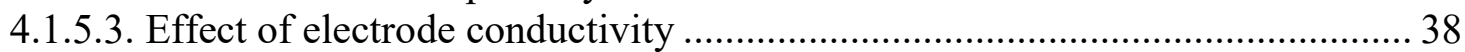

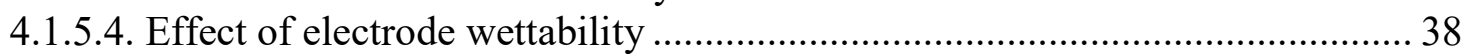

4.1.5.5. Effect of surface composition................................................................... 39

4.1.5.6. Effect of cathode potential / current density and $\mathrm{H}_{2}$ evolution overvoltage.... 41

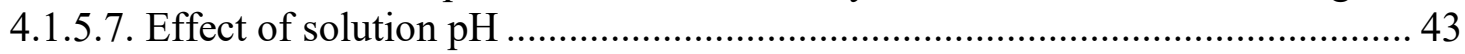

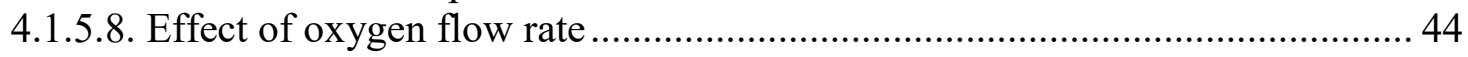

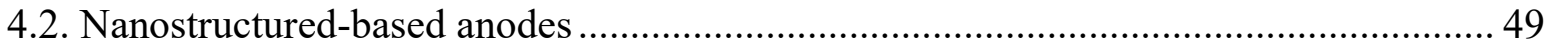


4.2.1. General requirement for anode characteristics.

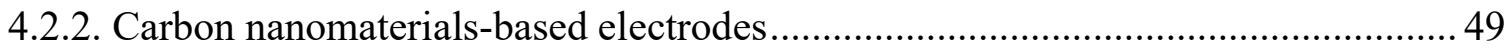

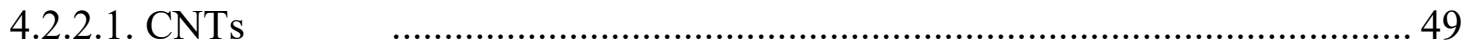

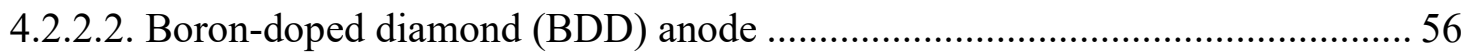

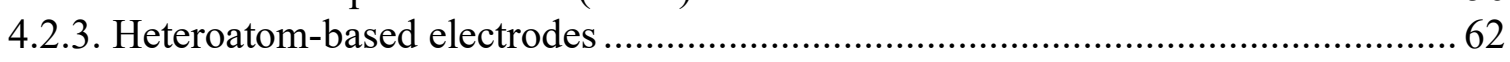

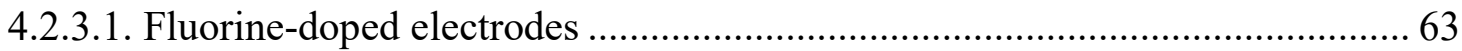

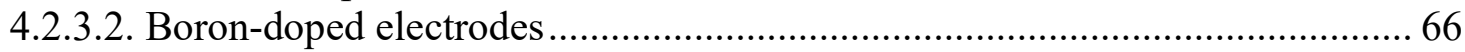

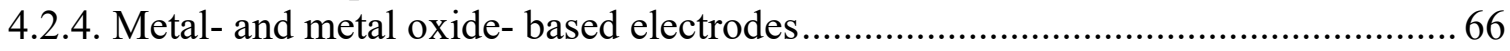

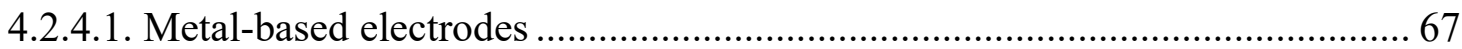

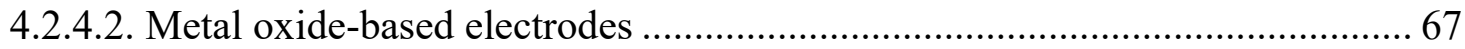

4.2.5. Mixed metal- / metal-oxide and carbon-based electrodes ..................................... 72

5 Assessment of electrodes performance in water/wastewater treatment ................... 73

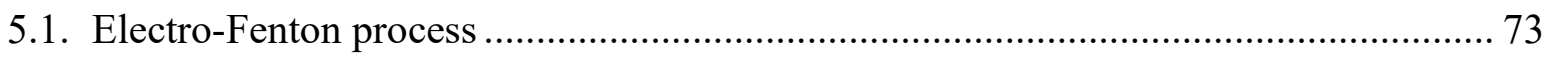

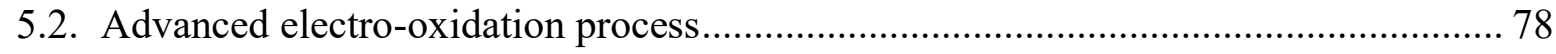

5.3. Solar/artificial light induced photo-electrocatalytic processes ................................... 85

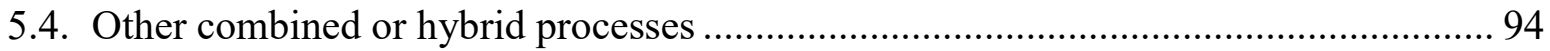

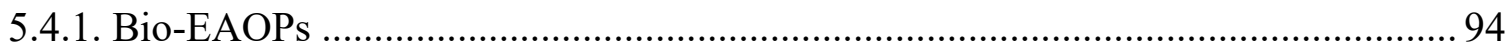

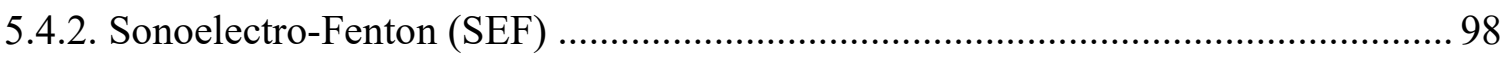

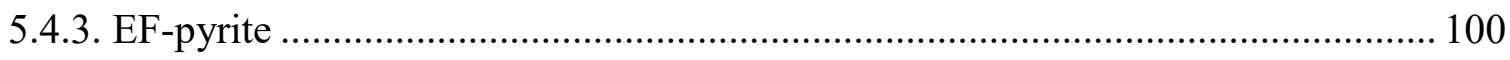

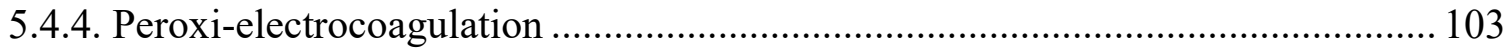

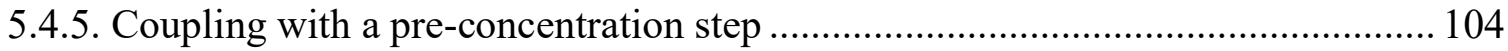

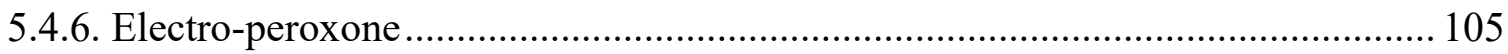

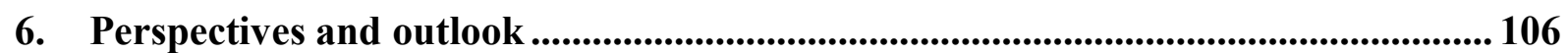

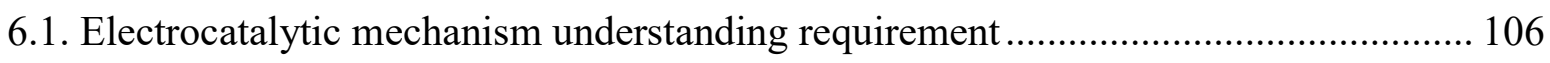

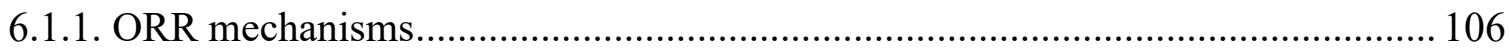

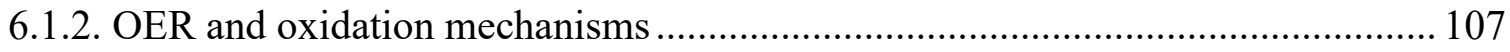

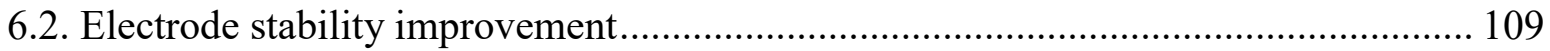

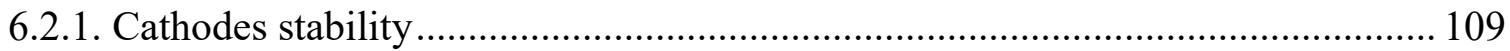

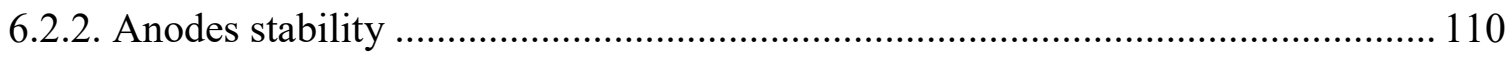

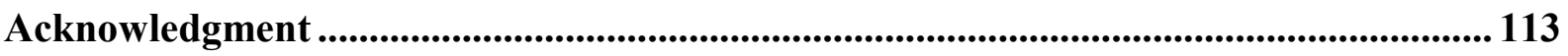

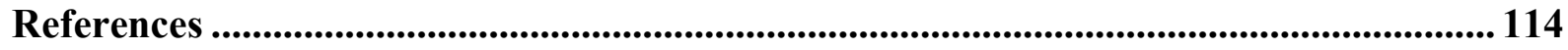




\begin{tabular}{|c|c|}
\hline Abbreviation & Definition \\
\hline $3 \mathrm{D}$ & Three-dimensional \\
\hline $\mathrm{ACF}$ & Activated carbon fiber \\
\hline AFM & Atomic force spectroscopy \\
\hline AHPS & 4-amino-3-hydroxy-2-p-tolylazo-naphthalene-1-sulfonic acid \\
\hline $\mathrm{ANC}$ & Activated N-doped carbon \\
\hline AOPs & Advanced oxidation processes \\
\hline AR 73 & Acid Red 73 \\
\hline ATZ & Atrazine \\
\hline AY1 & Acid Yellow 1 \\
\hline BDD & Boron-doped diamond \\
\hline BDDNW & BDD nanowire \\
\hline BET & Brunauer-Emmett-Teller \\
\hline Blue-TNAs & Blue $\mathrm{TiO}_{2}$ nanotube arrays (Blue-TNAs) \\
\hline $\mathrm{BOD}_{5}$ & Biochemical oxygen demand after 5 days \\
\hline $\mathrm{CF}$ & Carbon felt \\
\hline CHE & Computational hydrogen electrode \\
\hline CNT & Carbon nanotube \\
\hline COD & Chemical oxygen demand \\
\hline CPET & Coupled proton-electron transfers \\
\hline $\mathrm{CV}$ & Cyclic voltammetry \\
\hline DFT & Density-functional theory \\
\hline DO & Dissolved oxygen \\
\hline DSA & Dimensionless stable anode \\
\hline EAOPS & Electrochemical advanced oxidation processes \\
\hline EDX & Energy-dispersive X-ray spectroscopy \\
\hline EEGr & Electrochemically exfoliated graphene \\
\hline $\mathrm{EF}$ & Electro-Fenton \\
\hline EIS & Electrochemical impedance spectroscopy \\
\hline FTIR & Fourier-transform infrared spectroscopy \\
\hline FTO & Fluorine-doped tin oxide \\
\hline
\end{tabular}




\begin{tabular}{|c|c|}
\hline $\mathrm{GC}$ & Glassy carbon \\
\hline GDE & Gas diffusion electrode \\
\hline GF & Graphite felt \\
\hline HARN & High aspect ratio nanostructures \\
\hline HER & Hydrogen evolution reaction \\
\hline HFs & Hierarchical flower-like structure \\
\hline HPCS-S & Hollow porous carbon sphere-sulfur composite \\
\hline h-PEF & Heterogeneous photo-electro-Fenton \\
\hline LSV & Linear sweep voltammetry \\
\hline MCE & Mineralization current efficiency \\
\hline $\mathrm{MeOH}$ & Methanol \\
\hline MMO & Mixed metal oxide \\
\hline MNC & Mesoporous N-doped carbon \\
\hline MO & Methyl orange \\
\hline MOF & Metal organic framework \\
\hline MWCNTs & Multi-walled carbon nanotubes \\
\hline NADE & Natural air diffusion electrode \\
\hline NB & nitrobenzene \\
\hline NCNT & N-doped multi-walled carbon nanotube \\
\hline NF & Nickel foam \\
\hline $\mathrm{N} / \mathrm{F}-\mathrm{CNC}$ & Nitrogen/fluoride co-doped carbon nanocages \\
\hline NP & Nanoparticle \\
\hline NS & Not specified \\
\hline NTs & Nanotubes \\
\hline NTA & Nanotube arrays \\
\hline TNTs & $\mathrm{TiO}_{2}$ nanotubes \\
\hline OEP & Oxygen evolution potential \\
\hline OER & Oxygen evolution reaction \\
\hline ORR & Oxygen reduction reaction \\
\hline PAN & Polyacrylonitrile \\
\hline PANI & Polyaniline \\
\hline $\mathrm{PC}$ & Photocatalysis \\
\hline PEC & Photoelectrocatalysis \\
\hline
\end{tabular}




$\begin{array}{ll}\text { PEF } & \text { Photoelectro-Fenton } \\ \text { PFOA } & \text { Perfluorooctanoic acid } \\ \text { ppi } & \text { Pores per inch } \\ \text { PPM } & \text { Polymeric precursor method } \\ \text { PTFE } & \text { Polytetrafluoroethylene } \\ \text { PVD } & \text { Physical vapor deposition } \\ \text { Rct } & \text { Charge transfer resistance } \\ \text { Rd } & \text { Dynamic resistance } \\ \text { REM } & \text { Reactive electrochemical membrane } \\ \text { RGO } & \text { Reduced graphene oxide } \\ \text { RHE } & \text { Reversible hydrogen electrode } \\ \text { ROS } & \text { Reactive oxygen species } \\ \text { RVC } & \text { Reticulated vitreous carbon } \\ \text { SBET } & \text { BET specific surface area } \\ \text { SBR } & \text { Sequencing batch reactor } \\ \text { SCE } & \text { Saturated calomel electrode } \\ \text { SEM } & \text { Scanning electron microscopy } \\ \text { SDBS } & \text { Sodium dodecyl benzene sulfonate } \\ \text { SHE } & \text { Standard hydrogen electrode } \\ \text { SS } & \text { Stainless steel } \\ \text { SWNTs } & \text { Single-walled carbon nanotubes } \\ \text { TBA } & \text { Tert-butyl alcohol } \\ \text { TEM } & \text { Transmission electron microscopy } \\ \text { TNA } & \text { Nanotube array } \\ \text { TGA } & \text { Thermal gravimetric analysis } \\ \text { TiOx } & \text { Sub-stoichiometric TiO } 2 \\ \text { TOC } & \text { Total organic carbon } \\ \text { XPS } & \text { X-ray photoelectron spectroscopy } \\ \text { XRD } & \text { X-ray diffraction } \\ & \end{array}$




\section{Introduction}

Nanostructure materials have been widely developed, particularly in the last ten years, with the rise of graphene - $\mathrm{sp}^{2}$-hybridized carbon atoms arranged in a honeycomb structure - and associated Nobel prize attribution in 2010 , and subsequent equivalent 2D materials as well as graphene-based materials $[1,2]$. Due to their ability to modify the raw material properties such as the electric and thermal conductivity, surface area, gas permeability as well as mechanical resistance, their implementation in electrochemistry area as electrode material became obvious [3]. It is important to note that nanostructured materials can be extended to nanostructured electrochemical interfaces that are usually encounter for example through defects and pinholes in self-assembled monolayers or catalytic nanoparticles spread throughout less reactive substrate [4].

In parallel, for more than 20 years, electrochemical applications for environmental protection especially in wastewater gained a considerable interest $[5,6]$. Those based on the generation of very strong oxidizing agents such as hydroxyl radical $\left({ }^{\circ} \mathrm{OH}\right)\left(\mathrm{E}^{0}\left({ }^{\circ} \mathrm{OH} / \mathrm{H}_{2} \mathrm{O}\right)=2.80 \mathrm{~V} / \mathrm{SHE}\right)$, namely electrochemical advanced oxidation processes (EAOPs), have shown impressive efficiency [7-13]. They have the ability to generate continuously and in situ the reactive agents in order to remove partially or completely - according to the treatment strategy [14] - a wide variety of organic pollutants, especially the most biorecalcitrant ones present either at high concentration (chemical oxygen demand $(\mathrm{COD})=1-100 \mathrm{~g}-\mathrm{O}_{2} \mathrm{~L}^{-1}$ ) or very low concentrations (i.e. micropollutant concentration in the range of $n g \mathrm{~L}^{-1}$ to $\mu \mathrm{g} \mathrm{L}^{-1}$ ) [15-24]. Still, the possibility to improve their performance by incorporating nanostructured materials for both cathode and anode has been tested in the last decades. The promise of improvement came up with numerous studies on this specific topic with an increasing number without having an overview that could help giving some requirement and directions based on a critical literature review. 
There are existing reviews on nanostructured carbon-based materials for some electrochemical

124 applications, but mainly for fuel cell, water splitting and electro-analysis [4,25-31]. There are

125

126

127 also few reviews on electrocatalytic treatments but the use of nanostructured electrode materials is not developed at all $[5,7-9,11,14,22,32-35]$. Thus, there is no detailed and systematic review on nanostructured (carbon-based, metallic-based) electrodes for EAOPs applications. Indeed, electrolytic treatment is implemented in EAOPs by applying current in order to make evolve non-spontaneous reactions. Contrastingly, spontaneous reactions are involved in fuel cell and microbial fuel cells systems to generate electrical energy. It means that the properties required for electrode materials are not the same in EAOPs and fuel cells, especially in terms of electrode potential and overvoltage requirements. Focusing only on electrocatalytic treatments is therefore a way to be exhaustive and to bring a critical overview on existing nanostructured materials and what could be the new insights required to improve the performance of such materials in terms of specific surface area, charge transfer kinetics, number of low-coordinated sites, quantum confinement, etc. [36].

This review intends to bring a synthetic and critical state of the art by screening the nanostructured electrode materials employed in electrocatalytic treatments that induce oxidative stress represented mainly by EAOPs, which excludes the other kinds of electrochemical processes such as fuel cells. As it is the first time that a detailed and exhaustive review is published on this topic, this review can further serve as a baseline in the targeted research area. The general electrolytic mechanisms involved at either cathode or anode materials are presented before exposing the main preparation routes and characterization techniques of the nanostructured materials. The properties obtained with these different kinds of materials are then reviewed in detail with added benefits of nano-structure, followed by the thorough presentation of their contribution in the EAOPs efficiency for wastewater treatment. 
147 Finally, perspectives and outlook are disclosed regarding the mechanism understanding requirement and electrode stability improvement.

\section{General electrocatalytic mechanisms}

\subsection{Two-electron oxygen reduction reaction (ORR) pathway}

152

153

The two-electron oxygen reduction reaction (ORR) pathway leads to the electrogeneration of hydrogen peroxide $\left(\mathrm{H}_{2} \mathrm{O}_{2}\right)$ at the cathode surface and involve adsorbed $* \mathrm{OOH}$ as intermediate species (Eq. 1) [25,37].

$\mathrm{O}_{2}+2 \mathrm{H}^{+}+2 \mathrm{e}^{-} \rightarrow{ }^{*} \mathrm{OOH}+\mathrm{H}^{+}+\mathrm{e}^{-} \rightarrow \mathrm{H}_{2} \mathrm{O}_{2}$

$\mathrm{E}^{0}=0.70 \mathrm{~V} / \mathrm{SHE}$

$\mathrm{H}_{2} \mathrm{O}_{2}$ is an interesting oxidant $\left(\mathrm{E}_{\left(\mathrm{H}_{2} \mathrm{O}_{2} / \mathrm{H}_{2} \mathrm{O}\right)}^{0}=1.76 \mathrm{~V} / \mathrm{SHE}\right)$ since it is a precursor for the production of a strong oxidizing agent, i.e., ${ }^{\circ} \mathrm{OH}\left(\mathrm{E}^{0}\left({ }^{\circ} \mathrm{OH} / \mathrm{H}_{2} \mathrm{O}\right)=2.80 \mathrm{~V} / \mathrm{SHE}\right)$, that are produced through Fenton reaction (Eq. 2) [7,38].

$\mathrm{Fe}^{2+}+\mathrm{H}_{2} \mathrm{O}_{2} \rightarrow \cdot \mathrm{OH}+\mathrm{OH}^{-}+\mathrm{Fe}^{3+}$

This radical is widely implemented in environmental applications, as it is the main species responsible for the degradation and mineralization of organic pollutant as well as inhibition of microorganisms present in wastewater, as detailed in section 5. Moreover, the in situ production of $\mathrm{H}_{2} \mathrm{O}_{2}$ offer a promising safer alternative compared to the use of Fenton's reagent $\left(\mathrm{H}_{2} \mathrm{O}_{2}+\right.$ $\mathrm{Fe}^{2+}$ ) since the storage of $\mathrm{H}_{2} \mathrm{O}_{2}$ is delicate due to its explosive nature [39]. The difficulties in involving the partial two-electron ORR is that the full four-electron ORR (Eq. 3) can also occur through either associative mechanism (Eqs. 4a-4d) or dissociative mechanism (Eqs. 5a-5c) by implementing adsorbed oxygenated intermediates species $(* \mathrm{OOH}, * \mathrm{O}$ and/or $* \mathrm{OH})$ at the cathode surface $\left(^{*}\right)[25,37,40]$. The contribution of associative versus dissociative pathway is depending on the kind of anode material employed and on the applied anodic potential [40]. 
$\mathrm{O}_{2}+4 \mathrm{H}^{+}+4 \mathrm{e}^{-} \rightarrow{ }^{*} \mathrm{OOH}+3 \mathrm{H}^{+}+3 \mathrm{e}^{-}$

$172{ }^{*} \mathrm{OOH}+3 \mathrm{H}^{+}+3 \mathrm{e}^{-} \rightarrow 2\left({ }^{*} \mathrm{O}+2 \mathrm{H}^{+}+2 \mathrm{e}^{-}\right)$

$173{ }^{*} \mathrm{O}+2 \mathrm{H}^{+}+2 \mathrm{e}^{-} \rightarrow{ }^{*} \mathrm{OH}+\mathrm{H}^{+}+\mathrm{e}^{-}$

174

${ }^{*} \mathrm{OH}+\mathrm{H}^{+}+\mathrm{e}^{-} \rightarrow \mathrm{H}_{2} \mathrm{O}$

$175 \quad 1 / 2 \mathrm{O}_{2}+* \rightarrow{ }^{*} \mathrm{O}$

$176{ }^{*} \mathrm{O}+\mathrm{H}^{+}+\mathrm{e}^{-} \rightarrow{ }^{*} \mathrm{OH}$

$177{ }^{*} \mathrm{OH}+\mathrm{H}^{+}+\mathrm{e}^{-} \rightarrow \mathrm{H}_{2} \mathrm{O}+*$

178 The generation of $\mathrm{H}_{2} \mathrm{O}$ is thermodynamically favorable, meaning that the selectivity towards 179 the two-electron instead of four-electron pathway is therefore an important key issue. This has 180 then an impact on the kinetics of Fenton reaction (section 6) to generate ${ }^{\circ} \mathrm{OH}$. The ORR pathway 181 has been widely studied in its four-electron way [25,40], which is mainly due to the fuel cell 182 studies that currently occupy an important research area in electrochemistry, especially for the 183 promising industrial applications in energy (e.g., $\mathrm{H}_{2}$ electrogeneration).

Still, two-electron ORR mechanism study could be find in literature. Thermodynamic analyses have been proposed as first attempt to predict the reaction feasibility, especially regarding the ORR selectivity. Density-functional theory (DFT) calculation permitted to estimate the free 187 energy $(\Delta \mathrm{G})$ describing the adsorption energies of intermediates (including solvated protons and electron) at material surfaces [41]. Using the computational hydrogen electrode (CHE) model [40], $\Delta \mathrm{G}$ could be drawn as function of reaction coordinate for two-electron ORR, as 190 shown in the diagram illustrated in Fig. 1a for $\mathrm{PtHg}_{4}$ material $[25,41]$. It highlights that at 0.70

V (i.e., equilibrium potential) the first reaction step is uphill, which makes difficult the reaction, 
while at $0.63 \mathrm{~V}$ it is easier and it corresponds to the limiting potential since it is the maximum potential value for which the steps are downhill.

In addition, the electron transfer is fast in ORR, so that it is usually not considered as the kinetic rate limiting step [25]. Generally, the adsorption of oxygen $\left(\mathrm{O}_{2}\right)$ on the cathode surface has been considered as the limiting step in literature, especially on carbon materials $[42,43]$. Deeper studies emphasized the fact that the formation or removal of ${ }^{*} \mathrm{OOH}$ intermediates species from the surface are the limiting steps in two-electron ORR [25] (Fig. 1a). Volcano plot allowed visualizing the optimal binding energy of intermediate $\left({ }^{*} \mathrm{OOH}\right)$ that need to be operated in order to have electrogeneration of $\mathrm{H}_{2} \mathrm{O}_{2}$ (Fig. 1b). This binding need to be not too strong (solid purple line) and not too weak (solid green line). Several materials have shown to correspond to this property such as Pt and Pd mercury alloys [41,44] as well as some carbon structures [45].

Beyond these thermodynamics data, it has been shown that parallel reactions 1 an $4 \mathrm{~b}$ interfere in the $\mathrm{H}_{2} \mathrm{O}_{2}$ selectivity $[41,46]$ :

It means that the $\mathrm{O}-\mathrm{O}$ bond dissociation from adsorbed ${ }^{\circ} \mathrm{OOH}$ should be avoided in order to favor $\mathrm{H}_{2} \mathrm{O}_{2}$ generation [25]. It further indicates that the catalyst must have weak oxygen binding energies to avoid ${ }^{\circ} \mathrm{O}$ formation [25]. Experimental data evidenced the selectivity towards $\mathrm{H}_{2} \mathrm{O}_{2}$ when using weak oxygen binding cathodes such as $\mathrm{Au}(111)$ [47] or carbon-based materials [48-51]. It is interesting to note that Au material does not thermodynamically favor the generation of $\mathrm{H}_{2} \mathrm{O}_{2}$, which is not in agreement with the laboratory results [25]. It means that the kinetics need also to be taken into account as highlighted in the free energy diagram for the two- and four-electron ORR on $\mathrm{Au}(111)$ in Fig. 1c. 
(a)

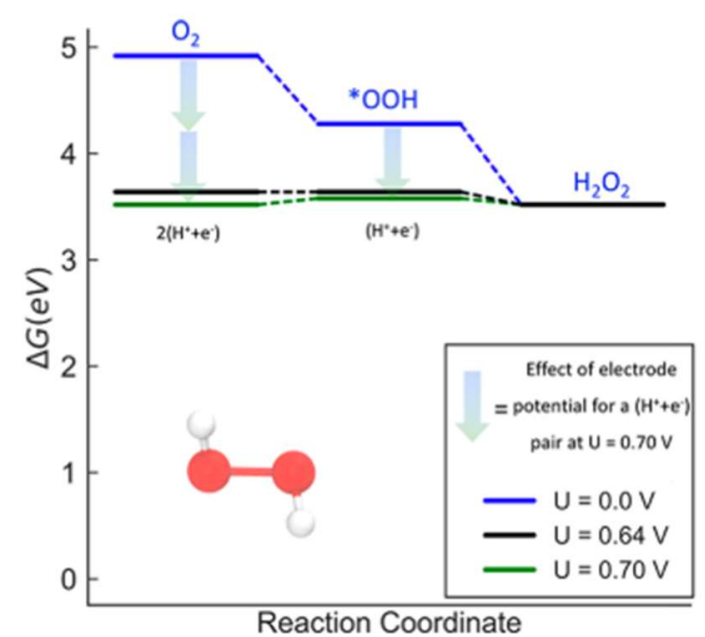

(b)

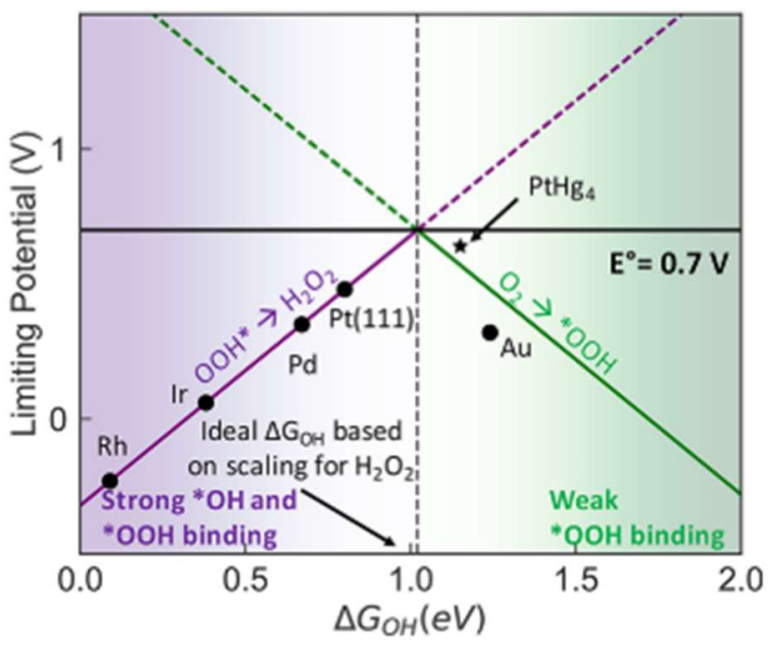

(c)

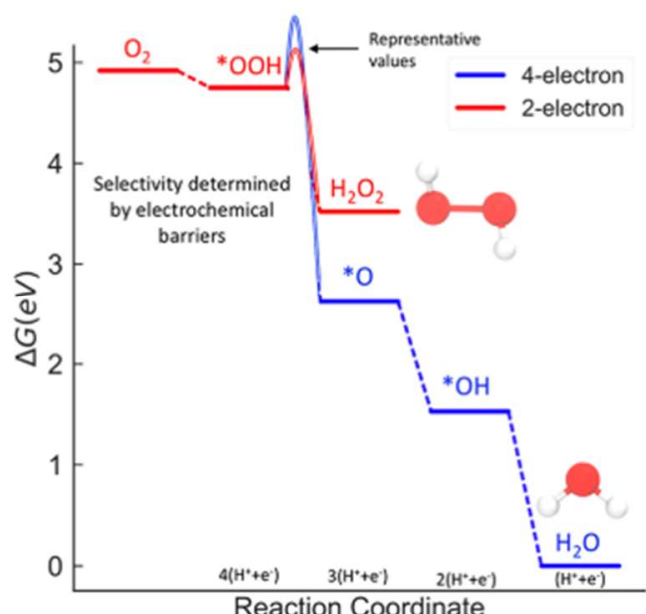

Figure 1. (a) Free energy diagram for the two-electron $\mathrm{ORR}$ on $\mathrm{PtHg}_{4}$, (b) volcano plot for the two-electron ORR, (c) Free energy diagram for the two- and four-electron ORR on $\mathrm{Au}(111)$. Reprinted with permission from [25]. Copyright 2018, American Chemical Society.

\subsection{Oxygen evolution reaction (OER) pathway for high overvoltage anodes}

220 Electrooxidation of pollutants in aqueous solution can be obtained by performing the electrolysis at high anodic potentials. Depending on the potential at which the oxygen evolution reaction (OER) occur, this process does not need to add catalysts into the solution and does not produce any byproducts [52-54]. Generally, there are two types of anode materials: (1) active anodes (Pt, $\mathrm{IrO}_{2}$, and $\mathrm{RuO}_{2}$ and other mixed metal oxide (MMO) anodes) with low $\mathrm{O}_{2}$ over- 
potential and (2) non-active anodes $\left(\mathrm{SnO}_{2}, \mathrm{PbO}_{2}\right.$, sub oxide of $\mathrm{TiO}_{2}\left(\right.$ like $\left.\mathrm{Ti}_{4} \mathrm{O}_{7}\right)$ and borondoped diamond (BDD)) with high $\mathrm{O}_{2}$ over-potential. It is supposed that $\mathrm{H}_{2} \mathrm{O}$ is oxidized on anode $\mathrm{M}$ to produce physisorbed hydroxyl radical $\left(\mathrm{M}\left({ }^{\circ} \mathrm{OH}\right)\right)$ through Eq. 6 , leading to the degradation and/or mineralization of organic pollutants as detailed in section 5 . The surface of a non-active anode interacts so weakly with ${ }^{\circ} \mathrm{OH}$ that it allows the direct reaction of organic pollutants (R) with $\mathrm{M}\left({ }^{\circ} \mathrm{OH}\right)($ Eq. 7$)[33,55]$.

$\mathrm{M}+\mathrm{H}_{2} \mathrm{O} \rightarrow \mathrm{M}\left({ }^{\circ} \mathrm{OH}\right)+\mathrm{H}^{+}+\mathrm{e}^{-}$

$\mathrm{M}\left({ }^{\bullet} \mathrm{OH}\right)+\mathrm{R} \rightarrow \mathrm{M}+$ intermediates $\rightarrow \rightarrow \rightarrow \mathrm{CO}_{2}+\mathrm{H}_{2} \mathrm{O}+$ inorganic ions

The oxygen evolution potential (OEP) of an anode is very important since the higher the OEP, the weaker the interaction of $\mathrm{M}\left({ }^{\circ} \mathrm{OH}\right)$ with the anode surface and the higher is the chemical reactivity toward organics oxidation. To improve OEP, many approaches have been attempted, e.g., elemental doping and nano-structure construction. For example, when $\mathrm{TiO}_{2}$ nanotubes (TNTs) were introduced to $\mathrm{Ti} / \mathrm{SnO}_{2}-\mathrm{Sb}$, the $\mathrm{OEP}$ was found to increase from $2.00 \mathrm{~V}$ to 2.18 V/SHE [56]. In other works it was observed that the OEP increased from $1.73 \mathrm{~V}$ to $2.20 \mathrm{~V} /$ Saturated calomel electrode (SCE) after $\mathrm{TiO}_{2}$ nanotubes (TNTs) base introduced into $\mathrm{PbO}_{2}$ [57]. Therefore, nano-structure introduction could decline the activity of OER and improve the catalytic activity.

\section{Preparation and characterization of nanostructured-based electrodes}

\subsection{Preparation methods}

\subsubsection{Cathode materials}

The preparation of the material is a particularly important step regarding the properties and stability of the electrode once employed in electrochemical applications. The preparation of the 
cathodes materials depends in general on the catalyst's composition and the desired structure. For this purpose, a wide range of methods is used to prepare or to modify the electrodes based on chemical, thermal and/or physicochemical methods.

\subsubsection{Polymeric precursor method for metal oxide supported on carbon materials}

The polymeric precursor method (PPM) is used mainly in the preparation of nanostructured metal oxide electrocatalysts. Firstly, citric acid was dissolved in ethylene glycol at $60^{\circ} \mathrm{C}$ and then the metal precursor was added to this mixture to obtain a viscous resin [58]. Then, a desired amount of the carbon was added to the solution precursor prepared previously in order to produce the electrocatalyst. Finally, the mixture containing the electrocatalyst and the resin was homogenized in an ultrasonic bath for $1 \mathrm{~h}$ and then thermally treated at $400^{\circ} \mathrm{C}$ during $2 \mathrm{~h}$ under $\mathrm{N}_{2}$ flow [59].

\subsubsection{Hydrothermal functionalization for the heteroatoms-doped carbon nanomaterials}

Hydrothermal synthesis is largely used for the preparation of nanostructured materials as nanosheets, nanospheres and the famous carbon nanotubes (Fig. 2a). This method allows the morphology control of the desired compounds by the means of temperature flexibility reaching a very high values [60]. This approach is also commonly used in the case of the heteroatomsdoped carbon nanomaterials. An appropriate mass ratio of the desired heteroatoms source and the carbon nanomaterials were mixed in the autoclave and heated at high temperature for a necessary time, depending on the characteristics of the final product [61]. Then, the autoclave was cooled to room temperature and some post synthesis treatments like carbonization under inert gas (e.g., argon) were performed to form the nanostructure [62,63]. After that, a washing 
treatment with hydrofluoric acid can be performed to dope the carbon with fluorine heteroatom [63] (Fig. 2a).

\subsubsection{Plasma discharge treatment for nanostructured preparation}

The plasma nanofabrication arouses a huge interest in the nanomaterials manufacturing (Fig. 2b). This method exhibits more environmental and economic advantages compared to the chemical process and it allows achieving the wanted structural and electronics properties [64]. For electro-Fenton cathode, this approach was used to create a nanostructure as the case for graphite. Khataee et al. [65] modified the graphite cathode to nanoflakes by the AC glow plasma discharge and they increase drastically the surface area of the cathode. Briefly the plasma was created by the interaction between the electric current with high voltage and gas generating several particles: ions, ionized ions, radicals and electrons inside the chamber reactor as shown in Fig. 2b [65], thus altering the targeted surface.

\subsubsection{Electrochemical exfoliation synthesis of graphene followed by ink-coating method}

Electrochemical exfoliation synthesis is the method used only for the graphene cathode preparation from graphite powder [66-68]. The principle of this method consists on the application of voltage between two electrodes: the compressed graphite as working electrode and any counter electrode. Under the influence of the potential, the ionic species of the electrolyte goes into the graphite electrode creating an heterogeneity in the inter-layer distance, namely exfoliation step [69] (Fig. 2c).

The exfoliated graphene can then be mixed with a binder (e.g., PTFE, Nafion) in a water/ethanol mixture to obtain a suspension, namely ink, using ultrasonic bath for $1 \mathrm{~h}[67,70]$. The raw carbon material can be then soaked in the ink and heated in furnace at $250^{\circ} \mathrm{C}$ for $1 \mathrm{~h}[67,70]$. 
(a)

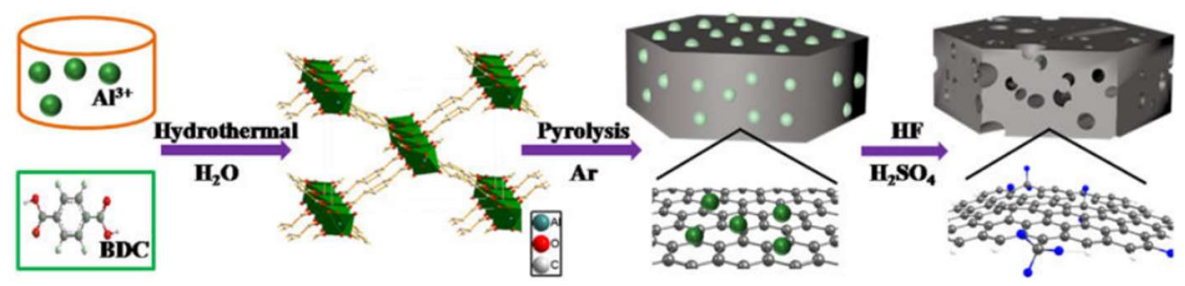

(b)

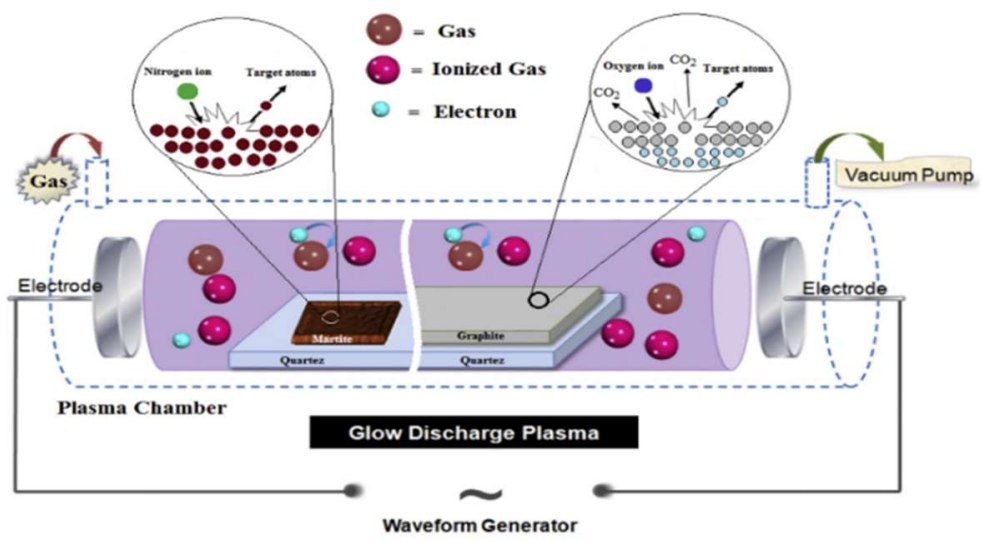

(c)

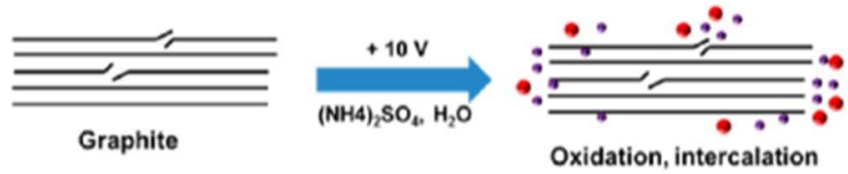

- $\mathrm{H}_{2} \mathrm{O} \rightarrow \mathrm{SO}_{4}{ }^{2 \cdot} \mathrm{O} \mathrm{O}_{2} \odot \mathrm{CO} \mathrm{OsO}$
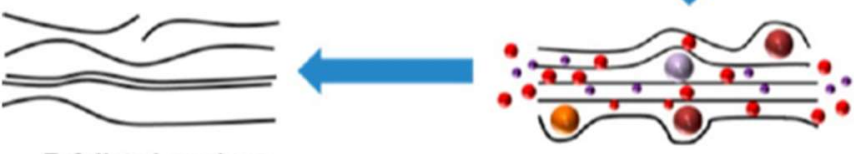

Exfoliated graphene

Expansion of graphite layers

Figure 2. (a) Hydrothermal treatment for heteroatoms functionalization (Reprinted with permission from [63]. Copyright 2018, Elsevier), (b) Plasma discharge reactor for nanostructure preparation (Reprinted with permission from [65]. Copyright 2017, Elsevier) and (c) electrochemical exfoliation mechanism of the graphite to graphene (Reprinted with permission from [71]. Copyright 2014, American Chemical Society). 


\subsubsection{Electrophoretic deposition}

Electrophoretic deposition consists in using the raw conductive substrate material to coat as an anode, while an inert counter-electrode (e.g., Pt) can be used [72,73]. Then the graphene oxide, which has a negative charge in solution, adheres to the anode material. A reduction is subsequently done by reversing the polarity so that the graphene oxide deposited on the material is reduced $[72,73]$. This method avoids the use of a binder.

\subsubsection{Microemulsion and co-precipitation to prepare bi metallic nanoparticles and mixed metal oxides nanostructures}

Microemulsion is among the known method used for the preparation of nanoparticles with an easier control of the particles size and distribution. It consists basically on the mixing of two surfactant microemulsions, i.e., one with the precursor metal and another one with a reducing agent $[74,75]$. The metallic nanoparticles were obtained after a series of chemical and physical transformation, including the interaction between the two microemulsions and then the chemical reaction occurs to allow the formation of the metal nuclei that is growing thereafter [74]. Félix-Navarro et al. [75] reported the formation of a bimetallic Pd-Pt nanoparticles using the microemulsion method.

Co-precipitation is another low-cost way used to prepare MMOs with high surface area. The obtained material surface contains an important number of active sites allowing an efficient adsorption of the molecules on the surface [76]. For the preparation of metal oxide nanoparticles, a salt precursor containing the metal was firstly dissolved in solvent with a base to favor the formation of the metal hydroxide precipitate. Then, the nucleation and the growth phases leads to the final dispersed nanoparticles [76]. A MMO nano spherical bismuth molybdates $\left(\mathrm{Bi}_{2} \mathrm{Mo}_{3} \mathrm{O}_{12}\right)$ by the co-precipitation route could be also synthetized [77]. The 
prepared compound was served as a coating on titanium mesh to form a high effective nanostructured cathode for the electrogeneration of $\mathrm{H}_{2} \mathrm{O}_{2}$ [77].

\subsubsection{Anode materials}

In general, the preparation methods of nanostructured anode could be divided into two main groups: (1) chemical methods and (2) physical methods. For chemical methods, the techniques used consist of thermochemical deposition, electrodeposition and chemical vapor deposition (CVD). Physical vapor deposition (PVD) belongs to physical method. Different synthesis strategies have been chosen to introduce different components on anode support. Fig. 3 summarizes some chemical methods for anode preparation including thermochemical decomposition, electrodeposition and CVD.

\subsubsection{Thermochemical decomposition}

Thermochemical decomposition method is the most widely applied among all the chemical methods, especially for preparation of $\mathrm{SnO}_{2}$ or $\mathrm{IrO}_{2}$-based anodes (Fig. 3a) [78-80]. In a typical thermochemical decomposition procedure, metal precursor and alcoholic solvent were mixed to drop or brush, and then dried and annealed at certain temperature. The isopropanol, ethanol or butanol was widely used as solvent to dissolve precursors. A high temperature is necessary for this method because it is beneficial to catalytic performance. The effects of preparation temperatures in the range of $450-850{ }^{\circ} \mathrm{C}$ for $\mathrm{Eu}$ doped $\mathrm{Ti} / \mathrm{SnO}_{2}-\mathrm{Sb}$ electrodes on phenol removal were investigated [81]. It was observed that smaller $\mathrm{SnO}_{2}$ grain sizes (e.g., 8 - $10 \mathrm{~nm}$ ) were obtained at $750{ }^{\circ} \mathrm{C}$. The removal efficiency first increased and then decreased with the increase of the pyrolysis temperature, and reached the maximum at $750{ }^{\circ} \mathrm{C}(96.4 \%)$ with the same energy consumption. However, high pyrolysis temperature $\left(>600^{\circ} \mathrm{C}\right)$ was not conductive for the service life of $\mathrm{Ti} / \mathrm{SnO}_{2}-\mathrm{Sb}_{2} \mathrm{O}_{5}$ anode; it was only $0.5-24 \mathrm{~h}$ [82]. When the pyrolysis temperature was $500{ }^{\circ} \mathrm{C}$, the service life exceeded $180 \mathrm{~h}$. 
The advantage of this method is to be easy in preparation and simple in operation. However, this method still faces some disadvantage [83]: (1) poor reproducibility due to generation of cracks at high internal pressure; (2) easy loss of some metals and (3) uneven surface coating.

To solve these problems, sol-gel method has been developed. This method is based on the solvolysis of organic solvent and inorganic or organic salts and water. The precursor was condensed at refluxing device, and achieved the required viscosity at room temperature. Thin films are prepared by dip or roll coating at intermediate temperatures and further annealed at high temperatures. Makgae et al. [79] prepared a series of $\mathrm{MMOs}\left(\mathrm{SnO}_{2}-\mathrm{RuO}_{2}-\mathrm{IrO}_{2}, \mathrm{Ta}_{2} \mathrm{O}_{5}-\right.$ $\mathrm{IrO}_{2}$ and $\mathrm{RhO}_{2}-\mathrm{IrO}_{2}$ ) fixed on a Ti substrate using sol-gel method, which exhibited higher stability with surface roughness and internal porosity. These anodes were used to degrade phenol, achieving more than $90 \%$ removal efficiency.

\subsubsection{Electrodeposition}

Electrodeposition can be regarded as a facile method for the anode preparation [84-86]. In a typical electrodeposition procedure, plating bath containing metal precursor and electrolyte is controlled to regulate deposition performance via acidity and depositing current as well as depositing temperature to obtain oxide film (Fig. 3b). The advantage of this method [83] is that it is easy to prepare complex electrodes and that larges surface areas can be deposited. However, this method still has some disadvantages [83]: (1) high energy consumption, (2) generation of acidic and toxic wastewater, and (3) uneven surface coating.

Electrodeposition method is more often used for electrodeposition of $\mathrm{PbO}_{2}$ anode (Fig. 3b). The temperature is one of the most critical parameters for electrodeposition of $\mathrm{PbO}_{2}$, while high temperature is beneficial to nucleation, growth and rough coating $[87,88]$. The current density is favorable to improve the polycrystallinity due to massive nucleation and high degree of 
porosity [87]. A high current density or potential polarization is important to form high surface

377 area [89]. Increasing of $\mathrm{pH}$ has significant influence on the surface morphology and crystal

378 forms, resulting in the decrease of current density [90].

379

380

\subsubsection{3. $C V D$}

381 CVD is a relatively less used method for anode preparation because of complicated preparation, 382 expensive equipment and troublesome preparation conditions (Fig. 3c). In a typical CVD 383 procedure, chemical interaction is generated between the molecules of the volatile precursor and active sites of the substrate surface at vacuum conditions. This process can be repeated several times, and then an inert gas is purged to remove excess reactant and volatile by-products.

This method exhibits some advantages such as excellent reproducibility and uniform coating.

$387 \mathrm{SnO}_{2}$ coating on Ti plates via CVD method using $\mathrm{SnEt}_{4}$ and $\mathrm{O}_{2}$ as reactive gas mixture was prepared, which exhibited conformal-coverage of the surface roughness [91]. CVD method

389 demonstrated excellent uniformity of coating, resulting in the increased service life and 390 improved reproducibility compared with dip coating process [91,92]. The service life of BDD 391 electrode prepared by CVD method was long and exhibited high removal and mineralization of 392 phenol [93]. 

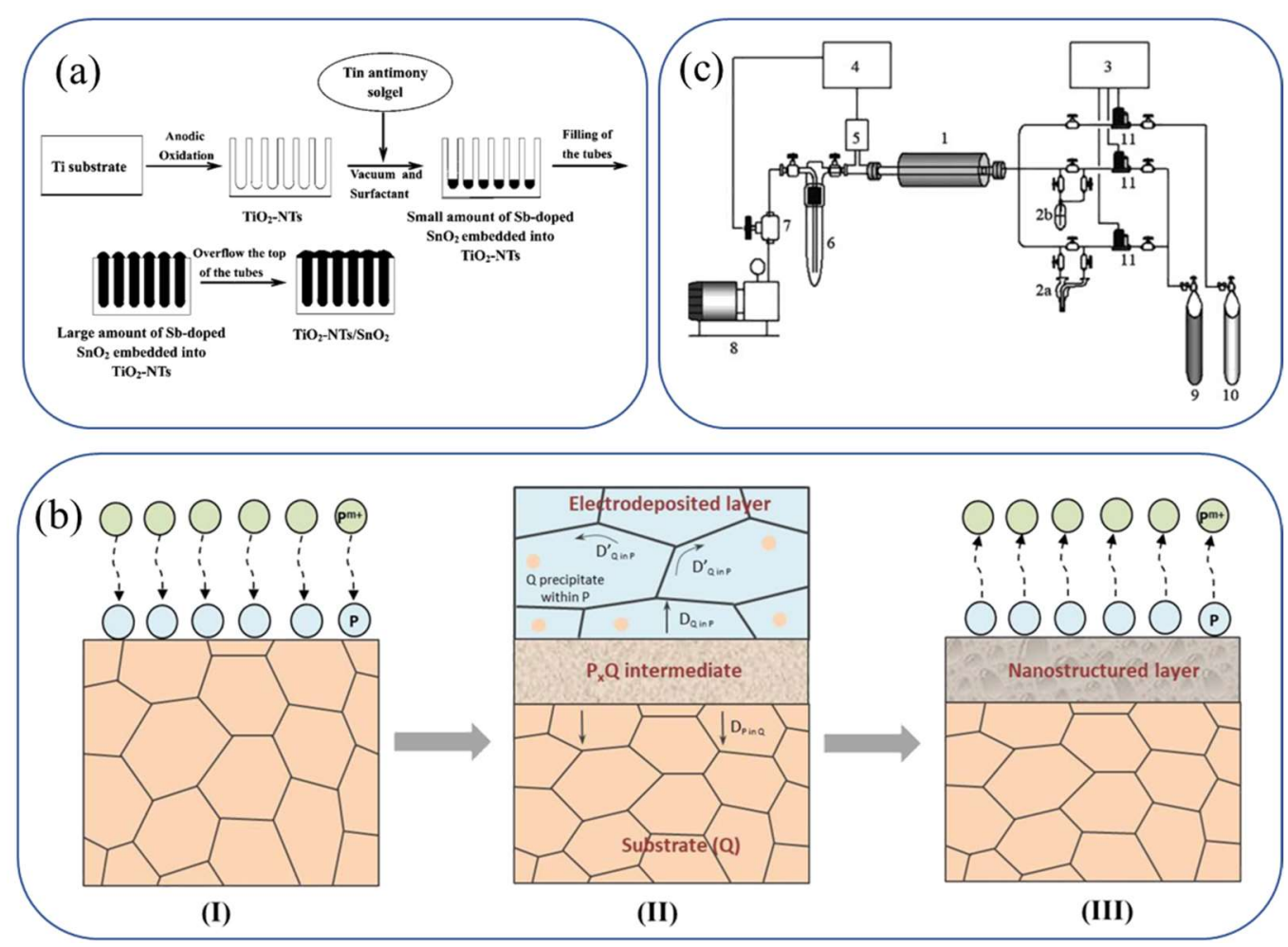

Figure 3. (a) Schematic illustration for the growth of a $\mathrm{TiO}_{2}-\mathrm{NTs} / \mathrm{SnO}_{2}$ electrode via thermochemical decomposition. Reproduced with permission from Ref [94]. Copyright (2009) American Chemical Society; (b) Electrodeposition method: schematic diagram for electrolytic metal-atoms enabled manufacturing of nanostructured sensor electrodes. (I) Electrodeposition of the metal atoms $(\mathrm{P})$ from its corresponding ion form $(\mathrm{Pm}+)$ onto a substrate (Q); (II) Representation of interactions at the interface between the electrodeposited layer of P and the substrate Q; and (III) Electro-dissolution of P from the substrate. Reproduced with permission from Ref [95]. Copyright (2020) Electrochemical Society. (c) CVD apparatus: (1) Hot-wall CVD reactor. (2a) $1^{\text {st }}$ bubbler for (MeCp) $\operatorname{Ir}(\mathrm{COD}) .(2 \mathrm{~b}) 2^{\text {nd }}$ bubbler for TET. (3) Gas flow controller. (4) Pressure controller. (5) Pressure gauge. (6) Cold trap. (7) Throttle valve. (8) Vacuum pump. (9) He tank. (10) $\mathrm{O}_{2}$ tank. (11) Mass-flow controller. Reproduced with permission from Ref [92]. Copyright (2010) Kluwer Academic 


\subsubsection{PVD}

PVD is a physical method, applying metal oxides instead of volatile precursor in CVD. In a typical PVD procedure, the precursor is vapored to gas which is mixed with inert gas to deposit on substrate via condensation method to generate film. The advantage of this method is the careful controlling of the relative ratios of precursors. $\mathrm{Ir}_{\mathrm{x}} \mathrm{Ru}_{1-\mathrm{x}} \mathrm{O}_{2}$ mixed metal oxide nanowires were synthesized by PVD method using $\mathrm{IrO}_{2}$ and $\mathrm{RuO}_{2}$ as precursors, forming highly single crystalline [96]. However, because of troublesome preparation conditions such as complicated preparation, expensive equipment and limitations in complex substrate, very few reports have been found about anodic oxidation of organics using anode prepared by PVD.

\subsection{Characterization techniques}

Different characterization techniques have been applied to assess the physicochemical and electrochemical properties presented in section 4: "Nanostructured-based electrode properties" whose fabrication methods have been exposed in previous sub-section 3.1. The techniques include: scanning electron microscopy (SEM), transmission electron microscopy (TEM), energy-dispersive X-ray spectroscopy (EDX), atomic force microscopy (AFM), contact angle measurements, X-Ray diffraction (XRD), X-ray photoelectron spectroscopy (XPS), Fouriertransform infrared (FTIR) spectroscopy, Raman spectroscopy, thermal gravimetric analysis (TGA), cyclic voltammetry (CV), linear sweep voltammetry (LSV), electrochemical impedance spectroscopy (EIS), Mott-Schottky measurements and UV-vis spectra.

Examples of characterization performance for some cathodes are illustrated in Figs. 4 and 6, while they are depicted in Figs. 5 and 7 for some anodes.

SEM, TEM and AFM could be used to observe the morphology and internal structure of materials. The nanoflowers made of carbon supported by $\mathrm{MnO}_{2}$ to enhance the ORR activity 
of cathode could be observed by SEM (Fig. 4a) [97]. AFM images of plasma treated graphite cathode could depict more roughness because of the higher number of peaks (bright part) and valley (dark part) allocated on all the surface of the material (Fig. 4b) [65]. Similarly, the more uniform nano- $\mathrm{TiO}_{2}$ anode film prepared by CVD method was observed by Chang et al. [98]; SEM and AFM observation showed that it exhibited smaller particle size ranged from 50 to 100 nm with an average height of $250 \mathrm{~nm}$ (Fig. 5a). Besides, the $\mathrm{Cr}_{2} \mathrm{O}_{3} / \mathrm{Fe}_{2} \mathrm{O}_{3}$ anode was showed with regular particles $(15 \mathrm{~nm})$ and uniform distribution of elements based on the TEM characterization and EDX elemental mapping (Fig. 5b) [99].

The hydrophilicity could be given by contact angle measurement as it has shown to play a role on ORR activity of cathodes. Graphene foam displayed high hydrophobicity, with a contact angle of $128.30^{\circ}$ (Fig. 4c) [51], which was in concordance with the high number of apolar aromatic rings in such structure.

Crystal structure of electrodes could be obtained from XRD spectrum. For instance, $\mathrm{CeO}_{2}$ high aspect ratio nanostructures (HARN)/C-based electrocatalyst was investigated by XRD and it showed no difference of spectra with the substrate (Fig. 4d) [100]. It meant that the semicrystalline structure was not altered during the hydrothermal synthesis of the material. Another example is given by the crystal lattices of TNTs on anode. The average size of anatase $\mathrm{TiO}_{2}$ nanoparticles were found to be around $20 \mathrm{~nm}$ according to the Scherrer equation calculation from XRD spectra [98]. In addition, rutile and brookite $\mathrm{TiO}_{2}$ were also observed from XRD spectrum (Fig. 5c) [101]. The surface electronic state and the composition of the electrodes could be obtained from XPS spectrum. $\mathrm{C}_{60}$-CNT cathode material in deconvoluted XPS plot (Fig. 4e) suggested the higher number of $\mathrm{C}=\mathrm{O}$ and $\mathrm{C}-\mathrm{OH}$ bonds on the hybrid structure compared to the raw materials [102]. Furthermore, the typical peak of $\mathrm{Sn}$ in nitrogen doped multi-walled CNTs (N-C@SnO $/$ MWCNTs) anode was obtained and the characteristic of $\mathrm{Sn}^{4+}$ in $\mathrm{Sn} 3 \mathrm{~d}_{3 / 2}$ and $\mathrm{Sn} 3 \mathrm{~d}_{5 / 2}$ high-resolution spectra appeared (Fig. 5d) [103]. It indicated that the 
content of nitrogen element was $3.4 \%$, ascribed to the pyridinic $\mathrm{N}$ and pyrrolic $\mathrm{N}$, which could enhance electrochemical reactivity and electronic conductivity. The Raman spectra could be used to evaluate defect structure and crystalline quality providing powerful information for peak shift, resulting in change of catalytic activity. The Raman spectra of graphene and N-doped graphene cathodes highlighted a higher $\mathrm{I}_{\mathrm{D}} / \mathrm{I}_{\mathrm{G}}$ intensity ratio with the $\mathrm{N}$-doped material (Fig. $4 \mathrm{f}$ ) [104]. This resulted in an increase of defects that should increase the number of active sites. In addition, the blue-shift of anatase with peak broadening was observed in Raman spectra of the anode, ascribed to the localized defects related to $\mathrm{Ti}^{3+}$ or oxygen vacancies (Fig. 5e) [105]. These findings were combined with XPS results, indicating that more surface hydroxyl groups were generated in new O1s peak. The FTIR spectra were used to analyze the surface functional group. The spectrum of $\mathrm{Bi}_{2} \mathrm{Mo}_{3} \mathrm{O}_{12}$ deposited on Ti cathode could highlight the Mo-O stretching vibration $\left(952,937,908,849 \mathrm{~cm}^{-1}\right)$, the dioxo bridge vibration $\left(716,672 \mathrm{~cm}^{-1}\right)$ and the Bi-O stretching vibration $\left(593 \mathrm{~cm}^{-1}\right)$ (Fig. $4 \mathrm{~g}$ ) [77]. Moreover, the $\mathrm{N}-\mathrm{H}$ at around $3100-3200 \mathrm{~cm}^{-1}$ could be ascribed to the ammonium group vibrations in methylammonium lead bromide $\left(\mathrm{MAPbBr}_{3}\right)$ microcrystals of anode material (Fig. 5f) [106]. The peaks at $1546 \mathrm{~cm}^{-1}, 1471 \mathrm{~cm}^{-1}$ and $916 \mathrm{~cm}^{-1}$ were attributed to the $\mathrm{N}-\mathrm{H}, \mathrm{C}-\mathrm{H}$ and $-\mathrm{CH}_{3}$ bonding modes, respectively. In addition, the TGA curve could be used to evaluate the thermochemical stability of electrode. TGA curve reported that the carbonization of aluminum-based metal organic framework (MOF) (MIL-53 (Al)) occurred at temperature higher than $600^{\circ} \mathrm{C}$ (Fig. 4h) [63]. Another example revealed that the content of $\mathrm{SnO}_{2}$ in $\mathrm{N}-\mathrm{C} @ \mathrm{SnO}_{2} / \mathrm{MWCNT}$ composite anode was $64.35 \mathrm{wt} \%$ when the temperature was higher than $500^{\circ} \mathrm{C}$ (Fig. 5g) [103]. 
(a)

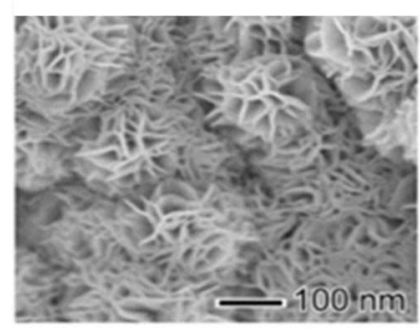

(d)

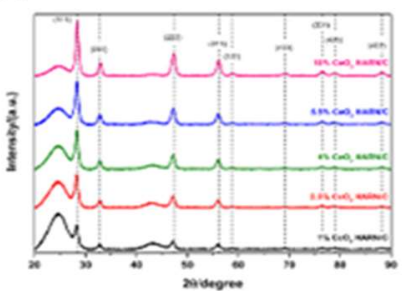

(f)

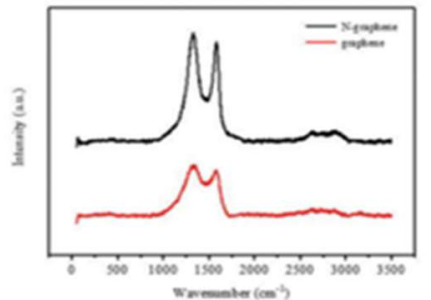

(h)

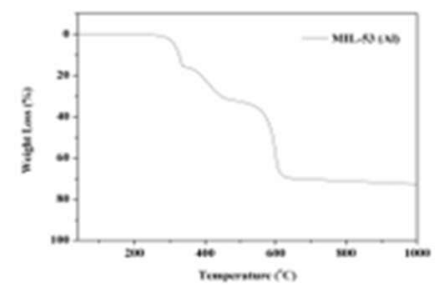

(b)

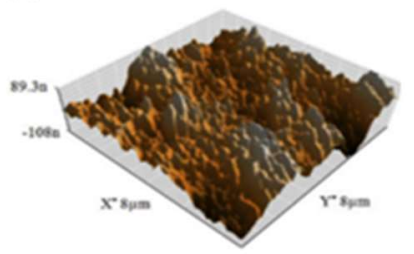

(c)

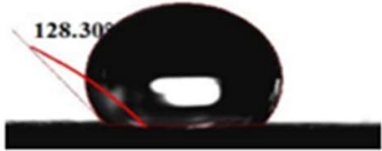

(e)

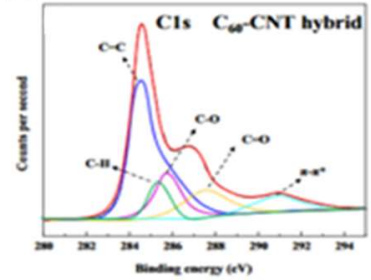

(g)

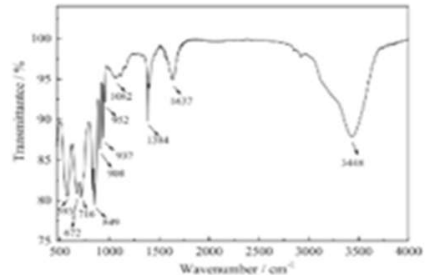

$479 \quad$ Figure 4. (a) SEM image of carbon supported $\mathrm{MnO}_{2}$ nanoflowers (Reprinted with permission from [97]. Copyright 2018, Elsevier), (b) 3D AFM images of plasma treated graphite

481 electrode (Reprinted with permission from [65]. Copyright 2017, Elsevier), (c) contact angle measurement of graphene foam (Reprinted with permission from [51]. Copyright 2016,

Elsevier), (d) XRD patterns of $\mathrm{CeO}_{2} \mathrm{HARN}$-based carbon cathodes with different proportions of $\mathrm{CeO}_{2} \mathrm{HARN}$ (Reprinted with permission from [100]. Copyright 2018, Elsevier), (e) C 1s core level of $\mathrm{C}_{60}-\mathrm{CNT}$ hybrid in deconvoluted XPS plot (Reprinted with permission from [102]. Copyright 2019, Springer Nature), (f) Raman spectrum of graphene and N-doped graphene cathodes (Reprinted with permission from [104]. Copyright 2019, Royal Society of 

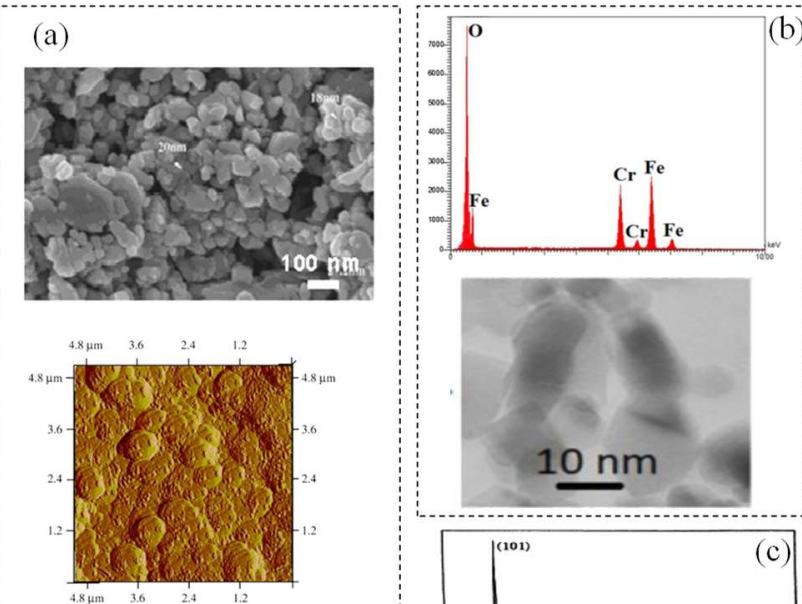

(b)
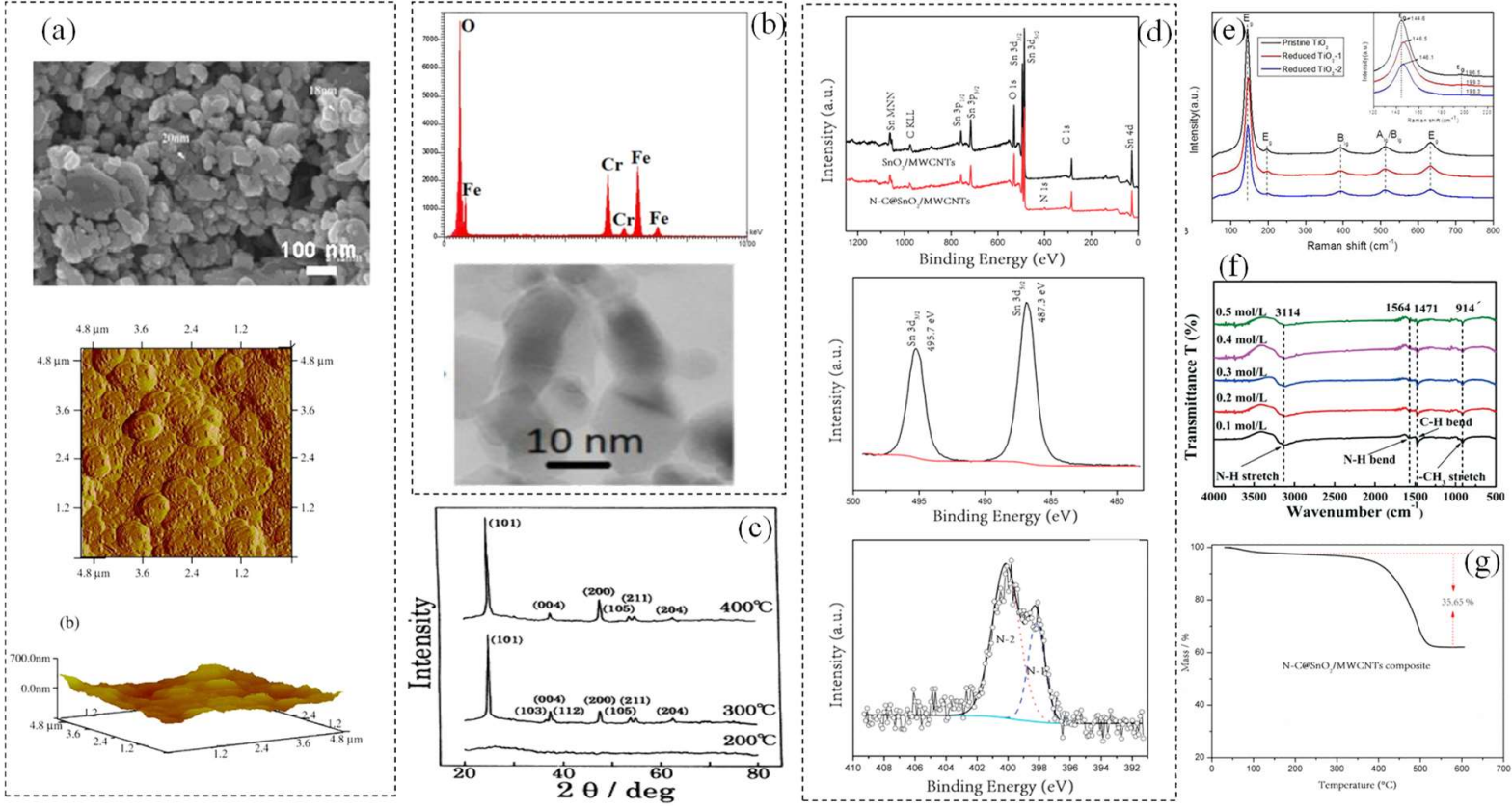

Figure 5. (a) FESEM and AFM images of nano- $\mathrm{TiO}_{2}$ electrode films CVD coating.

Reproduced with permission from Ref. [98]. Copyright (2009) Elsevier; (b) EDX analysis and

Elsevier; (c) XRD pattern of the nano- $\mathrm{TiO}_{2}$ electrode. Reproduced with permission from Ref. [101]. Copyright (1998) Elsevier; (d) XPS spectra for the $\mathrm{SnO}_{2} / \mathrm{MWCNTs}$ composite and the

(2014) Royal Society of Chemistry; (e) Raman spectra of pristine and reduced $\mathrm{TiO}_{2}$ nanotube arrays (NTA) after post-oxidization. Reproduced with permission from Ref [105]. Copyright (2017) Elsevier; (f) FTIR of the methylammonium lead bromide with different sizes. 
Reproduced with permission from Ref [106]. Copyright (2019) Royal Society of Chemistry;

(g) TGA curve recorded for the N-C@SnO 2 /MWCNTs composite under air flow. Reproduced with permission from Ref [103]. Copyright (2014) Royal Society of Chemistry.

In general, CV, LSV and EIS curve were used to test electrical conductivity and electrochemical activity. CV of graphene modified and unmodified carbon felt (CF) cathodes (Fig. 6a) permit to show that the electroactive surface area was ten times higher than the reduced graphene oxide (RGO)/CF, determined by the Randles-Sevcik equation [73]. Moreover, EIS depicted through the Nyquist plot that the charge transfer resistance (Rct) value was $0.21 \Omega$ against $2.38 \Omega$ for RGO/CF and CF, respectively (Fig. 6b) [73]. The graphene-based material could enhance the cathode conductivity. LSV could further address the ORR activity by emphasizing the 3.1-fold enhancement of ORR using the graphene coated brush as compared to the raw carbon fiber brush cathode (Fig. 6c) [67]. Further examples with anode materials illustrated that the blue $\mathrm{TiO}_{2}$ nanotube arrays (Blue-TNAs) exhibited much lower Rct (32 $\Omega$ ) and dynamic resistance (Rd) $(682 \Omega)$ compared with the TNA (333 $\Omega$ and $2848 \Omega$, respectively) (Fig. 7b) [55]. In addition, the higher $\mathrm{O}_{2}$ overpotential $(2.52 \mathrm{~V} / \mathrm{SCE})$ was obtained from $\mathrm{CV}$ curve (Fig. 7a). Furthermore, the LSV revealed that the current response increased with the increase of $\mathrm{Co}\left(\mathrm{NO}_{3}\right)_{2}$ concentration until $5 \mathrm{mM}$, while the OEP decreased from 2.12 to $1.78 \mathrm{~V} / \mathrm{SCE}$, indicating that the anodic oxidation capacity would also decrease after Co doping (Fig. 7f) [107]. UV-vis reflectance spectra could be used to study the absorbance and bandgap. BlueTNA had a stronger infrared adsorption than TNA, while the $\mathrm{Fe}_{2} \mathrm{O}_{3} / \mathrm{TiO}_{2} \mathrm{NTs}$ exhibited lower absorbance intensity in UV region, and higher absorbance intensity in visible light region than TNTs (Fig. 7d) [108]. Mott-Schottky was used to investigate the semiconductor lies in the Fermi. The Blue-TNA was still the n-type semiconductor characteristics from Mott-Schottky 

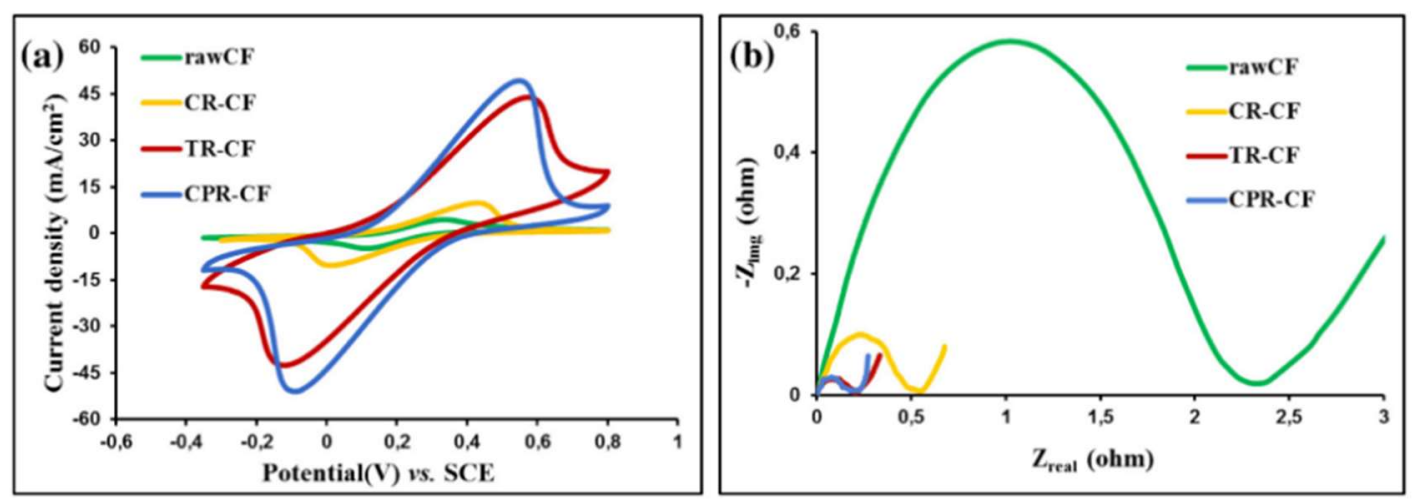

(c)

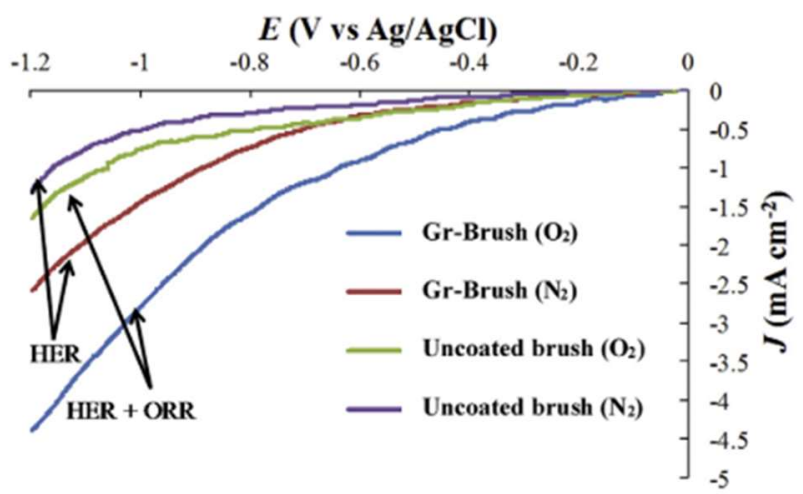

plots. At the same time, the donor densities were calculated from the Mott-Schottky equation, which increased to improve the charge conductivity (Fig. 7c) [55].

The service lifetime is also important for anode stability. The accelerated lifetime test indicated that the incorporation of ruthenium for ruthenium doped $\mathrm{SnO}_{2}-\mathrm{RuO}_{2}$ and $\mathrm{Ce}-\mathrm{Ru}-\mathrm{SnO}_{2}(318 \mathrm{~h}$ and $340 \mathrm{~h}$, respectively) could prolong the lifetime compared with $\mathrm{SnO}_{2}-\mathrm{Sb}_{2} \mathrm{O}_{5}$ anode $(1.42 \mathrm{~h})$ (Fig. 7e) [80].

Figure 6. (a) CVs and (b) EIS of graphene modified and unmodified carbon felt (CF) cathodes (Reprinted with permission from [73]. Copyright 2015, Elsevier), (c) ORR activity of graphene-coated carbon fiber brush (Gr-Brush) compared with uncoated brush given by LSV curves in $\mathrm{N}_{2}$ - and $\mathrm{O}_{2}$-saturated solutions (Reprinted with permission from [67]. Copyright 2017, Elsevier). 

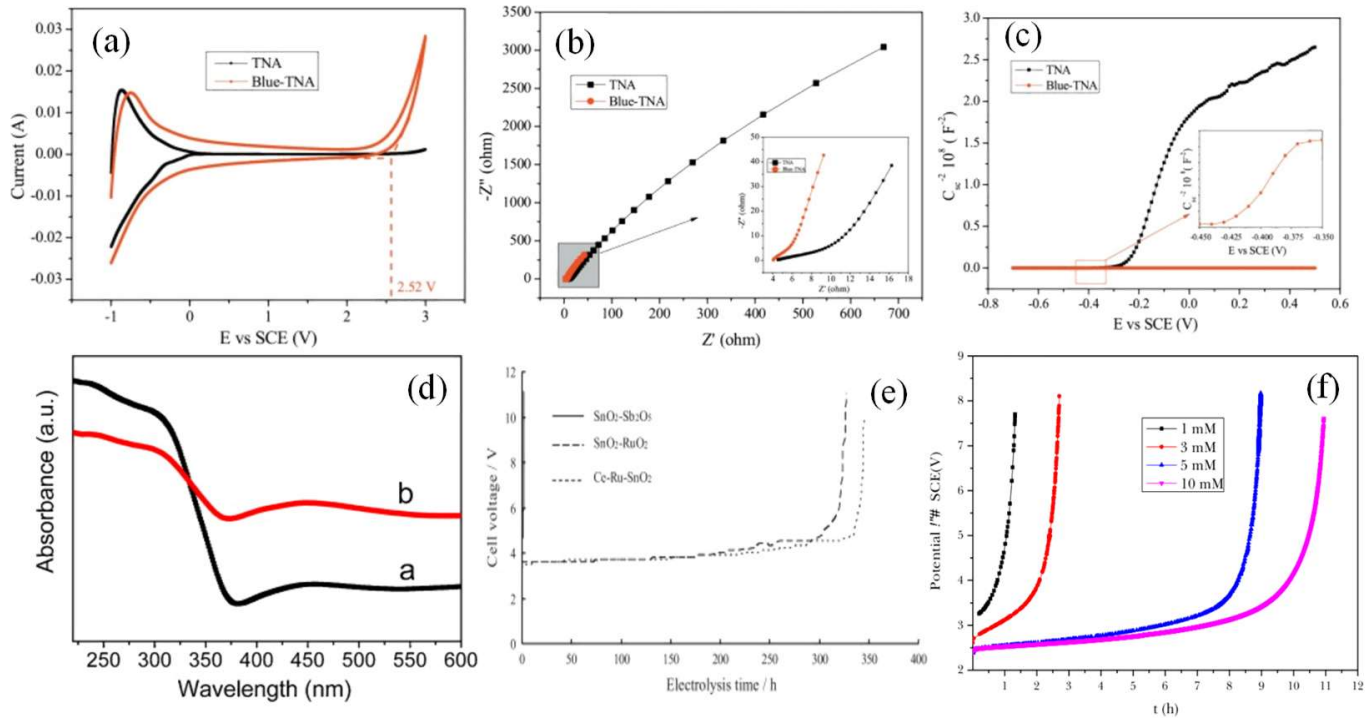

542 Figure 7. (a) CV, (b) EIS and (c) Mott-Schottky plots of TNAs and blue-TNAs. Reproduced with permission from Ref [55]. Copyright (2019) Elsevier; (d) UV-vis diffuse reflectance spectra of TNTs and $\mathrm{Fe}_{2} \mathrm{O}_{3} / \mathrm{TiO}_{2}$ nanotubes prepared by electrochemical deposition method. Reproduced with permission from Ref [108]. Copyright (2012) Elsevier; (e) Accelerated life tests of modified $\mathrm{SnO}_{2}$ anodes. Reproduced with permission from Ref [80]. Copyright (2012)

\section{Nanostructured-based electrode properties}

\subsection{Nanostructured-based cathodes}

The cathode property is an important parameter for $\mathrm{H}_{2} \mathrm{O}_{2}$ electrogeneration efficiency. A wide range of nanostructured cathodes have been developed in literature and they have been divided into four category as follow: (i) carbon nanomaterials-based cathodes including carbon nanotubes and graphene [102,109]; carbon and graphite felt modified with graphene $[66,67,110]$, (ii) heteroatoms-doped carbon cathodes, such as fluorine-doped [63,111],

557 nitrogen-doped [112] and phosphore-doped [61], (iii) metal or metal oxides deposited on carbon 
558 support, like cerium oxide, vanadium, manganese oxide, tungsten oxide, zirconium and

559 tantalum $[59,61,97,113-116]$, (4) metal oxide cathode. All the nanostructured-based cathodes

560 developed for $\mathrm{H}_{2} \mathrm{O}_{2}$ electrogeneration have been listed in Table 1. The percentage of

561 development of each cathode category is illustrated in Fig. 8a, according to articles found in

562 literature.

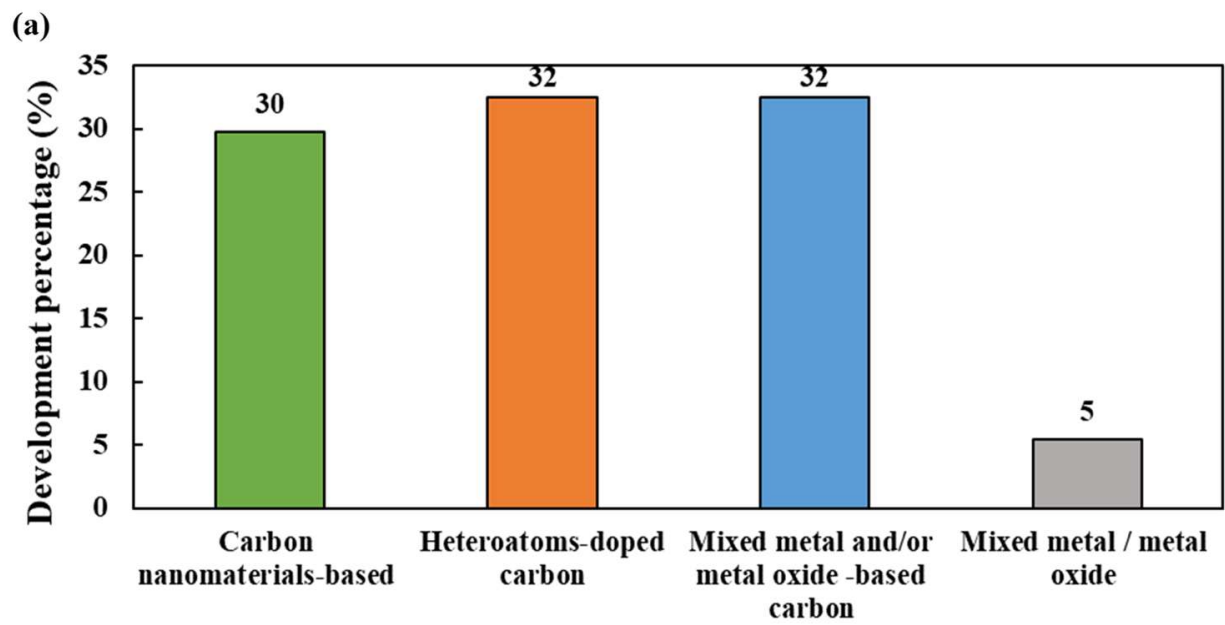

(b)

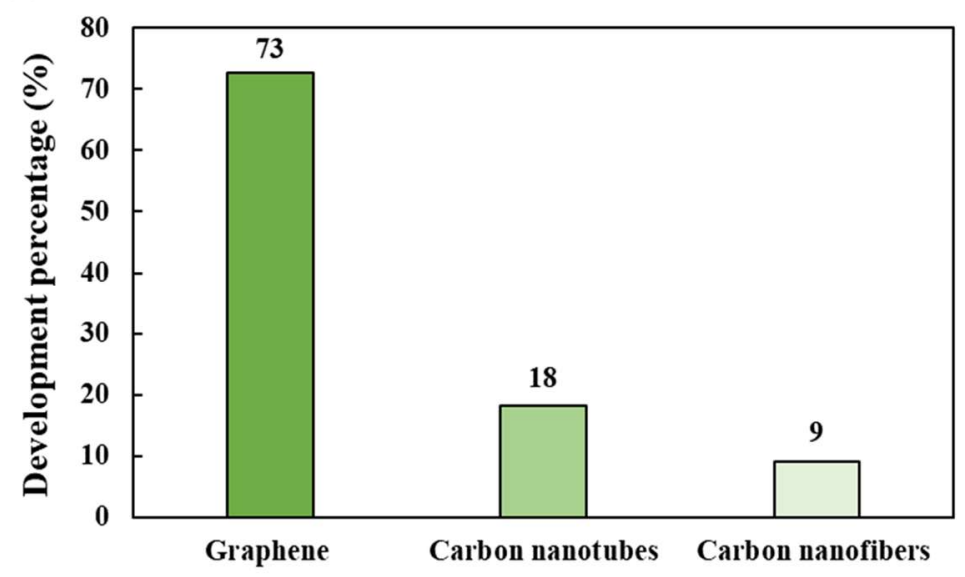

(c)

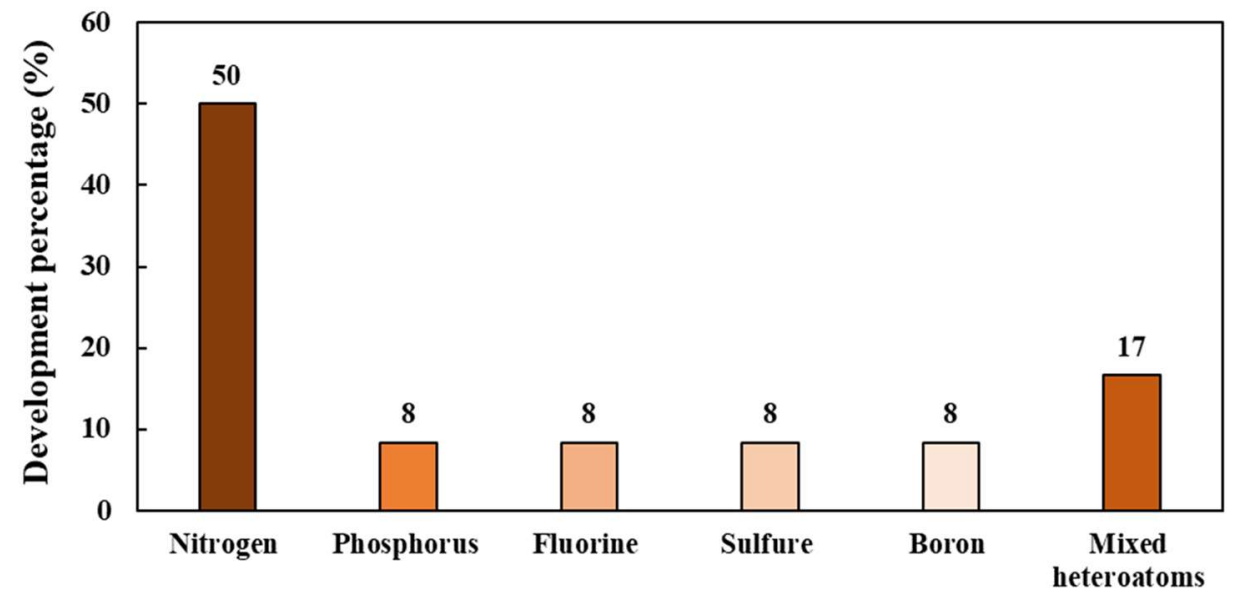


Figure 8. (a) Percentage of development of each cathode category, (b) Carbon nanomaterialsbased cathodes repartition, (c) Heteroatoms-doped carbon cathodes repartition.

It can be seen that heteroatoms-doped carbon materials as well as mixed metal /metal oxidebased carbon materials have been both developed at the same level (32.5\%), while $30 \%$ of the nanostructured materials found in literature are made of carbon nanomaterials. Mixed metal / metal oxide materials have been studied in a lesser extent until now (5\%). Generally, carbonbased materials used either as raw material or as nanomaterials catalysts have been developed extensively, since it represents $95 \%$ of the studies. This is to be linked with the reliable properties of carbon material to promote the two-electron ORR as discussed in section 2.1 $[66,117-124]$.

\subsubsection{Carbon nanomaterials-based cathodes}

Among the carbon nanomaterials-based cathode developed, there is a variety of materials (Fig. 8b) such as graphene, CNTs and carbon nanofibers coated on different carbon substrate like reticulated vitreous carbon (RVC), graphite felt (GF) and CF [125]. The cathodes having a three-dimensional (3D) porous structure are known to favor $\mathrm{H}_{2} \mathrm{O}_{2}$ electrogeneration thanks to their high active area, high chemical stability and low $\mathrm{H}_{2}$ evolution overvoltage. In parallel, gas diffusion electrodes (GDEs) was proposed and could also reach high $\mathrm{H}_{2} \mathrm{O}_{2}$ yields [123]. The combination between 3D porous $\mathrm{CF}$ with GDEs could even improve the $\mathrm{H}_{2} \mathrm{O}_{2}$ electrogeneration yield due to the enhanced oxygen mass transfer $[51,126]$. Another way is to modify CF cathode for $\mathrm{H}_{2} \mathrm{O}_{2}$ electrogeneration improvement [127].

Still the GDEs and/or 3D porous carbons modifications with nanostructured carbon basedmaterials have been suggested in literature to further raise the $\mathrm{H}_{2} \mathrm{O}_{2}$ production. Thanks to their electrochemical and physical properties, the growth of graphene and CNTs is of great interest for electro-Fenton process as working electrodes. The honeycomb structure of graphene 
containing $\mathrm{sp}^{2}$ hybridized carbon enhance the specific surface area [125]. The carbon containing oxygen groups serve as an active site for oxygen adsorption and conversion to $\mathrm{H}_{2} \mathrm{O}_{2}$ through ORR [128]. Recently, Hasanzadeh et al. (2019) [102] performed a highly efficient nanocarbon cathode for the hydrogen peroxide electrogeneration with fullerene $\mathrm{C}_{60}$ covalently bonded to the CNT surface. This hybrid structure promotes the electron transfer and increase the surface area of the cathode offering to this material a high performance toward the oxygen reduction through the two-electron route, reaching a rate as high as $28 \mathrm{mM}\left(\mathrm{h} \mathrm{cm}^{2}\right)^{-1}$ [102]. Other works focused on the modification of non-nanostructured cathodes with graphene or nanocarbon materials such as graphene ink-coated carbon cloth [70], graphite felt modified with electrochemically exfoliated graphene [66], GDEs with CNTs [129] and CF coated with reduced graphene [72]. It was highlighted that the nanostructured modification of the raw material improves the activity of the cathode and consequently its selectivity towards the hydrogen peroxide production [109].

\subsubsection{Heteroatom-based cathodes}

Doping carbon materials is a way to control the ORR activity by incorporating heteroatoms in the carbon lattice atoms [130]. The most widely used dopants were nitrogen, phosphorus, fluorine, sulfur and boron (Fig. 8c) due to their different size and electronegativity with carbon atoms, the structure distortion and charge density were modulated [131].

Recently N-doped materials received more attention for $\mathrm{H}_{2} \mathrm{O}_{2}$ electrosynthesis. The works about N-doped graphene and modified graphite felt electrode with nitrogen-doped porous carbon illustrated the ability of these cathodes to reach a high yield of $\mathrm{H}_{2} \mathrm{O}_{2}$ production and selectivity, with high generation rate of $1.6 \mathrm{mmol}\left(\mathrm{h} \mathrm{cm}^{2}\right)^{-1}$ and a current efficiency of $68 \%$ [112]. Yu et al. (2019) reported the performances of the modified graphite felt electrode with

$\mathrm{N}$-doped porous carbon, the $\mathrm{H}_{2} \mathrm{O}_{2}$ generation rate was $0.13 \mathrm{mmol}\left(\mathrm{h} \mathrm{cm}^{2}\right)^{-1}$ [132]. Moreover, 
some recent works demonstrated that $\mathrm{N}$-doped carbon materials could improve activity for $\mathrm{H}_{2} \mathrm{O}_{2}$ synthesis, while the $\mathrm{N}$-doped graphene could act as catalyst to convert the generated $\mathrm{H}_{2} \mathrm{O}_{2}$ into free radicals $[112,133]$. Further, it was reported that graphite $\mathrm{N}$ could promote $\mathrm{H}_{2} \mathrm{O}_{2}$ generation, while pyridinic $\mathrm{N}$ could catalyze $\mathrm{H}_{2} \mathrm{O}_{2}$ conversion into ${ }^{\circ} \mathrm{OH}$. Therefore, a novel in-situ metal-free EAOPs was developed for efficient degradation of organic pollutants at wide $\mathrm{pH}$ ranges in the absence of metal catalysts.

Fluorine is known as the highest electronegative atoms in Mendeleev table and its combination with carbon structure generate a redistribution in partials charges and more positives carbon atoms. This allows the adsorption of $\mathrm{O}_{2}$ and the ${ }^{*} \mathrm{OOH}$ desorption [134]. Fluorine-doped hierarchically porous carbon exhibited a high activity towards $\mathrm{H}_{2} \mathrm{O}_{2}$ electro-generation with the enhancement of selectivity and yield with $\mathrm{H}_{2} \mathrm{O}_{2}$ production rate of $3.11 \mathrm{mmol}\left(\mathrm{h} \mathrm{cm}^{2}\right)^{-1}$ [63]. In addition, P-doped carbon single walled nanotube was also investigated for ORR activity, mainly for $\mathrm{H}_{2} \mathrm{O}_{2}$ electrosynthesis. $\mathrm{P}$ as a donor atom presented a high affinity towards oxygen, modifying the charge transfer properties and improving the electrocatalysis of the doped material [135]. Moreover, according to Xia et al. [61] P-CNTs GDE cathode could reach 88\% of current efficiency of $\mathrm{H}_{2} \mathrm{O}_{2}$ formation against $65 \%$ with CNTs cathode.

\subsubsection{Metal- and metal-oxide based cathodes}

The mixed metals or metal oxides have been generally used as an heterogeneous catalyst in a wide range of electrochemical and bio-electrochemical applications such as microbial fuel cells but rarely for $\mathrm{H}_{2} \mathrm{O}_{2}$ electrosynthesis from oxygen reduction [136]. As reported in several works about the electrodes materials used for the $\mathrm{H}_{2} \mathrm{O}_{2}$ electrosynthesis, the mixed metal or the metal oxides such as $\mathrm{CaSnO}_{3}, \mathrm{BiVO}_{4}, \mathrm{TiO}_{2}$ and $\mathrm{WO}_{3}$ were widely used for the anodic production of the $\mathrm{H}_{2} \mathrm{O}_{2}$ or as a photocatalysts [137], instead of doing ORR at cathode.

Yuan et al. (2013) [138] performed the two-electron ORR at the MMO made of $\mathrm{IrO}_{2} / \mathrm{Ta}_{2} \mathrm{O}_{5}$ coated on the titanium mesh (Ti/MMO). The maximum production of $\mathrm{H}_{2} \mathrm{O}_{2}$ achieved with this 
material was $0.06 \mathrm{mM}$, which is still very low compared to the metals oxide supported on carbon material [138]. The bismuth molybdate oxide coated on the titanium mesh $\left(\mathrm{Bi}_{2} \mathrm{Mo}_{3} \mathrm{O}_{12} / \mathrm{Ti}\right)$ cathode was also used by He et al. (2019) [77] for the production of hydrogen peroxide in electro-Fenton process. They report the effect of the catalyst structure on the electrochemical efficiency of the cathode. The catalyst performance was related to the presence of the oxygen vacancies in $\mathrm{Bi}_{2} \mathrm{Mo}_{3} \mathrm{O}_{12}$ lattice, which allows the chemisorption of the oxygen and its reduction to $\mathrm{H}_{2} \mathrm{O}_{2}$ [77].

\subsubsection{Mixed metal / metal oxide and carbon-based cathodes}

Some metals and metal oxides supported on GDEs have depicted considerable performance for oxygen reduction catalysis. Due to their abundance, low cost and high performance towards ORR, scientists have given great interest for their uses as cathode materials for $\mathrm{H}_{2} \mathrm{O}_{2}$ electrogeneration [139].

GDEs made by $\mathrm{Ta}_{2} \mathrm{O}_{5}$ nanoparticles supported on carbon black $\left(\mathrm{Ta}_{2} \mathrm{O}_{5} / \mathrm{C}\right)$ demonstrated high catalytic efficiency making it as a promising candidate cathode for wastewater treatment. Tantalum (V), known as acid oxide, increases the surface wettability inducing more active site for ORR [115]. In another work, $\mathrm{MnO}_{2} /$ Vulcan $\mathrm{XC}-72$ carbon nanoflowers were used to optimize the oxygen vacancy sites. $\mathrm{MnO}_{2} / \mathrm{C} 3 \%$ displayed the optimal catalytic activity because of the uniform structure of $\mathrm{MnO}_{2}$ nanoflowers improving the distribution on carbon support, the high oxygen concentration vacancies and the high active surface area reached with metal oxide incorporation [97]. Paz et al. [113] prepared a new cathode material with tungsten oxide nanoparticles on carbon and the mass ratio of 1:100 (W:C) demonstrated the high $\mathrm{H}_{2} \mathrm{O}_{2}$ yield and selectivity compared to the support without the metal oxide. Many other works about $\mathrm{H}_{2} \mathrm{O}_{2}$ electrogeneration by means of metal oxide nanostructured cathodes have been performed such as Vanadium/C [59], $\mathrm{CeO}_{2}$ [58] and $\mathrm{ZrO}_{2}$-nanostructured GDE [114]. 
Furthermore, Félix-Navarro et al. (2013) [75] reported the electrocatalytic activity of the Pt-Pd bimetallic nanoparticles on CNTs towards the $\mathrm{H}_{2} \mathrm{O}_{2}$ electrosynthesis. The mixed metal nanoparticles anchored on the multi-walled CNTs (MWCNTs) exhibited a high efficiency to produce $\mathrm{H}_{2} \mathrm{O}_{2}$ compared to the MWCNTs alone. The enhancement of the $\mathrm{H}_{2} \mathrm{O}_{2}$ yield is ascribed to the increase of the active surface area of the catalyst by the small particle sizes of the Pt-Pd distributed on the MWCNTs surface [75].

A heterogeneous cathode on which a confined interior iron cavity of CNTs $\left(\mathrm{Fe}^{0}\right.$-in-CNTs) with extremely low iron leaching was prepared, observing a much higher $\mathrm{H}_{2} \mathrm{O}_{2}$ yield and phenol removal rate (9.7 times faster) when compared with that of iron-confined external walls of CNTs ( $\mathrm{Fe}^{0}$-out-CNTs) [140]. It was found that iron valence on CNTs played an important role on the heterogeneous Fenton activity, supporting that $\mathrm{Fe}^{0}$ was beneficial for $\mathrm{H}_{2} \mathrm{O}_{2}$ selectivity of two-electron process (2.4 times higher) and phenol removal rate (21.44 times faster) than iron oxide. Consequently, the CNT cavity provided an isolate space for $\mathrm{Fe}^{0}$, which is decisive for phenol removal based surface of $\mathrm{Fe}^{0}$-in-CNTs reaction.

\subsubsection{General requirement for cathode characteristics and operating conditions}

The nanostructure of the cathode plays a major role in the in-situ production of $\mathrm{H}_{2} \mathrm{O}_{2}$. The structural morphology and the introduction of new functional groups with various physicochemical properties affect drastically the cathode performance. It is reported in several works that the active surface area, the conductivity, the porosity, the surface composition and the wettability are the main parameter to consider in the ORR activity $[109,141,142]$. Some operating parameters play also an important role on two-electron-ORR activity such as electrode potential (or current density), solution $\mathrm{pH}$ and oxygen flow rate.

\subsubsection{Effect of electrode surface area}

The surface area, defined by specific surface area using BET technique or electroactive surface area using EIS method, is a decisive parameter in the ORR activity enhancement [143]. The 
690

691

692

693

694

695

696

697

698

699

700

influence of BET specific surface area $\left(\mathrm{S}_{\mathrm{BET}}\right)$ on the amount of $\mathrm{H}_{2} \mathrm{O}_{2}$ electrogenerated at nanostructured-based cathode materials found in literature (Table 1) has been plotted in Fig. 9. It can be noted that the $\mathrm{S}_{\mathrm{BET}}$ as high as around $1000 \mathrm{~m}^{2}$ can be obtained by nanostructuring the materials. Interestingly, the higher surface area does not systematically lead to higher $\mathrm{H}_{2} \mathrm{O}_{2}$ electrogeneration. It is known that increasing the surface area make increase the number of active sites for adsorption and subsequent desorption of intermediates species. However, this will increase the $\mathrm{H}_{2} \mathrm{O}_{2}$ production until a certain optimal value of surface area. Fig. 9 defines this range of surface area between around 30 to $100 \mathrm{~m}^{2}$. The high surface areas do not provide higher $\mathrm{H}_{2} \mathrm{O}_{2}$ formation, since the rate of $\mathrm{O}_{2}$ transport from bulk to the electrode surface become then the rate-limiting step.

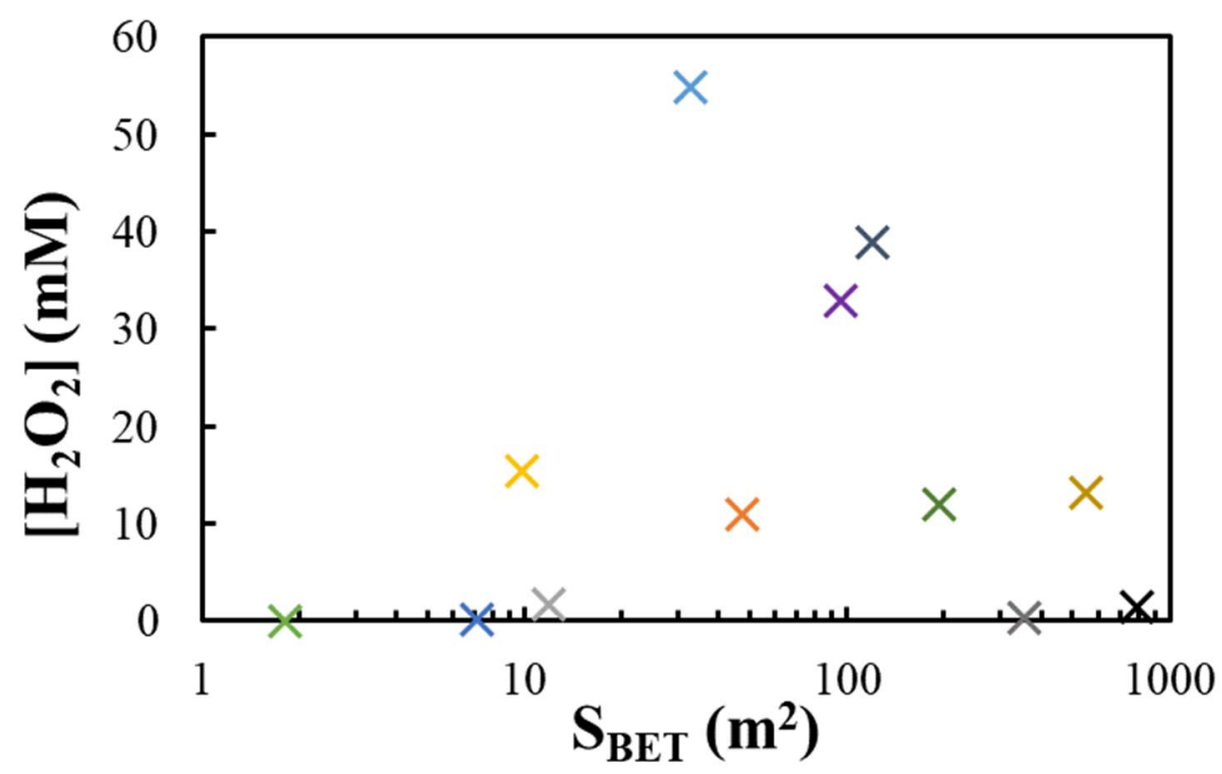

Figure 9. Influence of BET specific surface area $(\mathrm{S} B E T)$ on the amount of $\mathrm{H}_{2} \mathrm{O}_{2}$ electrogenerated at nanostructured-based cathode materials.

\subsubsection{Effect of electrode porosity}

The porous structure effect of the nanostructured cathodes was investigated in many articles. It has been demonstrated that the presence of large number of pores in the cathode material increases the mass transfer and facilitates the diffusion of the reactants and products through 
the cathode [109]. Also, this porous configuration limits the diffusion resistance and creates more active sites for oxygen reduction, enhancing in this way the ORR activity and the $\mathrm{H}_{2} \mathrm{O}_{2}$ yield [63]. Park et al. [144] reported the correlation between the well-ordered mesoporous structure of N-doped-carbon (3-4 nm) catalyst and its high selectivity toward the $\mathrm{H}_{2} \mathrm{O}_{2}$ electrosynthesis. In this work the effect of pores toward the $\mathrm{H}_{2} \mathrm{O}_{2}$ selectivity was investigated through a comparison study between the mesoporous N-doped carbon (MNC) and activated Ndoped carbon (ANC), using Koutecky-Levic plots and a rotating ring-disc electrode voltammetry [144]. High selectivity values are reached at MNC cathode compared to the ANC cathode; the mesopores of the MNC allow an easier release of the produced $\mathrm{H}_{2} \mathrm{O}_{2}$. In contrast, the micropores of the ANC increase the residence time and as a result, the formed $\mathrm{H}_{2} \mathrm{O}_{2}$ evolves to $\mathrm{H}_{2} \mathrm{O}$, thus affecting its selectivity [144].

\subsubsection{Effect of electrode conductivity}

The electrical conductivity of cathode material is another important factor that increase the rate of electron transfer to let occur electrochemical reaction, though this is not usually the ratelimiting step. This conductivity has been often characterized by the Rct given by EIS measurement $[67,70,73]$. The conductivity is affected by the thickness of material and by the defects on the nanostructure. It has been shown that the increase of graphene thickness (from graphene single layer to graphene foam) could decrease the resistivity of the material $[51,145,146]$. Moreover, the presence of oxygen functional groups on carbon nanomaterial can localize the $\pi$-electrons, which decrease their mobility and therefore the material conductivity [147].

\subsubsection{Effect of electrode wettability}

The hydrophilicity character of the cathode materials is considered in many studies about the electrogeneration of the $\mathrm{H}_{2} \mathrm{O}_{2}$. It has been shown that the hydrophobicity can also have a 
positive influence on the ORR activity by enhancing the $\mathrm{O}_{2}$ gas absorption on the porous carbon-based material [148]. Contrastingly, it was observed that the nanostructures with highest hydrophilic character exhibit a high $\mathrm{H}_{2} \mathrm{O}_{2}$ production because it improved the dissolved oxygen diffusion in water and its subsequent adsorption on the cathode material [73]. The metal oxides nanostructures such as tantalum, vanadium and cerium oxides supported on carbon materials have a Lewis acid sites providing thus the wettability to the surface and allowing the interaction with adsorbed oxygen through the two-electron pathway $[59,115]$.

Paz et al. [149] reported improved performance of $\mathrm{H}_{2} \mathrm{O}_{2}$ production at the tungsten oxide nanoparticles modified carbon cathode. Contact angle measurements performed emphasized the importance of hydrophilic character of the modified carbon compared to the unmodified one. Authors attributed this finding to the presence of tungsten nanoparticles as acidic entities on the surface. The presence of tungsten atoms as a Lewis acid promotes interactions with the oxygen entities through the Pauling model (two-electron way), resulting in the production of $\mathrm{H}_{2} \mathrm{O}_{2}$ [149]. The selectivity toward $\mathrm{H}_{2} \mathrm{O}_{2}$ formation was performed at modified carbon and unmodified carbon electrodes. The modified carbon materials (Printex 6L and Vulcan XC72) presented a higher $\mathrm{H}_{2} \mathrm{O}_{2}$ selectivity than the unmodified one confirming the effect of the tungsten oxide on the wettability and therefore on the oxygen reduction through the twoelectron mechanism [113].

\subsubsection{Effect of surface composition}

The nanostructured carbon cathodes are widely used for the $\mathrm{H}_{2} \mathrm{O}_{2}$ electrogeneration. Interestingly, the incorporation of some heteroatoms such as nitrogen, fluorine, phosphorus and sulfur to these material further increases their performance towards the oxygen reduction [150]. The common feature of these dopant atoms is the difference of electronegativity and size with the carbon atoms. 
$\mathrm{N}$-doped carbon materials emerge as the main studied cathodes in literature for $\mathrm{H}_{2} \mathrm{O}_{2}$ electrosynthesis, and became models of heterostructured materials for mechanisms understanding. As known, the nitrogen is more electronegative and voluminous than carbon.

Consequently, the $\mathrm{C}-\mathrm{N}$ bond become polarized and creates a partial positive charge on the carbon atoms allowing its activation [132]. The oxygen is firstly adsorbed on the activated carbon and then protonated as illustrated in Fig. 10 [151].

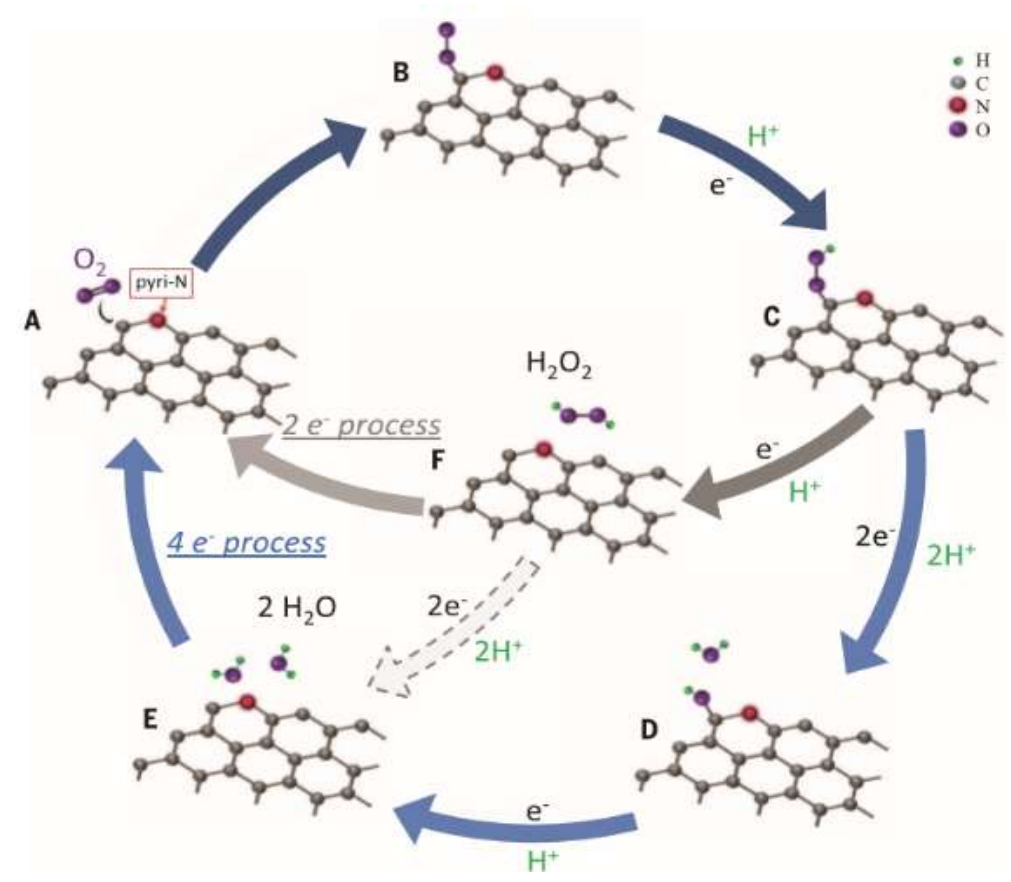

Figure 10. Mechanism of the ORR on nitrogen-doped carbon materials (Reproduced with permission from Ref [151]. Copyright (2018) Wiley).

In addition to the nitrogen dopant atom, other heteroatoms with similar properties have been used to dope carbon materials. Phosphorus incorporated on CNTs exhibits a high $\mathrm{H}_{2} \mathrm{O}_{2}$ yield [61]. This result is assimilated to the structural distortion of the surface caused by the C-P bonding which promotes the oxygen adsorption. Moreover, the electron donor character of the phosphorus atom boosts the electron density of the CNTs surface and enhances the electroactivity of the cathode towards the ORR [150]. Furthermore, at molecular level, it was 
demonstrated that the fluorine doped on carbon material played a determining role in $\mathrm{H}_{2} \mathrm{O}_{2}$ selectivity. The incorporation of heteroatoms in carbon framework promotes the oxygen adsorption on the surface and the ${ }^{*} \mathrm{OOH}$ desorption leading to the two-electron route mechanism as shown in the Fig. 11 [63].

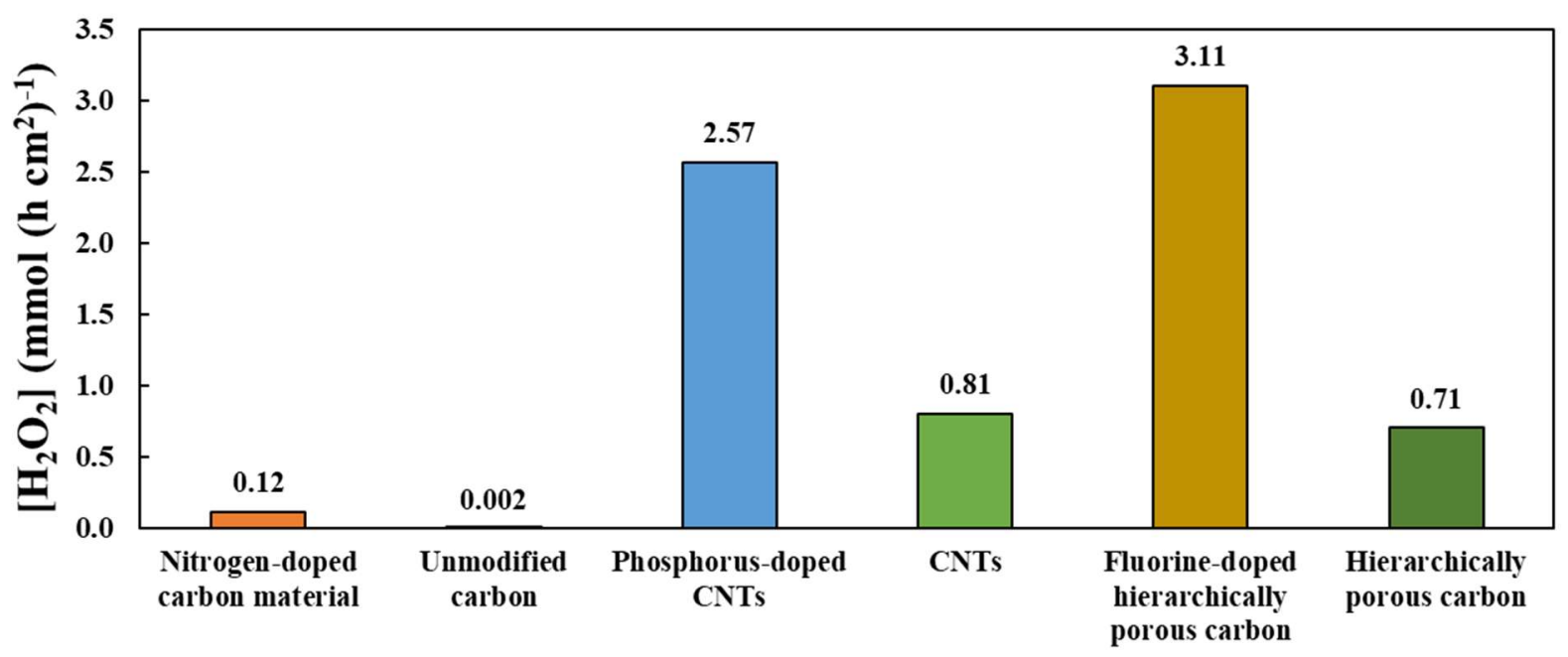

Figure 11. $\mathrm{H}_{2} \mathrm{O}_{2}$ generation rate at heteroatoms doped-carbon and the corresponding unmodified cathode (Adapted with permission from Ref $[61,63,132]$. Copyrights $(2018,2019)$ Elsevier).

\subsubsection{Effect of cathode potential / current density and $\mathrm{H}_{2}$ evolution overvoltage}

The electrogeneration of $\mathrm{H}_{2} \mathrm{O}_{2}$ is often performed at a fixed potential value (potentiostatic) or at constant current (galvanostatic) mode in an undivided cell [125]. In this configuration, the concentration profile of $\mathrm{H}_{2} \mathrm{O}_{2}$ increases during the first minutes of the electrolysis and then achieves a plateau with constant $\mathrm{H}_{2} \mathrm{O}_{2}$ concentration [114].

Mousset et al. [51] investigated the effect of current density on $\mathrm{H}_{2} \mathrm{O}_{2}$ production on the range of $0.0016-1.6 \mathrm{~mA} \mathrm{~cm}^{-2}$ with three graphene cathodes. The increase in current density does not allow the increase in $\mathrm{H}_{2} \mathrm{O}_{2}$ concentration but there is an optimal applied current density giving the highest concentration that can be reached [51]. This behavior could be explained by the 

occurring of parallel reactions including the electroreduction of the $\mathrm{H}_{2} \mathrm{O}_{2}$ at the cathode (Eq. 8), the decomposition in the bulk electrolyte (Eq. 9) and the oxidation at anode following Eq. 10. The $\mathrm{H}_{2}$ evolution reaction (HER) was also evoked to be a parasite reaction under some cathode potential (Eq. 11) [67].

$$
\mathrm{H}_{2} \mathrm{O}_{2}+2 \mathrm{H}^{+}+2 \mathrm{e}^{-} \rightarrow 2 \mathrm{H}_{2} \mathrm{O}
$$

$\mathrm{H}_{2} \mathrm{O}_{2} \rightarrow 1 / 2 \mathrm{O}_{2}+\mathrm{H}_{2} \mathrm{O}$

$$
\mathrm{H}_{2} \mathrm{O}_{2} \rightarrow \mathrm{HO}_{2}^{\cdot}+\mathrm{H}^{+}+\mathrm{e}^{-}
$$

$2 \mathrm{H}^{+}+2 \mathrm{e}^{-} \rightarrow \mathrm{H}_{2}$

The influence of optimal cathode potential (reported versus SHE for reliable comparison) applied in literature (Table 1) at nanostructured-based cathode materials to electrogenerate $\mathrm{H}_{2} \mathrm{O}_{2}$ has been displayed in Fig. 12. This optimal potential can vary from 0 to $-1 \mathrm{~V} / \mathrm{SHE}$ according the cathode material. It is important to note that low cathode potentials could be applied thanks to the low hydrogen evolution overvoltage of such nanostructured-based material permitting the two-electron ORR to occur. The highest amount of $\mathrm{H}_{2} \mathrm{O}_{2}$ could be obtained at cathode potentials between $-0.5 \mathrm{~V} / \mathrm{SHE}$ and $-0.1 \mathrm{~V} / \mathrm{SHE}$. Too high cathode potentials then favor the four-electron ORR.

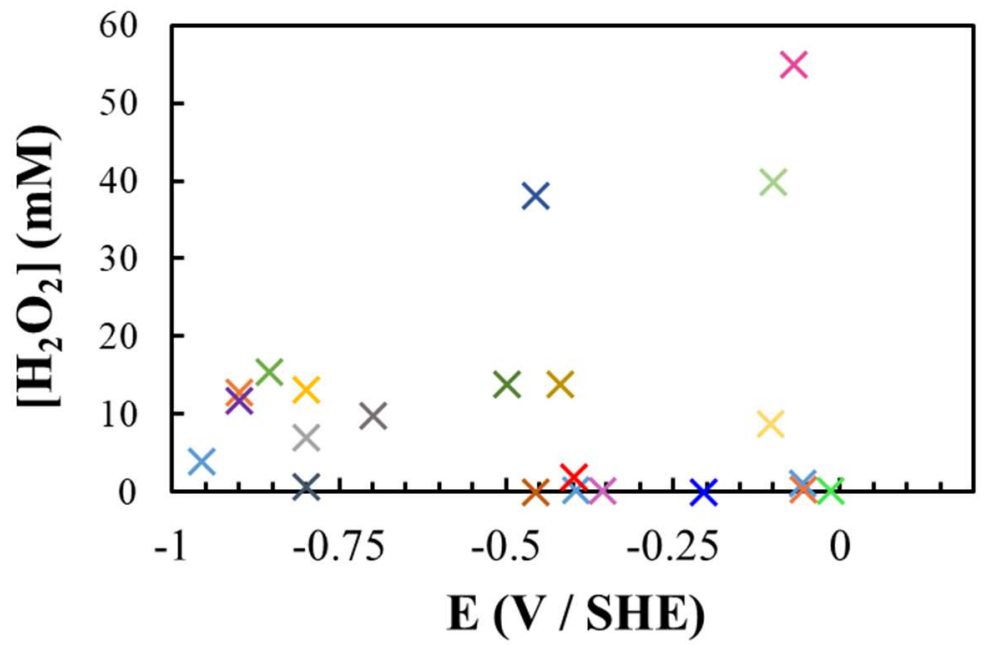

Figure 12. Influence of optimal cathode potential on the amount of $\mathrm{H}_{2} \mathrm{O}_{2}$ electrogenerated at nanostructured-based cathode materials. 


\subsubsection{Effect of solution $p H$}

The proton content of the electrolyte has a significant weight on the $\mathrm{H}_{2} \mathrm{O}_{2}$ production. In fact, the acidic or the alkaline medium can influence the parallel reactions and consequently the $\mathrm{H}_{2} \mathrm{O}_{2}$ yield. On the one hand, the electrogeneration of $\mathrm{H}_{2} \mathrm{O}_{2}$ at the cathode from the dissolved oxygen needs the presence of protons. On the other hand, the higher amount of protons in the solution can promote the hydrogen peroxide decomposition following Eq. 8 or the HER (Eq. 11) [132].

Moreover, at low $\mathrm{pH}$ value the ORR occurs via the four-electron mechanism to produce water at the cathode, leading to the decrease in $\mathrm{H}_{2} \mathrm{O}_{2}$ concentration [61]. It is further important to note that the acid dissociation constant $\left(\mathrm{pKa}\right.$ ) of $\mathrm{H}_{2} \mathrm{O}_{2} / \mathrm{HO}_{2}{ }^{-}$couple is 11.7 , and $\mathrm{HO}_{2}{ }^{-}$is not only a weaker oxidant but also is not able to produce ${ }^{\circ} \mathrm{OH}$ from Fenton reaction. Consequently, the implementation of ORR in alkaline media (Eq. 12) has to be avoided [61]:

Many researches have studied the effect of the electrolyte $\mathrm{pH}$ medium on the electrogeneration of $\mathrm{H}_{2} \mathrm{O}_{2}$. Yu et al. [132] have performed the electrogeneration of $\mathrm{H}_{2} \mathrm{O}_{2}$ at different $\mathrm{pH}$ values of 3, 5, 7 and 9 and they have observed the increase of the $\mathrm{H}_{2} \mathrm{O}_{2}$ concentration with increase of the $\mathrm{pH}$ from 3 to 7 and it decrease significantly at $\mathrm{pH}$ equal to 9 . This trend is confirmed by Xia et al. [61] with a similar study. Depending on the nanostructured cathode material an optimum

$830 \mathrm{pH}$ value lead to a maximum $\mathrm{H}_{2} \mathrm{O}_{2}$ concentration (Fig. 13). At the acidic $\mathrm{pH}$, an excess of 831 protons are released in the solution and can be reduced at the cathode to form $\mathrm{H}_{2}$, competing with the $\mathrm{H}_{2} \mathrm{O}_{2}$ formation [66]. When the $\mathrm{pH}$ increase, the quantity of protons needed to form $\mathrm{H}_{2} \mathrm{O}_{2}$ become insufficient, resulting in low $\mathrm{H}_{2} \mathrm{O}_{2}$ yield [132]. 
(a)

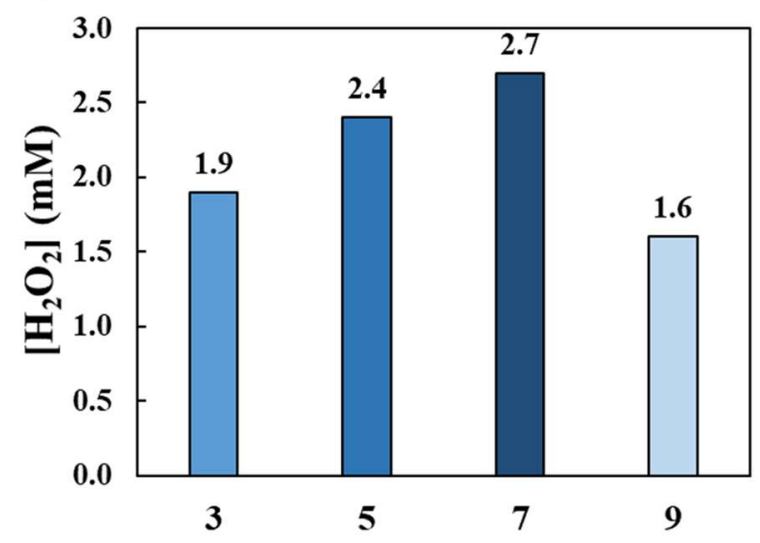

(c)

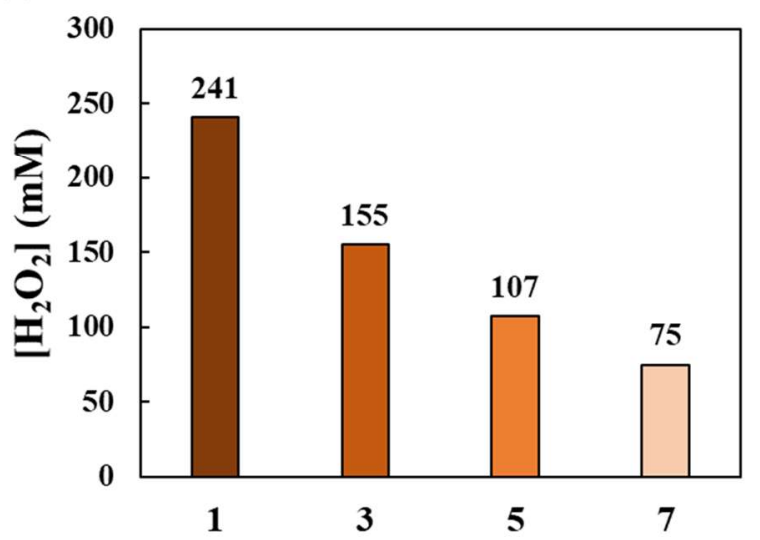

(b)

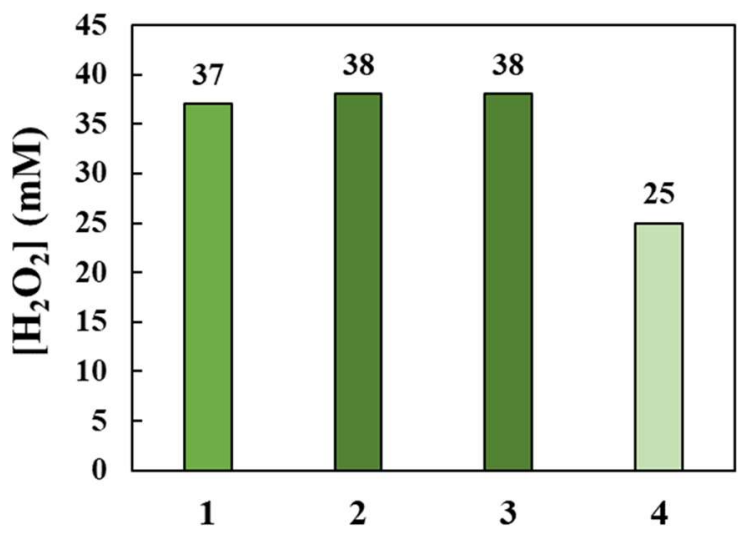

(d)

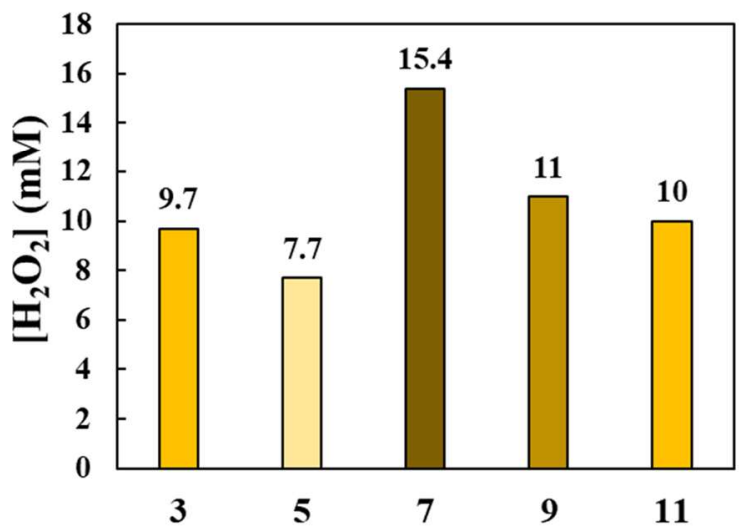

834

842 Oxygen is the main reagent for $\mathrm{H}_{2} \mathrm{O}_{2}$ electrogeneration. It has been demonstrated that the 843 oxygen flow rate controls the kinetic of the ORR and consequently the $\mathrm{H}_{2} \mathrm{O}_{2}$ yield and the oxygen supply. With air supply, the DO concentration is $8 \mathrm{mg} \mathrm{L}^{-1}$ at $23{ }^{\circ} \mathrm{C}$ and this value depend

Chemistry).

\subsubsection{Effect of oxygen flow rate} current efficiency [125]. The dissolved oxygen (DO) concentration depends on the nature of remarkably on the purity of the oxygen supplies, and solution temperature [152]. 
847 The accumulation of hydrogen peroxide at P-doped CNTs cathode was studied at different

848 oxygen flow rates [61]. Despite the absence of oxygen supply, the $\mathrm{H}_{2} \mathrm{O}_{2}$ was accumulated at 849 the cathode thanks to the oxygen formed at the anode level from water oxidation. The increase 850 of $\mathrm{O}_{2}$ flow rate improves the oxygen mass transfer to the cathode and promotes the $\mathrm{H}_{2} \mathrm{O}_{2}$ 851 formation. However, the high flow rates create an excessive mass bubbles at the cathode surface 852 minimizing the access to the active sites. Additionally, the superfluous conditions maximize 853 the electrolyte resistance and consequently decrease the ORR activity [153]. 
Table 1. Experimental conditions and hydrogen peroxide production performances at the different kinds of nanostructured cathode materials.

\begin{tabular}{|c|c|c|c|c|c|c|c|}
\hline Cathode & pH & $\begin{array}{l}\text { Specific } \\
\text { surface } \\
\text { area } \\
\left(\mathrm{S}_{\mathrm{BET}}\right) \\
\left(\mathrm{m}^{2} \mathrm{~g}^{-1}\right)\end{array}$ & $\begin{array}{l}\text { Current } \\
\text { density (mA } \\
\text { cm }^{-2} \text { ) or } \\
\text { cathodic } \\
\text { potential } \\
\text { (V/SHE) }\end{array}$ & $\begin{array}{l}\mathrm{O}_{2} \text { flow } \\
\text { rate }(\mathrm{L} \\
\left.\text { min }^{-1}\right)\end{array}$ & $\begin{array}{l}{\left[\mathrm{H}_{2} \mathrm{O}_{2}\right]} \\
\left(\mathrm{mmol}^{2}(\mathrm{~h}\right. \\
\left.\left.\mathrm{cm}^{2}\right)^{-1}\right)^{*}\end{array}$ & $\begin{array}{l}\text { Current } \\
\text { efficiency } \\
(\%)\end{array}$ & Ref. \\
\hline \multicolumn{8}{|c|}{ Nanostructured carbon-based material } \\
\hline $\begin{array}{l}\text { Carbon fiber brush } \\
\text { coated with graphene } \\
\text { ink }\end{array}$ & 3 & NS & $\begin{array}{l}1.25 \\
-0.8\end{array}$ & 0.2 & 0.07 & 95 & {$[67]$} \\
\hline Pristine graphene & 3 & NS & $\begin{array}{l}0.4 \\
-0.39\end{array}$ & NS & 0.0117 & 13 & {$[51]$} \\
\hline Graphene/graphite & 3 & 11.8 & $\begin{array}{l}20 \\
\mathrm{NS}^{1}\end{array}$ & 0.06 & 0.23 & 16 & [109] \\
\hline $\begin{array}{l}\text { Graphene ink coated } \\
\text { carbon cloth }\end{array}$ & 3 & NS & $\begin{array}{l}1.25 \\
-0.4\end{array}$ & 0.2 & 0.03 & 23 & {$[70]$} \\
\hline $\begin{array}{l}\text { Graphite felt modified } \\
\text { with electrochemically } \\
\text { exfoliated graphene }\end{array}$ & 7 & 9.8 & $\begin{array}{l}\text { NS } \\
-0.856\end{array}$ & 0.7 & 0.23 & 60 & {$[66]$} \\
\hline Modified graphite felt & 7 & NS & $\begin{array}{l}300 \mathrm{~mA} \\
\mathrm{NS}\end{array}$ & 0.8 & 0.163 & 19.5 & [110] \\
\hline $\begin{array}{l}\text { Fullerene C60-Carbon } \\
\text { nanotubes } \\
\text { Covalent hybrid }\end{array}$ & 3 & 422 & $\begin{array}{l}\text { NS } \\
0.044\end{array}$ & NS & $\begin{array}{l}28 \mathrm{mM}(\mathrm{h} \\
\left.\mathrm{cm}^{2}\right)^{-1}\end{array}$ & 82.60 & [102] \\
\hline $\begin{array}{l}\text { CF modified with } \\
\text { electrochemically } \\
\text { exfoliated graphene }\end{array}$ & 3 & NS & $\begin{array}{l}16.66 \\
\text { NS }\end{array}$ & 1 & 0.90 & 23.5 & [127] \\
\hline $\begin{array}{l}\text { CF coated with } \\
\text { reduced graphene }\end{array}$ & 3 & NS & $\begin{array}{l}40 \mathrm{~mA} \\
\mathrm{NS}\end{array}$ & NS & - & NS & {$[72]$} \\
\hline Carbon nanofiber & NS & NS & $\begin{array}{l}200 \mathrm{~mA} \\
\mathrm{NS}\end{array}$ & NS & 0.05 & 27.6 & [154] \\
\hline $\begin{array}{l}\mathrm{PANI}^{2} / \mathrm{MWCNT}^{3} \\
\text { Nanocomposite on } \\
\text { Stainless Steel }\end{array}$ & 2 & 7.1 & $\begin{array}{l}\text { NS } \\
-0.356\end{array}$ & 0.3 & $1.37 \mathrm{mM} \mathrm{h}^{-1}$ & 40 & [155] \\
\hline \multicolumn{8}{|c|}{ Heteroatom-doped carbon cathode } \\
\hline $\begin{array}{l}\text { Phosphorus-doped } \\
\text { Carbon nanotubes } \\
\mathrm{GDE}^{4}\end{array}$ & 7 & 119 & $\begin{array}{l}\text { NS } \\
-0.456\end{array}$ & 0.21 & 2.57 & 88.5 & [61] \\
\hline N-Doped graphene & 7 & NS & $\begin{array}{l}\text { NS } \\
-0.9\end{array}$ & 0.75 & 1.6175 & 68 & [112] \\
\hline $\begin{array}{l}\text { Fluorine-doped porous } \\
\text { carbon }\end{array}$ & 1 & 1001 & $\begin{array}{l}\text { NS } \\
-0.156\end{array}$ & NS & 3.11 & NS & {$[63]$} \\
\hline
\end{tabular}




\begin{tabular}{|c|c|c|c|c|c|c|c|}
\hline $\begin{array}{l}\text { Modified graphite felt } \\
\text { electrode with } \\
\text { Nitrogen-Doped } \\
\text { porous Carbon }\end{array}$ & 7 & 1453 & $\begin{array}{l}12.5 \\
\mathrm{NS}\end{array}$ & NS & 0.12 & 10 & {$[132]$} \\
\hline $\begin{array}{l}\text { Graphite felt modified } \\
\text { with nitrogen doped } \\
\text { graphene }\end{array}$ & 3 & 13.8 & $\begin{array}{l}7 \\
-0.106\end{array}$ & 0.3 & 0.13 & 33 & {$[104]$} \\
\hline $\begin{array}{l}\text { Graphite felt modified } \\
\text { with nitrogen doped } \\
\text { exfoliated graphene }\end{array}$ & 7 & NS & $\begin{array}{l}\mathrm{NS} \\
\mathrm{NS}\end{array}$ & 1 & - & NS & {$[156]$} \\
\hline $\mathrm{NCNT}^{5} / \mathrm{NF}^{6} / \mathrm{CNT}^{7}$ & 3 & NS & $\begin{array}{l}30 \\
\text { NS }\end{array}$ & 0.4 & 0.18 & 33 & {$[157]$} \\
\hline $\mathrm{N} / \mathrm{F}-\mathrm{CNC}^{8}$ & $\begin{array}{l}13 \\
0.35\end{array}$ & NS & $\begin{array}{l}\mathrm{NS} \\
-1.36 \\
\mathrm{NS} \\
0.33\end{array}$ & NS & $\begin{array}{l}92 \%(\mathrm{~S}) \\
88 \%(\mathrm{~S})\end{array}$ & $\begin{array}{l}89.6 \\
88\end{array}$ & {$[158]$} \\
\hline $\begin{array}{l}\text { Glassy carbon coated } \\
\text { with HPCS-S } \\
\text { nanocrystals }\end{array}$ & NS & 794 & $\begin{array}{l}\text { NS } \\
0.3\end{array}$ & NS & $1.35 \mathrm{mmol}$ & 70 & {$[159]$} \\
\hline $\begin{array}{l}\text { Nitrogen and sulfur } \\
\text { doped carbon cathode } \\
\text { on } \mathrm{GC}^{10}\end{array}$ & 2.4 & NS & $\begin{array}{l}\text { NS } \\
\text { NS }\end{array}$ & NS & - & NS & {$[160]$} \\
\hline BDD & 3 & NS & $\begin{array}{l}40 \\
\text { NS }\end{array}$ & 0.3 & 0.04 & 0.09 & {$[161]$} \\
\hline $\begin{array}{l}\text { PAN }^{11} \text {-Carbon Fiber } \\
\text { Brush on Ti wire }\end{array}$ & 3 & NS & $\begin{array}{l}300 \mathrm{~mA} \\
-0.95\end{array}$ & 3 & $\begin{array}{l}0.063 \mathrm{mmol} \\
\mathrm{h}^{-1}\end{array}$ & 68 & {$[162]$} \\
\hline
\end{tabular}

\section{Mixed metal/metal oxide and carbon-based cathode}

\begin{tabular}{|c|c|c|c|c|c|c|c|}
\hline $\begin{array}{l}\mathrm{Ta}_{2} \mathrm{O}_{5} \text { nanoparticles } \\
\text { On carbon black }\end{array}$ & 2 & NS & $\begin{array}{l}\text { NS } \\
-0.8\end{array}$ & $0.2 \mathrm{bar}$ & 0.186 & 83.2 & [115] \\
\hline $\begin{array}{l}\mathrm{ZrO}_{2} \text {-Nanostructured } \\
\mathrm{GDE}^{4}\end{array}$ & 2 & NS & $\begin{array}{l}75 \\
\text { NS }\end{array}$ & 0.2 bar & 0.39 & 9 & [114] \\
\hline $\begin{array}{l}\text { Tungsten oxide } \\
\text { Nanoparticles } \\
\text { modified carbon }\end{array}$ & 2 & NS & $\begin{array}{l}\text { NS } \\
-0.42\end{array}$ & 0.2 bar & 8.21 & 96 & [113] \\
\hline $\begin{array}{l}\mathrm{CoS}_{2} \text {-Based Air- } \\
\text { diffusion cathode }\end{array}$ & 3 & 32.5 & $\begin{array}{l}100 \\
-0.071\end{array}$ & 0.5 & 2.75 & 49 & [163] \\
\hline $12 \% \mathrm{~V} / \mathrm{C} \mathrm{GDE}^{4}$ & NS & NS & $\begin{array}{l}\text { NS } \\
-1.36\end{array}$ & 0.2 bar & ${ }_{1}^{18.23 \mathrm{mM} \mathrm{h}^{-}}$ & NS & {$[59]$} \\
\hline $\begin{array}{l}4 \% \mathrm{CeO}_{2} / \mathrm{C} \\
\mathrm{GDE}^{4}\end{array}$ & NS & NS & $\begin{array}{l}\mathrm{NS} \\
-1.1\end{array}$ & 0.2 bar & $19.4 \mathrm{mM} \mathrm{h}^{-1}$ & NS & {$[58]$} \\
\hline $\begin{array}{l}\text { Carbon-Supported } \\
\mathrm{MnO}_{2} \text { Nanoflowers }\end{array}$ & 3 & 191 & $\begin{array}{l}\text { NS } \\
-0.9\end{array}$ & 0.2 bar & 0.6 & NS & [97] \\
\hline $\begin{array}{l}\text { Tungsten oxide } \\
\text { Nanoparticles } \\
\text { modified carbon }\end{array}$ & 3 & NS & $\begin{array}{l}\text { NS } \\
-2.3\end{array}$ & 0.2 bar & 1.93 & 44 & [149] \\
\hline
\end{tabular}




\begin{tabular}{|c|c|c|c|c|c|c|c|}
\hline $\begin{array}{l}\text { Pt-Pd bimetallic } \\
\text { nanoparticles on } \\
\text { MWCNTs }^{3} / \text { RVC }\end{array}$ & NS & NS & $\begin{array}{l}\text { NS } \\
0.699\end{array}$ & NS & 0.43 & - & {$[75]$} \\
\hline $\begin{array}{l}\mathrm{Mn} / \mathrm{Fe} \text { nanoparticles } \\
\text { porous carbon }\end{array}$ & NS & 351 & $\begin{array}{l}\text { NS } \\
-0.056\end{array}$ & NS & 0.07 & - & {$[62]$} \\
\hline $\begin{array}{l}\text { Gold nanoparticles } \\
\text { deposited on the } \\
\text { graphite cathode }\end{array}$ & 3 & NS & $\begin{array}{l}0.5 \mathrm{~mA} \\
-0.056\end{array}$ & NS & $\begin{array}{l}0.84 \mathrm{mM}(\mathrm{h} \\
\left.\mathrm{cm}^{2}\right)^{-1}\end{array}$ & - & [164] \\
\hline $\begin{array}{l}\text { Cobalt (II) } \\
\text { Phthalocyanine/C } \\
\mathrm{GDE}^{4}\end{array}$ & NS & NS & $\begin{array}{l}\text { NS } \\
-0.7\end{array}$ & NS & 0.14 & 81.5 & [165] \\
\hline $\begin{array}{l}\text { NiFe nanostructure } \\
\text { /Graphite }\end{array}$ & 2 & NS & $\begin{array}{l}300 \mathrm{~mA} \\
-0.016\end{array}$ & NS & 0.015 & 0.15 & [166] \\
\hline Nanostructured martite & 6 & 1.8 & $\begin{array}{l}300 \mathrm{~mA} \\
-0.206\end{array}$ & NS & 0.038 & 0.2 & {$[65]$} \\
\hline \multicolumn{8}{|c|}{ Mixed metal/metal oxide cathode } \\
\hline $\mathrm{Bi}_{2} \mathrm{Mo}_{3} \mathrm{O}_{12} /$ Ti cathode & 3 & NS & $\begin{array}{l}0.9 \\
-0.456\end{array}$ & NS & $\begin{array}{l}0.044 \mathrm{mmol} \\
\mathrm{h}^{-1}\end{array}$ & - & {$[77]$} \\
\hline $\mathrm{MMO}^{12} / \mathrm{Ti}$ & 4 & NS & $\begin{array}{l}40 \mathrm{~mA} \\
\mathrm{NS}\end{array}$ & NS & 0.1 & 6 & [138] \\
\hline
\end{tabular}




\subsection{Nanostructured-based anodes}

864

865

866

867

868

869

870

871

872

873

874

875

876

877

878

879

880

881

882

883

884

885

\subsubsection{General requirement for anode characteristics}

Different anodes have different electrochemical properties, e.g., electrode area, OEP and conductivity. Thus some electrochemical characterization methods are employed, for example, CV and EIS Nyquist plot [167]. When nanostructure is introduced into anode, some electrode properties would change. It was found that the introduction of $\mathrm{TiO}_{2}$ nanostructure into $\mathrm{Ti} / \mathrm{SnO}_{2}$ $\mathrm{Sb}$ anode resulted in a higher oxidation peak. The Rct obtained from EIS was 203 and $380 \Omega$ for $\mathrm{Ti} / \mathrm{TiO}_{2} / \mathrm{SnO}_{2}-\mathrm{Sb}$ and $\mathrm{Ti} / \mathrm{SnO}_{2}-\mathrm{Sb}$ anodes, respectively, indicating the enhanced electrochemical conductivity [56]. This result was also supported by another work according to which the value of Rct was decreased from $74.62 \Omega$ to $2.57 \Omega$ after the introduction of Pt at the nanoscale into $\mathrm{Ti} / \mathrm{SnO}_{2}-\mathrm{Sb}$ electrode [168].

\subsubsection{Carbon nanomaterials-based electrodes}

\subsubsection{CNTS}

CNT as anode is prone to corrosion at potential higher than 1.7-1.9 V/SCE [83], but it has been widely used as adsorbents for pollutants adsorption and electrocatalysts for pollutants electrooxidation or electrosorption in a range of small potentials and currents due to unique hollow structure and high surface area $[169,170]$.

\section{- Raw CNTs}

In order to improve the electrochemical oxidation kinetics and mass transport, electrochemical filters with 3D nanostructure have attracted much attention (Fig. 14a). In general, CNT was filtered onto the PTFE membrane as anode for use in electrochemical filtration system. A fivelayer electrochemical CNT-polyvinylidene fluoride filter was constructed for single-pass nitrobenzene removal by sequential reduction-oxidation, but not oxidation-reduction [171]. 
Aqueous dyes could be adsorbed by CNT filter surface without current application. However, over $90 \%$ of dyes from influent could be oxidized when anodic potential was 2 and 3 $\mathrm{V} /(\mathrm{Ag} / \mathrm{AgCl})$ (residence time $\leq 1.2 \mathrm{~s})[172,173]$. When CNT networks were used for removal of methyl orange (MO), the primary removal mechanism during electrochemical filtration was oxidative degradation rather than physical adsorption. Compared with $\mathrm{MO}$, tetracycline (TC) with multiple functional groups/moieties, tended to adsorb onto the $\mathrm{sp}^{2}$ conjugated $\mathrm{CNT}$ sidewalls. However, the MO removal was more effective at high potential with high energy consumption [174]. It was observed that the efficiency of electrochemical filtration was a function of CNT surface chemistry [172]. When CNT networks were used to remove nonsorptive ferrocyanide, electro-oxidation kinetics of ferrocyanide had good relationship with BET specific surface area of the CNT at a low anodic potential $(\leq 0.2 \mathrm{~V} /(\mathrm{Ag} / \mathrm{AgCl})$, indicating that the $\mathrm{sp}^{2}$ sidewalls were the predominant reaction sites. At a higher anodic potential $(\geq 0.3$ $\mathrm{V} /(\mathrm{Ag} / \mathrm{AgCl})$, the differential ferrocyanide electrooxidation kinetics in CNT tips and sidewalls correlated well with the $\mathrm{O} / \mathrm{C}$ ratio of the CNT networks. It illustrated that the oxy-tips also contributed to attain faster electrochemical kinetics [175]. Aqueous chloride and iodide were also oxidized with minimal overpotential, which was limited by active sites on CNT surface [173].

Therefore, many parameters have effected the electrochemical filtration system, e.g., oxidative fluxes and anodic potential. 95\% 17ß-estradiol and 17 $\alpha$-ethinylestradiol were removed by CNT electrochemical filter when the oxidative fluxes were more than $2.94 \pm 0.05 \mathrm{mmol} \mathrm{h}^{-1} \mathrm{~m}^{-2}$ at the voltage of $2.5 \mathrm{~V}$ [176]. An anodic MWCNT micro-filter was applied to remove and inactivate viruses $\left(\mathrm{MS}_{2}\right)$ and bacteria (Escherichia coli $($ E. coli)). When the anodic potential was $2 \mathrm{~V}$ and $3 \mathrm{~V} /(\mathrm{Ag} / \mathrm{AgCl})$, the sieved bacteria and adsorbed viruses could be removed over $75.0 \%$ and $99.6 \%$ for $30 \mathrm{~s}$ post-filtration, respectively, indicating that it was promising at the point-of-use of drinking water treatment [173]. In addition, graphene is another kind of carbon 
nanomaterials with large surface area and conductivity, which also exhibit $\mathrm{sp}^{2}$ carbon atoms with CNT. The addition of graphene to CNT increased the water permeation rate and decreased the liquid residence time to $0.44 \mathrm{~s}$. When graphene: CNT ratio was 7:3, the filter performance was the best because it achieved the balance between low specific surface area and high conductivity of CNTs [177].

Additionally, the target pollutants were degraded into intermediates, which coated electrodes by forming polymer. The presence of polymer and intermediate may negatively affect the efficacy and efficiency of the device toward practical application. When an anodic potential of 1.6 V/(Ag/ $\mathrm{AgCl})$ was applied to CNT network for $4 \mathrm{~h}$, CNT film was passivated due to pollutants polymerization on the CNT network, reducing reaction current and electrochemical performance (Fig. 14b). To obtain an active (non-passivated) CNT network to remove polymer on electrode, electrode regeneration was necessary, and it was more effective to prevent the formation of polymers at higher potentials (Fig. 14c). The method of calcination and redispersion was effective ( $>97 \%$ ) for the removal of the passivating electropolymer coating [178].

The oxidation and adsorption at the CNT electrode, especially for Fenton reaction (Fe was loaded in cathode materials), could be combined, allowing a promising process for effective wastewater treatment [179-182]. The increase in surface area of cathode led to decrease the cathodic resistance for charge transfer, which was beneficial to anodic potential and electrooxidation [183]. The total organic carbon (TOC) removal rate by the coupled process between anodic oxidation and EF was 4 times higher than that of individual processes [184]. In addition, electrochemical oxidation could combine with other technology (forward osmosis and ozonation) based on the CNT filter $[175,185]$. This could simultaneously achieve the removal of both phenol (3.2-fold increase) and soluble salts in forward osmosis, and decrease polymer 

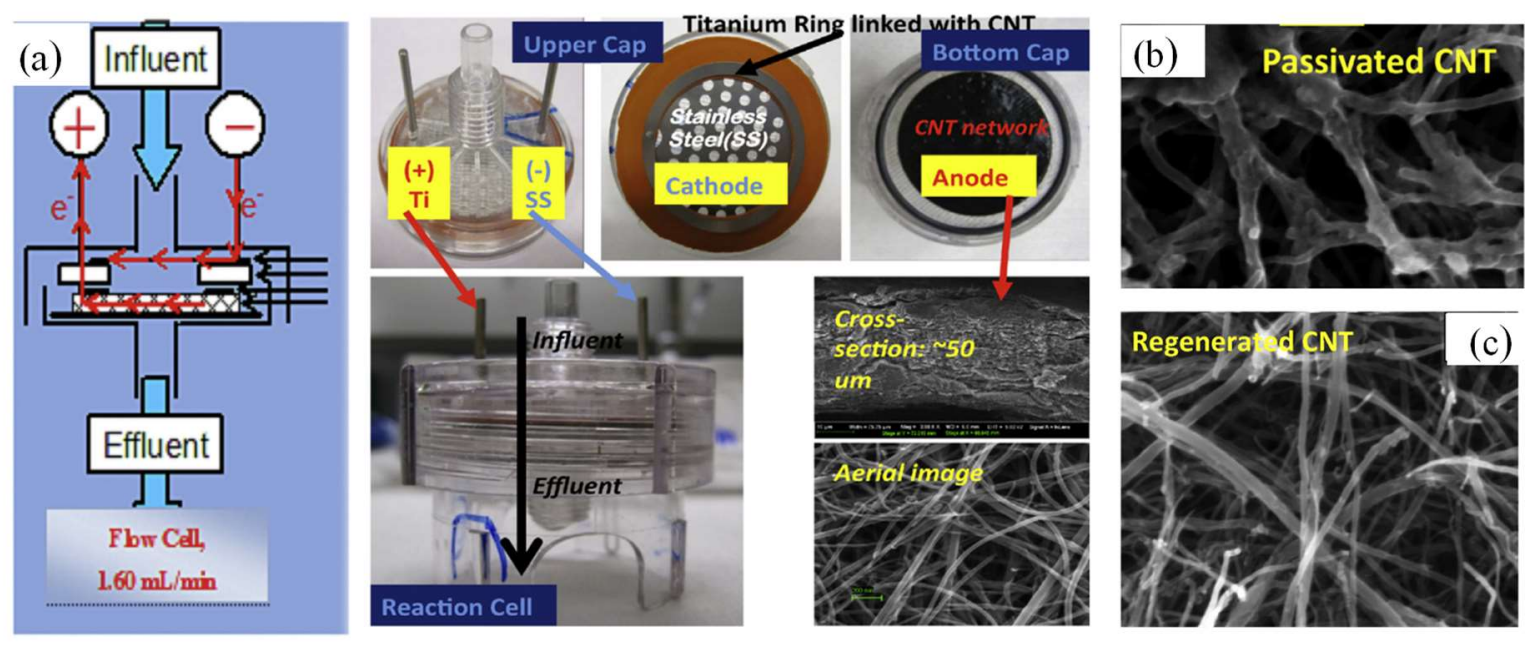

Figure 14. (a) Depiction and images of the CNT electrochemical filtration apparatus, i.e. real images of the whole reaction cell (including the upper cap and bottom cap), anode components (titanium ring and CNT network with cross-section and aerial images) and cathode (the perforated stainless steel), (b) SEM image of the fresh and passivated CNT network, respectively, and (c) SEM image of regenerated CNT. Reproduced with permission from Ref. [178]. Copyright (2013) Elsevier.

\section{- CNTs modification}

\section{(1) Chemical surface treatments}

After anodic oxidation, CNT will inevitably undergo surface oxidation, which has certain effect on electrochemical performance. Calcination of CNT to remove amorphous carbon can lead to the opening of the ends of crude CNTs. Oxygen functional groups were generated during acid treatment. $\mathrm{HCl}$ treatment is advantageous compared to $\mathrm{HNO}_{3}$ treatment since CNT exhibits 
more surface $\mathrm{sp}^{2}$-bonded carbon positively charged in the former case and this leads to adsorb pollutants negatively charged. In the case of $\mathrm{HNO}_{3}$ treatment CNT has negatively charged surface oxy-groups that have a longer effective retention time for adsorption and oxidation of pollutants with positive charged [172]. The pre-anodization of CNT sodium sulfate electrolyte increased hydroxyl group (-COH) and decreased carboxyl group (-COOH) compared with raw CNT, resulting in an increased anodic phenol mineralization by two-time [184]. However, when CNT was refluxed in nitric acid, the decisive functional group was $-\mathrm{COOH}$, resulting in a decrease of phenol mineralization by two-time (Fig. 15a). The reason was that hydrophilic $\mathrm{COH}$ groups were beneficial to electron transfer (Fig. 15b) and exhibited more defect sites under a similar $\mathrm{O} / \mathrm{C}$ ratio. In addition, the formation of $-\mathrm{COOH}$ would lead to breaking of $\mathrm{C}-\mathrm{C}$ bond conducting to a negative effect on CNT electrochemical activity [184].

In another work, CNT was modified by sodium dodecyl benzene sulfonate (SDBS) and then dipped on polyurethane sponges as conductive nano-sponge filtration [186]. The removal efficiency of tetracycline decreased when excess SDBS was treated by concentrated $\mathrm{HNO}_{3}$. The electro-oxidation flux of this system could reach $0.87 \pm 0.04 \mathrm{~mol} \mathrm{~h}^{-1} \mathrm{~m}^{-2}$, which was 36 -folds more than raw CNT filtration due to the decrease of the actual filter cross-sectional area [183]. However, forming polymer/precipitate from intermediates was easier to block the active sites, decreasing the catalytic activity.

\section{(2) Heteroatom doping}

Heteroatom doping of CNT was developed to improve its electrochemical filtration action for effective oxidation of pollutants. Boron and nitrogen-doping (B-CNT, N-CNT) with $1 \%$ of heteroatom as well as raw CNT were used as anode for phenol removal. It was found that the three anodes were all able to remove approximately 7 to $8 \mathrm{mg} \mathrm{C} \mathrm{L}^{-1}$ of the influent TOC within the $1 \mathrm{~s}$ liquid residence time at the anodic potential of $1.6 \mathrm{~V} /(\mathrm{Ag} / \mathrm{AgCl})(\mathrm{Fig} .15 \mathrm{c})$ [187]. 
Although, the TOC removal was similar for all anodes, B-CNT led to a greater extent of phenol oxidation and yield to a higher fraction of by-products that did not polymerize. According to the TGA and current change measurements, the B-CNT exhibited most stable and resistance performance toward electrochemical passivation with the lowest extent of electrochemical polymer and precipitate formation (Fig. 15d). It was suggested that it might be the optimal CNT for anodic processes [187].

\section{(3) Metal doping}

Sb-doped $\mathrm{SnO}_{2} \mathrm{CNT}\left(\mathrm{Sb}-\mathrm{SnO}_{2}-\mathrm{CNT}\right)$ exhibited high over-potential and electrocatalytic surface area compared with heteroatom doping CNT [172]. A nanoscale tin oxide modified CNT $\left(\mathrm{SnO}_{2}-\mathrm{CNT}\right)$ was prepared via electrosorption-hydrothermal protocol to apply it in a continuous-flow system as anode. $\mathrm{SnO}_{2}$ nanoparticles were uniformly distributed on the sidewalls of CNT, resulting in a rougher tubular surface and an increased tube diameter [188]. The OEP of $\mathrm{SnO}_{2}$-CNT and BTO-CNT (CNT uniformly coated with bismuth-doped tin oxide nanoparticles) was, respectively, $580 \mathrm{mV}$ and $440 \mathrm{mV}$ higher than that of raw CNT (1.27 V vs $\mathrm{Ag} / \mathrm{AgCl})$. It resulted in an excellent anodic stability for ammonia transformation over three consecutive cycles $[188,189]$. TOC removal by BTO-CNT was two to eight-time higher and energy consumption was 0.2-time than that of raw CNT anode [189]. CNT loaded with Sb$\mathrm{SnO}_{2}$ and $\mathrm{Bi}-\mathrm{Sb}-\mathrm{SnO}_{2}$ enhanced the degradation rate of phenol by 1.5 and 2.1 -folds, respectively and this enhancement was attributed to an effective generation of ${ }^{\circ} \mathrm{OH}$ [190]. Only $0.8 \mathrm{mg} \mathrm{L}^{-1} \mathrm{Sn}^{4+}$ was measured after $1.5 \mathrm{~h}$ electrolysis, indicating good stability of the anode materials [188]. In addition, $\mathrm{Ti}^{4+}$ was adsorbed on the CNT surface and further formed the $\mathrm{TiO}_{2}$ modified $\mathrm{CNT}$ filters $\left(\mathrm{TiO}_{2}-\mathrm{CNT}\right)$ via electrosorption-hydrothermal process. In this electroactive filter system, simultaneous detoxification and sequestration of $\mathrm{Sb}$ (III) were fulfilled within $\mathrm{pH}$ ranging from 3 to 11 [188]. Therefore, metal doping CNTs as anode 
(a)
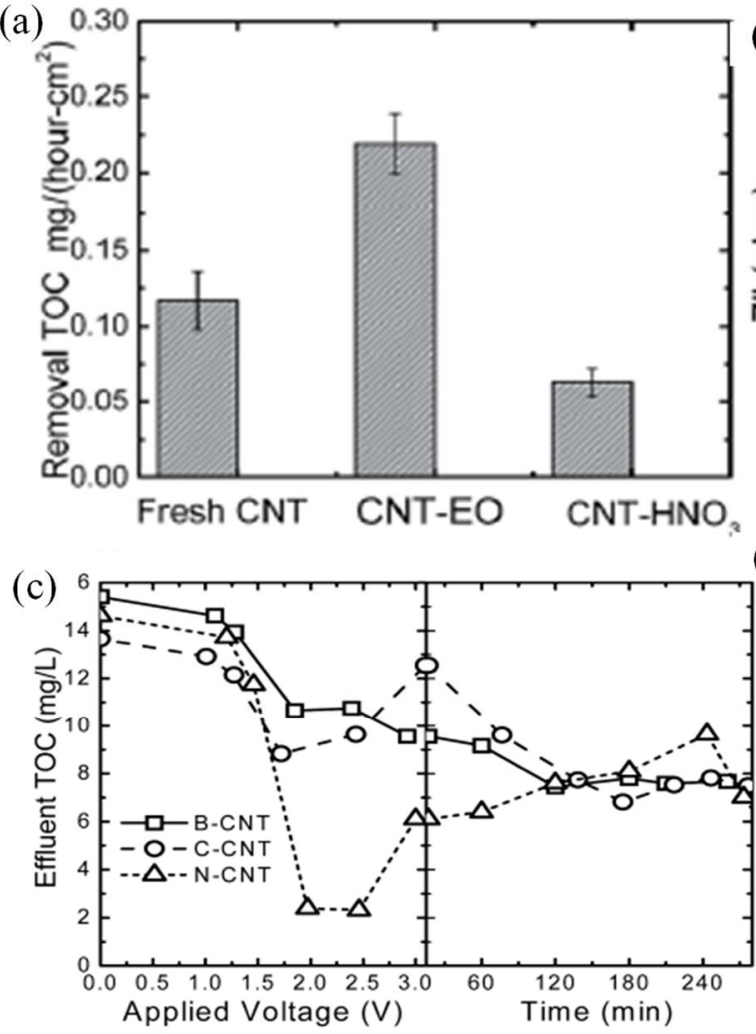
increased conductivity, OEP and stability.

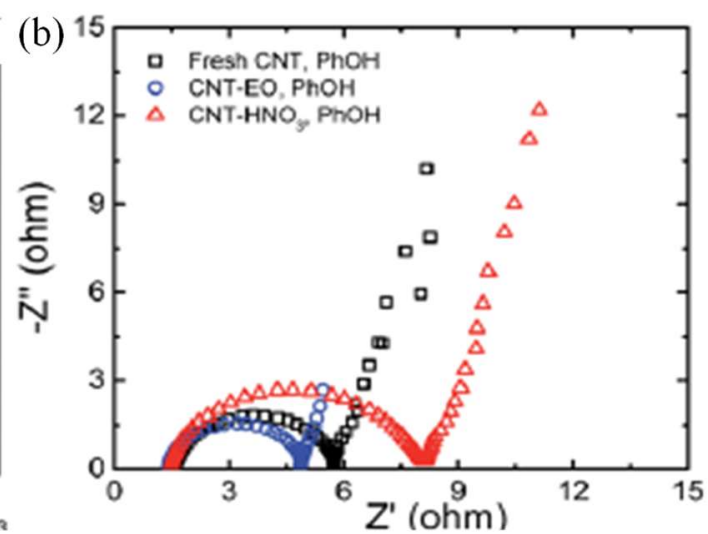

(d)

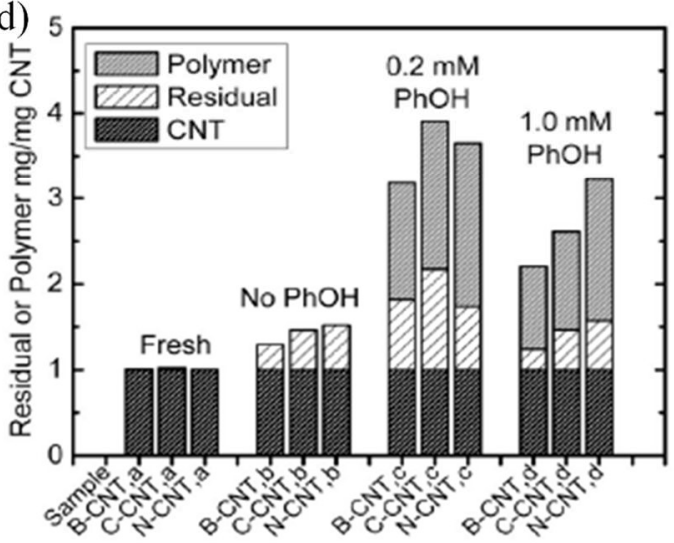

1004

1005

1006

1007

1008

1009

1010

exhibited excellent reactivity, current efficiency and lower energy consumption due to

1003

Figure 15. Anodic performance evaluation of the CNT samples. Electrochemical conditions were flow rate $=1.6 \mathrm{~mL} \mathrm{~min}^{-1}$, $[\mathrm{phenol}]=1.0 \mathrm{mM}$ and $\left[\mathrm{Na}_{2} \mathrm{SO}_{4}\right]=100 \mathrm{mM}$ unless otherwise noted. (a) Average TOC removal rate over 180 minutes of continued electrochemical filtration at an anodic potential of $1.6 \mathrm{~V} /(\mathrm{Ag} / \mathrm{AgCl})$; (b). EIS was measured with a three-electrode system over a frequency range of $0.1-10^{6} \mathrm{~Hz}$. Reproduced with permission from Ref. [184]. Copyright (2015) Royal Society of Chemistry. Effluent total organic carbon (mg C L ${ }^{-1}$ ) versus applied voltage (V) and time (min) (c) and percent CNT, residual, and polymer versus CNT network (d). Reproduced with permission from Ref. [187]. Copyright (2012) American Chemical Society. 
1014

1015

1016

1017

1018

1019

1020

1021

1022

1023

1024

1025

1026

1027

1028

1029

1030

1031

1032

1033

1034

1035

1036

\subsubsection{Boron-doped diamond (BDD) anode}

BDD is one of the most promising electrodes in the field of electrocatalysis due to its low background current, noise signals, wide potential window, high mechanical strength and corrosion resistance and long-term response stability [191]. BDD has been considered as an excellent anode material for the electrochemical treatment of wastewater at a wide $\mathrm{pH}$ range, due to its unique and excellent properties compared with dimensionally stable anodes (DSA) [192-194]. At present, BDD electrode has promising prospect in wastewater treatment especially for mineralization of bio-refractory organic pollutants [195,196]. Furthermore, when BDD was used as anode in electro-Fenton $(\mathrm{EF})$ process, the pollutants removal would be greatly improved [17,197]. It has been proved that boron doping level of BDD had obvious effect on the diamond crystallites and the active sites on the surface, resulting in a better oxidation performance.

\section{- Substrates-based BDD anode}

\section{(1) Titanium substrate}

After BDD film deposition on Ti substrate via CVD process (Fig. 15a), porous Ti was uniformly covered by BDD film, showing well-faceted crystal with the crystal size being in the range of 1-2 $\mu \mathrm{m}$ [198]. 3D structure of porous Ti/BDD exhibited excellent electrochemical effective surface area for electron transfer (3.2-time) and high OEP for ${ }^{\circ} \mathrm{OH}$ generation compared to flat Ti/BDD [199]. The contact angle of porous Ti/BDD electrodes were $135^{\circ}$ compared to $72^{\circ}$ of flat $\mathrm{Ti} / \mathrm{BDD}$ electrodes, indicating that the microstructure of polycrystalline BDD could also improve the hydrophobicity to some extent. The thickness of diffusion layer of porous Ti/BDD $(69 \mu \mathrm{m})$ was much less than that of flat BDD $(117 \mu \mathrm{m})$, which was decisive for mass transfer coefficient of porous Ti/BDD $\left(1.31 \times 10^{-5} \mathrm{~m} \mathrm{~s}^{-1}\right)$ compared to that of flat BDD $\left(7.71 \times 10^{-6} \mathrm{~m} \mathrm{~s}^{-1}\right)$ 
1037

1038

1039

1040

1041

1042

1043

1044

1045

1046

1047

1048

1049

1050

1051

1052

1053

1054

1055

1056

1057

1058

1059

1060

[200]. With the increase of boron concentration, the grain size of Ti/BDD was more obvious, exhibiting more stable electrochemical properties (Fig. 17a-b) [201]. Through LSV curve measurements, it was found that oxidation peak for aspirin was observed, shifting positively with the increase of aspirin concentration. Importantly, porous Ti/BDD electrode exhibited outstanding direct electrochemical oxidation ability for aspirin with the step currents 1.4-1.8 times of the values of flat Ti/BDD electrode, which was beneficial to direct oxidation of aspirin. The apparent rate constants $\left(k_{\mathrm{app}}\right)$ of porous Ti/BDD for anodic oxidation of aspirin was 1.98 times of flat $\mathrm{BDD}$ and 7.20 times of $\mathrm{PbO}_{2}$ electrode, which could be ascribed to the more active sites provided by porous film to generate ${ }^{\circ} \mathrm{OH}$ [202]. Porous Ti/BDD electrodes exhibited excellent stability (service life: $111 \mathrm{~h}$ ) than plate Ti/BDD $(89 \mathrm{~h})$, indicating that porous Ti improved the stability of Ti/BDD electrode (Fig. 17c) [198]. The different utilization efficiency of porous electrode surface led to discrepancy between promotion of current efficiency and enhancement of ${ }^{\circ} \mathrm{OH}$ [203]. On the other hand, the current efficiency of porous Ti/BDD was smaller than that of plate anode because the surface could not be exploited completely in a mass transport control situation (Fig. 17d).

Porous Ti/BDD anode presented excellent potential in anodic oxidation and mineralization of different pollutants (e.g., dyes, pharmaceuticals, phenols, etc.) [199,202,204,205].

\section{(2) Silicon substrate}

A BDD nanowire (BDDNW) electrode via metal-assisted chemical etching of $\mathrm{Si}$ and electrostatic self-assembly of nanodiamond seeding was prepared (Fig. 16b) [206]. The average length and thickness of nanocrystalline BDD on Si substrate were $200 \mathrm{~nm}$ and $750 \mathrm{~nm}$, respectively. The effective surface area of BDDNW was 3 times higher than that of plat BDD, providing substantially greater electrochemical reaction sites for ${ }^{\circ} \mathrm{OH}$ generation. The phenol removal by BDDNW and plate BDD was $97 \%$ and $79 \%$, respectively, and the phenol 
mineralization by BDDNW was 2.27-folds than that of plate BDD anode. These results suggested that BDDNW electrode was much more efficient in electrooxidation of phenol.

\section{(3) Platinum substrate}

In addition, 3D-Pt nanosheet perpendicular to BDD film was prepared by the double template method (hydrogen bubble template and metallic $\mathrm{Zn}$ template for displacement reaction) to control the morphology. The length and thickness of the Pt nanosheet were about 1 $\mu \mathrm{m}$ and $10 \mathrm{~nm}$, respectively. Due to the size effect of the Pt and active effect of the BDD, Pt nanosheet/BDD electrode had higher electrocatalytic activity and active sites, facilitating the pollutants degradation [207].

\section{(4) Nickel foam substrate}

The BDD could also be loaded on the Ni foam by CVD to form the 3D-BDD [208]. Compared with 2D-BDD (Ti sheet as substrate), the electroactive surface area of 3D-BDD increased by 20-time. Thanks to the fluid flow channel, the 3D-BDD electrode exhibited highly efficient electrochemical oxidation of RB-19. The apparent reaction rate constant, energy consumption, and mineralization current efficiency (MCE) were $1.487 \mathrm{~min}^{-1}, 0.03 \mathrm{kWh}(\mathrm{gTOC})^{-1}$ and $326 \%$, respectively (electrolyte: $0.1 \mathrm{M} \mathrm{Na}_{2} \mathrm{SO}_{4}$ was $0.1 \mathrm{M}$; current was $0.3 \mathrm{~A}$; $400 \mathrm{mg} \mathrm{L}^{-1} \mathrm{RB}-19$; time: $180 \mathrm{~min}$ ) 3D-BDD electrodes prepared with different ppi (pores per inch) of Ni foam had different electro-oxidation performance [209]. The COD removal rate and energy consumption of $3 \mathrm{D}-\mathrm{BDD}_{1}(50 \mathrm{ppi})$ were 1.5 -time and $25 \%$ of that of $3 \mathrm{D}-\mathrm{BDD}_{2}(35$ ppi-30), respectively.

\section{- Composite electrodes with BDD and other materials}

\section{(1) $\mathrm{TiO}_{2}$}

$\mathrm{TiO}_{2} / \mathrm{BDD}$ heterojunction electrodes were prepared via CVD method by dip-coating $\mathrm{TiO}_{2}$ nanoparticles onto BDD electrodes at $700^{\circ} \mathrm{C}$, exhibiting $20 \mathrm{~nm} \mathrm{TiO} 2$ nanoparticles. When boron $\left(2 \times 10^{21} \mathrm{~cm}^{-3}\right) /$ carbon $\left(\left(2 \times 10^{19} \mathrm{~cm}^{-3}\right)\right)$ _ratio in gas phase $1000 \mathrm{ppm}$ and covered $500 \mathrm{~nm}$ thick 
$\mathrm{TiO}_{2}$ layer, this nanostructure of p-n junction was beneficial to the hole injection [210]. The photoelectrocatalytic activity of mixed-phase $\mathrm{TiO}_{2} / \mathrm{BDD}$ electrode in $700{ }^{\circ} \mathrm{C}$ was 3 -fold of that obtained at pure anatase $\mathrm{TiO}_{2} / \mathrm{BDD}$ electrode in $450{ }^{\circ} \mathrm{C}$, which was caused by the improvement of the active area [211]. When composite $\mathrm{TiO}_{2} / \mathrm{BDD}$ electrode was prepared via electrophoretically deposited method, the thickness of $\mathrm{TiO}_{2}$ layer on the BDD surface was 14.68 $\mu \mathrm{m}$, exhibiting great ability and stability [212]. The electrocatalytic activity of $\mathrm{TiO}_{2} / \mathrm{BDD}$ was proved to be improved due to the greater electroactive area compared with BDD. For instance, the degradation of Acid Blue 80 by $\mathrm{TiO}_{2} / \mathrm{BDD}$ in photoelectrocatalysis (PEC) was enhanced compared to $\mathrm{BDD}$ due to the higher electroactive area of the nanostructured $\mathrm{TiO}_{2}$ deposition, showing promising prospect for application [212].

\section{(2) $\mathrm{SnO}_{2}$}

Sb-doped $\mathrm{SnO}_{2}$ film was constructed on $\mathrm{BDD}\left(\mathrm{Sb}-\mathrm{SnO}_{2} / \mathrm{BDD}\right)$ by a sol-gel method [213] with a bifunctional electrode interface: innumerable, uniform, nanosized $\mathrm{SnO}_{2}$ particles and some BDD polycrystallites. For clofibric acid degradation, the reaction rate constant of Sb$\mathrm{SnO}_{2} / \mathrm{BDD}$ was 1.6-time higher than with BDD. This effect has been explained by its high OEP $(2.23 \mathrm{~V} / \mathrm{SCE})$ versus that of BDD $(2.35 \mathrm{~V} / \mathrm{SCE})$ and good conductivity (with electrical resistance of $175 \Omega$ compared to that of BDD: $3850 \Omega$ ). It would therefore be a promising anode for wastewater remediation.

\section{(3) $\mathrm{Ni}$}

Polycrystalline BDD on Ta substrate via electron-assisted hot filament CVD and Ninanoparticle-assisted plasma etching was prepared, providing a method for obtaining a regular porous nanostructure on the BDD surface (Fig. 16c) [214]. The etching process and the formation of the porous nanostructure on the BDD were investigated by changing the $\mathrm{Ni}$ sputtering time and the BDD etching time. When a porous BDD film was sputtered with Ni for $10 \mathrm{~s}$ and etched for $2 \mathrm{~min}$, holes less than $200 \mathrm{~nm}$ size were densely distributed on the BDD 
surface, with square and triangular holes present on the (100) and (111) phases, respectively. Compared with plate BDD electrode, porous BDD/Ta exhibited excellent electron transfer via effective electroactive surface area $(2.43$-fold $)$ and a pseudo-first-order reaction rate of 0.02 $\min ^{-1}$ for electrochemical oxidation of methylene blue.

\section{(4) $\mathrm{Au}$}

The dendritic Au/BDD was successfully prepared with well-defined fractal structure and 0.24 $\mathrm{nm}$ space between the branch and the trunk [215]. This structure exhibited better reversibility than BDD electrode due to the difference between anodic and cathodic peaks. The dendritic $\mathrm{Au} / \mathrm{BDD}$ with single crystal dendritic Au with dominant (111) facet exhibited numerous physisorption and chemisorption sites [215]. It was indicated that dendritic Au/BDD exhibited better electrocatalytic oxidation for the sulfur containing target contaminant with higher selectivity than phenol due to preferential adsorption of target molecules to form $\mathrm{Au}-\mathrm{S}$ bonds, resulting in electron transfer between $\mathrm{Au}$ and S [215].

In summary, nanostructuring the surface of BDD anodes (e.g., porous diamond, diamond nanowires, etc.) enhanced the degradation performance towards organic pollutants. It could further improve the electrochemical performance due to the increasing surface area for adsorption capacity, porous structure for electron transfer and rough surface for extending the life of the composite electrode. 
(a)

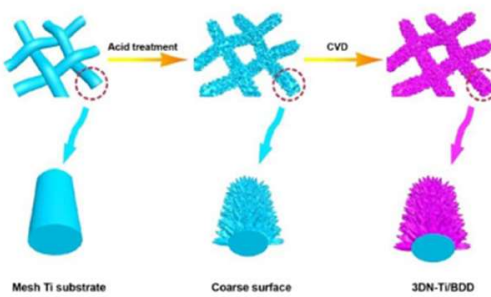

(c)

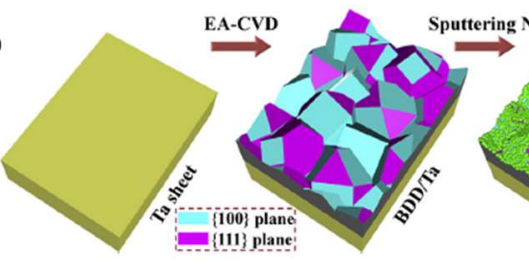

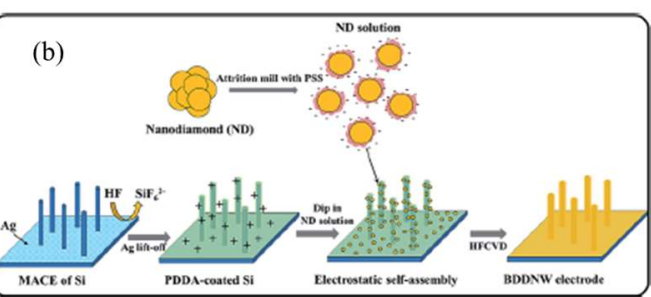

$\mathrm{H}_{2} /$ Ar plasma etching ind $\quad$ Removal of $\mathrm{Ni}$

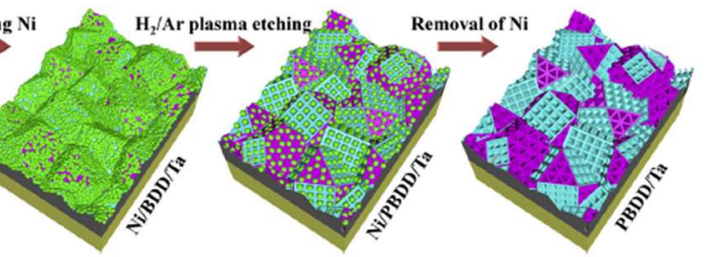

Figure 16. (a) Schematic diagram of fabrication process for 3DN-BDD film electrode.

Reproduced with permission from Ref. [200]. Copyright (2016) Royal Society of Chemistry;

(b) Schematic of the fabrication process for a BDDNW electrode. Reproduced with 
(a)

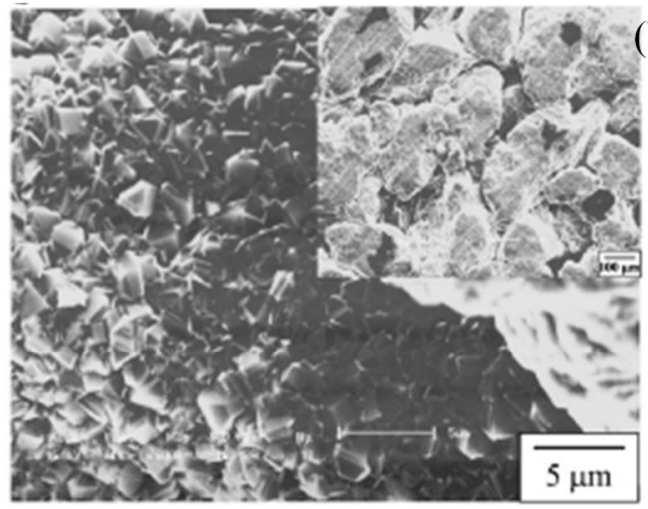

(c)

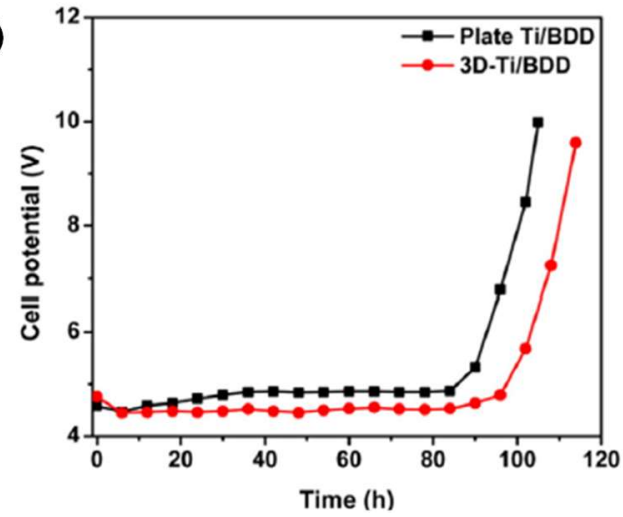

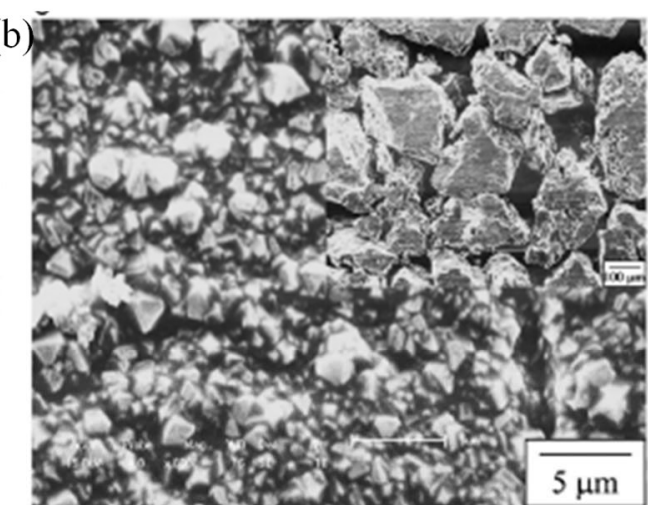

(d)

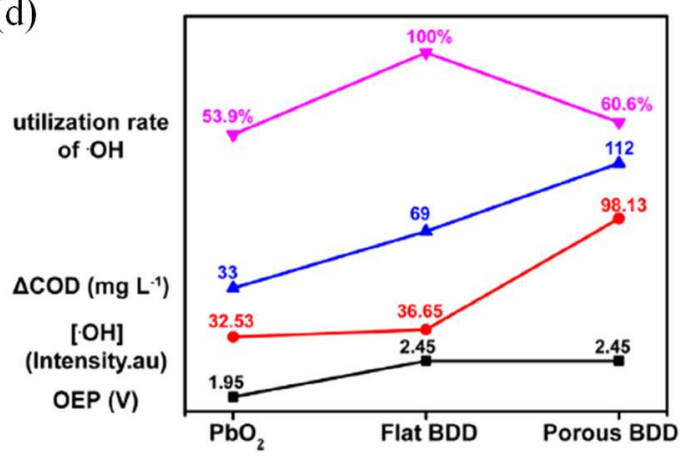

Figure 17. SEM images porous Ti/BDD electrodes: (a) Ti/BDD electrode for high boron concentration and (b) low boron concentration; inset: SEM images with low magnification corresponding to the electrodes. Reproduced with permission from Ref. [201]. Copyright (2012) Elsevier. (c) Accelerated life between plate and 3D-Ti/BDD electrodes in $3 \mathrm{~mol} \mathrm{~L}^{-1}$ $\mathrm{H}_{2} \mathrm{SO}_{4}$ solution. Reproduced with permission from Ref. [198]. Copyright (2015) Elsevier. Hydroxyl radical utilization rate as a function of electrode material (d) Reproduced with permission from Ref. [202]. Copyright (2015) Elsevier.

\subsubsection{Heteroatom-based electrodes}

1148 The interaction between the catalyst and interacting media could be improved when heteroatom was doped in nanostructured materials to increased active surface area and electric properties 


\subsubsection{Fluorine-doped electrodes}

Fluorine (F) doping with high potential anode could inhibit $\mathrm{O}_{2}$ evolution to improve the anodic oxidation of pollutants [217]. Because $\mathrm{F}^{-}$and $\mathrm{O}^{2-}$ have similar ionic radius, the oxygen sites on the surfaces can be replaced by $\mathrm{F}^{-}$anions [218], so that $\mathrm{F}-\mathrm{PbO}_{2}$ exhibit more regular morphology with better oriented crystals of lower size $(16.203 \mathrm{~nm})$ than for raw $\mathrm{PbO}_{2}(24.305 \mathrm{~nm})$ $[219,220]$. When F-PbO 2 film electrode was prepared by anode co-deposition, the deposition potential had obvious effect on morphology, resulting in thinner crystal grains on the F-doped $\mathrm{PbO}_{2}$ surface (Fig. 18). The spherical crystallites appeared when deposition potential was low, i.e. when F content was high (Fig. 18a-1). On the contrary, when the deposition potential was high, cracks were observed on the electrode surface (Fig. 18a-2).

(a)

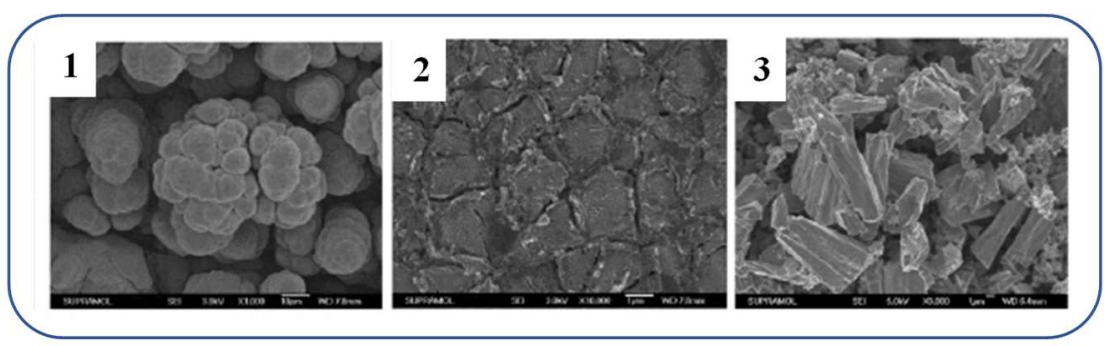

(b)

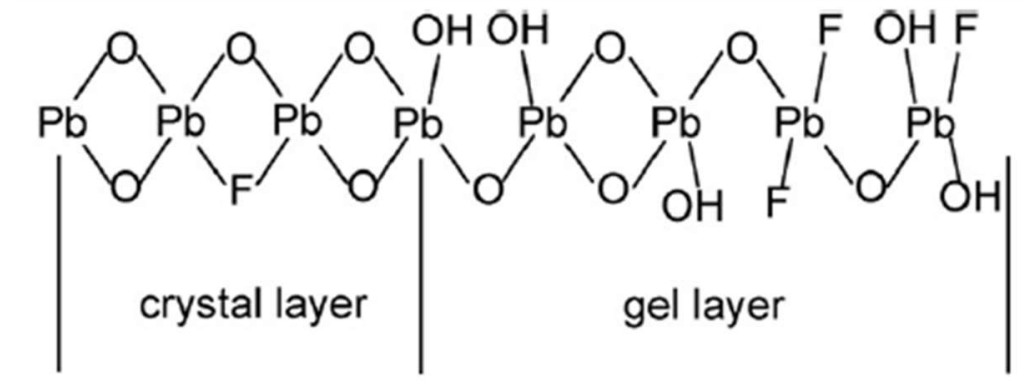

(c)

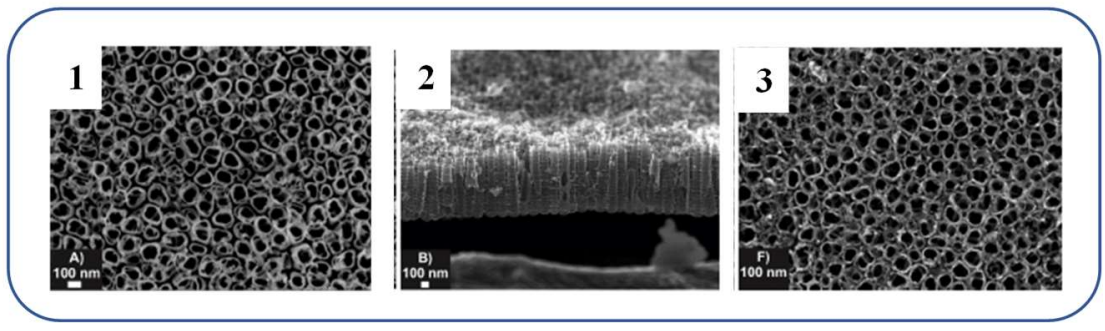

Figure 18. (a) SEM micrographs of the $\mathrm{F}-\mathrm{PbO}_{2}$ electrode with different doping content of $\mathrm{F}$ (atomic ratio of $\mathrm{F}$ to $\mathrm{Pb}, 1: 0.075: 2: 0.07: 1,3$ : free-doped $\mathrm{PbO}_{2}$ electrode). Reproduced with permission from Ref [218]. Copyright (2013) Wiley. (b) Schematic diagram of the structure 
of F-PbO 2 electrode system. Reproduced with permission from Ref. [220]. Copyright (2009) Elsevier. (c) FEG-SEM images of (1) top view of $\mathrm{TiO}_{2} \mathrm{NTs}$; (2) cross-section of $\mathrm{TiO}_{2} \mathrm{NTs}$; and (3) top view of boron-doped $\mathrm{TiO}_{2} \mathrm{NTs}$ with addition of $560 \mathrm{ppm}$ of $\mathrm{NaBF}_{4}$ in the electrolyte of nanotubes growth. Reproduced with permission from Ref [221]. Copyright (2015) Elsevier.

$\mathrm{F}-\mathrm{PbO}_{2}$ anode via decomposition methods was prepared to explore the mechanism of the effect of $\mathrm{F}$ doping on lifetime and electrochemical and degradation activity of $\mathrm{PbO}_{2}$ [220]. In Fig. 17b, $-\mathrm{OH}$ sites in gel layer were replaced by $\mathrm{F}^{-}$anions in $\mathrm{F}-\mathrm{PbO}_{2}$, decreasing free move of oxygen atoms and coverage of reactive oxygen species (ROS) [222]. The $\mathrm{O}^{2-}$ sites in crystal layer were also replaced by $\mathrm{F}^{-}$anions, decreasing the formation of free oxygen and occupying the channels of the diffusion of the free oxygen atoms $[219,222]$. Therefore, the service life of $\mathrm{F}-\mathrm{PbO}_{2}$ anode $(140 \mathrm{~h})$ was three times higher than that of $\mathrm{PbO}_{2}$. Because the average surface coverage by $\mathrm{F}$ doping was only $6 \%$, ROS on $\mathrm{F}-\mathrm{PbO}_{2}$ was still higher than raw $\mathrm{PbO}_{2}$, and the weight loss of $\mathrm{F}$ $\mathrm{PbO}_{2}$ after $140 \mathrm{~h}$ was only $2.1 \%$. In addition, removal efficiency of 4-chlorophenol reached $97 \%$ at 120 min by $\mathrm{F}-\mathrm{PbO}_{2}$ anode, while it was $88 \%$ for non-doped $\mathrm{PbO}_{2}$. The doping of the $\mathrm{PbO}_{2}$ electrode with $\mathrm{F}$ atom only had a significant effect on the pollutant degradation, but TOC removal was barely altered $[223,224]$ because of modification of surface properties to improve pollutants adsorption.

At present, fluorine-doped tin oxide (FTO), which exhibits good chemical and physical stability, high temperature resistance, low preparation cost and high electrochemical performance, was widely used as anode $[225,226]$. The FTO as non-active anode could produce reactive ${ }^{\circ} \mathrm{OH}$ to enhance oxidation efficiency. The degradation rate and mineralization yield of phenol by FTO anode could reach $0.014 \mathrm{~min}^{-1}$ and $(76 \pm 1) \%$, respectively [227]. Besides, FTO 
have a sufficiently transparent material to allow UV penetration. Therefore, it was modified in many photochemical processes [227,228].

In addition, the novel $\mathrm{F}$-doped $\mathrm{Ti} / \mathrm{SnO}_{2}$ electrode prepared by $\mathrm{SnF}_{4}$ as the single-source precursor was used for electrochemical degradation of aqueous perfluorooctanoic acid (PFOA) [229]. Compared with other $\mathrm{Ti} / \mathrm{SnO}_{2}-\mathrm{X}(\mathrm{X}=\mathrm{Cl}, \mathrm{Br}, \mathrm{I}$, or $\mathrm{Sb})$ anode, $\mathrm{Ti} / \mathrm{SnO}_{2}-\mathrm{F}$ anode exhibited smooth surface, even after accelerated lifetime test, preventing penetrating of electrolyte and generating bubbles. Therefore, higher PFOA degradation within $30 \mathrm{~min}$ and improved accelerated lifetime $(104 \mathrm{~h})$ was achieved by $\mathrm{Ti} / \mathrm{SnO}_{2}-\mathrm{F}$ than with other halogen-doped electrodes (less than 5h) (Figs. 18b and 19a). In Fig. 19c, Ti/SnO $2-F$ electrode had larger resistance and higher OEP [218,219], which was benefit to obtain electron from $\mathrm{H}_{2} \mathrm{O}$ or PFOA and to physical adsorption of ${ }^{\bullet} \mathrm{OH}$ on non-active anode. Therefore, it was possible that $\mathrm{F}$-doping decreased the amount of oxygen vacancy in $\mathrm{SnO}_{2}$ and provided lower possibility of oxygen transfer from ${ }^{\circ} \mathrm{OH}$ into crystal lattice. This further improved the stability of electrode material.
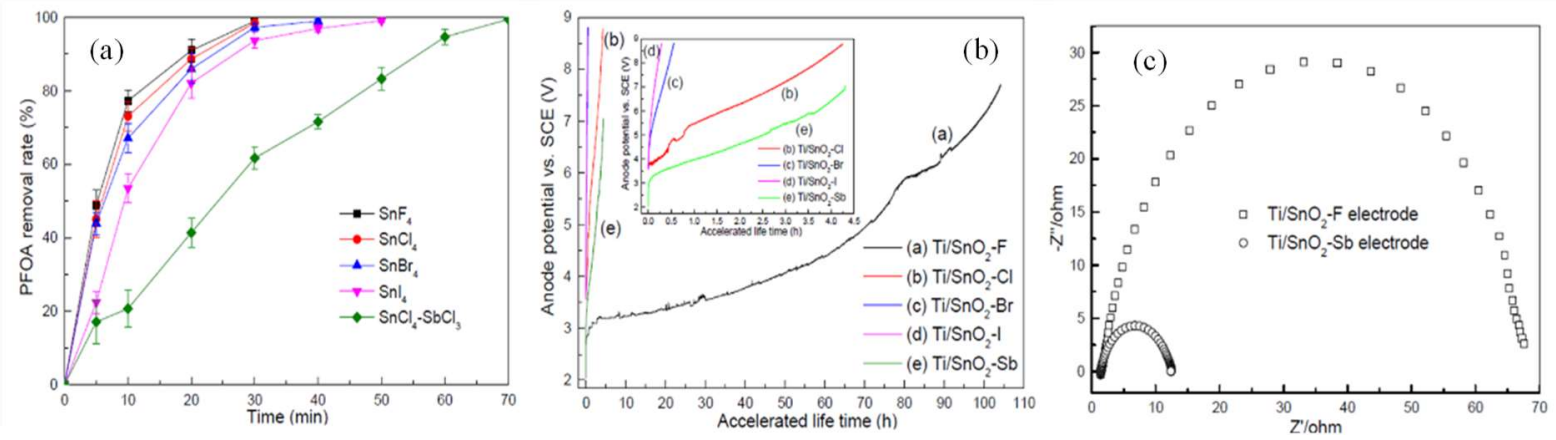

Figure 19. Effect of different precursors on the degradation rate of PFOA using different Snbased anodes (a); Accelerated life test of freshly prepared electrodes (b), the inset being the enlarged view of accelerated life tests for the prepared electrodes except $\mathrm{Ti} / \mathrm{SnO}_{2}-\mathrm{F}$ electrode); and Nyquist plot for $\mathrm{Ti} / \mathrm{SnO}_{2}-\mathrm{F}$ and $\mathrm{Ti} / \mathrm{SnO}_{2}-\mathrm{Sb}$ electrode (c). Measurement conditions: EIS (solution $=10 \mathrm{mM} \mathrm{NaClO}_{4}$, voltage amplitude $=5 \mathrm{mV}$, frequency range $=10^{-}$ 
${ }^{1} \sim 10^{5} \mathrm{~Hz}$, bias $\left.=1.8 \mathrm{~V} / \mathrm{SCE}\right)$. Reproduced with permission from Ref [229]. Copyright (2015) Elsevier.

\subsubsection{Boron-doped electrodes}

Due to its high electrical conductivity, the BDD anode was widely used in EAOPs. Therefore, the boron doped on other anode materials were suggested to achieve even higher activity. Bdoped $\mathrm{TiO}_{2}$ nanotubes $\left(\mathrm{B}-\mathrm{TiO}_{2} \mathrm{NTs}\right.$ ) made by electrochemical anodization (one-step doping) using $\mathrm{NaBF}_{4}$ as a boron source were prepared to degrade the dye Acid Yellow 1 (AY1) in photoelectrocatalytic processes [221]. The introduction of B did not change the morphology of $\mathrm{TiO}_{2}$ nanotubes. Different content of $\mathrm{NaBF}_{4}$ was introduced to have the $\mathrm{B}$ content from 0.4 to 0.7 at. \% in $\mathrm{B}_{-} \mathrm{TiO}_{2}$ NTs. The mineralization efficiency (90\%) of PEC for AY1 was higher than that of photocatalysis $(\mathrm{PC})$ process at $90 \mathrm{~min}$, indicating the effectiveness of $\mathrm{B}-\mathrm{TiO}_{2} \mathrm{NTs}$ in electrocatalysis process. However, the photogenerated holes can produce more hydroxyl radicals, promoting an increased mineralization rate after B-doping. There is still very limited understanding in the mechanism of B-doped electrodes for electrocatalysis. In addition, Bdoped porous $\mathrm{Si}$ (B-doped $\mathrm{pSi}$ ) nanoplates were design via air-oxidation process to decrease the resistance and surface oxidation and obtain high crystallinity, achieving high initial coulombic efficiency and long cycling stability [230].

\subsubsection{Metal- and metal oxide- based electrodes}

The main employed anodes categorized as either metal or metal oxide based nanostructured material are summarized in Fig. 20. 


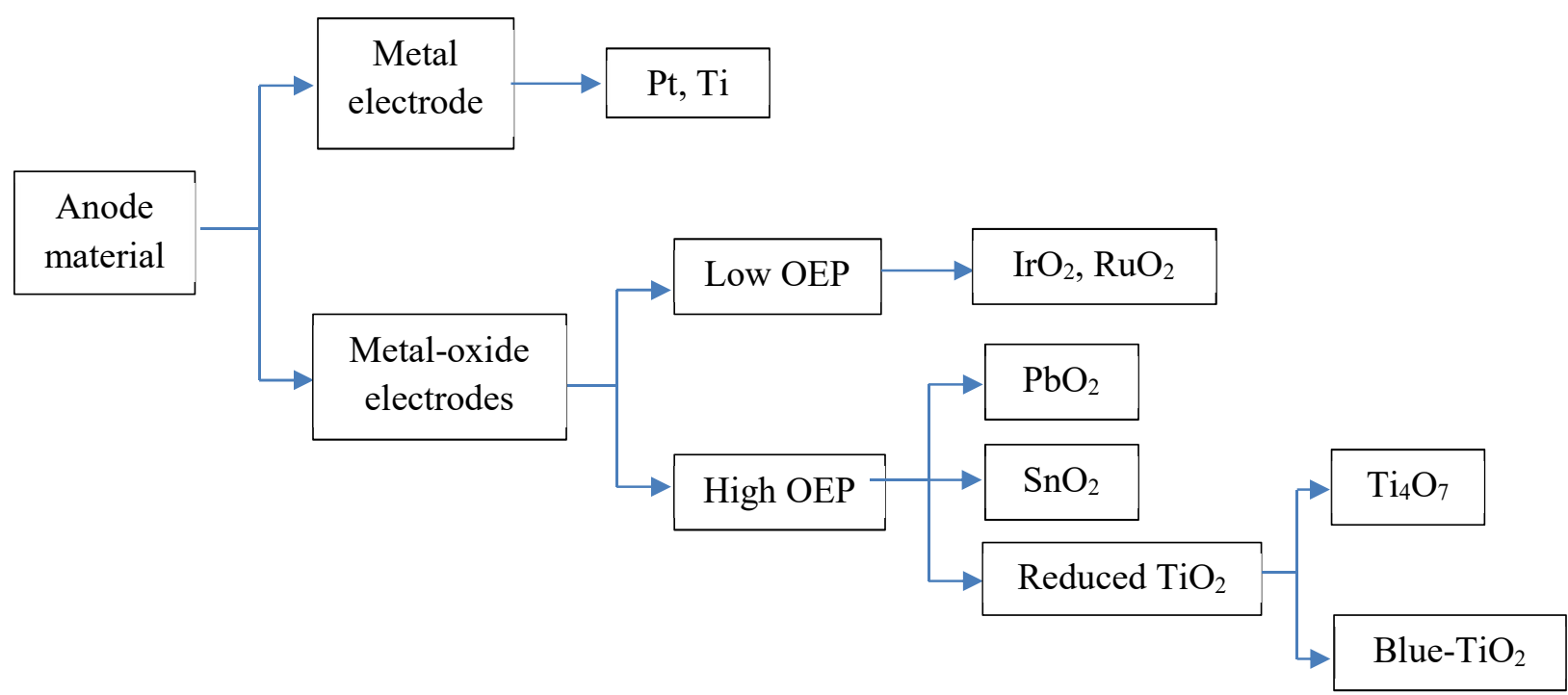

Figure 20. Classification of metal and metal-oxide based nanostructured anodes.

\subsubsection{Metal-based electrodes}

As an active anode, Pt electrode is probably the most used metal electrode for pollutants degradation due to its excellent electrocatalysis performance [231,232]. Yoon et al. (2012) investigated the use of $\mathrm{Pt}$ for degradation of phenol and 2-chlorophenol, observing 94\% phenol and 95\% 2-chlorophenol degradation at the current $300 \mathrm{~mA}$ for $3 \mathrm{~h}$. However, this performance was worse when compared to BDD anode [232]. To improve the performance of Pt anode, Chen et al. (2019) introduced nano-sized Pt (1.2-2.2 nm) into $\mathrm{Al}_{2} \mathrm{O}_{3}$ using the ethylene glycol reduction method, confirming that the decrease of the Pt particle size led to the enhancement of the catalyst ability of degrading benzene [233].

\subsubsection{Metal oxide-based electrodes}

- $\mathrm{SnO}_{2}$ electrodes

1249 Pure $\mathrm{SnO}_{2}$ cannot be used as electrode material due to a low conductivity at room temperature; 
236]. In particular, $\mathrm{Sb}-\mathrm{SnO}_{2}$ is one of the most commonly used anode in electrochemical applications.

Acting as the catalytic layer, $\mathrm{SnO}_{2}$ electrode has been widely used for pollutants degradation through the formation of heterogeneous ${ }^{\circ} \mathrm{OH}$. Zhou et al. (2019) used sol-gel method to prepare a porous $\mathrm{Ti} / \mathrm{SnO}_{2}$-Sb electrode, achieving the degradation efficiency of more than $97 \%$ in only $10 \mathrm{~min}$ at a current density of $0.2 \mathrm{~mA} \mathrm{~cm}{ }^{-2}$ [237]. Recently, self-assembled 3D hierarchical nano-structures from low dimensional nanoscale building blocks via interactions has received considerable attention. The 3D hierarchical structure assembled by two-dimensional nanoplates or nanosheets can expose larger specific surface area, therefore, they are more suitable and efficient [208,234]. Wang et al. (2019) introduced a 3D hierarchical flower-like structure (HFs) constructed by $2 \mathrm{D}$ nanosheets on Ti-based $\mathrm{SnO}_{2}$ electrode by hydrothermal method. Characterized by SEM, this $\mathrm{Ti} / \mathrm{SnO}_{2}-\mathrm{Sb}-\mathrm{HFs}$ electrode showed a denser surface layer with the nanosheet of $29 \mathrm{~nm}$ than traditional $\mathrm{Ti}_{\mathrm{SnO}}$-Sb electrode (Fig. 21). It also had a higher oxygen evolution potential $2.25 \mathrm{~V} / \mathrm{SCE}$, and a larger electrochemical active surface area (2.28-times higher) than traditional $\mathrm{Ti} / \mathrm{SnO}_{2}$-Sb electrode. Thus, for the degradation of Acid Red 73 (AR 73), the rate constant on $\mathrm{Ti} / \mathrm{SnO}_{2}$-Sb-HFs electrode was 1.58 -time higher than that of $\mathrm{Ti} / \mathrm{SnO}_{2}$ Sb electrodes [238]. 

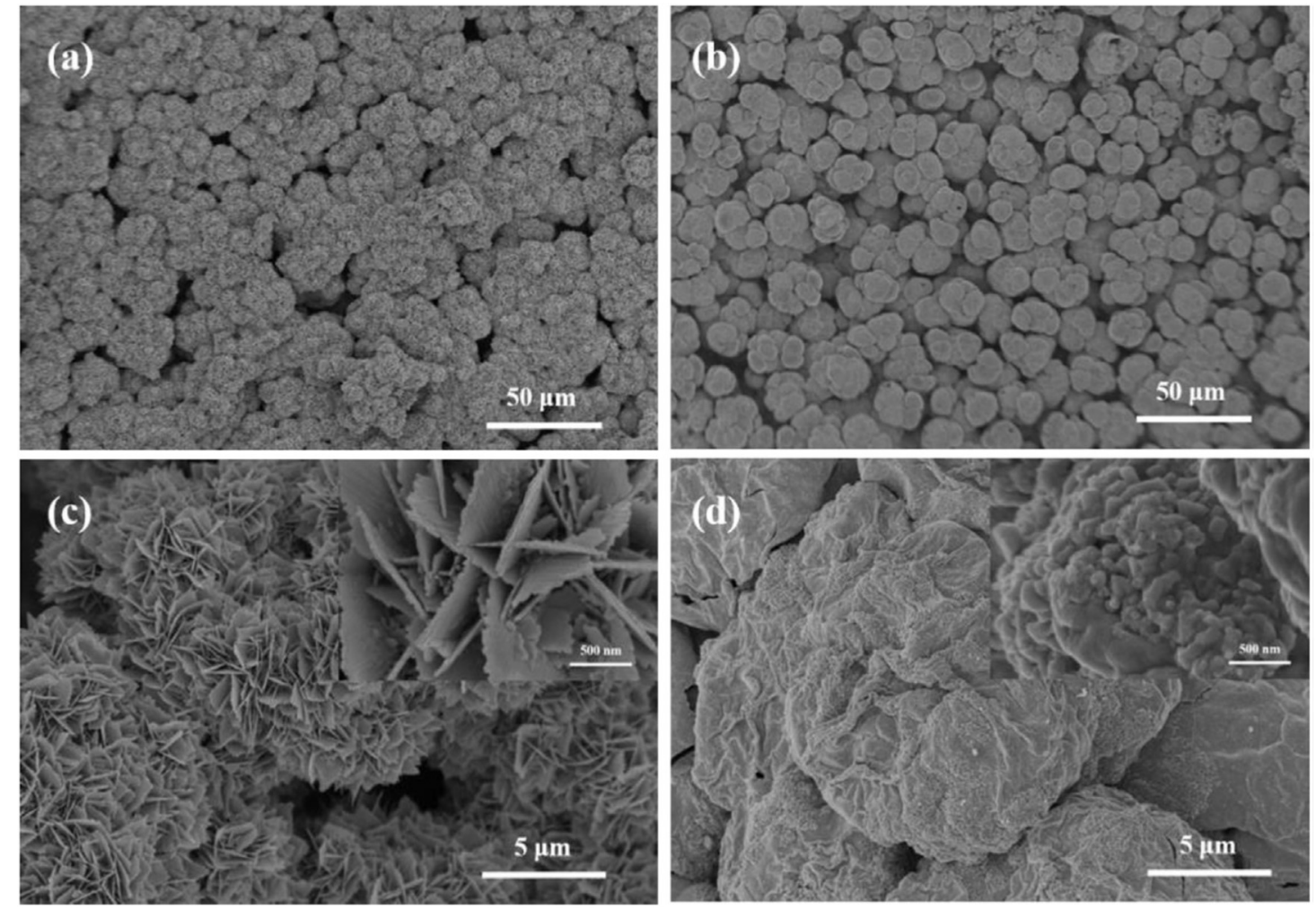

Figure 21. Surface morphologies of (a and c) Ti/ $\mathrm{SnO}_{2}-\mathrm{Sb}-\mathrm{HFs}$ electrode, $\left(\mathrm{b}\right.$ and d) $\mathrm{Ti} / \mathrm{SnO}_{2}-$

1271 On the other hand, the practical application of $\mathrm{SnO}_{2}$ anode is hampered by its poor stability

1272 because $\mathrm{SnO}_{2}$ film is easily fall of the substrate. To overcome this problem, $\mathrm{SnO}_{2}$ is always applied as the middle layer while other metal oxide as catalytic layer [239-241]. Wang et al.

1274 (2020) introduced $\mathrm{PbO}_{2}$ as the catalytic layer into $\mathrm{SnO}_{2}$ middle layer, which improved the

1275 electrocatalytic activity of $\mathrm{PbO}_{2}$ electrode because the $\mathrm{SnO}_{2}$ particles in $\mathrm{PbO}_{2}$ films improved 1276 the amount of active sites on the surface, oxygen evolution potential and ${ }^{\circ} \mathrm{OH}$ generation rate 1277 [242]. Duan et al. (2019) also introduced $\mathrm{SnO}_{2}$ nanoparticle as the middle layer, which reduced 1278 the grain size of $\mathrm{PbO}_{2}$ crystal and improved the EOP and ${ }^{\circ} \mathrm{OH}$ generation capacity obtaining a 1279 better electrochemical activity for degradation of 3-chlorophenol [243].

1280 Besides, the substrate is also an important factor for anode materials. When the nanostructure 1281 is introduced into the anode, it exhibits good electron transportation properties and help to 
generate ${ }^{\circ} \mathrm{OH}$ on electrode surface. For example, the $\mathrm{TiO}_{2}$ NTA, due to its stake structure, effectively improved the service life of the combination of $\mathrm{SnO}_{2}-\mathrm{Sb}$ function layer [241,244,245]. Chen et al. (2019) prepared a novel enhanced $\mathrm{TiO}_{2}$ nanotube arrays (ENTA)/SnO $2-\mathrm{Sb}$ electrode by the sol-gel method, which possessed a higher oxygen evolution potential and electrochemical stability when compared with the conventional $\mathrm{Ti} / \mathrm{SnO}_{2}-\mathrm{Sb}$ electrode. Its performance for the destruction of a common biocide of 2-methyl-4-isothiazolin3-one was better than that of $\mathrm{Ti} / \mathrm{SnO}_{2}-\mathrm{Sb}[56]$.

\section{- $\mathrm{PbO}_{2}$ electrodes}

$\mathrm{PbO}_{2}$ electrode has been extensively studied for organic pollutant degradation due to its good conductivity and high OEP. However, its catalysis performance is still not as satisfactory as BDD anodes [239,246-248]. Therefore, nanostructured $\mathrm{PbO}_{2}$ study has been a research trend. Tan et al. (2011) fabricated $\mathrm{PbO}_{2} / \mathrm{TNT}$ s anode which possessed stronger oxidation ability than that traditional $\mathrm{PbO}_{2}$ electrode owing to the unique microstructure [247].

\section{- ZnO electrodes}

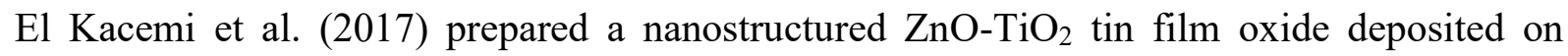
graphite felt for degradation of organic pollutants [249]. This electrode was used as anode in anodic oxidation and EF processes to remove efficiently the dye Amido Black 10B. Complete mineralization of $74 \mathrm{mg} \mathrm{L}^{-1}$ dye solution was achieved in $6 \mathrm{~h}$ at $100 \mathrm{~mA}$ constant current electrolysis [249].

\section{- $\quad$ Reduced TNT anode: $\mathrm{Ti}_{4} \mathrm{O}_{7}$ electrodes}

TNT has a poor conductivity, and many efforts have been made to improve its conductivity. One of the approach is the hydrogen reduction to obtain $\mathrm{Ti}_{4} \mathrm{O}_{7}$ electrode. Prepared by the gas mixture of $\mathrm{H}_{2}$ and $\mathrm{N}_{2}$ or $\mathrm{Ar}$ at high temperature, $\mathrm{Ti}_{4} \mathrm{O}_{7}$ electrode was used for degradation of organic pollutants because of its high conductivity and corrosion resistance. Geng et al. (2015) 
fabricated pure Magnéli $\mathrm{Ti}_{4} \mathrm{O}_{7}$ NTA by reducing $\mathrm{TiO}_{2} / \mathrm{NTA}$ with hydrogen at $850{ }^{\circ} \mathrm{C}$ for 30 min [167]. The as-prepared $\mathrm{NTA} / \mathrm{Ti}_{4} \mathrm{O}_{7}$ had a highly-ordered tubular structure with high crystallinity, large electrochemical window of water electrolysis $(2.4 \mathrm{~V} /(\mathrm{Ag} / \mathrm{AgCl}$ at $\mathrm{pH}=6.0))$ and low Ret. This anode had a $20 \%$ higher COD removal than $\mathrm{Ti}_{4} \mathrm{O}_{7}$, and was even more efficient than BDD and other types of Magnéli NTA. Wang et al. (2018) prepared $\mathrm{Ti} / \mathrm{Ti}_{4} \mathrm{O}_{7}$ electrode by plasma spraying through reducing $\mathrm{TiO}_{2}$ nanopowder [250]. They used it for the degradation of tetracycline and obtained $95.8 \%$ of degradation efficiency in $40 \mathrm{~min}$ [250]. A reactive electrochemical membrane (REM) composed of high purity $\mathrm{Ti}_{4} \mathrm{O}_{7}$ was found to be promising for water treatment applications. It achieved the highest convection-enhanced rate constant for $\mathrm{Fe}(\mathrm{CN})_{6}{ }^{4-}$ oxidation in an electrochemical flow-through reactor [251]. Oturan's group found that plasma elaborated sub-stoichiometric $\mathrm{Ti}_{4} \mathrm{O}_{7}$ ceramic electrode could constitute an alternative to BDD anode for a cost effective electro-oxidation process, and this electrode was more efficient for paracetamol degradation in $\mathrm{SO}_{4}{ }^{2-}, \mathrm{NO}_{3}{ }^{-}$and $\mathrm{ClO}_{4}{ }^{-}$media, but less effective in $\mathrm{Cl}^{-}$medium [252,253]. Their other works on imatinib degradation by EF process proved that the $\mathrm{Ti}_{4} \mathrm{O}_{7}$ anode exhibited better mineralization performance than DSA and $\mathrm{Pt}$ anode, reaching $82 \%$ TOC removal efficiency at $12.5 \mathrm{~mA} \mathrm{~cm}^{-2}$ [254].

\section{- Reduced TNT anode: Blue-TNA electrodes}

The second approach to improve the conductivity of TNT is the electrochemical reduction into Blue-TNT anode. During the electrochemical reduction of TNA, the color of TNA turns from gray to blue, forming the so-called Blue-TNA, which has been explored as the anode for electrooxidation [105,255-260]. Kim et al. (2014) revealed that Blue-TNA exhibited excellent electrocatalytic activity in generating chlorine and hydroxyl radicals, which was comparable to the commercial DSA and BDD electrodes, respectively. Thus this Blue-TNA was suggested as a potential cost-effective anodic material in industrial electrochemistry [261]. Chang et al. (2014) investigated the performance of Blue-TNA for degradation of salicylic acid (SA) [262]. It 
possessed a much higher over-potential than Pt electrode for OER, exhibiting a 6.3 times higher electrocatalytic activity toward SA oxidation. Stability tests indicated that Blue-TNA electrodes were very stable during eight cycles of electrochemical oxidation of SA [262]. The high electrocatalytic activity and stability of Blue-TNA enabled by the facile electrochemical reduction can be attributed to the decrease of $\mathrm{Ti}(\mathrm{IV})$, the increase of $\mathrm{Ti}(\mathrm{II})$ and $\mathrm{Ti}(\mathrm{III})$ and the increase of the oxygen vacancies, as well as significant improvement in the donor density. Cai et al. (2019) prepared Blue-TNA having a higher ${ }^{\circ} \mathrm{OH}$ production activity than BDD), inducing a higher TOC and COD removal of phenol with a lower energy consumption of $9.9 \mathrm{kWh}(\mathrm{kg}$ $\mathrm{COD})^{-1}[55]$

\subsubsection{Mixed metal-/ metal-oxide and carbon-based electrodes}

Due to the fact that carbon-based materials are cheaper and more modular to be adapted to specific reactor design, nanostructured metal or metal oxide deposited on the carbon material would reduce the cost of metal-based material while the electrocatalytic activity would be usually enhanced [263-266].

For the carbon based metal electrodes, the commonly used one is Pt/C. Li et al. (2013) prepared the $\mathrm{Pt}-\mathrm{Bi} / \mathrm{C}$ nanostructured electrode using square-wave potential method for the degradation of MO dye, greatly reducing the energy consumption when compared with carbon fiber electrode [263]. Besides, different supporting carbon materials significantly affect the performance of the supported Pt nano-particles. Chen et al. (2010) compared single-walled carbon nanotubes (SWNTs), MWNTs and Vulcan XC-72 carbon as the supporting carbon materials to prepare Pt electrode [264]. It indicated that Pt/SWNTs exhibited the highest current density, the lowest onset oxidation potential and the best stability for methanol electrooxidation [264]. 
1355 For the carbon-based metal oxide anodes, the mainly used one is $\mathrm{RuO}_{2}-\mathrm{TiO}_{2}$ electrodes. $\mathrm{Li}$ et al. (2018) prepared $\mathrm{RuO}_{2}-\mathrm{TiO}_{2}$ nano-graphite electrode using sol-gel and hot press technology for the degradation of ceftriaxone sodium, achieving a 97\% removal efficiency which was much higher than that on raw nano-graphite electrode (77\%) [266]. Tsele et al. (2017) indicated that the prepared $\mathrm{TiO}_{2}-\mathrm{MWCNT}$ and $\mathrm{RuO}_{2}-\mathrm{MWCNT}$ electrodes gave the best electron transport properties towards the oxidation of epinephrine compared with $\mathrm{MWCNT}, \mathrm{RuO}_{2}$ and $\mathrm{TiO}_{2}$ electrodes [265].

\section{Assessment of electrodes performance in water/wastewater} treatment

The treatment at the source of water polluted by toxic/persistent micropollutants turns out to be the most efficient and cost-effective way to avoid the contamination of natural water body [7,267-269]. The so-called methods advanced oxidation processes (AOPs) have been developed to offset the non-effectiveness of conventional treatment techniques to remove such contaminants from water $[9,33,270]$. The AOPs are the processes based on the in situ generation of strong oxidants (mainly the hydroxyl $\left({ }^{\circ} \mathrm{OH}\right)$ radicals) under mild conditions [271]. The EAOPs were emerged during last decades as among the most efficient processes for the degradation of persistent organic micropollutant $[8,16,34,272,273]$.

\subsection{Electro-Fenton process}

Among the EAOPs, the electro-Fenton (EF) process has become a popular electrochemical process for effective destruction of organic pollutants [7,273].

$\mathrm{EF}$ is an indirect EAOPs; it originates from Fenton's chemistry, which constitutes a chemical way to produce ${ }^{\circ} \mathrm{OH}$ in acidic medium from activation of $\mathrm{H}_{2} \mathrm{O}_{2}$ by ferrous iron, via the Fenton reaction (Eq. 2) [274,275]. Although the Fenton process has been applied to the treatment of 
industrial wastewater since the 1980s, the presence of several inconveniences (use of large amount of chemicals, the generation of process sludge, low efficiency due to the involvement of parasitic reactions) disadvantaged its development [267,276,277]. Therefore, the EF process has been implemented and developed in the late 1990s in two versions; gas diffusion cathode (Brillas' team) and CF cathode (Oturan's team) to overcome the major drawbacks of conventional Fenton process [278,279].

The main features of EF process are the continuous electrogeneration of $\mathrm{H}_{2} \mathrm{O}_{2}$ in the solution to be treated from electroreduction of DO (Eq. 1), avoiding the cost and risks associated to the production, transport and storage of $\mathrm{H}_{2} \mathrm{O}_{2}$ and the electro-regeneration of the catalyst $\left(\mathrm{Fe}^{2+}\right)$ (Eq. 12), avoiding thus the formation and management of process sludge. Therefore, reactions (1), (2) and (12) ensure a permanent catalytic production of ${ }^{\circ} \mathrm{OH}$, allowing destruction of organic micropollutants [7,280,281].

$\mathrm{Fe}^{3+}+\mathrm{e}^{-} \rightarrow \mathrm{Fe}^{2+}$

The in situ generation of $\mathrm{H}_{2} \mathrm{O}_{2}$ in a controlled way by the application of an appropriate current or potential to the electrochemical reactor is one of the main characteristics of the EF process. Therefore, the use of suitable cathode materials is primordial. The first cathode materials used in this process to produce $\mathrm{H}_{2} \mathrm{O}_{2}$ were mercury pool [282], carbon-PTFE- $\mathrm{O}_{2}$ gas diffusion cathode [278]. Then 3D carbonaceous materials such as CF [280], carbon sponge [124,283], activated carbon fiber [284], graphite [285,286], [287] and graphene foam were introduced and applied as a cathode in the EF process. Indeed, carbon-based cathodes are material of interest as discussed in sections $2.1,3.1$ and 4.1, especially because of their large $\mathrm{H}_{2}$ evolution overpotential, good electrical conductivity stability and low cost. Recently, modified carbonbased materials [254,288-291] in which iron ions incorporated were successfully used to perform the heterogeneous EF process in mild $\mathrm{pH}$ conditions. The development and use of CNT composite cathodes $[292,293]$ or graphene-based cathodes $[156,294]$ constitutes new trends in 
1403

1404

1405

1406

1407

1408

1409

1410

1411

1412

1413

1414

1415

1416

1417

1418

1419

1420

1421

1422

1423

1424

1425

1426

EF process. For instance, Yang et al. (2019) [156] reported strongly high concentration (400 mg L ${ }^{-1}$ ) of $\mathrm{H}_{2} \mathrm{O}_{2}$, using $\mathrm{CF}$ modified with electrochemically exfoliated graphene (EEGr) cathode compared to the raw $\mathrm{CF}$ cathode $\left(400 \mathrm{mg} \mathrm{L}^{-1}\right)$. Once produced, $\mathrm{H}_{2} \mathrm{O}_{2}$ reacts with $\mathrm{Fe}^{2+}$ ion to produce ${ }^{\bullet} \mathrm{OH}$, which is a nonselective strong oxidant and is able to oxidize any organic pollutants $[10,254,295]$. The $\mathrm{Fe}^{2+}$ ion is externally added at a catalytic amount (mostly in sulfate salt) and regenerated in the process through $\mathrm{Fe}^{3+} / \mathrm{Fe}^{2+}$ cycle. Therefore, there is no accumulation of the following wasting reactions (Eqs. 13 and 14) of the Fenton process because they occur at high $\mathrm{H}_{2} \mathrm{O}_{2}$ and $\mathrm{Fe}^{2+}$ concentrations, respectively:

$\cdot \mathrm{OH}+\mathrm{H}_{2} \mathrm{O}_{2} \rightarrow \mathrm{H}_{2} \mathrm{O}+\mathrm{HO}_{2}^{\cdot}$

$\cdot \mathrm{OH}+\mathrm{Fe}^{2+} \rightarrow \mathrm{Fe}^{3+}+\mathrm{OH}^{-}$

Moreover, this process has other practical advantages such as easy handling, degradation/mineralization efficiency, amenability and versatility since it can be applied to effluents with a large range of organic matter [7,273,290,296].

The nature of anode material is also of great importance in the EF process efficiency. In fact, by using an appropriate anode (M) material, the anodic oxidation processes can be incorporated into the EF process. In this case, there is production of supplementary hydroxyl radicals $\mathrm{M}\left({ }^{\circ} \mathrm{OH}\right)$ on the surface of the anodes from oxidation of water (Eq. 15), increasing thus the process efficiency.

$\mathrm{M}+\mathrm{H}_{2} \mathrm{O} \rightarrow \mathrm{M}\left({ }^{\circ} \mathrm{OH}\right)+\mathrm{H}^{+}+\mathrm{e}^{-}$

The extent of the contribution of the heterogeneous hydroxyl radicals, $\mathrm{M}\left({ }^{\circ} \mathrm{OH}\right)$, to the EF process efficiency is directly related to the anode material. In the case of active anodes, i.e., Pt, DSA, M( $\left.{ }^{\circ} \mathrm{OH}\right)$ are strongly adsorbed on the anode surface and therefore less available for reacting with organic pollutants $[7,267]$. In contrast, $\mathrm{M}\left({ }^{\circ} \mathrm{OH}\right)$ generated on non-active anodes $\left(\mathrm{BDD}, \mathrm{PbO}_{2}, \mathrm{Ti}_{4} \mathrm{O}_{7}\right)$ are loosely adsorbed on the surface and are more available for participating 
in the oxidative degradation/mineralization of organic pollutants $[197,252,297,298] . \mathrm{M}\left({ }^{\circ} \mathrm{OH}\right)$ generated from the latter kind of anodes are particularly efficient for the mineralization of carboxylic acids resistant to homogeneous ${ }^{\circ} \mathrm{OH}$. Nanostructured materials have also been developed for enhancing the oxidation of pollutants at the anode, as discussed in the next section (5.2).

Apart from electrode material, several operating parameters such as solution $\mathrm{pH}$, applied current, catalyst nature and concentration, electrolyte composition, etc., influence the EF efficiency for the removal of organics from water [7]. The optimal value of some of these parameters, such as the solution $\mathrm{pH}$ value (around 3), nature and concentration of the electrolyte $\left(0.05 \mathrm{M} \mathrm{Na}_{2} \mathrm{SO}_{4}\right)$ for the $\mathrm{CF}$ version and catalyst nature and concentration (about $0.1 \mathrm{mM} \mathrm{Fe}^{2+}$ ) are now well-known $[8,299,300]$. The inconvenient of working at $\mathrm{pH} 3$ can be overcome using the heterogeneous EF process as explained above or by using solid catalysts such as pyrite, iron oxides (magnetite, goethite, hematite) and MOF derived composite catalysts [301-305].

Since EF is an electrochemical process, the current (undivided cell) or potential (divided cell) applied to the cell are obviously of great importance for the process efficiency because these parameters directly affect the rate of $\mathrm{H}_{2} \mathrm{O}_{2}$ generation (Eq. 1), the rate of regeneration of $\mathrm{Fe}^{2+}$ (Eq. 12) and consequently the rate of formation of ${ }^{\circ} \mathrm{OH}$ (Eq. 14) [285,306-308]. It influences also strongly the production of $\mathrm{M}\left({ }^{\circ} \mathrm{OH}\right)$, particularly at low currents $[7,309,310]$. In general, oxidation/mineralization efficiency increases with rising the current up to an optimal value for which parasitic reactions (HER at the cathode and/or $\mathrm{O}_{2}$ evolution reaction at the anode) start to harm the efficiency of the process. High currents above this optimal value can also lead to the enhancement of wasting reactions given in Eqs. 16 and 17. This situation also conducts to lower current efficiency and increases energy consumption [8,123,311-314]. An example of the effect of current on the oxidation efficiency of the antibiotic sulfamethazine and TOC removal rate of its aqueous solution is depicted in Fig. 22. 
1452

1453

1454

1455

1456

1457

1458

1459

1460

1461

1462

1463

1464

1465

1466

1467

1468

1469

1470

$\mathrm{H}_{2} \mathrm{O}_{2}+{ }^{\cdot} \mathrm{OH} \rightarrow \mathrm{HO}_{2}{ }^{-}+\mathrm{H}_{2} \mathrm{O}$

$2 \mathrm{M}\left({ }^{\circ} \mathrm{OH}\right) \rightarrow 2 \mathrm{M}+\mathrm{O}_{2}(\mathrm{~g})+2 \mathrm{H}^{+}+2 \mathrm{e}^{-}$

Therefore, to reach a high oxidation efficiency, MCE and low energy cost, the EF process should be conducted under optimized conditions: optimal current, suitable electrodes (anode and cathode), solution $\mathrm{pH}$ near 3 (for homogeneous process), suitable catalyst nature $\left(\mathrm{Fe}^{2+}\right)$ and concentration, air/ $\mathrm{O}_{2}$ flow rate to saturate the solution to be treated and high stirring rate (batch reactor) or liquid flow rate (flow reactor) [7,272,273,313]. The electrolyte composition is also important, since chloride and ammonia ions can lead to the formation of chlorinated and nitrogen intermediates that can be unwanted (e.g. chlorate, nitrate, etc.) $[315,316]$. Considering the high numbers of influent parameters, the modeling of the EF process is not easy. However, an interesting kinetic modeling for mineralization route of phenol, including the formation of several intermediates and their successive oxidation steps until complete mineralization was recently carried out by Mousset et al. (2016) [317].
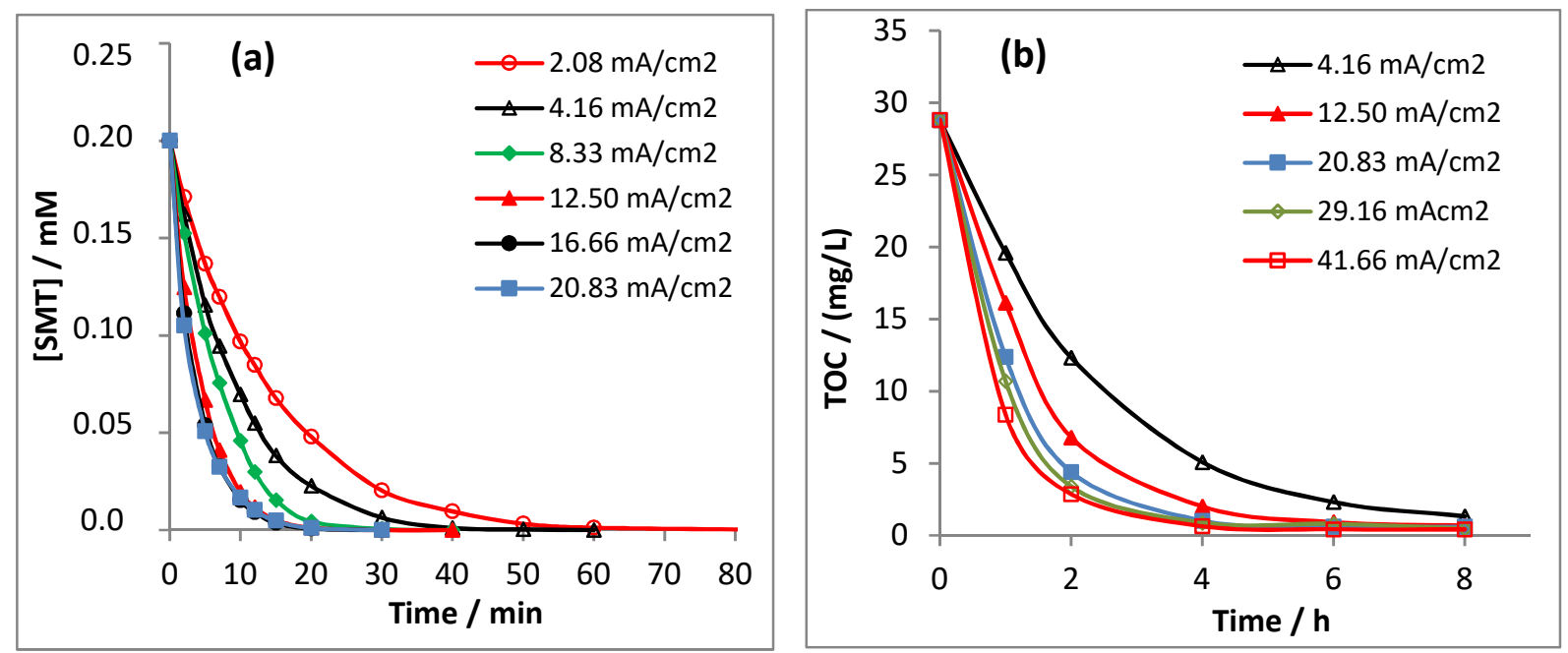

Figure 22. Effect of applied current density on (a) the decay kinetics and (b) TOC removal efficiency during EF treatment of $0.2 \mathrm{mM}\left(57.5 \mathrm{mg} \mathrm{L}^{-1}\right)$ of $300 \mathrm{~mL}$ sulfamethazine solution in $0.05 \mathrm{M} \mathrm{Na}_{2} \mathrm{SO}_{4}$ solution at $\mathrm{pH} 3$ and room temperature using the BDD anode/graphite felt cathode. Reprinted with permission from Sopaj et al., 2016 [248]. Copyright 2016 Elsevier. 


\subsection{Advanced electro-oxidation process}

1472 Advanced electro-oxidation processes are based on the development of suitable anode materials 1473 for promotion of the oxidation of organic pollutants. Various mechanisms can be involved as 1474 thoroughly described in section 2.2. Direct electron transfer can occur at the electrode-solution 1475 interface, thus resulting in selective oxidation of some organic compounds. Anode materials 1476 with high overvoltage for OER can also generate physisorbed hydroxyl radicals ( $\left.{ }^{\circ} \mathrm{OH}\right)(\mathrm{Eq} .19)$ 1477 from the one-electron oxidation of water [9,33]. These radicals are available for reaction with organic compounds in a non-selective way, but they are accumulated only in a thin layer close to the anode surface $(<1.0 \mu \mathrm{m})$ because of their short lifetime [318]. The formation of sulfate radicals $\left(\mathrm{SO}_{4}{ }^{-}\right)$, known as very powerful oxidant species, have also been reported in the literature $[9,55]$ during the electro-oxidation process when using sodium sulfate as electrolyte.

Besides, mediated oxidation in the bulk solution can be promoted depending on the reaction of inorganic compounds in the solution to treat. Particularly, the formation of active chlorine from oxidation of chloride ions as well as persulfate (that can be then further activated to sulfate radicals) from oxidation of sulfate ions are usually the most predominant mechanisms of mediated oxidation of organic compounds in the bulk [9,319]. The reactivity of nanostructured electrodes and their ability to promote these different reaction mechanisms tightly depend on their chemical characteristics, as described in section 4. Another important parameter is the electro-active surface area of anode materials to favour reactions with organic pollutants at the electrode-solution interface. Nano-structured electrodes present a key advantage in this area.

The advanced electro-oxidation process also faces the problem of mass transport of organic pollutants from the bulk to the anode surface $[24,33,251,320,321]$. As a result of the fast kinetic 1493 processes at the anode surface, treatment systems using electrodes in parallel plate configuration are usually limited by the diffusion of organics to the electrode surface, particularly for treating low concentrations of pollutants. The diffusion boundary layer is 
usually in the range of $10-100 \mu \mathrm{m}$. Thus, features of nanostructured electrode roughness are smaller than the diffusion length and become averaged into the diffusion field [322]. The use of nanostructured electrode in flow-through configuration is therefore a key parameter to really take advantage of their high electro-active surface area. In fact, electro-oxidation is strongly enhanced because of the fast mass transport inside small pores as well as the possibility to increase the convective mass transport by simply increasing the filtration flux $[251,323]$.

The Table 2 gives an overview of the efficiency of advanced electro-oxidation process using nanostructured electrodes. Two groups of materials have been mainly investigated. First, several studies have focused on the use of materials based on CNTs. This kind of nanostructured material present several advantages including high conductivity, large specific surface area (50 $-1000 \mathrm{~m}^{2} \mathrm{~g}^{-1}$ ) and good mechanical strength [323]. Both sorption and oxidation mechanisms have to be taken into consideration in order to explain the removal of organic pollutants from water. CNT-based electrodes have been mainly used in flow-through configuration. Most of CNT-based electrochemical filters are made of a thin layer (e.g., $41 \mu \mathrm{m})$ of randomly oriented multi-walled CNT supported by a porous membrane (e.g., PTFE membrane). Small pore size can be obtained depending on the nature of CNT. For example, the average pore size was 115 $\pm 47 \mathrm{~nm}$ by using CNT of $15 \mathrm{~nm}$ diameter and $100 \mu \mathrm{m}$ of length [323]. Thus, convectionenhanced mass transport combined with fast mass transport inside the CNT network can result in very fast degradation of target compounds. A single passage through the CNT network with a flow rate of $130 \mathrm{~L} \mathrm{~m}^{-2} \mathrm{~h}^{-1}$ (resulting in a residence time in the filter of $\tau \leq 1.2 \mathrm{~s}$ ) was able to

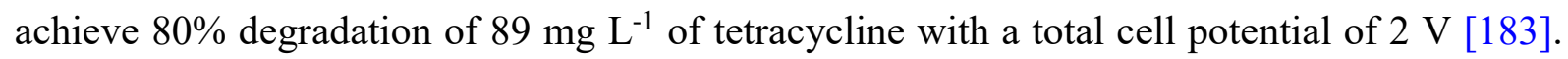
Most importantly, the energy consumption of advanced electro-oxidation can be significantly improved. For example, energy consumption below $1.0 \mathrm{kWh} \mathrm{m}^{-3}$ or even below $0.1 \mathrm{kWh} \mathrm{m}^{-3}$ was reported (Table 2). However, CNT-based electrodes also present some critical drawbacks. CNTs are usually operated under very low current density or anodic potential (Table 2) in order 
to avoid corrosion. For example, corrosion of uncoated CNT was reported to start from 1.4 $\mathrm{V} /(\mathrm{Ag} / \mathrm{AgCl})$ [189]. CNTs also present low overpotential for OER (active electrode), thus 1523 limiting the generation of nonselective oxidizing species such as ${ }^{\circ} \mathrm{OH}$. The OEP of uncoated $1524 \mathrm{CNT}$ was, for example, $1.27 \mathrm{~V} /(\mathrm{Ag} / \mathrm{AgCl})$ in $0.5 \mathrm{M} \mathrm{H}_{2} \mathrm{SO}_{4}$ [189]. By comparison, the OEP of $1525 \mathrm{BDD}$ (gold standard for advanced electro-oxidation) is around $2.1 \mathrm{~V} /(\mathrm{Ag} / \mathrm{AgCl})$. As a 1526 consequence, CNT-based electrodes present selective oxidation features. While fast 1527 degradation of target pollutants is usually reported, only partial mineralization is achieved 1528 because of the recalcitrance of some degradation by-products. One of the most explored ways 1529 to improve the effectiveness of CNTs is to synthesize modified CNTs (e.g., chemical surface 1530 modification, incorporation of Bi-doped $\mathrm{SnO}_{2} \mathrm{NPs}$ ) in order to increase the overvoltage of OER 1531 or to promote interaction (particularly adsorption) between the electrode surface and target 1532 pollutants. For example, negligible corrosion was obtained up to $2.2 \mathrm{~V} /(\mathrm{Ag} / \mathrm{AgCl})$ and the OEP 1533 was increased to $1.71 \mathrm{~V} /(\mathrm{Ag} / \mathrm{AgCl})$ by using a Bi-doped $\mathrm{SnO}_{2}$-coated CNT network [189]. 
Table 2. Overview of the efficiency of advanced electro-oxidation processes for the removal of organic pollutants reported in recent studies using nano-structured electrode materials.

\begin{tabular}{|c|c|c|c|c|c|c|c|c|c|c|c|c|c|c|c|c|c|c|}
\hline \multirow{3}{*}{ Anode } & \multirow{3}{*}{ Cathode } & \multirow{3}{*}{$\mathbf{P} / \mathbf{G}$} & \multicolumn{7}{|c|}{ Operating conditions } & \multicolumn{2}{|c|}{ Treated solution } & \multirow{3}{*}{$\begin{array}{l}\text { Deg. / } \\
\text { Time } \\
\% / h\end{array}$} & \multicolumn{5}{|c|}{ Process efficiency } & \multirow{3}{*}{ Ref } \\
\hline & & & CD & An. Pot. & $\begin{array}{l}\text { Cell } \\
\text { Pot. }\end{array}$ & $\begin{array}{c}\text { An. } \\
\text { Surface }\end{array}$ & $\begin{array}{c}\text { Batch } \\
\text { (Volume) }\end{array}$ & $\mathbf{S} / \mathbf{V}$ & $\begin{array}{l}\text { Flow- } \\
\text { through }\end{array}$ & $\begin{array}{c}\text { Pollutant } \\
\text { C }\end{array}$ & $\begin{array}{c}\text { Electrolyte } \\
\mathrm{C}\end{array}$ & & $\mathbf{k}_{\text {app }}$ & $\begin{array}{l}\text { Min. / } \\
\text { Time }\end{array}$ & MCE & \multicolumn{2}{|c|}{ EC } & \\
\hline & & & $\underset{2}{m A ~} \mathrm{~cm}^{-}$ & $\begin{array}{c}V /( \\
\mathrm{Ag} / \mathrm{AgCl})\end{array}$ & V & $\mathrm{cm}^{2}$ & $m L$ & $\mathrm{~cm}^{-1}$ & $L m^{-2} h^{-1}$ & $m g L^{-1}$ & $m M$ & & $\min _{\left(x 10^{-1}\right)}$ & $\% / h$ & $\%$ & $\begin{array}{l}k W h \\
m^{-3}\end{array}$ & $\begin{array}{c}k W h \\
k g C O D^{-1}\end{array}$ & \\
\hline CNT & CNT & $\mathrm{P}$ & - & - & 10 & 28 & - & - & 1700 & $\begin{array}{c}X-3 B \\
50\end{array}$ & - & $94 / 1.5$ & - & $58 / 1.5$ & 26 & & 150 & [324] \\
\hline & & & - & - & 2 & & & & & MO & & 70 / SP & - & - & - & 0.22 & 4 & \\
\hline Modified CNT & SS & $\mathrm{P}$ & - & - & & 7 & - & - & 130 & & $\begin{array}{l}\mathrm{Na}_{2} \mathrm{SO}_{4} \\
100\end{array}$ & $92 / \mathrm{SP}$ & - & - & - & 0.96 & 15 & [172] \\
\hline & & & - & - & 3 & & & & & $\begin{array}{l}\text { Phenol } \\
97\end{array}$ & & - & - & 20 / SP & - & - & - & \\
\hline & & & 1.4 & $<1.1$ & 2.7 & & & & & & & 50 / SP & - & 50 / SP & 100 & - & $\begin{array}{c}5 \\
(\mathrm{TOC})\end{array}$ & \\
\hline $\begin{array}{l}\text { CNT/Bi-doped } \\
\mathrm{SnO}_{2} \mathrm{NP}\end{array}$ & SS & G & 8.6 & 2 & 4.3 & 7 & - & - & 130 & $\begin{array}{c}\text { Oxalate } \\
367\end{array}$ & $\begin{array}{l}\mathrm{Na}_{2} \mathrm{SO}_{4} \\
10\end{array}$ & 95 / SP & - & 95 / SP & 30 & - & $\begin{array}{c}30 \\
(\mathrm{TOC})\end{array}$ & [189] \\
\hline CNT/Graphene & $\mathrm{Ti}$ & $\mathrm{P}$ & 0.4 & 0.8 & 2.5 & 7 & - & - & 130 & $\begin{array}{l}\text { Phenol } \\
51\end{array}$ & $\begin{array}{l}\text { real } \\
\text { reservoir } \\
\text { water }\end{array}$ & 76 / SP & - & Partial & - & 0.075 & 1.9 & {$[177]$} \\
\hline CNT & CNT & $\mathrm{P}$ & 1 & & 2 & 7 & - & - & 130 & $\begin{array}{c}\text { Tetracycline } \\
\quad 89\end{array}$ & $\begin{array}{l}\mathrm{Na}_{2} \mathrm{SO}_{4} \\
10\end{array}$ & 80 / SP & - & Partial & - & 0.084 & - & [183] \\
\hline $\begin{array}{c}\text { Carboxylated } \\
\text { CNT }\end{array}$ & $\mathrm{Ti}$ & $\mathrm{P}$ & & 0.9 & 2 & 9.5 & - & - & 130 & $\begin{array}{l}\text { Ibuprofene } \\
20\end{array}$ & $\begin{array}{c}\mathrm{NaCl} \\
10\end{array}$ & 75 / SP & & Partial & - & - & - & [325] \\
\hline $\begin{array}{l}\text { CNT/PANI UF } \\
\text { membrane }\end{array}$ & $\mathrm{Ti}$ & $\mathrm{P}$ & & 1.7 & 3 & 4 & & 0.1 & & $\begin{array}{c}\mathrm{MB} \\
5\end{array}$ & $\begin{array}{l}\text { Cl from } \\
\text { MB salt }\end{array}$ & & - & - & - & & - & [326] \\
\hline & & & - & & & & - & - & 20 & & & 85 / SP & - & - & - & 2.5 & - & \\
\hline $\begin{array}{c}\text { BDD/Sb-doped } \\
\mathrm{SnO}_{2} \mathrm{NP}\end{array}$ & $\mathrm{Ti}$ & G & 20 & - & - & 1.2 & Batch & - & - & $\begin{array}{c}2,4-\mathrm{D} \\
100\end{array}$ & $\begin{array}{c}\mathrm{Na}_{2} \mathrm{SO}_{4} \\
100\end{array}$ & $98.5 / 2$ & - & $82.2 / 2$ & 19.8 & 3.3 & - & [327] \\
\hline
\end{tabular}




\begin{tabular}{|c|c|c|c|c|c|c|c|c|c|c|c|c|c|c|c|c|c|c|}
\hline $\begin{array}{l}\text { Ti/Sb-doped } \\
\mathrm{SnO}_{2} \text { modified } \\
\text { with CNT }\end{array}$ & $\mathrm{Ti}$ & G & 50 & - & - & 8 & 150 & 0.05 & - & $\begin{array}{c}\text { AR } 73 \\
1000\end{array}$ & $\begin{array}{c}\mathrm{Na}_{2} \mathrm{SO}_{4} \\
100\end{array}$ & $96 / 3$ & 1.6 & $80 / 3$ & 58 & - & 121 & [241] \\
\hline $\begin{array}{c}\text { TNT/Fe-doped } \\
\mathrm{PbO}_{2}\end{array}$ & $\mathrm{Ti}$ & G & - & - & - & 5 & 100 & 0.05 & - & $\begin{array}{c}\mathrm{p}- \\
\text { nitrophenol } \\
50\end{array}$ & $\begin{array}{c}\mathrm{Na}_{2} \mathrm{SO}_{4} \\
30\end{array}$ & $90 / 1$ & 6.9 & - & - & - & 280 & [328] \\
\hline TNT & $\mathrm{Pt}$ & G & 5 & - & - & 1 & - & - & - & $\begin{array}{l}\text { Salicyclic } \\
\text { acid } \\
30\end{array}$ & $\begin{array}{c}\mathrm{H}_{2} \mathrm{SO}_{4} \\
100\end{array}$ & - & 11.5 & - & - & - & - & [262] \\
\hline $\mathrm{TNT} / \mathrm{PbO}_{2}$ & $\mathrm{Ti}$ & G & 10 & - & - & 5 & 100 & 0.05 & - & $\begin{array}{c}\mathrm{p}- \\
\text { nitrophenol } \\
50\end{array}$ & $\begin{array}{c}\mathrm{Na}_{2} \mathrm{SO}_{4} \\
30\end{array}$ & $82 / 3$ & - & $42 / 3$ & - & 9.5 & - & [329] \\
\hline $\begin{array}{c}\text { Nano- } \\
\text { graphite/TiO2- } \\
\mathrm{RuO}_{2}\end{array}$ & $\mathrm{Ti}$ & $\mathrm{P}$ & - & - & 2 & - & 40 & - & - & $\begin{array}{c}\text { Ceftriaxone } \\
10\end{array}$ & $\begin{array}{c}\mathrm{Na}_{2} \mathrm{SO}_{4} \\
100\end{array}$ & $90 / 1.7$ & - & - & - & - & - & [330] \\
\hline $\mathbf{T i}_{4} \mathbf{O}_{7} \mathbf{N T}$ & $\mathrm{Ti}_{4} \mathrm{O}_{7} \mathrm{NT}$ & G & 2.5 & - & - & - & Batch & - & - & $\begin{array}{l}\text { Phenol } \\
100\end{array}$ & $\begin{array}{c}\mathrm{Na}_{2} \mathrm{SO}_{4} \\
100\end{array}$ & $85 / 2$ & 1.5 & $95 / 3$ & 43 & - & - & [167] \\
\hline $\begin{array}{c}\text { TNT/Sb-doped } \\
\text { SnO }_{2}\end{array}$ & SS & G & 10 & - & - & 5 & 100 & 0.05 & - & $\begin{array}{l}\text { Phenol } \\
50\end{array}$ & $\begin{array}{c}\mathrm{Na}_{2} \mathrm{SO}_{4} \\
100\end{array}$ & $70 / 2$ & 1 & - & - & - & - & [244] \\
\hline Blue TNT & Blue TNT & G & 5 & & 5.2 & 6 & Batch & - & - & $\begin{array}{l}\text { Wastewater } \\
330 \text { (COD) }\end{array}$ & - & - & - & $60 / 2$ & - & - & 150 & [331] \\
\hline $\mathbf{T i}_{4} \mathbf{O}_{7}$ & SS & $\mathrm{P}$ & - & 2.65 & - & 0.35 & - & - & 789 & $\begin{array}{l}\text { Terephtalic } \\
\text { acid } \\
16.6\end{array}$ & $\begin{array}{c}\mathrm{NaClO}_{4} \\
100\end{array}$ & 60 / SP & - & - & - & - & - & [332] \\
\hline Blue TNT & SS & G & 2.5 & - & - & 3 & 100 & 0.05 & - & $\begin{array}{l}\text { Phenol } \\
100\end{array}$ & $\begin{array}{c}\mathrm{Na}_{2} \mathrm{SO}_{4} \\
100\end{array}$ & $97 / 5$ & 0.7 & $60 / 5$ & 90 & - & 9.9 & {$[55]$} \\
\hline
\end{tabular}

2,4-D: 2,4-dichlorophénoxyacétique ; An. Pot.: anodic potential; An. Surface: geometric anodic surface ; AR 73 : acid red 73 ; C: concentration ; CD: current density ; Cell Pot.: cell potential ; CNT: carbon nanotube ; COD : chemical oxygen demand ; Deg.: degradation ; EC : energy consumption ; G: galvanostatic ; $\mathrm{k}_{\mathrm{app}}$ : apparent degradation rate constant ; MB : methylene blue ; MCE : mineralization current efficiency ; Min.: mineralization ; MO : methyl orange ; NP: nanoparticles ; NT: nanotube ; P: potentiostatic ; PANI : polyaniline ; S: surface ; SP : single passage ; TNT: $\mathrm{TiO}_{2}$ nanotube ; TOC : total organic carbon ; UF : ultrafiltration; V: volume ; X-3B : reactive brilliant red 
The second group of materials is those having high overvoltage for OER, also called as nonactive electrodes. Materials based on $\mathrm{TiO}_{2}$ NTA have been mostly studied. They present an interesting nanostructuration for the application in water treatment. For example, by following a conventional anodization method, $\mathrm{TiO}_{2}$ NTA obtained by [55] presented a length of approximately $15 \mu \mathrm{m}$, a diameter of $100 \mathrm{~nm}$ and a tube wall of $54 \mathrm{~nm}$. However, anatase $\mathrm{TiO}_{2}$ NTA present a very low conductivity [261]. One of the strategies for solving this issue is the deposition of conductive metal oxide layer. $\mathrm{IrO}_{2}$ and $\mathrm{RuO}_{2}$ layers resulted in the formation of active anodes with low overpotential for OER, while a layer of $\mathrm{PbO}_{2}$ and $\mathrm{SnO}_{2}$ (with possible addition of doping agents such as $\mathrm{Sb}$ ) can form non-active anodes with high overpotential for OER. Therefore, these latter are able to generate nonselective oxidants such as $\mathrm{M}\left({ }^{\circ} \mathrm{OH}\right)$ and both degradation and mineralization of complex organic compounds can be achieved as reported in Table 2. Another strategy for improving the reactivity and stability of TNT arrays comes from the synthesis of Blue and Black $\mathrm{TiO}_{2}$ NTA from cathodic polarization and reduction of a variable number of Ti(IV) sites to Ti(III). By comparison with Magnéli phases obtained from high temperature thermal processes, cathodic polarization might be more a costeffective method. These materials are able to generate both ${ }^{\circ} \mathrm{OH}$ and $\mathrm{SO}_{4}{ }^{--}$radicals $[55,331]$, thus resulting also in high mineralization rate of organic compounds (see Table 2). However, none studies have been reported on the use of electrodes based on $\mathrm{TiO}_{2} \mathrm{NTA}$ in flow-through configuration. Advanced electro-oxidation in batch configuration is therefore limited by the mass transport of organic compounds through the diffusion boundary layer. Therefore, such nanostructured electrodes do not significantly improve energy consumption of advanced electro-oxidation and become only cost-effective for treating concentrated effluents. As regards to non-active electrodes, only sub-stoichiometric titanium oxide $\left(\mathrm{TiO}_{\mathrm{x}}\right)$ electrodes have been successfully applied in flow-through configuration. Most of recent studies have focused on microstructured materials with pore size in the range $1-5 \mu \mathrm{m}[251,322,333]$, however Nayak 
1559

1560

1561

1562

1563

1564

1565

1566

1567

1568

1569

1570

1571

1572

1573

1574

1575

1576

1577

1578

1579

1580

1581

1582

1583

and Chaplin (2018) [332] also showed that nanostructuration of such materials (using a simple chemical etching step) was also able to increase the rate of oxidation of probe molecules such as oxalic acid or terephthalic acid.

Overall, CNT-based electrodes operated in flow-through configuration are promising materials for improving the energy consumption of advanced electro-oxidation because of the high electro-active surface area and suitable properties for optimization of mass transport of organic pollutants at the electrode/solution interface. A high degradation rate of organic pollutants can be achieved after only a single passage through such electrochemical filter. The main drawback of these electrodes is their low overvoltage for OEP that reduces their capacity for generation of nonselective oxidant species and results in selective oxidation of organic compounds and low mineralization rate. By comparison, electrodes based on $\mathrm{TiO}_{2} \mathrm{NTA}$ arrays or $\mathrm{TiO}_{\mathrm{x}}$ are able to achieve a higher mineralization rate of complex organics, thanks to the generation of hydroxyl and/or sulphate radicals. However, further studies are required on the implementation of such nanostructured electrodes in flow-through configuration in order to avoid mass transport limitations.

For all nanostructured electrodes used in advanced electro-oxidation, two important challenges can be highlighted. The first one is related to the development of methods for synthesizing large geometric surface area to scale-up such processes. Most of data reported in the literature have been obtained with electrodes presenting a geometric surface area in the range of 3 to $9 \mathrm{~cm}^{2}$ (Table 2). The second challenge is related to the lifetime of these electrodes. The optimization of the synthesis method [331], surface modification [172] and the addition of doping agents [189] have been mainly studied for improving corrosion resistance and lifetime. However, in the case of $\mathrm{TiO}_{2}$ NTA-based and $\mathrm{TiO}_{\mathrm{x}}$ electrodes, a promising strategy for the regeneration of the oxidation capacity might also be the implementation of sequential cathodic polarization $[331,334]$. 


\subsection{Solar/artificial light induced photo-electrocatalytic processes}

1585 As reported previously, organic pollutants can be electrochemically oxidized through different

1586

1587

1588

1589

1590

1591

1592

1593

1594

1595

1596

1597

1598

1599

1600

1601

1602

1603

1604

1605

1606

1607 pathways. Solar or artificial light represents an additional source of energy allowing the generation of further oxidant species. The main pathways of degradation of organic pollutants during photochemical processes include, (i) direct photolysis and (ii) reaction with ${ }^{\circ} \mathrm{OH}$ generated from PC when using a suitable photocatalyst. Photoelectrocatalytic processes can be implemented either in sequential reactors or in hybrid reactors where photochemical and electrochemical mechanisms are combined into a single reactor. This latter type of reactor allows for the promotion of synergistic effects and is therefore the focus of most of recent studies [296,335-341].

The photoelectro-Fenton (PEF) has been developed to obtain a more efficient process, mainly by Brillas and coworkers and great results have been obtained for the degradation and mineralization of organic compounds [335,337]. It is based on the application of the EF process as described in section 5.1 but with an additional source of energy from artificial or solar light. Therefore, as described previously, nanostructured materials can be mainly used for the enhancement of the $\mathrm{H}_{2} \mathrm{O}_{2}$ production at the cathode or for improving the reactivity of the iron source when using heterogeneous catalysts. The main synergistic effects induced from the artificial/solar light is related to the photolysis of Fe(III)-monohydroxy complex under UVA irradiation that leads to the formation of additional ${ }^{\circ} \mathrm{OH}$ and the enhanced regeneration of $\mathrm{Fe}(\mathrm{III})$ into $\mathrm{Fe}(\mathrm{II})$ (Eq. 18).

$[\mathrm{Fe}(\mathrm{OH})]^{2+}+h v \rightarrow \mathrm{Fe}^{2+}+{ }^{\cdot} \mathrm{OH}$

Therefore, faster degradation and mineralization kinetics are observed compared to the EF process. Several authors have also proposed various reactor designs for pre-industrial applications using the well-known CF or gas-diffusion carbon cathodes [342,343]. Compared 
to the EF process, reactor design must also take into consideration the optimization of the irradiation of the solution.

There are also several different ways to combine electrochemical and photochemical processes. EAOPs can also be implemented as described in sections 5.1 and 5.2, while, in addition, a photocatalytic material as well as artificial or solar light is provided to the system. Such treatment strategies allow the formation of additional oxidant species by combining different pathways for the generation of oxidant species into a single reactor [227,339,344]. Nanostructured materials can therefore be used for improving the effectiveness of each single pathway. Various synergistic effects can also take place such as the formation of ${ }^{\circ} \mathrm{OH}$ by homolytic cleavage of electrochemically generated $\mathrm{H}_{2} \mathrm{O}_{2}$ or photoactivation of other electrochemically generated species such as $\mathrm{S}_{2} \mathrm{O}_{8}{ }^{2-}$ into sulfate radicals or $\mathrm{HClO}$ into chloride and hydroxyl radicals $[339,345]$. A particular attention must also be given to the reactor design in order to be able to promote all the different pathways at the same time. For example, the use of transparent electrode materials (e.g. fluorine-doped $\mathrm{SnO}_{2}$ ) has been proposed for improving light irradiation inside the reactor [227].

Interestingly, it is also possible to combine electrochemical and photochemical processes by using a single material playing the role of both photocatalyst and electrode. These photoelectrocatalytic (PEC) processes aim at reducing charge recombination occurring during PC by coating the photocatalytic material on a so-called photo-anode. Thus, both photocatalytic and electrooxidation processes can take place at the same time with high synergistic effects. In this area, several nanostructured materials have been recently developed in order to increase the reactive surface area of the heterogeneous photo-electrocatalysts. An overview of the effectiveness of the PEC process using nanostructured materials is given in Table 3 . The synergistic effects occurring during PEC have been highlighted in several publications comparing the effectiveness of PC, electro-oxidation and PEC. For example, using blue- $\mathrm{TiO}_{2}$ 
nanotubes as photo-anode for the degradation of $100 \mu \mathrm{g} \mathrm{L}^{-1}$ of 4-chlorophenol at anodic potential of $1.43 \mathrm{~V} /(\mathrm{Ag} / \mathrm{AgCl})(\mathrm{KCl}, 3 \mathrm{M})$ during $2 \mathrm{~h}$, standalone electrooxidation and $\mathrm{PC}$ only achieved $<5 \%$ and $30 \%$ degradation, respectively, while PEC achieved $>99 \%$ abatement of 4 chloropenol [346]. In an another example, $\mathrm{RGO}$-polyaniline/ $\mathrm{TiO}_{2}$ was used as photo-anode for the degradation of $10 \mathrm{mg} \mathrm{L}^{-1}$ of phenol at anodic potential of $1.03 \mathrm{~V} /(\mathrm{Ag} / \mathrm{AgCl})(\mathrm{KCl}, 3 \mathrm{M})$ during $8 \mathrm{~h}$; standalone electrooxidation and PC only achieved $68 \%$ and $42 \%$ degradation, respectively, while PEC achieved $>99 \%$ degradation [347]. The Table 3 highlights also some important trends on the way to implement PEC as well as on the effectiveness of this process.

Degradation kinetics reported in the literature are usually lower than the ones reported for advanced electro-oxidation. First-order apparent degradation kinetics reported in the literature are usually in the range $0.4-3 \mathrm{~min}^{-1}$ and more than one hour of treatment is usually required for achieving $90 \%$ degradation of the target pollutant. Complete mineralization of organic pollutant is not always reported but several studies have shown promising results with more than $80 \%$ of TOC removal in a few hours. It is also interesting to highlight that PEC has been mainly implemented using anodic potential in the range $0.5-1.5 \mathrm{~V} /(\mathrm{Ag} / \mathrm{AgCl})$. These values are lower than anodic potentials usually reported for advanced electro-oxidation. In fact, the generation of hydroxyl radicals from water oxidation at the surface of electrodes with high overpotential for OER requires performing electro-oxidation in the potential region of water discharge. Similarly, low current density (in the range $0.1-5 \mathrm{~mA} \mathrm{~cm}^{-2}$ ) is usually used for performing experiments under galvanostatic conditions. Performing electrochemical processes at low current density/potential is usually beneficial for lowering the energy consumption. However, such data are still very rare in the literature. Ding et al. (2014) [348] reported high MCE (47\%), which seems to confirm the potential high energy-efficiency of PEC. It is also important to note that mainly potentiostatic experiments in small-scale stirred batch reactors have been performed for testing the effectiveness of this emerging process. It is therefore 
currently difficult to assess the potential of PEC for full-scale applications. Besides, mass transport limitations related to the transfer of pollutants from the bulk to the photo-electrode could also be further investigated in order to improve the effectiveness of PEC.

Very interesting results have also been obtained by combination of PEC and PEF using either a homogeneous or heterogeneous iron source. This treatment strategy seems very promising since it allows the combination of the synergistic effects from both electro-Fenton/PC and electrooxidation/PCs. Compared to $\mathrm{PEC}, \mathrm{PEC} / \mathrm{PEF}$ process allows a strong increase of degradation kinetics. For example, Hernandez et al. (2018) reported $57 \%$ and $>99 \%$ degradation of $78.6 \mathrm{mg} \mathrm{L}^{-1}$ of paracetamol by using PEC and combined PEC/PEF processes, respectively [349]. Thus, degradation kinetics are usually much more rapid for PEC/PEF compared to PEC. Complete degradation of the target pollutants are usually reported in less than $1 \mathrm{~h}$. Furthermore, high MCE can be achieved, as reported by [340], who achieved $84.6 \%$ to TOC removal with a quiet high MCE of $87.6 \%$ during the treatment of Indigo Carmine dye solution.

A new PEF system using a superhydrophobic natural air diffusion electrode (NADE) for the fast $\mathrm{H}_{2} \mathrm{O}_{2}$ production (101.67 $\mathrm{mg} \mathrm{h}^{-1} \mathrm{~cm}^{-2}$ ) and high oxygen utilization efficiency (44.5\%64.9\%) without external oxygen-pumping equipment was suggested [50]. In this system, organic contaminants can be efficiently destroyed by the combined action of $\mathrm{Fe}^{2+} / \mathrm{H}_{2} \mathrm{O}_{2}$, $\mathrm{UV} / \mathrm{H}_{2} \mathrm{O}_{2}$ and $\mathrm{UV}$ radiation to reach high mineralization rate $(>83.5 \%)$ at low current $(50 \mathrm{~mA})$. In addition, the use of the NADE in EAOPs significantly reduced energy consumption compared with aeration system [111]. 
Table 3. Overview of the efficiency of nanostructured materials for photo-electrocatalytic (PEC) processes and combined photo-electrocatalytic / photo-electro-Fenton (PEC / PEF) processes

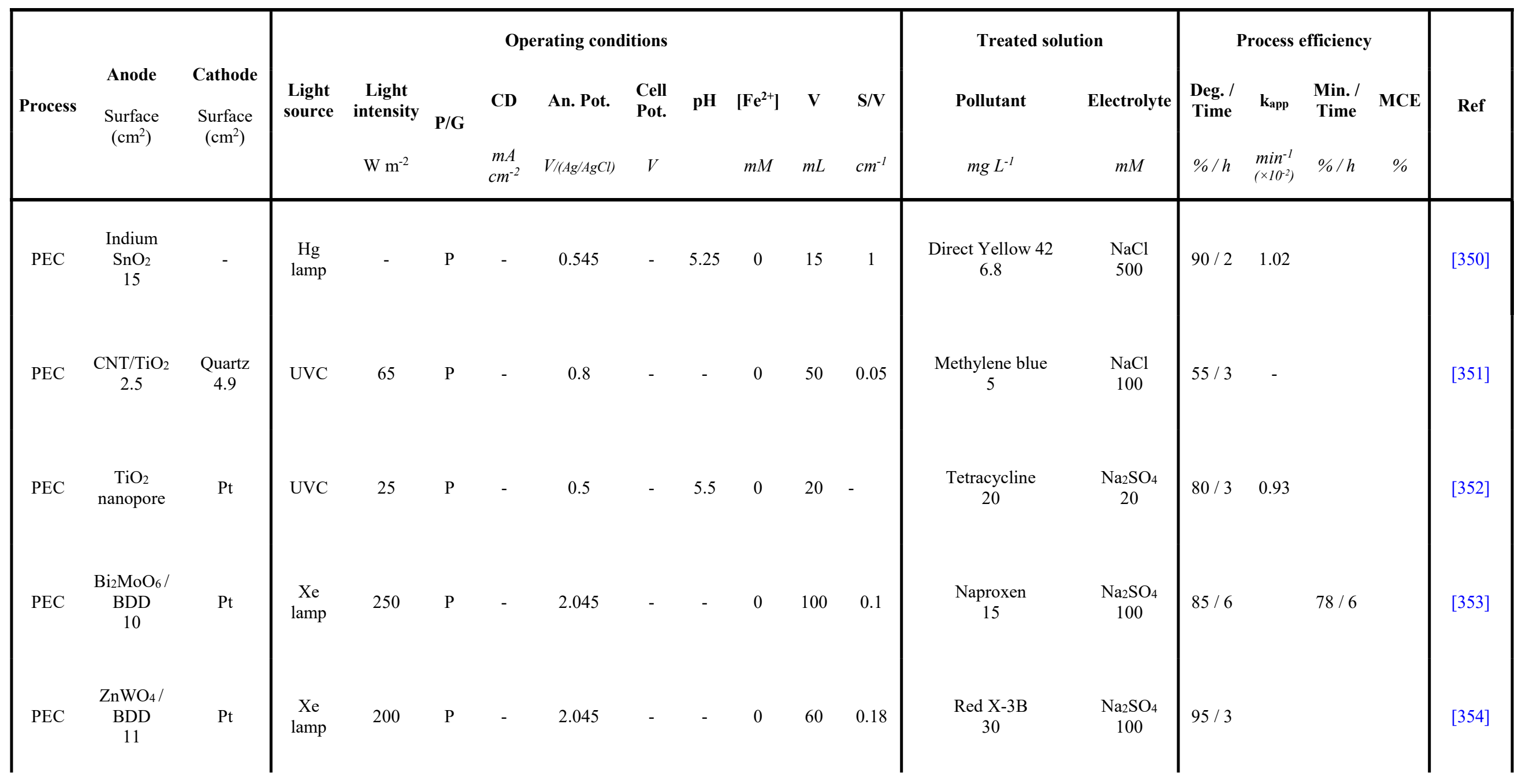




\begin{tabular}{|c|c|c|c|c|c|c|c|c|c|c|c|c|c|c|c|c|c|c|c|}
\hline PEC & $\begin{array}{l}\mathrm{TiO}_{2} \\
25\end{array}$ & $\mathrm{Pt}$ & $\begin{array}{c}\mathrm{Hg} \\
\text { lamp }\end{array}$ & 27.3 & G & 0.4 & - & - & 2 & 0 & 1000 & 0.025 & $\begin{array}{c}\text { Indigo Carmine } \\
24\end{array}$ & $\begin{array}{c}\mathrm{Na}_{2} \mathrm{SO}_{4} \\
100\end{array}$ & $\begin{array}{l}99 / \\
0.5\end{array}$ & 3 & $75 / 6$ & 75 & [355] \\
\hline PEC & $\mathrm{TiO}_{2} \mathrm{NTA}$ & $\mathrm{Pt}$ & $\begin{array}{c}\mathrm{Hg} \\
\text { lamp }\end{array}$ & - & $P$ & - & 0.645 & - & - & 0 & 60 & - & $\begin{array}{l}\text { Methyl orange } \\
10\end{array}$ & $\begin{array}{c}\mathrm{Na}_{2} \mathrm{SO}_{4} \\
100\end{array}$ & $58 / 3$ & 0.49 & & & {$[356]$} \\
\hline PEC & $\begin{array}{c}\mathrm{WO}_{3} / \\
\mathrm{TiO}_{2} \\
1\end{array}$ & $\mathrm{Pt}$ & $\begin{array}{c}\mathrm{Xe} \\
\text { lamp }\end{array}$ & - & $P$ & - & 1 & - & 2 & 0 & 30 & 0.033 & $\begin{array}{c}\text { Indigo Carmine } \\
24\end{array}$ & $\begin{array}{c}\mathrm{Na}_{2} \mathrm{SO}_{4} \\
100\end{array}$ & $96 / 2$ & 1.13 & $62 / 2$ & & [357] \\
\hline PEC & $\begin{array}{c}\text { B-doped } \\
\mathrm{TiO}_{2} \text { NTA } \\
25\end{array}$ & $\mathrm{Ti} / \mathrm{Ru}$ & $\underset{\text { lamp }}{\mathrm{Hg}}$ & - & $P$ & - & 1.2 & - & 2 & 0 & 500 & 0.05 & Acid Yellow 1 & $\begin{array}{c}\mathrm{Na}_{2} \mathrm{SO}_{4} \\
10\end{array}$ & $95 / 1$ & 2.35 & $95 / 2$ & & [221] \\
\hline PEC & $\begin{array}{c}\text { Reduced } \\
\mathrm{TiO}_{2} \text { NTA } \\
4\end{array}$ & - & $\begin{array}{c}\mathrm{Xe} \\
\text { lamp }\end{array}$ & - & $P$ & - & 0.445 & - & - & 0 & 80 & 0.05 & $\begin{array}{c}\text { diclofenac } \\
5\end{array}$ & $\begin{array}{c}\mathrm{Na}_{2} \mathrm{SO}_{4} \\
100\end{array}$ & $99 / 8$ & & & & [358] \\
\hline PEC & $\begin{array}{c}\mathrm{Au} / \mathrm{TiO}_{2} \\
7\end{array}$ & $\mathrm{Pt}$ & $\begin{array}{c}\mathrm{Hg} \\
\text { lamp }\end{array}$ & - & G & 4.3 & - & - & 6.7 & 0 & - & - & $\begin{array}{c}\text { Methyl Orange } \\
5.2\end{array}$ & $\begin{array}{c}\mathrm{Na}_{2} \mathrm{SO}_{4} \\
100\end{array}$ & $\begin{array}{l}83 / \\
1.5\end{array}$ & & & & [359] \\
\hline PEC & $\begin{array}{c}{\mathrm{Blue} \mathrm{TiO}_{2}}_{\mathrm{NTA}} \\
4\end{array}$ & $\begin{array}{c}\text { SS } \\
4\end{array}$ & $\begin{array}{c}\text { Xe } \\
\text { lamp }\end{array}$ & 10000 & $P$ & - & 1.43 & - & 6 & 0 & 80 & 0.05 & $\begin{array}{c}\text { 4-chlorophenol } \\
12.8\end{array}$ & $\begin{array}{c}\mathrm{Na}_{2} \mathrm{SO}_{4} \\
100\end{array}$ & $99 / 2$ & & $99 / 6$ & & [346] \\
\hline
\end{tabular}




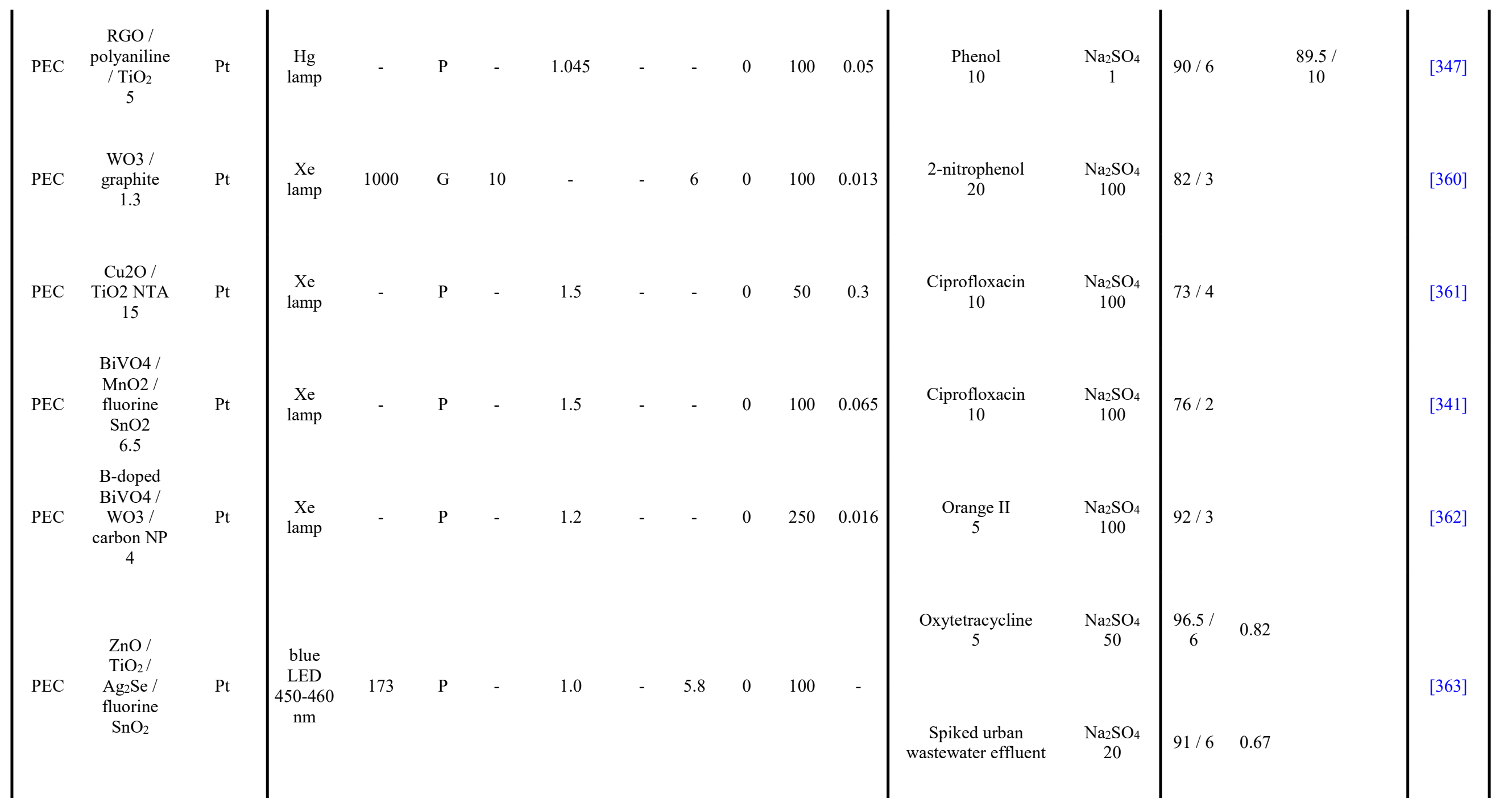




\begin{tabular}{|c|c|c|c|c|c|c|c|c|c|c|c|c|c|c|c|c|c|c|c|}
\hline PEC & $\begin{array}{l}\mathrm{BiVO}_{4} / \\
\mathrm{Ag}_{2} \mathrm{~S} / \\
\text { fluorine } \\
\mathrm{SnO}_{2} \\
6.5\end{array}$ & $\mathrm{Pt}$ & $\begin{array}{c}\text { Xe } \\
\text { lamp }\end{array}$ & - & $\mathrm{P}$ & - & 1.2 & - & - & 0 & 50 & 0.13 & $\begin{array}{l}\text { Sulfamethoxazole } \\
10\end{array}$ & $\begin{array}{c}\mathrm{Na}_{2} \mathrm{SO}_{4} \\
100\end{array}$ & $86 / 2$ & & & & [364] \\
\hline PEC & $\begin{array}{c}{\text { Blue } \mathrm{TiO}_{2}} \\
\text { NTA } \\
3.7\end{array}$ & $\begin{array}{c}\text { SS } \\
3.75\end{array}$ & $\begin{array}{c}\mathrm{Xe} \\
\text { lamp }\end{array}$ & 800 & $\mathrm{P}$ & - & - & 2.4 & 5 & 0 & 100 & - & $\begin{array}{c}2,4- \\
\text { dichlorophenoxyacetic } \\
\text { acid } \\
10\end{array}$ & $\begin{array}{l}\mathrm{Na}_{2} \mathrm{SO}_{4} \\
50\end{array}$ & $80 / 1$ & 2.95 & & & [365] \\
\hline $\begin{array}{l}\text { PEC/ } \\
\text { PEF }\end{array}$ & $\begin{array}{l}\mathrm{TiO}_{2} \\
9.4\end{array}$ & $\begin{array}{l}\text { Carbon } \\
\text { cloth } \\
265\end{array}$ & $\begin{array}{c}\mathrm{Hg} \\
\text { lamp }\end{array}$ & 750 & $\mathrm{P}$ & - & $\begin{array}{l}\text { Cat. Pot. } \\
-0.27\end{array}$ & - & 2 & 0.25 & 250 & $\begin{array}{l}0.038 \\
\text { (an.) } \\
1.06 \\
\text { (cat.) }\end{array}$ & $\begin{array}{c}\text { Direct Yellow } 52 \\
2\end{array}$ & $\begin{array}{l}\mathrm{Na}_{2} \mathrm{SO}_{4} \\
50\end{array}$ & $\begin{array}{l}74 / \\
0.83\end{array}$ & - & $\begin{array}{l}66 / \\
0.33\end{array}$ & & [366] \\
\hline $\begin{array}{l}\mathrm{PEC} / \mathrm{h} \\
\mathrm{PEF}\end{array}$ & $\begin{array}{c}\alpha-\mathrm{Fe}_{2} \mathrm{O}_{3} / \\
\mathrm{TiO}_{2} \mathrm{NTA}^{-} \\
5\end{array}$ & Nickel & W lamp & - & $\mathrm{P}$ & - & - & 5 & 3 & 0 & 100 & 0.05 & $\begin{array}{l}\text { Phenol } \\
10\end{array}$ & $\begin{array}{l}\mathrm{Na}_{2} \mathrm{SO}_{4} \\
200\end{array}$ & $99 / 1$ & & & & [108] \\
\hline $\begin{array}{l}\mathrm{PEC} / \mathrm{h} \\
\mathrm{PEF}\end{array}$ & $\begin{array}{c}\mathrm{Bi}_{2} \mathrm{WO}_{6} / \\
\text { fluorine } \\
\mathrm{SnO}_{2} \\
3\end{array}$ & $\begin{array}{c}\mathrm{Fe} @ \mathrm{Fe}_{2} \mathrm{O}_{3} \\
\mathrm{ACF} \\
3\end{array}$ & W lamp & & G & 0.1 & - & 1.2 & 6.2 & 0 & - & - & $\begin{array}{c}\text { Rhodamine B } \\
5\end{array}$ & $\begin{array}{l}\mathrm{Na}_{2} \mathrm{SO}_{4} \\
50\end{array}$ & $80 / 2$ & 1.36 & $87 / 3$ & 47 & [348] \\
\hline $\begin{array}{l}\text { PEC / } \\
\text { PEF }\end{array}$ & $\begin{array}{c}\mathrm{TiO}_{2} \mathrm{NT} \\
4\end{array}$ & $\begin{array}{c}\text { Carbon } \\
\text { PTFE air } \\
\text { diffusion } \\
3\end{array}$ & $\begin{array}{c}\mathrm{Hg} \\
\text { lamp }\end{array}$ & - & G & 16.7 & - & - & 3 & 0.5 & 500 & 0.008 & $\begin{array}{c}\text { Orange } \mathrm{G} \\
84.5\end{array}$ & $\begin{array}{l}\mathrm{Na}_{2} \mathrm{SO}_{4} \\
50\end{array}$ & $\begin{array}{c}99 / \\
0.1\end{array}$ & 65 & $97 / 2$ & 10 & [367] \\
\hline $\begin{array}{l}\text { PEC / } \\
\text { Fenton }\end{array}$ & $\begin{array}{c}\mathrm{RGO} / \\
\mathrm{CeO}_{2} / \\
\mathrm{TiO}_{2} \mathrm{NTA} \\
6\end{array}$ & $\mathrm{Pt}$ & $\begin{array}{c}\mathrm{Xe} \\
\text { lamp }\end{array}$ & 1100 & $\mathrm{P}$ & - & - & 9 & 5 & 1 & 100 & & $\begin{array}{c}\text { Bisphenol A } \\
10\end{array}$ & $\begin{array}{l}\mathrm{Na}_{2} \mathrm{SO}_{4} \\
50\end{array}$ & $80 / 2$ & 1.46 & & & [368] \\
\hline
\end{tabular}




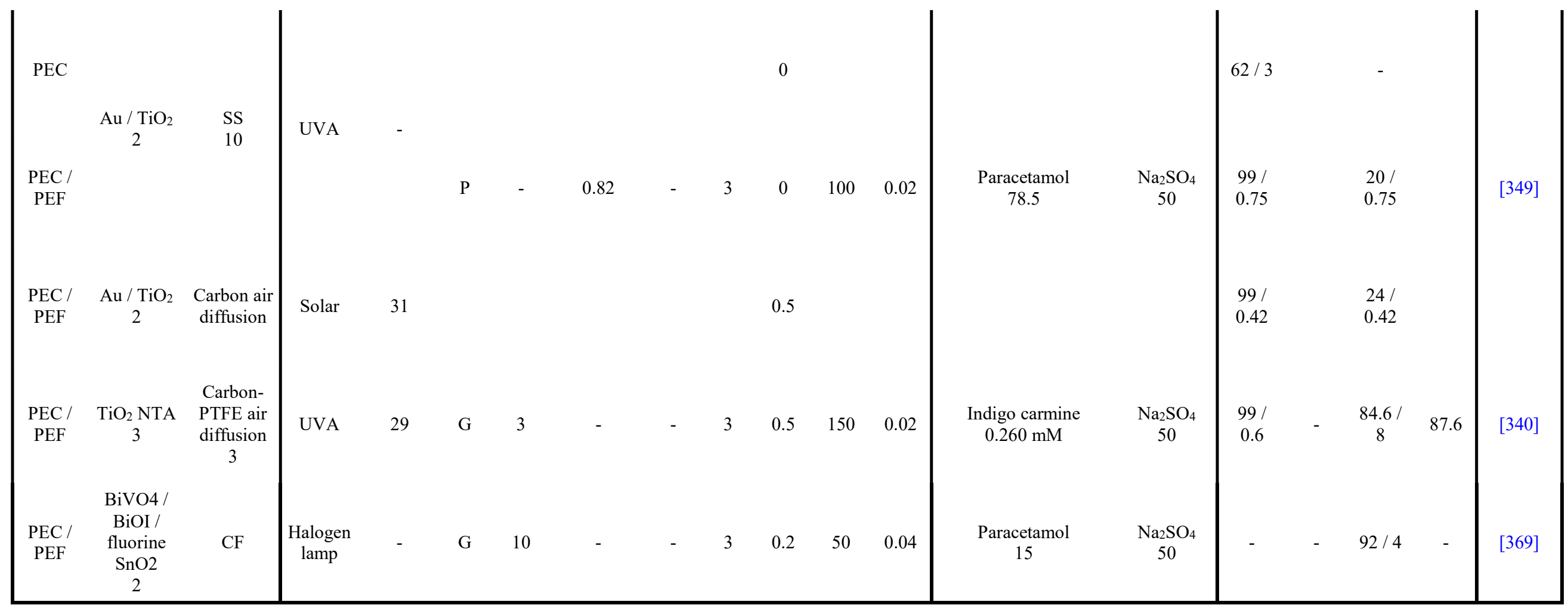

An. Pot.: anodic potential; BDD: boron-doped diamond; Cell. Pot: cell potential; CNT: carbon nanotube; Deg.: degradation; G: galvanostatic mode; hPEF: heterogeneous photo-electro-Fenton; MCE: mineralization current efficiency; Min: mineralization; NP: nanoparticle; NT: nanotube; NTA: nanotube area; P: potentiostatic mode; PEC: photo-electrocatalysis; PEF: photo-electro-Fenton; Ref: reference; RGO: reduced graphene oxide; S/V: ratio electrode surface / volume of the treated solution; SS: stainless steel; V: volume of the treated solution. 


\subsection{Other combined or hybrid processes}

1681 To enhance process efficiency and applicability of the EF process or to overcome some of its

1682

1683

1684

1685

1686

1687

1688

1689

1690

1691

1692

1693

1694

1695

1696

1697

1698

1699

1700

1701

1702

1703 inconvenience, different couplings with other techniques have been performed. PEF or solar PEF (see section 5.3) are among such hybrid processes. Bio-electro-Fenton (bio-EF), sonoelectro-Fenton (SEF), pyrite-electro-Fenton (pyrite-EF) and peroxi-electrocoagulation are some of these combined processes [7,273].

\subsubsection{Bio-EAOPS}

Hybrid processes coupling EAOPs with biological process were developed in order achieve cost-effective treatments [14]. The goal is to decrease the treatment time in order to save electrical energy or to produce electrical energy that is needed for EF treatment. Therefore, there are two types of bio-EF process: the coupling between EF and biological degradation that can be performed sequentially between EF and microbial degradation reactors (EF being generally the pretreatment step) or the coupling between two cells in a one-pot process: microbial fuel cell (MFC) and EF cell. In the latter case, a MFC containing biodegradable organic substrates generates electrical energy that is used by EF cell containing pollutants to be degraded; where the latter cell is operated by using the electrical energy generated by the MFC [370-372]. In fact, MCF works in this system as a "renewable energy" device converting chemical energy available in organic compounds into electricity, which is used to operate the EF reactor. This system has not yet managed to produce a high amount of electricity so that the EF reactor cannot operate with high degradation rate, and needs more investigation in the future.

In this chapter, our attention will be focused mainly on the bio-EF process performed sequentially between EF and biological treatment. It is well known that the treatment of persistent organics by EAOPs leads to the formation of more persistent or toxic intermediate 
products [373]. It causes a longer treatment time and consequently more energy consumption to reach a quasi-complete mineralization $\left(\mathrm{EC}_{\mathrm{TOC}}\right)[374,375]$. As shown in Fig. 23, long electrolysis times (to reach high mineralization rate) result in lower current efficiency and higher energy consumption. To avoid these drawbacks, a pioneer study coupling the EF process as a pretreatment step for a post-biological degradation was performed by Olvera-Vargas et al. (2016) [376]. In this scenario, the EF process serves to convert recalcitrant organic pollutants to biologically degradable end-products, in a relatively short electrolysis time. Indeed, several reports have demonstrated that the treatment of recalcitrant organic pollutants by AOPs enhances the biodegradability index, measured by $\mathrm{BOD}_{5} / \mathrm{COD}$ ratio (with $\mathrm{BOD}_{5}$, the 1713 biochemical oxygen demand after 5 days) of treated solutions [377-380]. It has been 1714 demonstrated that EF treatment allows the oxidation of mother molecules and leads to the 1715 formation of by-products with lower molecular weight, mainly short-chain carboxylic acids, that are biodegradables $[381,382]$. The key parameter taken into consideration in enhancement

1717 of biodegradability during combination of EF (as a pretreatment step) with biological 1718 degradation is the $\mathrm{BOD}_{5} / \mathrm{COD}$ ratio [383]. A threshold value of 0.4 attained during $\mathrm{EF}$ 1719 pretreatment allows the application of biological processes to mineralize the remaining organic 1720 substrates. 

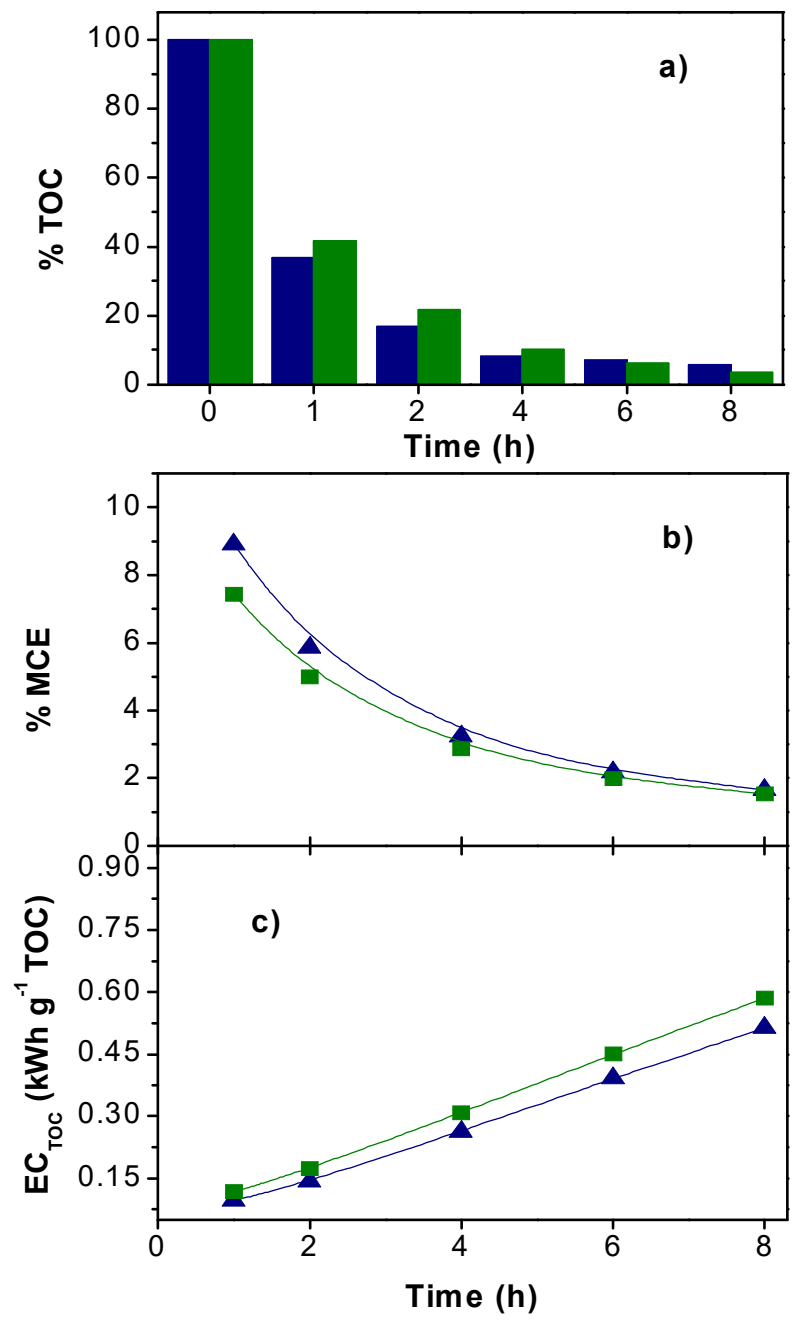

1723 Figure 23. (a) Evolution of TOC removal, (b) MCE and (c) $\mathrm{EC}_{\mathrm{TOC}}$ during the mineralization 1724 of $230 \mathrm{~mL}$ of $0.1 \mathrm{mM} \mathrm{FRSM} \mathrm{( \square )} \mathrm{and} \mathrm{RNTD} \mathrm{( \square )} \mathrm{aqueous} \mathrm{solutions} \mathrm{(both} \mathrm{in} 0.05 \mathrm{M} \mathrm{Na}_{2} \mathrm{SO}_{4}$ 1725 medium at $\mathrm{pH} 3.0$, room temperature and $500 \mathrm{~mA}$ of current) using a BDD/CF cell with $1726\left[\mathrm{Fe}^{2+}\right]=0.1 \mathrm{mM}$. The equations used to determine MCE and $\mathrm{EC}_{\text {TOC }}\left(\right.$ in $\left.\mathrm{kWh}(\mathrm{g} \mathrm{TOC})^{-1}\right)$ are 1727 given in the reference Brillas et al., 2009 [7]. Reprinted from Olvera-Vargas et al. 2016 [375], with permission. Copyright 2016 Elsevier.

In this context, an outstanding work showing the applicability of bio-EF hybrid process has 1731 been conducted by Olvera-Vargas et al. (2016) [376]. The solutions of $0.1 \mathrm{mM} \beta$-blocker metoprolol (MTPL) were treated by the EF process and an increase in the biodegradability index of treated solutions from 0.012 (strongly non-biodegradable) to 0.44 (biodegradable) was reached after a short electrolysis time of $1 \mathrm{~h}$ at $300 \mathrm{~mA}$. The evolution of the $\mathrm{BOD}_{5} / \mathrm{COD}$ ratio 
and that of average oxidation state (AOS) is depicted in Fig. 24a. These values clearly indicate that the remaining organic carbon is mainly composed of biocompatible short-chain carboxylic acids.

The initial TOC was reduced by $46 \%$ after $1 \mathrm{~h}$ EF pretreatment, and then it was efficiently decreased by $90 \%$ during the following 4 days-incubation under aerobic conditions (Fig. 24b). Moreover, toxicity tests based on the use of $V$. fischeri bioluminescent bacteria (Microtox ${ }^{\circledR}$ test) evidenced the presence of harmful intermediates formed during the EF treatment, which were also destroyed, as attested by the absence of toxicity after the EF stage [376]. Recently, Arellano et al. (2020) [384] have successfully applied this hybrid process to the removal of ionic liquids from water.

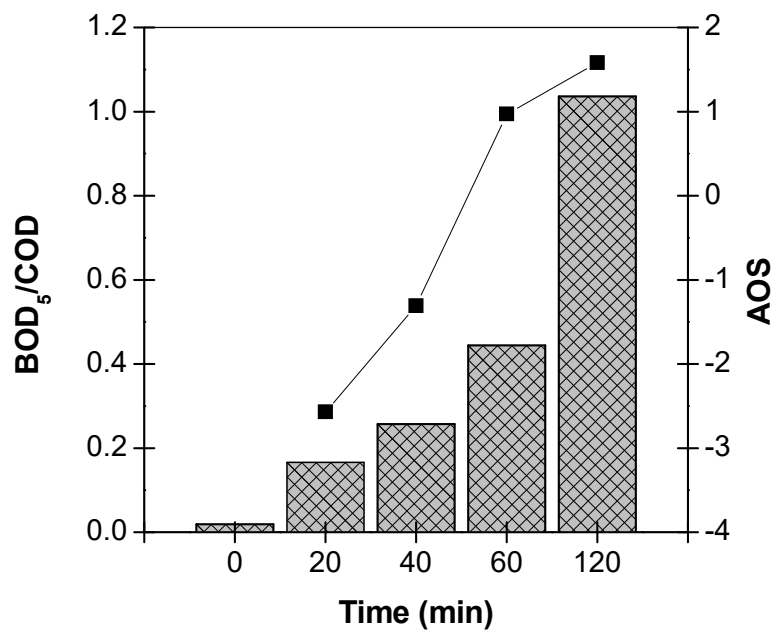

(a)

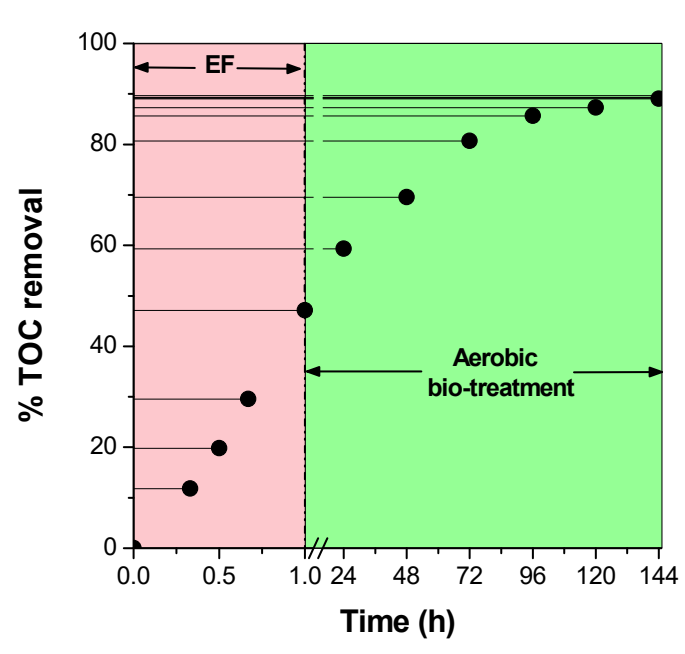

(b)

Figure 24. Treatment of beta-blocker metoprolol by Bio-EF process: (a) Evolution of the $\mathrm{BOD}_{5} / \mathrm{COD}(\otimes)$ ratio and of AOS (---) during EF treatment of $220 \mathrm{~mL}$ of $0.1 \mathrm{mM}$ of MTPL solution in $0.05 \mathrm{M} \mathrm{Na}_{2} \mathrm{SO}_{4}$ and $0.1 \mathrm{mM} \mathrm{Fe}^{2+}$ at $\mathrm{pH} 3.0$ using a CF/BDD cell operating at 300 $\mathrm{mA}$ and room temperature, and (b) Time-course of the overall TOC removal $26.74 \mathrm{mg} \mathrm{L}^{-1}$ (corresponding to $0.1 \mathrm{mM}$ ) solution. Biological phase was conducted under aerobic conditions using a mixture of 12 pure cultures of microorganisms. Reprinted with permission from Olvera-Vargas et al. (2016) [376]. Copyright 2016 Elsevier. 
1754 The bio-EF can also be used as post-treatment step after a biological treatment step. Ganzenko 1755 et al., (2018) [380] investigated the application of the EF process as a pre- or post-treatment 1756 step coupled with a biological process using a sequencing batch reactor during the treatment of 1757 a pharmaceutical wastewater spiked with the pharmaceutical caffeine and 5-fluoracil and found 1758 the first scenario (EF as pretreatment) more efficient. Indeed, EF could completely degrade 1759 both drugs and reached 60\% COD removal in $2 \mathrm{~h}$ at $200 \mathrm{~mA}$. The post SBR removed 30\% COD attaining an overall 90\% COD removal. It is noteworthy to use low currents during EF treatment to avoid higher energy consumption and mineralization of the biodegradable intermediates so that they will be removed by biological post-treatment.

\subsubsection{Sonoelectro-Fenton (SEF)}

1764 The coupling between EF and sonolysis was performed by Oturan et al. (2008) [385] where the term SEF was defined for the first time. In SEF, the solutions to be treated are submitted simultaneously to the degradation of pollutants by EF and ultrasonic irradiation [385-389]. The

1767 collapse of cavitation bubbles results in local high pressures and temperatures, leading to the 1768

$\left.\left.\left.\mathrm{H}_{2} \mathrm{O}+\right)\right)\right) \rightarrow \mathrm{OH}^{\bullet}+\mathrm{H}^{\bullet}$

1770 The application of ultrasound to the solutions under EF treatment, leads also to the formation 1771 of additional ${ }^{\circ} \mathrm{OH}$ from the dissociation of electrogenerated $\mathrm{H}_{2} \mathrm{O}_{2}$ under ultrasonic irradiation 1772 (Eq. 20).

$\left.\left.\left.1773 \mathrm{H}_{2} \mathrm{O}_{2}+\right)\right)\right) \rightarrow 2 \mathrm{OH}^{\bullet}$

1774 It was shown that a synergistic effect is obtained during SEF process, because of the additional 1775 effect of the enhancement of the mass transfer rate to the electrode by sonication [385]. A Pt/CF tank reactor was placed on a ceramic piezoelectric transducer placed on the base of $\mathrm{EF}(\mathrm{Pt} / \mathrm{CF})$ 
1777 batch used to compare the performance of the EF and the SEF processes during the degradation 1778 of the herbicides 2,4-dichlorophenoxyacetic acid and 4,6-dinitro-o-cresol. Results highlighted 1779 better performance of SEF compared with EF alone at low frequencies of $28 \mathrm{kHz}$ with low 1780 energy ultrasounds of 20 and $60 \mathrm{~W}$. In contrast, higher energy ultrasounds (i.e., $80 \mathrm{~W}$ ) inhibited 1781 the efficiency of the hybrid process, due to the depletion of $\mathrm{O}_{2}$ required for the EF process $1782[385]$.

Later, there were several studies on the application of the SEF. Li et al. (2010) [386] reported an enhancement in $\mathrm{H}_{2} \mathrm{O}_{2}$ production and dye degradation rate when using low frequency ultrasounds. Martínez and Uribe (2012) [390] reported quick degradation and efficient mineralization (85\% TOC removal) of the dye Azur B by the SEF. Lounis et al. (2016) [391] studied the degradation of Orange G by SEF in seawater and natural mineral water obtaining complete degradation rate in the former medium while $94 \%$ of the dye is degraded in the latter one. All above results concerned the application of SEF to dye solutions. Few studies have been conducted with other pollutants such as nitrotoluenes and 4-chlorophenol. SEF was applied to the degradation of dinitrotoluene and 2,4,6-trinitrotoluene) in wastewater [392]. Complete 1792 degradation of both nitrotoluenes was obtained despite the absence of oxygen bubbling in the 1793 solution. Authors explained this situation by $\mathrm{O}_{2}$ generation at the anode and its rapid transfer 1794 toward the cathode (for $\mathrm{H}_{2} \mathrm{O}_{2}$ generation) thanks to enhanced mass transfer rate of $\mathrm{O}_{2}$ caused by ultrasonic irradiation. On the other hand, Nazari et al. (2018) [393] investigated the degradation of 4-chlorophenol (4-CP) in aqueous solution using two Ti/mixed metal oxide 1797 electrodes. 4-CP was hardly degraded by sonolysis while a degradation rate of $83 \%$ was reached 1798 by EF. Complete degradation of 4-CP was attained by hybrid process SEF at in min under low 1799 energy $(20 \mathrm{kHz})$ ultrasounds. The main contribution of ultrasound irradiation was explained by the enhancement of the mass transfer rate. The use of low energy ultrasounds was suggested as 
a practical and efficient approach to support the EF process in order to work without the need to cool the solution.

\subsubsection{EF-pyrite}

The EF-pyrite is the heterogeneous version of the classical EF in which the soluble iron salt (as source of $\mathrm{Fe}^{2+}$ ion as catalyst) is replaced by natural pyrite $\left(\mathrm{FeS}_{2}\right)$ mineral as solid catalyst. The use of pyrite as catalyst in the EF process conducted to the description of a novel EF process, so-called EF-pyrite [268,277,302,394]. In contrast to other solid catalysts to perform heterogeneous EF processes, pyrite provides some additional interesting characteristics [272,301,395]. Besides its abundance in the nature and reusability, it possesses some very interesting properties for EF process. Indeed, once introduced into the solution to be treated, it behaves as a source of $\mathrm{H}^{+}$and $\mathrm{Fe}^{2+}$ ions according to Eqs. 21-23. Therefore, its use as a solid catalyst in the EF process presents several advantages such as self-regulation of solution $\mathrm{pH}$ and the possibility to avoid external addition of acid and soluble salt catalyst $\left(\mathrm{Fe}^{2+}\right)$ source [303].

$2 \mathrm{FeS}_{2}(\mathrm{~s})+7 \mathrm{O}_{2}(\mathrm{~g})+2 \mathrm{H}_{2} \mathrm{O} \rightarrow 2 \mathrm{Fe}^{2+}+4 \mathrm{SO}_{4}^{2-}+4 \mathrm{H}^{+}$

$2 \mathrm{FeS}_{2}(\mathrm{~s})+15 \mathrm{H}_{2} \mathrm{O}_{2} \rightarrow 2 \mathrm{Fe}^{3+}+14 \mathrm{H}_{2} \mathrm{O}+4 \mathrm{SO}_{4}{ }^{2-}+2 \mathrm{H}^{+}$

$2 \mathrm{FeS}_{2}(\mathrm{~s})+14 \mathrm{Fe}^{3+}+8 \mathrm{H}_{2} \mathrm{O} \rightarrow 15 \mathrm{Fe}^{2+}+2 \mathrm{SO}_{4}^{2-}+16 \mathrm{H}^{+}$

Another advantage is related to the reaction of pyrite reaction with electrogenerated $\mathrm{H}_{2} \mathrm{O}_{2}$ producing $\mathrm{Fe}^{3+}$ (Eq. 22) which is then reduced to $\mathrm{Fe}^{2+}$ (Eq. 23) contributing to the selfregulation of catalyst. Therefore, pyrite dosage constitutes a key parameter for oxidation kinetics of organic pollutants. The effect of this parameter has been investigated by Labiadh et al. (2015) [301] during the removal of the azo dye AHPS (4-amino-3-hydroxy-2-p-tolylazonaphthalene-1-sulfonic acid) from water (Fig. 25a). The increase in pyrite dosage from 0.5 to 2 
$\mathrm{g} \mathrm{L}^{-1}$ enhanced the degradation kinetics of AHPS but a further raising led to a weakened degradation kinetics, probably due to the release of an excess of $\mathrm{Fe}^{2+}$ ions wasting the ${ }^{\circ} \mathrm{OH}(\mathrm{Eq}$. 14).

The EF-pyrite process was successfully applied to the efficient removal (oxidative degradation/mineralization) of different organic pollutants from water. An example of mineralization kinetics, including MCE is given in Fig. 25b. An overview of other studies on the performance of the EF-pyrite process with experimental conditions and mineralization rates of treated solutions, are gathered in Table 4. This Table also includes a comparative study between EF-pyrite and classical $\mathrm{EF}$ with $\mathrm{Fe}^{2+}$ ions as a homogeneous catalyst. It is worthy of note that the excellent results were obtained with chalcopyrite $\left(\mathrm{CuFeS}_{2}\right)$ as a solid catalyst [396].

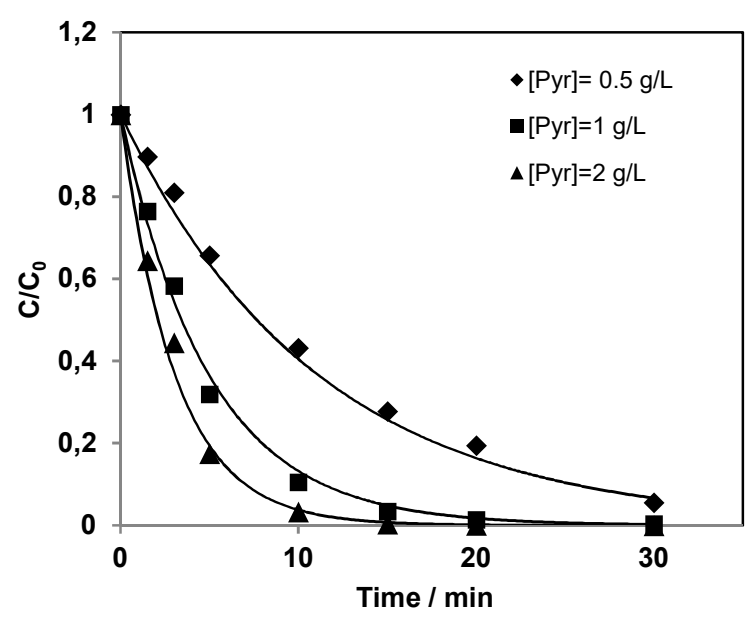

(a)

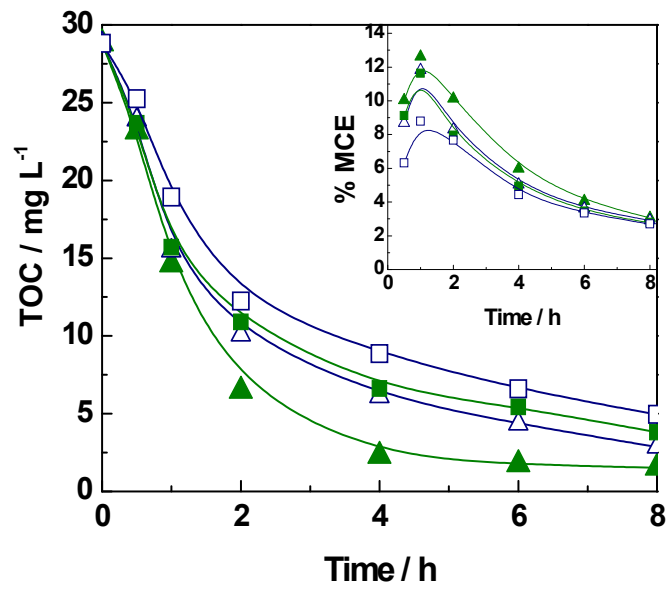

(b)

Figure 25. (a): Effect of pyrite dosage on the oxidative degradation kinetics of AHPS $\left(\mathrm{C}_{0}=\right.$ $175 \mathrm{mg} \mathrm{L}^{-1}$ ) in the EF-pyrite process and (b): Mineralization kinetics of $0.2 \mathrm{mM}$ sulfamethazine using $(\Delta, \Delta) \mathrm{BDD} / \mathrm{CF}$ and $(\square, \square) \mathrm{Pt} / \mathrm{CF}$ cells. The inset panel shows the corresponding MCE curves for $(\Delta, \square)$ EF-pyrite with $2.0 \mathrm{~g} \mathrm{~L}^{-1}$ pyrite and $(\Delta, \square)$ classical EF with $0.2 \mathrm{mM} \mathrm{Fe}^{2+}$. Experimental conditions: $I=300 \mathrm{~mA}$, $\left[\mathrm{Na}_{2} \mathrm{SO}_{4}\right]=50 \mathrm{mM}$. Adapted from Labiadh et al., 2015 [301] (a) and Barhoumi et al., 2016 [303] (b) with permission. Copyright 2015, 2016, Elsevier. 
Table 4. TOC removal efficiencies obtained during the EF-pyrite treatment of different contaminants and comparison with classic (homogeneous) EF process. Adapted from the reference [272], Copyright 2018, Springer

\begin{tabular}{|c|c|c|c|c|}
\hline Contaminant & Cell configuration & $\begin{array}{l}\text { \% TOC removal } \\
\text { (EF-Pyrite) }\end{array}$ & $\begin{array}{l}\text { \%TOC removal } \\
\text { (Classic EF) }\end{array}$ & Reference \\
\hline Levofloxacin & $\begin{array}{l}\text { BDD-CF undivided cell }(300 \mathrm{~mA}) \\
1 \mathrm{~g} \mathrm{~L}^{-1} \text { of pyrite }\end{array}$ & 95 in 8 h-treatment & & [395] \\
\hline Tyrosol & $\begin{array}{l}\text { BDD-CF undivided cell }(300 \mathrm{~mA}) \\
1 \mathrm{~g} \mathrm{~L}^{-1} \text { of pyrite }\end{array}$ & 89 in 6 h-treatment & $\begin{array}{l}88 \text { in } 6 \mathrm{~h}- \\
\text { treatment }\end{array}$ & [394] \\
\hline Synthetic dye AHPS & $\begin{array}{l}\text { BDD-CF undivided cell }(450 \mathrm{~mA}) \\
2 \mathrm{~g} \mathrm{~L}^{-1} \text { of pyrite }\end{array}$ & $>90$ in 5 h-treatment & $\begin{array}{l}70 \text { in } 5 \mathrm{~h}- \\
\text { treatment }\end{array}$ & [301] \\
\hline Sulfamethazine & $\begin{array}{l}\text { BDD-CF undivided cell }(300 \mathrm{~mA}) \\
2 \mathrm{~g} \mathrm{~L}^{-1} \text { of pyrite }\end{array}$ & 95 in 8 h-treatment & $\begin{array}{l}90 \text { in } 8 \mathrm{~h}- \\
\text { treatment }\end{array}$ & [303] \\
\hline Tetracycline & $\begin{array}{l}\text { BDD-CF undivided cell }(500 \mathrm{~mA}) \\
1 \mathrm{~g} \mathrm{~L}^{-1} \text { of chalcopyrite }\end{array}$ & $\begin{array}{l}92 \text { in } 2 \mathrm{~h}, 99 \text { in } 6 \mathrm{~h}- \\
\text { treatment }\end{array}$ & $\begin{array}{c}90 \text { in } 2 \text { h, } 98 \text { in } 6 \\
\text { h-treatment }\end{array}$ & [396] \\
\hline Tetracycline & $\begin{array}{l}\text { BDD-CF undivided cell }(300 \mathrm{~mA}) \\
2 \mathrm{~g} \mathrm{~L}^{-1} \text { of pyrite }\end{array}$ & $\begin{array}{c}99 \text { in } 8 \text { h-treatment } \\
87 \% \text { with Pt anode at } \\
300 \mathrm{~mA}\end{array}$ & $\begin{array}{l}96 \text { in } 8 \mathrm{~h}- \\
\text { treatment }\end{array}$ & [397] \\
\hline Vanillic acid & $\begin{array}{l}\text { Pt-CF undivided cell }(300 \mathrm{~mA}) \\
1 \mathrm{~g} \mathrm{~L}^{-1} \text { of pyrite }\end{array}$ & 89 in 4 h-treatment & - & [398] \\
\hline
\end{tabular}




\subsubsection{Peroxi-electrocoagulation}

1846 Peroxi-electrocoagulation (called also peroxi-coagulation) is a coupling between electrocoagulation and EF 1847 processes, developed and applied to wastewater treatment by Brillas et al. [399,400]. This hybrid process 1848 involves the EF process using a sacrificial iron anode to generate iron ions (Eq. 24) and a carbonaceous 1849 cathode to produce $\mathrm{H}_{2} \mathrm{O}_{2}$ according to Eq. 1 allowing the Fenton reaction (Eq. 2) to take place.

$1850 \quad \mathrm{Fe} \rightarrow \mathrm{Fe}^{2+}+2 \mathrm{e}^{-}$

1851 In addition, ferrous iron ions leached to the solution from the iron anode (Eq. 24) is oxidized in the solution 1852 by the DO and electrogenerate $\mathrm{H}_{2} \mathrm{O}_{2}$ (Eq. 1) to form ferric iron ions that promote the coagulation process 1853 through the formation of ferric hydroxide $\left(\mathrm{Fe}(\mathrm{OH})_{3}\right)$. Thus, pollutants contained in wastewater are removed 1854 by both oxidative attacks of ${ }^{\circ} \mathrm{OH}$ (produced from the Fenton reaction (Eq. 2)), and by coagulation 1855 (adsorption and entrapment in $\mathrm{Fe}(\mathrm{OH})_{3}$ precipitates). Therefore, Brillas and Casado (2002) [400] observed 1856 higher pollutants removal efficiency in peroxi-electrocoagulation compared to the EF process. In contrast 1857 to the electrocoagulation process in which pollutants are only eliminated by coagulation, the peroxi1858 electrocoagulation allows high organics removal efficiencies thank to the action of strong oxidant ${ }^{\bullet} \mathrm{OH}$ 1859 generated through EF process [401-404]. Moreover, to enhance the process efficiency, the peroxielectrocoagulation has also been coupled with UV irradiation $[405,406]$ for degradation of chlorophenoxy 1861 acid herbicides in aqueous media.

1862 Inversely to the $\mathrm{EF}$, solution $\mathrm{pH}$ increases during the peroxi-electrocoagulation process due to the HER at 1863 the cathode (Eq. 11) [407-409]. This increase promotes coagulation and results in a high amount of sludge 1864 production in the electrochemical reactor. The formation of sludge production can be reduced by setting the solution $\mathrm{pH}$ to approximately 3 . Under this condition, ferrous iron predominates in the solution, thus 1866 allowing the Fenton reaction to occur more efficiently. 
1867 The peroxi-electrocoagulation process was recently applied to the treatment of different types of wastewater. 1868 Lizama-Bahena et al., 2015 [410] studied a mixture of three herbicides (alachlor, atrazine, and 1869 chlorbromuron) and obtained complete removal of herbicides and COD at $75 \mathrm{~min}$ when combined with UV 1870 irradiation. Recently different research groups successfully applied this hybrid process to the treatment of 1871 composite wastewater [411], acrylonitrile [110], cooking wastewater [412], coke-plant wastewater [413],

1872 laundry wastewater [414] with 70\% COD removal in most of the cases.

\section{5.4.5. Coupling with a pre-concentration step}

1874 EAOPs are generally not cost-effective in the case of low/very low pollutant concentrations $\left(<10^{-3} \mathrm{mM}\right.$ or 1875 between $\mu \mathrm{g} \mathrm{L}^{-1}$ to $\mathrm{mg} \mathrm{L}^{-1}$ ) because of slow mass transfer rate requiring long electrolysis times and 1876 consequently high energy consumption for the removal of low amounts of pollutants. An appropriate pre1877 concentration step before EAOPs can constitute a solution. In this context, Trellu et al. (2018) [415] reported 1878 the adsorption of phenol on activated carbon fiber (ACF) and then the ACF was used as cathode in EF 1879 process with efficient desorption and mineralization efficiency. Furthermore, such a process was suggested 1880 for regeneration of spend ACF with high regeneration efficiency [415]. Thus, ACF can be used as filter to 1881 concentrate the pollutants of a very dilute (but toxic even at low concentration) pollutants and remove 1882 completely these pollutants by EF process with regeneration of ACF. Banuelos et al. (2013) [416] also 1883 proposed such approach for regeneration of granular activated carbon. Using sawdust as adsorbent material, 1884 Bouaziz et al. (2014) [417] also studied the regeneration of this material using advanced electro-oxidation 1885 with a BDD anode. Recently, Muñoz-Morales et al. (2020) [418] also applied this technique to the pre1886 concentration on granular activated carbon using a sequential three step processes: adsorption-desorption1887 electrolysis to treat low concentrated wastewater containing organochlorinated compounds. The process 1888 was successful for chlopyralid and perchloroethylene (8-time concentration) before electrochemical oxidation step while lindane was poorly concentrated. 
1890 Another strategy is to combine EAOPs with a pre-concentration step based on membrane filtration. The 1891 objective is to apply the electrochemical process on the retentate obtained after membrane filtration. For 1892 example, Lan et al. (2015) [419] have used nanofiltration for the removal of ciprofloxacin from an hospital 1893 effluent and have subsequently treated the retentate by advanced electro-oxidation using BDD anode with 1894 an energy consumption of $50 \mathrm{kWh}$ per $\mathrm{kg}$ of COD removed.

\subsubsection{Electro-peroxone}

1896 The peroxone process is an AOP used for the abatement of organic pollutants in water. This enhanced 1897 ozonation technology consists of the combination of conventional ozonation with $\mathrm{H}_{2} \mathrm{O}_{2}$. In fact, the reaction 1898 of $\mathrm{O}_{3}$ with $\mathrm{H}_{2} \mathrm{O}_{2}$ leads to the generation of ${ }^{\circ} \mathrm{OH}$ according to the Eq. $25[420,421]$. Thus, the $\mathrm{O}_{3}\left(\mathrm{E}^{\circ}=2.07\right.$ $1899 \mathrm{~V} / \mathrm{SHE})$ is transformed to a stronger oxidant $\left(\mathrm{E}^{\circ}=2.80 \mathrm{~V} / \mathrm{SHE}\right)$, able to oxidize pollutants until their 1900 mineralization.

$1901 \mathrm{H}_{2} \mathrm{O}_{2}+\mathrm{O}_{3} \rightarrow{ }^{\cdot} \mathrm{OH}+{ }^{\cdot} \mathrm{O}_{2}^{--}+\mathrm{H}^{+}+\mathrm{O}_{2}$

1902 When the $\mathrm{H}_{2} \mathrm{O}_{2}$ is electrochemically in situ generated from electro-reduction of $\mathrm{O}_{2}$ (Eq. 1), the process is 1903 called electro-peroxone [422,423] and considered as one of emerging EAOPs $[424,425]$. This process overcomes the limitation of conventional ozonation, such as the formation of toxic intermediates remaining in the treated solution, and can be easily implemented by installing a pair of electrodes (including a carbonaceous cathode) in existing ozone reactor with a minimal capital cost [426]. Therefore, different configurations of electro-peroxone process were applied to the treatment of organic pollutants. For example, Yang et al. (2018) [427] developed a dual electrode system to generate simultaneously $\mathrm{O}_{3}$ and $\mathrm{H}_{2} \mathrm{O}_{2}$ for efficient removal (97.6\%) of carbamazepine solution after 90 min electrolysis. A coupling between electroperoxone and biological treatment was developed for the treatment of a simulated hospital wastewater with 92.8\% of TOC removal efficiency [428]. Ghalebizade and Ayati (2019) [429] showed the ability of this process to treat the effluents with high pollutant concentration using a continuous circular flow reactor with $99 \%$ degradation efficiency of $500 \mathrm{mg} \mathrm{L}^{-1}$ of Acid Orange solution at $40 \mathrm{~min}$. Finally, Cornejo and Nava 
1914 (2021) [430] compared ozonation, $\mathrm{AO}-\mathrm{H}_{2} \mathrm{O}_{2}$ and electro-peroxone processes for the treatment of 1915 levofloxacin in a lab scale flow plant and reported the oxidation power in the following order: electro1916 peroxone $>$ ozonation $>\mathrm{AO}-\mathrm{H}_{2} \mathrm{O}_{2}$. Electro-peroxone was able to reach $63 \%$ of mineralization of 1917 levofloxacin solution with a low energy consumption of $0.27 \mathrm{kWh}(\mathrm{gTOC})^{-1}$. A flow-through electro1918 peroxone system was developed for the disinfection of two kinds of simulated ballast water, fulfilling the 1919 efficient generation of ${ }^{\bullet} \mathrm{OH}$ through the reaction of ozone with in-situ electrochemical generation $\mathrm{H}_{2} \mathrm{O}_{2}$. As 1920 a result, a higher E. coli inactivation of one order of magnitude was reached, with a very low energy 1921 consumption ( 0.33 and $0.12 \mathrm{kWh} \mathrm{m}^{-3}$ for treating both solutions) compared to ozonation and electrolysis

1922 [431]. This process was found also cost-effective and promising for simultaneous tetracycline removal and 1923 disinfection of municipal secondary effluents. The main disinfection by-products such as trihalomethanes, 1924 haloacetonitrile and halonitromethanes were particularly much lower than the WHO's thresholds for 1925 drinking water [432].

\section{Perspectives and outlook}

\subsection{Electrocatalytic mechanism understanding requirement}

\subsubsection{ORR mechanisms}

1930 Investigations about existing ORR studies illustrate the difficulties to predict the selectivity of ORR; more 1931 developed kinetic models are required in combination with thermodynamic analysis as well as $\mathrm{pH}$ 1932 dependence studies to deeper understand these mechanisms of selectivity [25].

1933 Moreover, there is a lack of studies about the influence of nanostructure on the ORR mechanisms. Still, a 1934 recent paper attempt to investigate in detail the influence of nitrogen-doped RGO on two- and four-electron 1935 ORR [433]. The authors identified the ORR active sites on $\mathrm{sp}^{2}$ carbon close to oxide location and highlighted 1936 the influence of oxygen functional groups. Moreover, heteroatom structure could interfere with the catalytic 1937 activity and selectivity through modification of chemical structure. They also highlighted that a coupled 
proton-electron transfers (CPETs) mechanism, i.e. the proton and electron are transferred simultaneously 1939 with a single transition state, mainly occurs with metal cathode. Contrastingly, there are different possible 1940 ORR pathways with carbon-based materials. It can occur through either CPETs or non-CPETs (i.e. 1941 decoupled proton and electron transfer) mechanisms, depending on the material composition, the surface 1942 functionalization and the solution $\mathrm{pH}$. This complexity of different ORR mechanisms emphasized in this 1943 specific study, has to be enlarged to other types of nanostructured-based cathode materials, which will help to get an overview of the different ORR mechanisms.

\subsubsection{OER and oxidation mechanisms}

1946 The mechanism of anodic oxidation of pollutants is mainly classified by two ways: direct electron transfer, 1947 and oxidation through the generated radicals. The direct electron transfer is usually verified by the LSV 1948 characterization via comparison of the output current in the presence/absence of pollutants. If the output 1949 current in the presence of pollutant is higher than that in the absence of pollutants, it can prove the role of 1950 direct electron transfer.

1951 For the role of radical oxidation, there are qualitative and quantitative methods including quenching study, 1952 radical probes and electron paramagnetic resonance method [434]. Table 5 lists some common radical 1953 scavenger and probes. Methanol (MeOH) is the scavenger for $\mathrm{SO}_{4}{ }^{-{ }^{-}}$and ${ }^{\circ} \mathrm{OH}$, and tert-butyl alcohol (TBA) 1954 is supposed to scavenge only ${ }^{\circ} \mathrm{OH}$. Atrazine (ATZ) can distinguish the role of radical and non-radical oxidation. $\mathrm{SO}_{4}{ }^{-\bullet}$ has a low reactivity to nitrobenzene (NB) oxidation and can determine the role of ${ }^{\circ} \mathrm{OH}$ and $\mathrm{SO}_{4}{ }^{\circ-}$. From the quenching study, it can be distinguished the role of ${ }^{\circ} \mathrm{OH}$ and $\mathrm{SO}_{4}{ }^{\circ}$, and furthermore the contribution of these two radicals could be calculated by Eqs. (26) and (27). In addition, there are two kinds of ${ }^{\circ} \mathrm{OH}$ that supposed to exist in electrochemical oxidation, homogeneous (free ${ }^{\circ} \mathrm{OH}$ ) and heterogeneous 1959 (surface ${ }^{\circ} \mathrm{OH}$ ), which can be detected using coumarin as the ${ }^{\circ} \mathrm{OH}$ probe. An ${ }^{\circ} \mathrm{OH}$ adduct product of 71960 hydroxycoumarin can be formed through Eq. (28) which is considered to be non-oxidizable by ${ }^{\circ} \mathrm{OH}$ [255]. 
1961 Therefore, the higher the intensity of 7-hydroxycoumarin, the higher contribution of ${ }^{\circ} \mathrm{OH}$ tended to be free $1962{ }^{\circ} \mathrm{OH}$. On the contrary, ${ }^{\circ} \mathrm{OH}$ is tended to be surface ${ }^{\circ} \mathrm{OH}$.

$1963 \lambda \cdot_{\mathrm{OH}}=\frac{k-k_{T B A}}{k} \times 100 \%$

$$
\lambda_{\mathrm{SO}_{4}{ }^{-}}=\frac{k_{M e O H}-k_{T B A}}{k} \times 100 \%
$$

1965 where $k$ was the rate constant of phenol degradation without addition of scavenger, $k_{\text {TBA }}$ was the rate constant 1966 with addition of TBA, $k_{\mathrm{MeOH}}$ was the rate constant with addition of $\mathrm{MeOH}$.

Table 5. Common scavengers and reactive radicals.

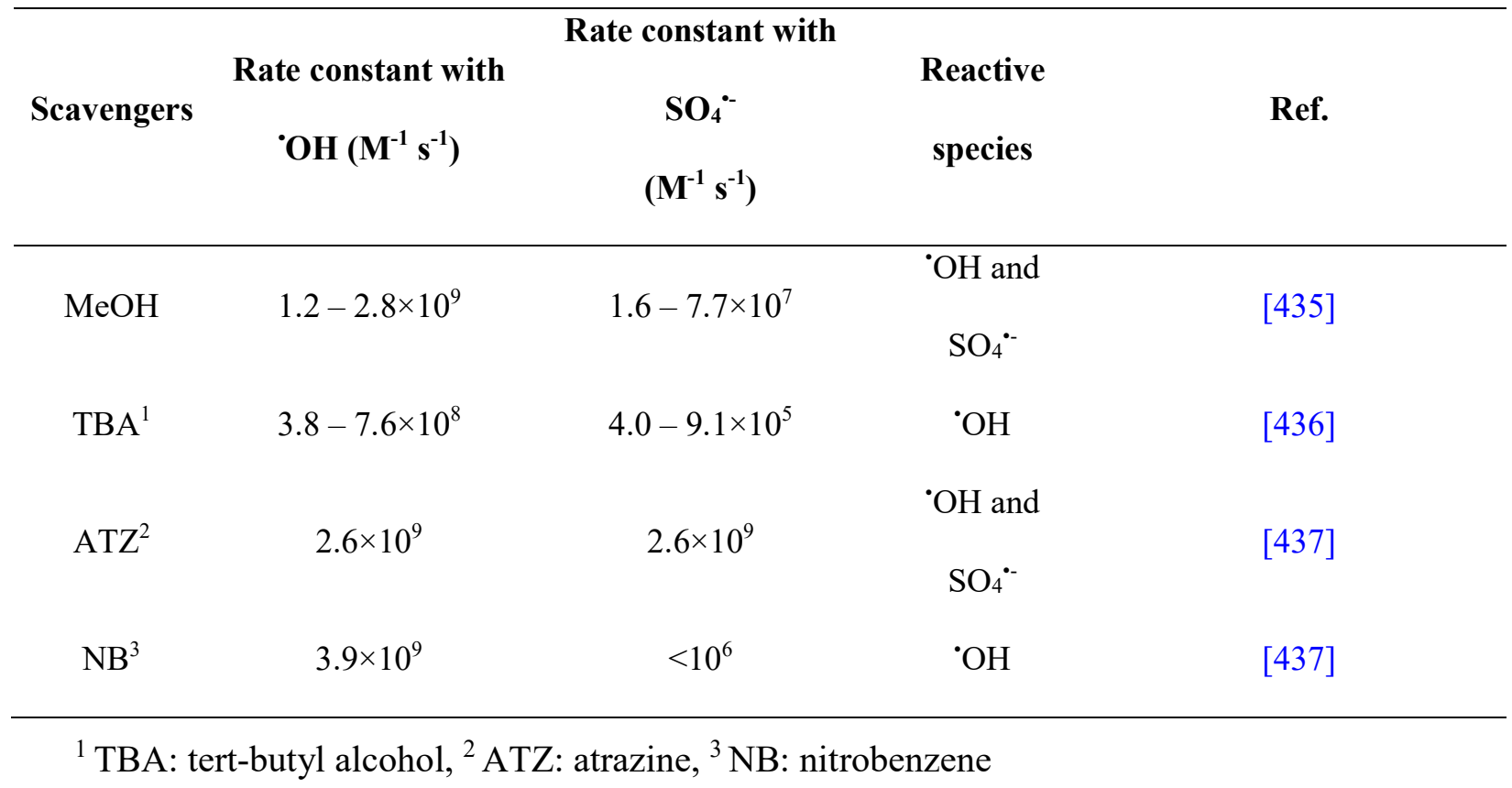

1971 Besides, the degradation intermediates are also important to disclose the possible degradation pathway and 1972 mechanism through analysis via gas chromatography mass spectrometry (GC-MS) or liquid 1973 chromatography mass spectrometry (LC-MS). However, these measurements are not sufficient for 
1974 understanding OER and oxidation mechanism. As an anodic interface process, there is an urgent need to 1975 develop the characterization and identification method for surface reaction especially for the real-time or in 1976 situ detection of possible radicals involved in the pollutant degradation, so that an intrinsic mechanism 1977 would be well disclosed to benefit OER mechanism understanding.

\section{6.2. Electrode stability improvement}

\section{6.2.1. Cathodes stability}

1980 The cathode performances does not stop at achieving the desired amount of the $\mathrm{H}_{2} \mathrm{O}_{2}$ but, the challenge is 1981 to keep the production capacity constant for a long time and to develop the process in a large-scale 1982 application [125]. Some papers focused on the nanostructured cathode stability or reusability by assessing 1983 either the $\mathrm{H}_{2} \mathrm{O}_{2}$ generation efficiency or contaminant degradation performances after several successive 1984 cycles of electrolysis. Table 6 presents some different works that deal with the stability of the cathode toward $1985 \mathrm{H}_{2} \mathrm{O}_{2}$ electrogeneration.

Yu et al. [132] used CF modified with nitrogen-doped carbon as the cathode for the production of $\mathrm{H}_{2} \mathrm{O}_{2}$. It was concluded that the $\mathrm{H}_{2} \mathrm{O}_{2}$ yield was kept relatively constant after 5 cycles with a slight loss of the concentration during the last run. Yang et al. [66] carried out the $\mathrm{H}_{2} \mathrm{O}_{2}$ electrogeneration rate at the EEGr/GF cathode. Due to the cathode modification, the stability of the material was boosted and the production rate stayed almost constant after 10 cycles.

In another work Zhao et al. [63] evaluated the stability of the fluorine-doped carbon cathodes toward the $\mathrm{H}_{2} \mathrm{O}_{2}$ after 8 cycles of $3 \mathrm{~h}$ each, and no significant decrease of performance was observed. Xia et al. [61] prepared a phosphorus-doped CNTs GDE and the reusability of the electrode was explored through the $\mathrm{H}_{2} \mathrm{O}_{2}$ yield after 6 cycles during $1 \mathrm{~h}$ each. The authors reported the unchanged cathode performance after the test, which was explained by the strong covalent bond between the phosphorus atoms and carbons 1996 framework. 
1997 Though promising stability have been assessed with some nanostructured modified raw cathode materials, 1998 especially those that favor chemical binding, the stability has to be proven for long-term use, i.e., over 1999 several weeks and months. Moreover, standard protocol to assess the life span performance should be 2000 established so that the international community would have a comparable and viable way to perform them.

Table 6. Literature on the nanostructured cathode stability towards the hydrogen peroxide yield.

\begin{tabular}{|c|c|c|c|c|c|c|c|c|}
\hline $\begin{array}{l}\text { Nanostructured } \\
\text { cathode }\end{array}$ & $\mathbf{p H}$ & $\begin{array}{l}\text { Current } \\
\text { density or } \\
\text { cathode } \\
\text { potential }\end{array}$ & $\begin{array}{l}\mathrm{O}_{2} \\
\text { flow } \\
\text { rate } \\
(\mathrm{L} \\
\left.\mathrm{min}^{-1}\right)\end{array}$ & $\begin{array}{l}\text { Time } \\
(\min )\end{array}$ & $\begin{array}{l}{\left[\mathrm{H}_{2} \mathrm{O}_{2}\right]} \\
\left(\mathrm{mM} \mathrm{cm}^{-}\right. \\
\left.{ }^{2}\right)\end{array}$ & $\begin{array}{l}\text { Number } \\
\text { of } \\
\text { successive } \\
\text { cycles }\end{array}$ & $\begin{array}{l}\text { Stability } \\
\text { (\% loss } \\
\text { of yield) }\end{array}$ & Reference \\
\hline $\begin{array}{l}\text { Phosphorus-doped } \\
\text { carbon nanotubes }\end{array}$ & 7 & $\begin{array}{l}-0.45 \mathrm{~V} \text { vs } \\
\text { SHE }\end{array}$ & 0.21 & 60 & 1.41 & 6 & $\mathrm{UP}^{1}$ & {$[61]$} \\
\hline Fluorine-doped HPC & 1 & $\begin{array}{l}-0.1 \mathrm{~V} \text { vs } \\
\mathrm{RHE}^{4}\end{array}$ & NS & 180 & 11.42 & 8 & $\mathrm{UP}^{1}$ & {$[63]$} \\
\hline $\begin{array}{l}\text { NiFe nanostructure } \\
\text { /Graphite }\end{array}$ & 3 & $\begin{array}{l}300 \mathrm{~mA} \\
\mathrm{~cm}^{-2}\end{array}$ & NS & NS & 0.015 & 15 & $3.59^{2}$ & [166] \\
\hline $\begin{array}{l}\text { Tungsten oxide } \\
\text { nanoparticles/C }\end{array}$ & NS & $\begin{array}{l}-0.5 \mathrm{~V} \text { vs } \\
\mathrm{SHE}\end{array}$ & NS & 180 & 2.34 & 12 & $6^{2}$ & [113] \\
\hline $\begin{array}{l}\text { Exfoliated } \\
\text { Graphene/graphite } \\
\text { felt }\end{array}$ & 7 & $\begin{array}{l}-0.856 \mathrm{~V} \text { vs } \\
\text { SHE }\end{array}$ & 0.7 & NS & $7.72^{2}$ & 10 & $\mathrm{UP}^{1}$ & {$[66]$} \\
\hline $\begin{array}{l}\text { Nitrogen-doped } \\
\text { carbon/graphite felt }\end{array}$ & 7 & $\begin{array}{l}12.5 \mathrm{~mA} \\
\mathrm{~cm}^{-2}\end{array}$ & 0 & NS & 0.4 & 5 & 9 & {$[132]$} \\
\hline GDE-CX 80 & 7 & $\begin{array}{l}-0.8 \mathrm{~V} \text { vs } \\
\text { SHE }\end{array}$ & NS & 120 & $6.60^{2}$ & 10 & $10^{2}$ & [438] \\
\hline $\begin{array}{l}\text { Carbon nanotubes } \\
\text { hybrid fullerene }\end{array}$ & 3 & $\begin{array}{l}0.044 \mathrm{~V} \mathrm{vs} \\
\text { SHE }\end{array}$ & NS & NS & 29 & 15 & 11.7 & {$[102]$} \\
\hline
\end{tabular}

${ }^{1}$ UP: unchanged performance, ${ }^{2}$ unit: $\left(\%\right.$ loss of $\mathrm{H}_{2} \mathrm{O}_{2}$ yield $),{ }^{3}$ unit: $\left(\mathrm{mM} \mathrm{h}^{-1}\right),{ }^{4} \mathrm{RHE}$ : reversible hydrogen electrode

\subsubsection{Anodes stability}

2006 As known, the electrode stability is an important parameter for industrial applications. There are two 2007 strategies to improve the electrode stability, one is the intermediate layer modification, the other is the 
electrode surface modification. Huang et al. (2020) introduced clustered TNTs intermediate layer on Ti mesh as substrate for mesh $\mathrm{Sb}-\mathrm{SnO}_{2}$ electrode $\left(\mathrm{M}-\mathrm{TNTs}-\mathrm{SnO}_{2}\right)$, which exhibited a higher TOC removal and MCE, and longer accelerated service lifetime of $105 \mathrm{~h}$ for electrochemical degradation of phenol when compared with Ti mesh or Ti plate /TNTs electrodes (Fig. 26a) [235]. This enhanced performance was mainly ascribed to the introduction of mutually self-supported TNTs clusters in different orientations [235]. $\mathrm{Xu}$ et al. (2017) explored Nb-doped TNTs interlayer for $\mathrm{Sb}-\mathrm{SnO}_{2}$ electrode [439]. The novel electrode has a larger surface area and smaller crystallite particles than conventional $\mathrm{SnO}_{2}-\mathrm{Sb}$ electrodes. Compared with $\mathrm{Ti} / \mathrm{SnO}_{2}-\mathrm{Sb}$ and $\mathrm{Ti} / \mathrm{TiO}_{2}-\mathrm{NTs} / \mathrm{SnO}_{2}-\mathrm{Sb}$, the electrode modified by $\mathrm{Nb}-\mathrm{TiO}_{2}-\mathrm{NTs}$ has a higher OEP of 2.29 $\mathrm{V} /(\mathrm{Ag} / \mathrm{AgCl})$, and a lower Rct with a decrease by $65 \%$ and $79 \%$, respectively. The service lifetime of $\mathrm{Nb}$ $\mathrm{Ti} / \mathrm{Nb}-\mathrm{TiO}_{2}-\mathrm{NTs} / \mathrm{SnO}_{2}-\mathrm{Sb}$ was 4.9 -time longer than that of $\mathrm{Ti} / \mathrm{SnO}_{2}-\mathrm{Sb}$ and 1.9-time longer than that of $\mathrm{Ti} / \mathrm{TiO}_{2}-\mathrm{NTs} / \mathrm{SnO}_{2}-\mathrm{Sb}$ (Fig. 26b) [439].

The anode surface modification was the more common way for improving electrode stability. Li et al. used sodium dodecyl sulfate (SDS) to modify $\mathrm{PbO}_{2}$ electrode by electro-deposition method, showing that SDS could obviously refine the coating particles, increase the OEP and accelerate charge transfer [440]. The modified $\mathrm{PbO}_{2}$ electrode had a better electro-catalytic performance and stability. The accelerated service life could reach $348 \mathrm{~h}$, which was almost 3.6 times longer than that of $\mathrm{PbO}_{2}$ electrode $(96 \mathrm{~h})$ under the same condition (Fig. 26c) [440]. Zhang et al. (2014) employed CNT to modify $\mathrm{Ti} / \mathrm{SnO}_{2}-\mathrm{Sb}$ using a pulse electrodeposition method [241]. The modified electrode had a smaller crystallite particles, a higher OEP and its service lifetime was 4.8-time longer than that of the $\mathrm{Ti} / \mathrm{SnO}_{2}-\mathrm{Sb}$ electrode [241]. It was reported that cobalt-doped Black TNT array anode had a longer lifetime (200 h) when compared with Blue-TNT (2.3 h) at $10 \mathrm{~mA} \mathrm{~cm}^{-2}$ in $30 \mathrm{mM} \mathrm{NaClO}_{4}$ (Fig. 26d) [441].

Up to now, many efforts on electrode fabrications have been made to make anodes with low cost, strong stability, long service lifetime and enhanced electrocatalytic activity. However, they are usually designed for small electrochemical devices to treat wastewater. Scale-up has not always been faced in the right way, 
2032 the full applications for industrial use, demonstration or even pilot scale applications are still very limited.

2033 This is probably due to the economic difficulties, immature electrode fabrication and lifetime duration as 2034 well as reliable reactor design. Thus, there is an urgent need to develop them at industrial scale to meet the 2035 practical demand [12].

(a)
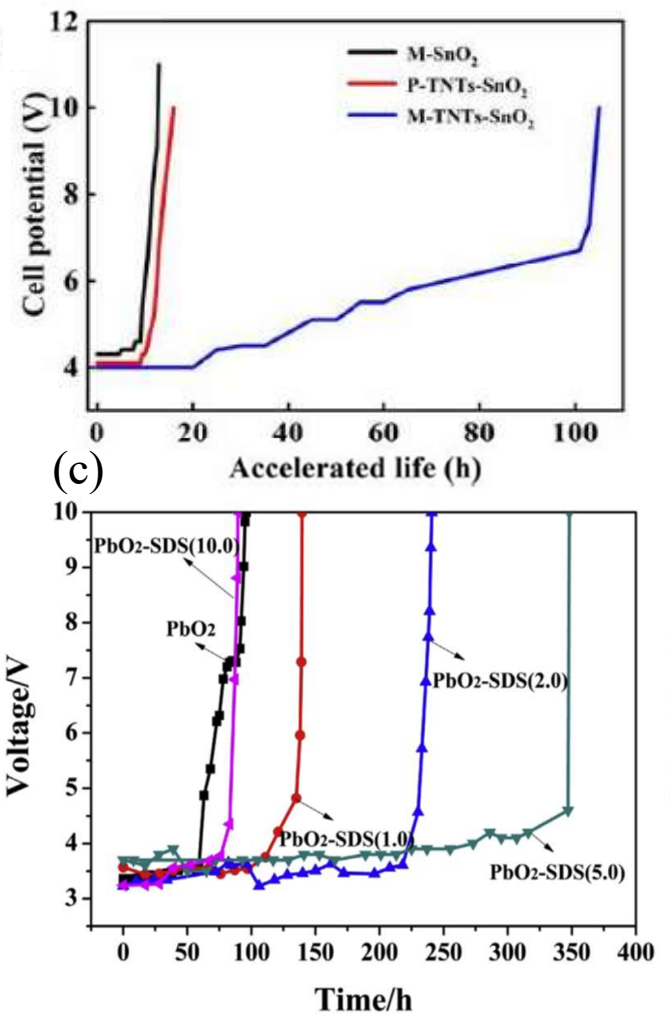

(b)

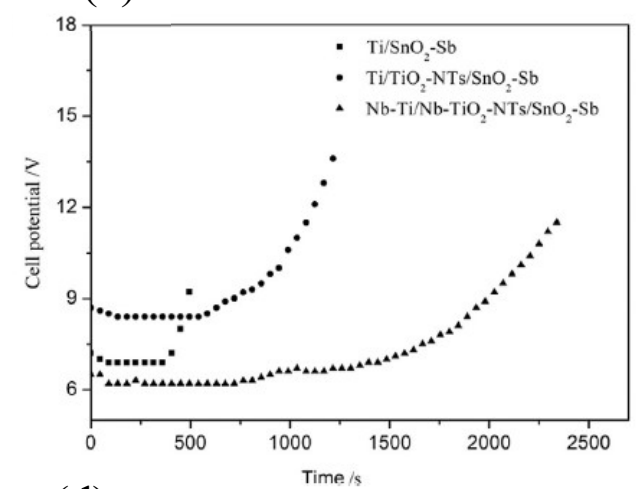

(d)

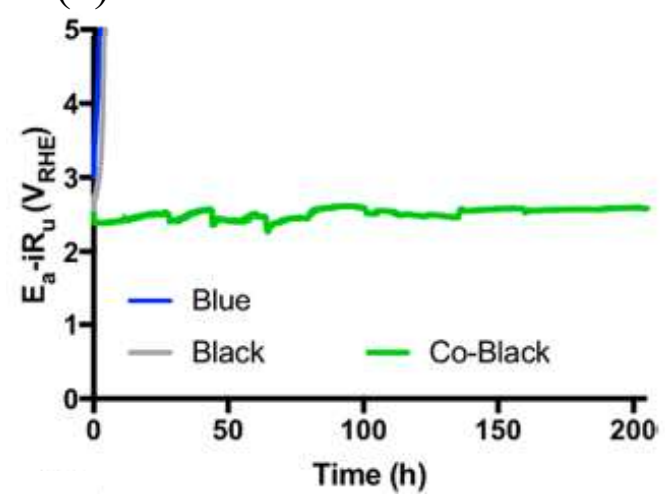

Figure 26. (a) variation of cell voltage during accelerated life tests, [235]. Copyright (2020) Elsevier; (b)

Accelerated service life tests on different electrodes in $0.5 \mathrm{M} \mathrm{H}_{2} \mathrm{SO}_{4}$ solution with a current density of $1 \mathrm{~A}$ $\mathrm{cm}^{-2}$ at $25^{\circ} \mathrm{C}$, [439]. Copyright (2017) Elsevier; (c) Accelerated life test of the different $\mathrm{PbO}_{2}$ electrodes ( $\mathrm{H}_{2} \mathrm{SO}_{4}: 3 \mathrm{M}$; current density: $500 \mathrm{~mA} \mathrm{~cm}{ }^{-2}$, [440], Copyright (2017) Elsevier and (d) Comparison of the anodic stability of the NTA electrodes in $30 \mathrm{mM} \mathrm{KClO}_{4}$ at a current density of $10 \mathrm{~mA} \mathrm{~cm}^{-2}$. [441],

Copyright (2018) Elsevier 


\section{Acknowledgment}

2046 M. Zhou and E. Mousset would like to thank the PRC CNRS-NFSC 2095 (France-China joint programme) 2047 for the funding of ADELWATCOZEP project (NSFC no. 21811530274). M. Zhou would also like to thank 2048 financial support by Natural Science Foundation of China (nos. 21976096 and 21273120), National high2049 level foreign experts project (G20190002011), Tianjin Science and Technology Program 2050 (19PTZWHZ00050), and Fundamental Research Funds for the Central Universities, Nankai University. 2051 M.A. Oturan acknowledges Nankai University and the Tianjin Foreign 1000 Talents programme for their 2052 logistic and financial supports. 


\section{References}

[1] A. Geim, K. Novoselov, The rise of graphene, Nat. Mater. 6 (2007) 183-191. http://www.nature.com/nmat/journal/v6/n3/abs/nmat1849.html.

[2] Y. Hancock, The 2010 Nobel Prize in physics-ground-breaking experiments on graphene, J. Phys. D-Applied Phys. 44 (2010).

[3] V. Chabot, D. Higgins, A. Yu, X. Xiao, Z. Chen, J. Zhang, A review of graphene and graphene oxide sponge: material synthesis and applications to energy and the environment, Energy Environ. Sci. 7 (2014) 1564. doi:10.1039/c3ee43385d.

[4] A. Oleinick, O. Sliusarenko, I. Svir, C. Amatore, Nanostructured electrodes as random arrays of active sites: Modeling and theoretical characterization, J. Electrochem. Soc. $167 \quad(2020) 013530$. doi:10.1149/2.0302001jes.

[5] C.A. Martínez-Huitle, M. Panizza, Electrochemical oxidation of organic pollutants for wastewater treatment, Curr. Opin. Electrochem. 11 (2018) 62-71. doi:10.1016/j.coelec.2018.07.010.

[6] E. Brillas, A review on the photoelectro-Fenton process as efficient electrochemical advanced oxidation for wastewater remediation. Treatment with UV light, sunlight, and coupling with conventional and other photoassisted advanced technologies, Chemosphere. 250 (2020) 126198. doi:10.1016/j.chemosphere.2020.126198.

[7] E. Brillas, I. Sirés, M.A. Oturan, Electro-Fenton process and related electrochemical technologies based on Fenton's reaction chemistry, Chem. Rev. 109 (2009) 6570-6631. doi:10.1007/s00894-008-0358-0.

[8] I. Sirés, E. Brillas, M.A. Oturan, M.A. Rodrigo, M. Panizza, Electrochemical advanced oxidation processes: today and tomorrow. A review., Environ. Sci. Pollut. Res. 21 (2014) 8336-8367. doi:10.1007/s11356-0142783-1.

[9] C.A. Martínez-Huitle, M.A. Rodrigo, I. Sirés, O. Scialdone, Single and coupled electrochemical processes and reactors for the abatement of organic water pollutants: A critical review, Chem. Rev. 115 (2015) 1336213407. doi:10.1021/acs.chemrev.5b00361.

[10] E. Mousset, N. Oturan, M.A. Oturan, An unprecedented route of $\mathrm{OH}$ radical reactivity evidenced by an electrocatalytical process: Ipso-substitution with perhalogenocarbon compounds, Appl. Catal. B Environ. 226 
(2018) 135-146. doi:10.1016/j.apcatb.2017.12.028.

[11] F.C. Moreira, R.A.R. Boaventura, E. Brillas, V.J.P. Vilar, Electrochemical advanced oxidation processes: A review on their application to synthetic and real wastewaters, Appl. Catal. B Environ. 202 (2017) 217-261. doi:10.1016/j.apcatb.2016.08.037.

[12] Z. Hu, J. Cai, G. Song, Y. Tian, M. Zhou, Anodic oxidation of organic pollutants: Anode fabrication, process hybrid and environmental applications, Curr. Opin. Electrochem. $26 \quad$ (2021) 100659. doi:10.1016/j.coelec.2020.100659.

[13] O. Garcia-Rodriguez, E. Mousset, H. Olvera-Vargas, O. Lefebvre, Electrochemical treatment of highly concentrated wastewater: A review of experimental and modeling approaches from lab- to full-scale, Crit. Rev. Environ. Sci. Technol. 0 (2020) 1-70. doi:10.1080/10643389.2020.1820428.

[14] E. Mousset, C. Trellu, H. Olvera-Vargas, Y. Pechaud, F. Fourcade, M.A. Oturan, Electrochemical technologies coupled with biological treatments, Curr. Opin. Electrochem. $26 \quad$ (2021) 100668. doi:https://doi.org/10.1016/j.coelec.2020.100668.

[15] E. Mousset, N. Oturan, E.D. van Hullebusch, G. Guibaud, G. Esposito, M.A. Oturan, Influence of solubilizing agents (cyclodextrin or surfactant) on phenanthrene degradation by electro-Fenton process - Study of soil washing recycling possibilities and environmental impact, Water Res. (2014). doi:10.1016/j.watres.2013.09.044.

[16] P. V. Nidheesh, G. Divyapriya, N. Oturan, C. Trellu, M.A. Oturan, Environmental applications of boron-doped diamond electrodes: 1. Applications in water and wastewater treatment, ChemElectroChem. 6 (2019) 1-20. doi:10.1002/celc.201801876.

[17] J. Cai, M. Zhou, Y. Pan, X. Lu, Degradation of 2,4-dichlorophenoxyacetic acid by anodic oxidation and electro-Fenton using BDD anode: Influencing factors and mechanism, Sep. Purif. Technol. 230 (2020) 115867. doi:10.1016/j.seppur.2019.115867.

[18] J.F. Pérez, J. Llanos, C. Sáez, C. López, P. Cañizares, M.A. Rodrigo, Towards the scale up of a pressurizedjet microfluidic flow-through reactor for cost-effective electro-generation of H2O2, J. Clean. Prod. 211 (2019) 1259-1267. doi:10.1016/j.jclepro.2018.11.225.

[19] E. Mousset, Unprecedented reactive electro-mixing reactor: Towards synergy between micro- and macro- 
reactors?, Electrochem. Commun. 118 (2020) 106787. doi:10.1016/j.elecom.2020.106787.

[20] P. Ma, H. Ma, S. Sabatino, A. Galia, O. Scialdone, Electrochemical treatment of real wastewater. Part 1: Effluents with low conductivity, Chem. Eng. J. 336 (2018) 133-140. doi:10.1016/j.cej.2017.11.046.

[21] I. Sirés, E. Brillas, Electro-Fenton Process: Fundamentals and Reactivity, in: M. Zhou, M.A. Oturan, I. Sires (Eds.), Electro-Fent. Process. Handb. Environ. Chem., Springer, Singapore, 2017: pp. 1-28. doi:10.1007/698_2017_40.

[22] C. Trellu, H.O. Vargas, E. Mousset, N. Oturan, M.A. Oturan, Electrochemical technologies for the treatment of pesticides, Curr. Opin. Electrochem. Just accep (2021).

[23] E. Mousset, N. Oturan, E.D. van Hullebusch, G. Guibaud, G. Esposito, M.A. Oturan, Treatment of synthetic soil washing solutions containing phenanthrene and cyclodextrin by electro-oxidation. Influence of anode materials on toxicity removal and biodegradability enhancement, Appl. Catal. B Environ. 160-161 (2014) 666-675. doi:10.1016/j.apcatb.2014.06.018.

[24] E. Mousset, Y. Pechaud, N. Oturan, M.A. Oturan, Charge transfer/mass transport competition in advanced hybrid electrocatalytic wastewater treatment: Development of a new current efficiency relation, Appl. Catal. B Environ. 240 (2019). doi:10.1016/j.apcatb.2018.08.055.

[25] A. Kulkarni, S. Siahrostami, A. Patel, J.K. Nørskov, Understanding catalytic activity trends in the oxygen reduction reaction, Chem. Rev. 118 (2018) 2302-2312. doi:10.1021/acs.chemrev.7b00488.

[26] J. Zhang, G. Chen, K. Müllen, X. Feng, Carbon-Rich Nanomaterials: Fascinating Hydrogen and Oxygen Electrocatalysts, Adv. Mater. 1800528 (2018) 1800528(1-22). doi:10.1002/adma.201800528.

[27] A. Ambrosi, C.K. Chua, A. Bonanni, M. Pumera, Electrochemistry of graphene and related materials., Chem. Rev. 114 (2014) 7150-7188. doi:10.1021/cr500023c.

[28] D. Chen, H. Feng, J. Li, Graphene oxide: Preparation, functionalization, and electrochemical applications, Chem. Rev. 112 (2012) 6027-6053. doi:10.1021/cr300115g.

[29] R.W. Murray, Nanoelectrochemistry: Metal nanoparticles, nanoelectrodes, and nanopores, Chem. Rev. 108 (2008) 2688-2720. doi:10.1021/cr068077e.

[30] Y. Fan, C. Han, B. Zhang, Recent advances in the development and application of nanoelectrodes, Analyst. 141 (2016) 5474-5487. doi:10.1039/C6AN01285J. 
[31] R. Das, C.D. Vecitis, A. Schulze, B. Cao, A.F. Ismail, X. Lu, J. Chen, S. Ramakrishna, Recent advances in nanomaterials for water protection and monitoring, Chem. Soc. Rev. 46 (2017) 6946-7020. doi:10.1039/c6cs00921b.

[32] B.P. Chaplin, Critical review of electrochemical advanced oxidation processes for water treatment applications, Environ. Sci. Process. Impacts. 16 (2014) 1182-1203. doi:10.1039/C3EM00679D.

[33] M. Panizza, G. Cerisola, Direct and mediated anodic oxidation of organic pollutants, Chem. Rev. 109 (2009) 6541-6569. doi:10.1021/cr9001319.

[34] M.A. Rodrigo, N. Oturan, M.A. Oturan, Electrochemically assisted remediation of pesticides in soils and water: a review, Chem. Rev. 114 (2014) 8720-8745. doi:10.1021/cr500077e.

[35] E. Mousset, K. Doudrick, A review of electrochemical reduction processes to treat oxidized contaminants in water, Curr. Opin. Electrochem. 22 (2020) 221-227. doi:10.1016/j.coelec.2020.07.008.

[36] E. Pomerantseva, C. Resini, K. Kovnir, Y. V. Kolen'ko, Emerging nanostructured electrode materials for water electrolysis and rechargeable beyond Li-ion batteries, Adv. Phys. X. 2 (2017) 211-253. doi:10.1080/23746149.2016.1273796.

[37] J.A. Keith, T. Jacob, Theoretical studies of potential-dependent and competing mechanisms of the electrocatalytic oxygen reduction reaction on Pt(111), Angew. Chemie - Int. Ed. 49 (2010) 9521-9525. doi:10.1002/anie.201004794.

[38] M.A. Oturan, J.-J. Aaron, Advanced Oxidation Processes in Water/Wastewater Treatment: Principles and Applications. A Review, Crit. Rev. Environ. Sci. Technol. 44 (2014) 2577-2641. doi:10.1080/10643389.2013.829765.

[39] Anderson, Ross, Reid, Doug, Hart, Peter, Rudie, Alan, Hydrogen peroxide (H 2 O 2 ) safe storage and handling, 2011.

[40] J.K. Nørskov, J. Rossmeisl, A. Logadottir, L. Lindqvist, J.R. Kitchin, T. Bligaard, H. Jónsson, Origin of the overpotential for oxygen reduction at a fuel-cell cathode, J. Phys. Chem. B. 108 (2004) 17886-17892. doi:10.1021/jp047349j.

[41] S. Siahrostami, A. Verdaguer-Casadevall, M. Karamad, D. Deiana, P. Malacrida, B. Wickman, M. EscuderoEscribano, E.A. Paoli, R. Frydendal, T.W. Hansen, I. Chorkendorff, I.E.L. Stephens, J. Rossmeisl, Enabling 
direct $\mathrm{H} 2 \mathrm{O} 2$ production through rational electrocatalyst design, Nat. Mater. 12 (2013) 1137-1143. doi:10.1038/nmat3795.

[42] I. Morcos, E. Yeager, Kinetic studies of the oxygen - peroxide couple on pyrolytic graphite, Electrochim. Acta. 15 (1970) 953-975. doi:10.1016/0013-4686(70)80037-8.

[43] E. Yeager, Dioxygen electrocatalysis: mechanisms in relation to catalyst structure, J. Mol. Catal. 38 (1986) 525. doi:10.1016/0304-5102(86)87045-6.

[44] A. Verdaguer-Casadevall, D. Deiana, M. Karamad, S. Siahrostami, P. Malacrida, T.W. Hansen, J. Rossmeisl, I. Chorkendorff, I.E.L. Stephens, Trends in the electrochemical synthesis of H2O2: Enhancing activity and selectivity by electrocatalytic site engineering, Nano Lett. 14 (2014) 1603-1608. doi:10.1021/n1500037x.

[45] J.W.F. To, J.W.D. Ng, S. Siahrostami, A.L. Koh, Y. Lee, Z. Chen, K.D. Fong, S. Chen, J. He, W.G. Bae, J. Wilcox, H.Y. Jeong, K. Kim, F. Studt, J.K. Nørskov, T.F. Jaramillo, Z. Bao, High-performance oxygen reduction and evolution carbon catalysis: From mechanistic studies to device integration, Nano Res. 10 (2017) 1163-1177. doi:10.1007/s12274-016-1347-8.

[46] P. Vassilev, M.T.M. Koper, Electrochemical reduction of oxygen on gold surfaces: A density functional theory study of intermediates and reaction paths, J. Phys. Chem. C. 111 (2007) 2607-2613. doi:10.1021/jp064515+.

[47] R.R. Adžić, S. Strbac, N. Anastasijević, Electrocatalysis of oxygen on single crystal gold electrodes, Mater. Chem. Phys. 22 (1989) 349-375. doi:10.1016/0254-0584(89)90005-9.

[48] T.P. Fellinger, F. Hasché, P. Strasser, M. Antonietti, Mesoporous nitrogen-doped carbon for the electrocatalytic synthesis of hydrogen peroxide, J. Am. Chem. Soc. 134 (2012) 4072-4075. doi:10.1021/ja300038p.

[49] Y. Liu, X. Quan, X. Fan, H. Wang, S. Chen, High-yield electrosynthesis of hydrogen peroxide from oxygen reduction by hierarchically porous carbon, Angew. Chemie - Int. Ed. 54 (2015) 6837-6841. doi:10.1002/anie.201502396.

[50] Q. Zhang, M. Zhou, G. Ren, Y. Li, Y. Li, X. Du, Highly efficient electrosynthesis of hydrogen peroxide on a superhydrophobic three-phase interface by natural air diffusion, Nat. Commun. 11 (2020) 1-11. doi:10.1038/s41467-020-15597-y.

[51] E. Mousset, Z. Wang, J. Hammaker, O. Lefebvre, Physico-chemical properties of pristine graphene and its 
performance as electrode material for electro-Fenton treatment of wastewater, Electrochim. Acta. (2016). doi:10.1016/j.electacta.2016.08.002.

[52] J. Rossmeisl, Z.W. Qu, H. Zhu, G.J. Kroes, J.K. Nørskov, Electrolysis of water on oxide surfaces, J. Electroanal. Chem. 607 (2007) 83-89. doi:10.1016/j.jelechem.2006.11.008.

[53] C. Zhang, X. Lu, Y. Lu, M. Ding, W. Tang, Titanium-boron doped diamond composite: A new anode material, Diam. Relat. Mater. 98 (2019) 107490. doi:10.1016/j.diamond.2019.107490.

[54] C.A. Martínez-Huitle, S. Ferro, Electrochemical oxidation of organic pollutants for the wastewater treatment: Direct and indirect processes, Chem. Soc. Rev. 35 (2006) 1324-1340. doi:10.1039/b517632h.

[55] J. Cai, M. Zhou, Y. Pan, X. Du, X. Lu, Extremely efficient electrochemical degradation of organic pollutants with co-generation of hydroxyl and sulfate radicals on Blue-TiO2 nanotubes anode, Appl. Catal. B Environ. 257 (2019) 117902. doi:10.1016/j.apcatb.2019.117902.

[56] M. Chen, C. Wang, Y. Wang, X. Meng, Z. Chen, W. Zhang, G. Tan, Kinetic, mechanism and mass transfer impact on electrochemical oxidation of MIT using Ti-enhanced nanotube arrays/SnO2-Sb anode, Electrochim. Acta. 323 (2019) 134779. doi:10.1016/j.electacta.2019.134779.

[57] L. Gui, J. Peng, P. Li, R. Peng, P. Yu, Y. Luo, Electrochemical degradation of dye on TiO2 nanotube array constructed anode, Chemosphere. 235 (2019) 1189-1196. doi:10.1016/j.chemosphere.2019.06.170.

[58] M.H.M.T. Assumpção, A. Moraes, R.F.B. De Souza, R.M. Reis, R.S. Rocha, I. Gaubeur, M.L. Calegaro, P. Hammer, M.R.V. Lanza, M.C. Santos, Degradation of dipyrone via advanced oxidation processes using a cerium nanostructured electrocatalyst material, Appl. Catal. A Gen. 462-463 (2013) 256-261. doi:10.1016/j.apcata.2013.04.008.

[59] A. Moraes, M.H.M.T. Assumpção, R. Papai, I. Gaubeur, R.S. Rocha, R.M. Reis, M.L. Calegaro, M.R.V. Lanza, M.C. Santos, Use of a vanadium nanostructured material for hydrogen peroxide electrogeneration, J. Electroanal. Chem. 719 (2014) 127-132. doi:10.1016/j.jelechem.2014.02.009.

[60] Y.X. Gan, A.H. Jayatissa, Z. Yu, X. Chen, M. Li, Hydrothermal Synthesis of Nanomaterials, J. Nanomater. 2020 (2020). doi:10.1155/2020/8917013.

[61] Y. Xia, H. Shang, Q. Zhang, Y. Zhou, X. Hu, Electrogeneration of hydrogen peroxide using phosphorus-doped carbon nanotubes gas diffusion electrodes and its application in electro-Fenton, J. Electroanal. Chem. 840 
(2019) 400-408. doi:10.1016/j.jelechem.2019.04.009.

[62] X. Zhou, D. Xu, Y. Chen, Y. Hu, Enhanced degradation of triclosan in heterogeneous E-Fenton process with MOF-derived hierarchical Mn/Fe@PC modified cathode, Chem. $\quad$ Eng. $\quad$ J. 384 (2020). doi:10.1016/j.cej.2019.123324.

[63] K. Zhao, Y. Su, X. Quan, Y. Liu, S. Chen, H. Yu, Enhanced H2O2 production by selective electrochemical reduction of $\mathrm{O} 2$ on fluorine-doped hierarchically porous carbon, J. Catal. 357 (2018) 118-126. doi:10.1016/j.jcat.2017.11.008.

[64] K. Vasilev, M.M. Ramiasa, Plasma nanoengineering and nanofabrication, 2016. doi:10.3390/nano6070122.

[65] A. Khataee, S. Sajjadi, A. Hasanzadeh, B. Vahid, S.W. Joo, One-step preparation of nanostructured martite catalyst and graphite electrode by glow discharge plasma for heterogeneous electro-Fenton like process, J. Environ. Manage. 199 (2017) 31-45. doi:10.1016/j.jenvman.2017.04.095.

[66] W. Yang, M. Zhou, J. Cai, L. Liang, G. Ren, L. Jiang, Ultrahigh yield of hydrogen peroxide on graphite felt cathode modified with electrochemically exfoliated graphene, J. Mater. Chem. A. 5 (2017) 8070-8080. doi:10.1039/C7TA01534H.

[67] E. Mousset, Z. Wang, J. Hammaker, O. Lefebvre, Electrocatalytic phenol degradation by a novel nanostructured carbon fiber brush cathode coated with graphene ink, Electrochim. Acta. 258 (2017) 607-617. doi:10.1016/j.electacta.2017.11.104.

[68] O. Garcia-Rodriguez, Y.Y. Lee, H. Olvera-Vargas, F. Deng, Z. Wang, O. Lefebvre, Mineralization of electronic wastewater by electro-Fenton with an enhanced graphene-based gas diffusion cathode, Electrochim. Acta. 276 (2018) 12-20. doi:10.1016/j.electacta.2018.04.076.

[69] T.C. Achee, W. Sun, J.T. Hope, S.G. Quitzau, C.B. Sweeney, S.A. Shah, T. Habib, M.J. Green, High-yield scalable graphene nanosheet production from compressed graphite using electrochemical exfoliation, Sci. Rep. 8 (2018) 1-8. doi:10.1038/s41598-018-32741-3.

[70] E. Mousset, Z.T. Ko, M. Syafiq, Z. Wang, O. Lefebvre, Electrocatalytic activity enhancement of a graphene ink-coated carbon cloth cathode for oxidative treatment, Electrochim. Acta. 222 (2016) 1628-1641. doi:10.1016/j.electacta.2016.11.151.

[71] K. Parvez, Z.S. Wu, R. Li, X. Liu, R. Graf, X. Feng, K. Müllen, Exfoliation of graphite into graphene in 
aqueous solutions of inorganic salts, J. Am. Chem. Soc. 136 (2014) 6083-6091. doi:10.1021/ja5017156.

[72] T.X.H. Le, M. Bechelany, J. Champavert, M. Cretin, A highly active based graphene cathode for the electroFenton reaction, RSC Adv. 5 (2015) 42536-42539. doi:10.1039/C5RA04811G.

[73] T.X.H. Le, M. Bechelany, S. Lacour, N. Oturan, M. a. Oturan, M. Cretin, High removal efficiency of dye pollutants by electron-Fenton process using a graphene based cathode, Carbon N. Y. 94 (2015) 1003-1011. doi:10.1016/j.carbon.2015.07.086.

[74] A. Zielinska-jurek, J. Nadolna, A. Zaleska-medynska, Microemulsions - An Introduction to Properties and Applications, 2012. doi:10.5772/2300.

[75] R.M. Félix-Navarro, M. Beltrán-Gastélum, M.I. Salazar-Gastélum, C. Silva-Carrillo, E.A. Reynoso-Soto, S. Pérez-Sicairos, S.W. Lin, F. Paraguay-Delgado, G. Alonso-Núñez, Pt-Pd bimetallic nanoparticles on MWCNTs: Catalyst for hydrogen peroxide electrosynthesis, J. Nanoparticle Res. 15 (2013). doi:10.1007/s11051-013-1802-3.

[76] A. Martínez-de la Cruz, S. Obregón Alfaro, Synthesis and characterization of nanoparticles of $\alpha$-Bi2Mo3O12 prepared by co-precipitation method: Langmuir adsorption parameters and photocatalytic properties with rhodamine B, Solid State Sci. 11 (2009) 829-835. doi:10.1016/j.solidstatesciences.2009.01.007.

[77] Y. He, Y. Ma, J. Meng, X. Zhang, Y. Xia, Dual electrochemical catalysis of Bi2Mo3O12/Ti cathode for hydrogen peroxide production in electro-Fenton system, J. Catal. 373 (2019) 297-305. doi:10.1016/j.jcat.2019.04.005.

[78] S. Ghasemian, S. Omanovic, Fabrication and characterization of photoelectrochemically-active Sb-doped Sn $\mathrm{x}-\mathrm{W}(100-\mathrm{x}) \%$-oxide anodes: Towards the removal of organic pollutants from wastewater, Appl. Surf. Sci. 416 (2017) 318-328. doi:10.1016/j.apsusc.2017.04.138.

[79] M.E. Makgae, M.J. Klink, A.M. Crouch, Performance of sol-gel Titanium Mixed Metal Oxide electrodes for electro-catalytic oxidation of phenol, Appl. Catal. B Environ. 84 (2008) 659-666. doi:10.1016/j.apcatb.2008.05.021.

[80] Y. Liu, H. Liu, J. Ma, J. Li, Preparation and electrochemical properties of Ce-Ru-SnO 2 ternary oxide anode and electrochemical oxidation of nitrophenols, J. Hazard. Mater. 213-214 (2012) 222-229. doi:10.1016/j.jhazmat.2012.01.090. 
[81] Y. Feng, Y.H. Cui, J. Liu, B.E. Logan, Factors affecting the electro-catalytic characteristics of Eu doped SnO2/Sb electrode, J. Hazard. Mater. 178 (2010) 29-34. doi:10.1016/j.jhazmat.2009.12.101.

[82] R.J. Watts, M.S. Wyeth, D.D. Finn, A.L. Teel, Optimization of Ti/SnO2-Sb2O5 anode preparation for electrochemical oxidation of organic contaminants in water and wastewater, J. Appl. Electrochem. 38 (2008) 31-37. doi:10.1007/s10800-007-9391-4.

[83] M. Shestakova, M. Sillanpää, Electrode materials used for electrochemical oxidation of organic compounds in wastewater, Rev. Environ. Sci. Biotechnol. 16 (2017) 223-238. doi:10.1007/s11157-017-9426-1.

[84] H. An, H. Cui, W. Zhang, J. Zhai, Y. Qian, X. Xie, Q. Li, Fabrication and electrochemical treatment application of a microstructured TiO2-NTs/Sb-SnO2/PbO2 anode in the degradation of C.I. Reactive Blue 194 (RB 194), Chem. Eng. J. 209 (2012) 86-93. doi:10.1016/j.cej.2012.07.089.

[85] S. Boukhchina, H. Akrout, D. Berling, L. Bousselmi, Highly efficient modified lead oxide electrode using a spin coating/electrodeposition mode on titanium for electrochemical treatment of pharmaceutical pollutant, Chemosphere. 221 (2019) 356-365. doi:10.1016/j.chemosphere.2019.01.057.

[86] D. Devilliers, E. Mahé, Modified titanium electrodes: Application to Ti/TiO2/PbO 2 dimensionally stable anodes, Electrochim. Acta. 55 (2010) 8207-8214. doi:10.1016/j.electacta.2010.01.098.

[87] I. Sirés, C.T.J. Low, C. Ponce-de-León, F.C. Walsh, The deposition of nanostructured $\beta$-PbO2 coatings from aqueous methanesulfonic acid for the electrochemical oxidation of organic pollutants, Electrochem. Commun. 12 (2010) 70-74. doi:10.1016/j.elecom.2009.10.038.

[88] X. Li, D. Pletcher, F.C. Walsh, A novel flow battery: A lead acid battery based on an electrolyte with soluble lead(II). Part VII. Further studies of the lead dioxide positive electrode, Electrochim. Acta. 54 (2009) 46884695. doi:10.1016/j.electacta.2009.03.075.

[89] P.K. Shen, X.L. Wei, Morphologic study of electrochemically formed lead dioxide, Electrochim. Acta. 48 (2003) 1743-1747. doi:10.1016/S0013-4686(03)00149-X.

[90] A.B. Velichenko, R. Amadelli, E. V. Gruzdeva, T. V. Luk’yanenko, F.I. Danilov, Electrodeposition of lead dioxide from methanesulfonate solutions, J. Power Sources. 191 (2009) 103-110. doi:10.1016/j.jpowsour.2008.10.054.

[91] P. Duverneuil, F. Maury, N. Pebere, F. Senocq, H. Vergnes, Chemical vapor deposition of SnO2 coatings on 
Ti plates for the preparation of electrocatalytic anodes, Surf. Coatings Technol. 151-152 (2002) 9-13. doi:10.1016/S0257-8972(01)01618-8.

[92] S. Klamklang, H. Vergnes, F. Senocq, K. Pruksathorn, P. Duverneuil, S. Damronglerd, Deposition of tin oxide, iridium and iridium oxide films by metal-organic chemical vapor deposition for electrochemical wastewater treatment, J. Appl. Electrochem. 40 (2010) 997-1004. doi:10.1007/s10800-009-9968-1.

[93] J. Lv, Y. Feng, J. Liu, Y. Qu, F. Cui, Comparison of electrocatalytic characterization of boron-doped diamond and SnO 2 electrodes, Appl. Surf. Sci. 283 (2013) 900-905. doi:10.1016/j.apsusc.2013.07.040.

[94] P. Li, G. Zhao, X. Cui, Y. Zhang, Y. Tang, Constructing stake structured TiO2-NTs/Sb-doped SnO2 electrode simultaneously with high electrocatalytic and photocatalytic performance for complete mineralization of refractory aromatic acid, J. Phys. Chem. C. 113 (2009) 2375-2383. doi:10.1021/jp8078106.

[95] J. Jiang, C. Wang, Review-Electrolytic Metal Atoms Enabled Manufacturing of Nanostructured Sensor Electrodes, J. Electrochem. Soc. 167 (2020) 037521. doi:10.1149/2.0212003jes.

[96] Y. Lee, H. Shin, S.H. Chun, J. Lee, W.J. Park, J.M. Baik, S. Yoon, M.H. Kim, Highly single crystalline IrxRu1-xO2 mixed metal oxide nanowires, J. Phys. Chem. C. 116 (2012) 16300-16304.

[97] L.R. Aveiro, A.G.M. da Silva, V.S. Antonin, E.G. Candido, L.S. Parreira, R.S. Geonmonond, I.C. de Freitas, M.R.V. Lanza, P.H.C. Camargo, M.C. Santos, Carbon-supported MnO2 nanoflowers: Introducing oxygen vacancies for optimized volcano-type electrocatalytic activities towards $\mathrm{H} 2 \mathrm{O} 2$ generation, Electrochim. Acta. 268 (2018) 101-110. doi:10.1016/j.electacta.2018.02.077.

[98] J.H. Chang, A. V. Ellis, Y.H. Hsieh, C.H. Tung, S.Y. Shen, Electrocatalytic characterization and dye degradation of Nano-TiO2 electrode films fabricated by CVD, Sci. Total Environ. 407 (2009) 5914-5920. doi:10.1016/j.scitotenv.2009.07.041.

[99] H. Salari, Kinetics and mechanism of enhanced photocatalytic activity under visible light irradiation using Cr2O3/Fe2O3 nanostructure derived from bimetallic metal organic framework, J. Environ. Chem. Eng. 7 (2019) 103092. doi:10.1016/j.jece.2019.103092.

[100] V.S. Pinheiro, E.C. Paz, L.R. Aveiro, L.S. Parreira, F.M. Souza, P.H.C. Camargo, M.C. Santos, Ceria high aspect ratio nanostructures supported on carbon for hydrogen peroxide electrogeneration, Electrochim. Acta. 259 (2018) 865-872. doi:10.1016/j.electacta.2017.11.010. 
[101] C. Natarajan, N. Fukunaga, G. Nogami, Titanium dioxide thin film deposited by spray pyrolysis of aqueous solution, Thin Solid Films. 322 (1998) 6-8. doi:10.1016/S0040-6090(97)01010-9.

[102] A. Hasanzadeh, A. Khataee, M. Zarei, Y. Zhang, Two-electron oxygen reduction on fullerene C60-carbon nanotubes covalent hybrid as a metal-free electrocatalyst, Sci. Rep. 9 (2019) 1-13. doi:10.1038/s41598-01950155-7.

[103] J. Xie, J. Yang, X. Zhou, A hybrid nanostructure encapsulating SnO2 nanoparticles as the anode material for lithium ion batteries with high electrochemical performance, RSC Adv. 4 (2014) 572-577. doi:10.1039/c3ra44242j.

[104] G. Li, Y. Zhang, Highly selective two-electron oxygen reduction to generate hydrogen peroxide using graphite felt modified with N-doped graphene in an electro-Fenton system, New J. Chem. 43 (2019) 12657-12667. doi:10.1039/c9nj02601k.

[105] X. Zhang, W. Hu, K. Zhang, J. Wang, B. Sun, H. Li, P. Qiao, L. Wang, W. Zhou, Ti3+ self-doped black TiO2 nanotubes with mesoporous nanosheet architecture as efficient solar-driven hydrogen evolution photocatalysts, ACS Sustain. Chem. Eng. 5 (2017) 6894-6901. doi:10.1021/acssuschemeng.7b01114.

[106] Q. Wang, T. Yang, H. Wang, J. Zhang, X. Guo, Z. Yang, S. Lu, W. Qin, Morphological and chemical tuning of lead halide perovskite mesocrystals as long-life anode materials in lithium-ion batteries, CrystEngComm. 21 (2019) 1048-1059. doi:10.1039/c8ce01779d.

[107] J. Cai, M. Zhou, X. Du, X. Xu, Enhanced mechanism of 2,4-dichlorophenoxyacetic acid degradation by electrochemical activation of persulfate on Blue-TiO2 nanotubes anode, Sep. Purif. Technol. 254 (2021) 117560. doi:10.1016/j.seppur.2020.117560.

[108] Y. Cong, Z. Li, Y. Zhang, Q. Wang, Q. Xu, Synthesis of $\alpha$-Fe2O3/TiO2 nanotube arrays for photoelectroFenton degradation of phenol, Chem. Eng. J. 191 (2012) 356-363. doi:10.1016/j.cej.2012.03.031.

[109] Z. Zhang, H. Meng, Y. Wang, L. Shi, X. Wang, S. Chai, Fabrication of graphene@graphite-based gas diffusion electrode for improving $\mathrm{H} 2 \mathrm{O} 2$ generation in Electro-Fenton process, Electrochim. Acta. 260 (2018) 112-120. doi:10.1016/j.electacta.2017.11.048.

[110] G. Ren, M. Zhou, P. Su, L. Liang, W. Yang, E. Mousset, Highly energy-efficient removal of acrylonitrile by peroxi-coagulation with modified graphite felt cathode: Influence factors, possible mechanism, Chem. Eng. J. 
343 (2018) 467-476. doi:10.1016/j.cej.2018.02.115.

[111] W. Wang, X. Lu, P. Su, Y. Li, J. Cai, Q. Zhang, M. Zhou, O. Arotiba, Enhancement of hydrogen peroxide production by electrochemical reduction of oxygen on carbon nanotubes modified with fluorine, Chemosphere. 259 (2020) 127423. doi:10.1016/j.chemosphere.2020.127423.

[112] P. Su, M. Zhou, X. Lu, W. Yang, G. Ren, J. Cai, Electrochemical catalytic mechanism of N-doped graphene for enhanced $\mathrm{H} 2 \mathrm{O} 2$ yield and in-situ degradation of organic pollutant, Appl. Catal. B Environ. 245 (2019) 583-595. doi:10.1016/j.apcatb.2018.12.075.

[113] E.C. Paz, L.R. Aveiro, V.S. Pinheiro, F.M. Souza, V.B. Lima, F.L. Silva, P. Hammer, M.R.V. Lanza, M.C. Santos, Evaluation of $\mathrm{H} 2 \mathrm{O} 2$ electrogeneration and decolorization of Orange II azo dye using tungsten oxide nanoparticle-modified carbon, Appl. Catal. $\quad$ B $\quad$ Environ. $232 \quad$ (2018) 436-445. doi:10.1016/j.apcatb.2018.03.082.

[114] J.F. Carneiro, F.L. Silva, A.S. Martins, R.M.P. Dias, G.M. Titato, Á.J. Santos-Neto, R. Bertazzoli, M.R.V. Lanza, Simultaneous degradation of hexazinone and diuron using $\mathrm{ZrO} 2$-nanostructured gas diffusion electrode, Chem. Eng. J. 351 (2018) 650-659. doi:10.1016/j.cej.2018.06.122.

[115] J.F. Carneiro, R.S. Rocha, P. Hammer, R. Bertazzoli, M.R.V. Lanza, Hydrogen peroxide electrogeneration in gas diffusion electrode nanostructured with Ta2O5, Appl. Catal. A Gen. 517 (2016) 161-167. doi:10.1016/j.apcata.2016.03.013.

[116] L. Liang, Y. An, M. Zhou, F. Yu, M. Liu, G. Ren, Novel rolling-made gas-diffusion electrode loading trace transition metal for efficient heterogeneous electro-Fenton-like, J. Environ. Chem. Eng. 4 (2016) 4400-4408. doi:10.1016/j.jece.2016.10.006.

[117] L. Zhou, Z. Hu, C. Zhang, Z. Bi, T. Jin, M. Zhou, Electrogeneration of hydrogen peroxide for electro-Fenton system by oxygen reduction using chemically modified graphite felt cathode, Sep. Purif. Technol. 111 (2013) 131-136. doi:10.1016/j.seppur.2013.03.038.

[118] C. Zhang, M. Zhou, G. Ren, X. Yu, L. Ma, J. Yang, F. Yu, Heterogeneous electro-Fenton using modified ironcarbon as catalyst for 2,4-dichlorophenol degradation: Influence factors, mechanism and degradation pathway, Water Res. 70 (2015) 414-424. doi:10.1016/j.watres.2014.12.022.

[119] X. Yu, M. Zhou, G. Ren, L. Ma, A novel dual gas diffusion electrodes system for efficient hydrogen peroxide 
generation used in electro-Fenton, Chem. Eng. J. 263 (2015) 92-100. doi:10.1016/j.cej.2014.11.053.

[120] L. Ma, M. Zhou, G. Ren, W. Yang, L. Liang, A highly energy-efficient flow-through electro-Fenton process for organic pollutants degradation, Electrochim. Acta. $200 \quad$ (2016) 222-230. doi:10.1016/j.electacta.2016.03.181.

[121] L. Zhou, M. Zhou, Z. Hu, Z. Bi, K.G. Serrano, Chemically modified graphite felt as an efficient cathode in electro-Fenton for p-nitrophenol degradation, Electrochim. Acta. 140 (2014) 376-383. doi:10.1016/j.electacta.2014.04.090.

[122] F. Yu, M. Zhou, X. Yu, Cost-effective electro-Fenton using modified graphite felt that dramatically enhanced on $\mathrm{H} 2 \mathrm{O} 2$ electro-generation without external aeration, Electrochim. Acta. 163 (2015) 182-189. doi:10.1016/j.electacta.2015.02.166.

[123] I. Sirés, J.A. Garrido, R.M. Rodríguez, E. Brillas, N. Oturan, M. a. Oturan, Catalytic behavior of the Fe3+/Fe2+ system in the electro-Fenton degradation of the antimicrobial chlorophene, Appl. Catal. B Environ. 72 (2007) 382-394. doi:10.1016/j.apcatb.2006.11.016.

[124] F. Sopaj, N. Oturan, J. Pinson, F.I. Podvorica, M.A. Oturan, Effect of cathode material on electro-Fenton process efficiency for electrocatalytic mineralization of the antibiotic sulfamethazine, Chem. Eng. J. 384 (2020) 123249. doi:10.1016/j.cej.2019.123249.

[125] W. Zhou, X. Meng, J. Gao, A.N. Alshawabkeh, Hydrogen peroxide generation from O2 electroreduction for environmental remediation: A state-of-the-art review, Chemosphere. 225 (2019) 588-607. doi:10.1016/j.chemosphere.2019.03.042.

[126] O. García-Rodríguez, J.A. Bañuelos, A. El-Ghenymy, L.A. Godínez, E. Brillas, F.J. Rodríguez-Valadez, Use of a carbon felt-iron oxide air-diffusion cathode for the mineralization of Malachite Green dye by heterogeneous electro-Fenton and UVA photoelectro-Fenton processes, J. Electroanal. Chem. 767 (2016) 4048. doi:10.1016/j.jelechem.2016.01.035.

[127] Y.T. Wang, C.H. Tu, Y.S. Lin, Application of graphene and carbon nanotubes on carbon felt electrodes for the electro-Fenton system, Materials (Basel). 12 (2019) 1-11. doi:10.3390/MA12101698.

[128] G. Divyapriya, P.V. Nidheesh, Importance of graphene in the electro-Fenton process, ACS Omega. 5 (2020) 4725-4732. doi:10.1021/acsomega.9b04201. 
[129] H. Yang, M. Zhou, W. Yang, G. Ren, L. Ma, Rolling-made gas diffusion electrode with carbon nanotube for electro-Fenton degradation of acetylsalicylic acid, Chemosphere. 206 (2018) 439-446. doi:10.1016/j.chemosphere.2018.05.027.

[130] K. Gao, B. Wang, L. Tao, B. V Cunning, Z. Zhang, S. Wang, R.S. Ruoff, L. Qu, Efficient metal-free electrocatalysts from N-doped carbon nanomaterials: Mono-doping and co-doping, Adv. Mater. 31 (2019) 111. doi:10.1002/adma.201805121.

[131] T. Zhang, T. Asefa, Heteroatom-doped carbon materials for hydrazine oxidation, Adv. Mater. 31 (2019) 1-17. doi:10.1002/adma.201804394.

[132] F. Yu, L. Tao, T. Cao, High yield of hydrogen peroxide on modified graphite felt electrode with nitrogendoped porous carbon carbonized by zeolitic imidazolate framework-8 (ZIF-8) nanocrystals, Environ. Pollut. 255 (2019). doi:10.1016/j.envpol.2019.113119.

[133] W. Yang, M. Zhou, L. Liang, Highly efficient in-situ metal-free electrochemical advanced oxidation process using graphite felt modified with N-doped graphene, Chem. Eng. J. 338 (2018) 700-708. doi:10.1016/j.cej.2018.01.013.

[134] G. Panomsuwan, N. Saito, T. Ishizaki, Simple one-step synthesis of fluorine-doped carbon nanoparticles as potential alternative metal-free electrocatalysts for oxygen reduction reaction, J. Mater. Chem. A Mater. Energy Sustain. 3 (2015) 9972-9981. doi:10.1039/C5TA00244C.

[135] J. Wu, Z. Yang, X. Li, Q. Sun, C. Jin, P. Strasser, R. Yang, Phosphorus-doped porous carbons as efficient electrocatalysts for oxygen reduction, J. Mater. Chem. A. 1 (2013) 9889-9896. doi:10.1039/c3ta11849e.

[136] S. Das, A. Mishra, M.M. Ghangrekar, Production of hydrogen peroxide using various metal-based catalysts in electrochemical and bioelectrochemical systems: Mini review, J. Hazardous, Toxic, Radioact. Waste. 24 (2020) 06020001. doi:10.1061/(asce)hz.2153-5515.0000498.

[137] S.C. Perry, D. Pangotra, L. Vieira, L.I. Csepei, V. Sieber, L. Wang, C. Ponce de León, F.C. Walsh, Electrochemical synthesis of hydrogen peroxide from water and oxygen, Nat. Rev. Chem. 3 (2019) 442-458. doi:10.1038/s41570-019-0110-6.

[138] S. Yuan, N. Gou, A.N. Alshawabkeh, A.Z. Gu, Efficient degradation of contaminants of emerging concerns by a new electro-Fenton process with Ti/MMO cathode., Chemosphere. 93 (2013) 2796-804. 
doi:10.1016/j.chemosphere.2013.09.051.

[139] V.S. Antonin, M.H.M.T. Assumpcao, J.C.M. Silva, L.S. Parreira, M.R.V. Lanza, M.C. Santos, Synthesis and characterization of nanostructured electrocatalystsbased on nickel and tin for hydrogen peroxide electrogeneration, Electrochim. Acta. 109 (2013) 245-251. doi:10.1016/j.electacta.2013.07.078.

[140] P. Su, M. Zhou, G. Ren, X. Lu, X. Du, G. Song, A carbon nanotube-confined iron modified cathode with prominent stability and activity for heterogeneous electro-Fenton reactions, J. Mater. Chem. A. 7 (2019) 24408-24419. doi:10.1039/c9ta07491k.

[141] C. Rajkumar, P. Veerakumar, S.M. Chen, B. Thirumalraj, K.C. Lin, Ultrathin sulfur-doped graphitic carbon nitride nanosheets as metal-free catalyst for electrochemical sensing and catalytic removal of 4-nitrophenol, ACS Sustain. Chem. Eng. 6 (2018) 16021-16031. doi:10.1021/acssuschemeng.8b02041.

[142] R. Pitchai, V. Thavasi, S.G. Mhaisalkar, S. Ramakrishna, Nanostructured cathode materials: A key for better performance in Li-ion batteries, J. Mater. Chem. 21 (2011) 11040-11051. doi:10.1039/c1jm10857c.

[143] E. Mousset, M. Zhou, Graphene-Based Nanostructured Materials for Advanced Electrochemical Water/Wastewater Treatment, in: S. Thomas, A. Thankappan (Eds.), Polym. Nanostructured Mater., Apple Acad, 2019: pp. 321-358. doi:10.1201/b22428-21.

[144] J. Park, Y. Nabae, T. Hayakawa, M.A. Kakimoto, Highly selective two-electron oxygen reduction catalyzed by mesoporous nitrogen-doped carbon, ACS Catal. 4 (2014) 3749-3754. doi:10.1021/cs5008206.

[145] Z. Chen, W. Ren, L. Gao, B. Liu, S. Pei, H.-M. Cheng, Three-dimensional flexible and conductive interconnected graphene networks grown by chemical vapour deposition., Nat. Mater. 10 (2011) 424-428. doi:10.1038/nmat3001.

[146] J. Hass, F. Varchon, J.E. Millán-Otoya, M. Sprinkle, N. Sharma, W.A. de Heer, C. Berger, P.N. First, L. Magaud, E.H. Conrad, Why Multilayer Graphene on 4H-SiC(0001) Behaves Like a Single Sheet of Graphene, Phys. Rev. Lett. 100 (2008) 125504(4). doi:10.1103/PhysRevLett.100.125504.

[147] S. Pei, H.M. Cheng, The reduction of graphene oxide, Carbon N. Y. 50 (2012) 3210-3228. doi:10.1016/j.carbon.2011.11.010.

[148] M. Zhou, Q. Yu, L. Lei, The preparation and characterization of a graphite-PTFE cathode system for the decolorization of C.I. Acid Red 2, Dye. Pigment. 77 (2008) 129-136. doi:10.1016/j.dyepig.2007.04.002. 
[149] E.C. Paz, V.S. Pinheiro, L.R. Aveiro, F.L. Souza, M.R. V. Lanzac, M.C. Santos, Hydrogen Peroxide Electrogeneration by Gas Diffusion Electrode Modified With Tungsten, J. Brazilian Chem. Soc. 00 (2019) 112.

[150] J.P. Paraknowitsch, A. Thomas, Doping carbons beyond nitrogen: An overview of advanced heteroatom doped carbons with boron, sulphur and phosphorus for energy applications, Energy Environ. Sci. 6 (2013) 28392855. doi:10.1039/c3ee41444b.

[151] R. Shibuya, T. Kondo, J. Nakamura, Active sites in nitrogen-doped carbon materials for oxygen reduction reaction, Carbon-Based Met. Catal. Des. Appl. 1-2 (2018) 227-249. doi:10.1002/9783527811458.vol1-ch8.

[152] Z. Qiang, J.H. Chang, C.P. Huang, Electrochemical generation of hydrogen peroxide from dissolved oxygen in acidic solutions, Water Res. 36 (2002) 85-94. doi:10.1016/S0043-1354(01)00235-4.

[153] H. Luo, C. Li, C. Wu, W. Zheng, X. Dong, Electrochemical degradation of phenol by in situ electro-generated and electro-activated hydrogen peroxide using an improved gas diffusion cathode, Electrochim. Acta. 186 (2015) 486-493. doi:10.1016/j.electacta.2015.10.194.

[154] A. Fdez-Sanromán, V. Acevedo-García, M. Pazos, M.Á. Sanromán, E. Rosales, Iron-doped cathodes for electro-Fenton implementation: Application for pymetrozine degradation, Electrochim. Acta. 338 (2020) 111. doi:10.1016/j.electacta.2020.135768.

[155] R. Babaei-Sati, J. Basiri Parsa, Electrodeposition of PANI/MWCNT nanocomposite on stainless steel with enhanced electrocatalytic activity for oxygen reduction reaction and electro-Fenton process, New J. Chem. 41 (2017) 5995-6003. doi:10.1039/c7nj00744b.

[156] W. Yang, M. Zhou, N. Oturan, Y. Li, P. Su, M.A. Oturan, Enhanced activation of hydrogen peroxide using nitrogen doped graphene for effective removal of herbicide 2,4-D from water by iron-free electrochemical advanced oxidation, Electrochim. Acta. 297 (2019) 582-592. doi:10.1016/j.electacta.2018.11.196.

[157] Q. Tang, D. Wang, D.M. Yao, C.W. Yang, Y.C. Sun, Highly efficient electro-generation of hydrogen peroxide using NCNT/NF/CNT air diffusion electrode for electro-Fenton degradation of p-nitrophenol, Water Sci. Technol. 73 (2016) 1652-1658. doi:10.2166/wst.2015.647.

[158] N. Jia, T. Yang, S. Shi, X. Chen, Z. An, Y. Chen, S. Yin, P. Chen, N,F-codoped carbon nanocages: An efficient electrocatalyst for hydrogen peroxide electroproduction in alkaline and acidic solutions, ACS Sustain. Chem. 
Eng. 8 (2020) 2883-2891. doi:10.1021/acssuschemeng.9b07047.

[159] G. Chen, J. Liu, Q. Li, P. Guan, X. Yu, L. Xing, J. Zhang, R. Che, A direct H2O2 production based on hollow porous carbon sphere-sulfur nanocrystal composites by confinement effect as oxygen reduction electrocatalysts, Nano Res. 12 (2019) 2614-2622. doi:10.1007/s12274-019-2496-3.

[160] V. Perazzolo, C. Durante, A. Gennaro, Nitrogen and sulfur doped mesoporous carbon cathodes for water treatment, J. Electroanal. Chem. 782 (2016) 264-269. doi:10.1016/j.jelechem.2016.10.037.

[161] R.F. Gutiérrez-Hernández, R. Bello-Mendoza, J.F. Valle-Mora, J.M. Peralta-Hernández, E.A. Malo, A. Hernández-Ramírez, H.A. Nájera-Aguilar, Rapid prediction of hydrogen peroxide concentration eletrogenerated with boron doped diamond electrodes, J. Adv. Oxid. Technol. 20 (2017). doi:10.1515/jaots2017-0037.

[162] G. Xia, Y. Lu, H. Xu, Electrogeneration of hydrogen peroxide for electro-Fenton via oxygen reduction using polyacrylonitrile-based carbon fiber brush cathode, Electrochim. Acta. 158 (2015) 390-396. doi:10.1016/j.electacta.2015.01.102.

[163] C. Ridruejo, F. Alcaide, G. Álvarez, E. Brillas, I. Sirés, On-site H2O2 electrogeneration at a CoS2-based airdiffusion cathode for the electrochemical degradation of organic pollutants, J. Electroanal. Chem. 808 (2018) 364-371. doi:10.1016/j.jelechem.2017.09.010.

[164] A.Y. Mounia, Z. Djilali, Electrogeneration of hydrogen peroxide for electro-Fenton system by oxygen reduction using gold nanoparticle electrodeposited on graphite cathode, Desalin. Water Treat. 56 (2015) $1657-$ 1668. doi:10.1080/19443994.2014.954144.

[165] R.B. Valim, R.M. Reis, P.S. Castro, A.S. Lima, R.S. Rocha, M. Bertotti, M.R. V Lanza, Electrogeneration of hydrogen peroxide in acidic medium using gas diffusion electrodes modified with cobalt (II) phthalocyanine, Electrochim. Acta. 104 (2013) 12-18. doi:10.1016/j.electacta.2013.04.079.

[166] S. Sajjadi, A. Hasanzadeh, A. Khataee, Two-electron oxygen reduction on NiFe alloy enclosed carbonic nanolayers derived from NiFe-metal-organic frameworks, (2019). doi:10.1016/j.jelechem.2019.04.025.

[167] P. Geng, J. Su, C. Miles, C. Comninellis, G. Chen, Highly-ordered magnéli Ti4O7 nanotube arrays as effective anodic material for electro-oxidation, Electrochim. Acta. 153 (2015) 316-324. doi:10.1016/j.electacta.2014.11.178. 
[168] C. Shao, J. Yu, X. Li, X. Wang, K. Zhu, Influence of the Pt nanoscale interlayer on stability and electrical property of $\mathrm{Ti} / \mathrm{Pt} / \mathrm{Sb}-\mathrm{SnO} 2$ electrode: A synergetic experimental and computational study, J. Electroanal. Chem. 804 (2017) 140-147. doi:10.1016/j.jelechem.2017.09.057.

[169] B. Liu, K.H. Kim, V. Kumar, S. Kim, A review of functional sorbents for adsorptive removal of arsenic ions in aqueous systems, J. Hazard. Mater. 388 (2020) 121815. doi:10.1016/j.jhazmat.2019.121815.

[170] C. Thamaraiselvan, J. Wang, D.K. James, P. Narkhede, S.P. Singh, D. Jassby, J.M. Tour, C.J. Arnusch, Laserinduced graphene and carbon nanotubes as conductive carbon-based materials in environmental technology, Mater. Today. 34 (2020) 115-131. doi:10.1016/j.mattod.2019.08.014.

[171] G. Gao, Q. Zhang, C.D. Vecitis, CNT-PVDF composite flow-through electrode for single-pass sequential reduction-oxidation, J. Mater. Chem. A. 2 (2014) 6185-6190. doi:10.1039/c3ta14080f.

[172] G. Gao, C.D. Vecitis, Electrochemical carbon nanotube filter oxidative performance as a function of surface chemistry, Environ. Sci. Technol. 45 (2011) 9726-9734. doi:10.1021/es202271z.

[173] C.D. Vecitis, G. Gao, H. Liu, Electrochemical carbon nanotube filter for adsorption, desorption, and oxidation of aqueous dyes and anions, J. Phys. Chem. C. 115 (2011) 3621-3629. doi:10.1021/jp111844j.

[174] F. Li, Q. Xia, Q. Cheng, M. Huang, Y. Liu, Conductive cotton filters for affordable and efficient water purification, Catalysts. 7 (2017) 1-12. doi:10.3390/catal7100291.

[175] H. Liu, J. Liu, Y. Liu, K. Bertoldi, C.D. Vecitis, Quantitative 2D electrooxidative carbon nanotube filter model: Insight into reactive sites, Carbon N. Y. 80 (2014) 651-664. doi:10.1016/j.carbon.2014.09.009.

[176] G. dos S. Cunha, B.M. de Souza-Chaves, D.M. Bila, J.P. Bassin, C.D. Vecitis, M. Dezotti, Insights into estrogenic activity removal using carbon nanotube electrochemical filter, Sci. Total Environ. 678 (2019) 448456. doi:10.1016/j.scitotenv.2019.04.342.

[177] Y. Liu, J.H. Dustin Lee, Q. Xia, Y. Ma, Y. Yu, L.Y. Lanry Yung, J. Xie, C.N. Ong, C.D. Vecitis, Z. Zhou, A graphene-based electrochemical filter for water purification, J. Mater. Chem. A. 2 (2014) 16554-16562. doi:10.1039/c4ta04006f.

[178] G. Gao, C.D. Vecitis, Electrocatalysis aqueous phenol with carbon nanotubes networks as anodes: Electrodes passivation and regeneration and prevention, Electrochim. Acta. 98 (2013) 131-138. doi:10.1016/j.electacta.2013.02.127. 
[179] Z. Li, C. Shen, Y. Liu, C. Ma, F. Li, B. Yang, M. Huang, Z. Wang, L. Dong, S. Wolfgang, Carbon nanotube filter functionalized with iron oxychloride for flow-through electro-Fenton, Appl. Catal. B Environ. 260 (2020) 118204. doi:10.1016/j.apcatb.2019.118204.

[180] Y. Liu, J. Xie, C.N. Ong, C.D. Vecitis, Z. Zhou, Electrochemical wastewater treatment with carbon nanotube filters coupled with in situ generated H2O2, Environ. Sci. Water Res. Technol. 1 (2015) 769-778. doi:10.1039/c5ew00128e.

[181] M.H. Schnoor, C.D. Vecitis, Quantitative examination of aqueous ferrocyanide oxidation in a carbon nanotube electrochemical filter: Effects of flow rate, ionic strength, and cathode material, J. Phys. Chem. C. 117 (2013) 2855-2867. doi:10.1021/jp3112099.

[182] S. Yang, Y. Liu, C. Shen, F. Li, B. Yang, M. Huang, M. Yang, Z. Wang, W. Sand, Rapid decontamination of tetracycline hydrolysis product using electrochemical CNT filter: Mechanism, impacting factors and pathways, Chemosphere. 244 (2020) 125525. doi:10.1016/j.chemosphere.2019.125525.

[183] Y. Liu, H. Liu, Z. Zhou, T. Wang, C.N. Ong, C.D. Vecitis, Degradation of the Common Aqueous Antibiotic Tetracycline using a Carbon Nanotube Electrochemical Filter, Environ. Sci. Technol. 49 (2015) 7974-7980. doi:10.1021/acs.est.5b00870.

[184] G. Gao, M. Pan, C.D. Vecitis, Effect of the oxidation approach on carbon nanotube surface functional groups and electrooxidative filtration performance, J. Mater. Chem. A. 3 (2015) 7575-7582. doi:10.1039/c4ta07191c.

[185] B.M. Souza-Chaves, M. Dezotti, C.D. Vecitis, Synergism of ozonation and electrochemical filtration during advanced organic oxidation, J. Hazard. Mater. 382 (2020) 121085. doi:10.1016/j.jhazmat.2019.121085.

[186] Y. Liu, F. Li, Q. Xia, J. Wu, J. Liu, M. Huang, J. Xie, Conductive 3D sponges for affordable and highlyefficient water purification, Nanoscale. 10 (2018) 4771-4778. doi:10.1039/c7nr09435c.

[187] G. Gao, C.D. Vecitis, Doped carbon nanotube networks for electrochemical filtration of aqueous phenol: Electrolyte precipitation and phenol polymerization, ACS Appl. Mater. Interfaces. 4 (2012) 1478-1489. doi:10.1021/am2017267.

[188] F. Li, X. Peng, Y. Liu, J. Mei, L. Sun, C. Shen, C. Ma, M. Huang, Z. Wang, W. Sand, A chloride-radicalmediated electrochemical filtration system for rapid and effective transformation of ammonia to nitrogen, Chemosphere. 229 (2019) 383-391. doi:10.1016/j.chemosphere.2019.04.180. 
[189] H. Liu, A. Vajpayee, C.D. Vecitis, Bismuth-doped tin oxide-coated carbon nanotube network: Improved anode stability and efficiency for flow-through organic electrooxidation, ACS Appl. Mater. Interfaces. 5 (2013) 10054-10066. doi:10.1021/am402621v.

[190] S.Y. Yang, C.D. Vecitis, H. Park, Electrocatalytic water treatment using carbon nanotube filters modified with metal oxides, Environ. Sci. Pollut. Res. 26 (2019) 1036-1043. doi:10.1007/s11356-017-8495-6.

[191] Y. V. Pleskov, M.D. Krotova, V. V. Elkin, V.P. Varnin, I.G. Teremetskaya, A. V. Saveliev, V.G. Ralchenko, Benzene oxidation at diamond electrodes: Comparison of microcrystalline and nanocrystalline diamonds, ChemPhysChem. 13 (2012) 3047-3052. doi:10.1002/cphc.201101059.

[192] S.T. McBeath, D.P. Wilkinson, N.J.D. Graham, Application of boron-doped diamond electrodes for the anodic oxidation of pesticide micropollutants in a water treatment process: A critical review, Environ. Sci. Water Res. Technol. 5 (2019) 2090-2107. doi:10.1039/c9ew00589g.

[193] M. Zhou, L. Liu, Y. Jiao, Q. Wang, Q. Tan, Treatment of high-salinity reverse osmosis concentrate by electrochemical oxidation on BDD and DSA electrodes, Desalination. 277 (2011) 201-206. doi:10.1016/j.desal.2011.04.030.

[194] M. Zhou, H. Särkkä, M. Sillanpää, A comparative experimental study on methyl orange degradation by electrochemical oxidation on BDD and MMO electrodes, Sep. Purif. Technol. 78 (2011) 290-297. doi:10.1016/j.seppur.2011.02.013.

[195] S.O. Ganiyu, C.A. Martínez-Huitle, Nature, mechanisms and reactivity of electrogenerated reactive species at thin-film boron-doped diamond (BDD) electrodes during electrochemical wastewater treatment, ChemElectroChem. 6 (2019) 2379-2392. doi:10.1002/celc.201900159.

[196] X. Yu, M. Zhou, Y. Hu, K. Groenen Serrano, F. Yu, Recent updates on electrochemical degradation of biorefractory organic pollutants using BDD anode: A mini review, Environ. Sci. Pollut. Res. 21 (2014) 84178431. doi:10.1007/s11356-014-2820-0.

[197] N. Oturan, E. Brillas, M.A. Oturan, Unprecedented total mineralization of atrazine and cyanuric acid by anodic oxidation and electro-Fenton with a boron-doped diamond anode, Environ. Chem. Lett. 10 (2012) 165-170. doi:10.1007/s10311-011-0337-z.

[198] Y. He, W. Huang, R. Chen, W. Zhang, H. Lin, Improved electrochemical performance of boron-doped 
diamond electrode depending on the structure of titanium substrate, J. Electroanal. Chem. 758 (2015) 170177. doi:10.1016/j.jelechem.2015.08.017.

[199] Y. He, Y. Dong, W. Huang, X. Tang, H. Liu, H. Lin, H. Li, Investigation of boron-doped diamond on porous Ti for electrochemical oxidation of acetaminophen pharmaceutical drug, J. Electroanal. Chem. 759 (2015) 167-173. doi:10.1016/j.jelechem.2015.11.011.

[200] Y. He, H. Lin, X. Wang, W. Huang, R. Chen, H. Li, A hydrophobic three-dimensionally networked borondoped diamond electrode towards electrochemical oxidation, Chem. Commun. 52 (2016) 8026-8029. doi:10.1039/c6cc03866b.

[201] J. Sun, H. Lu, H. Lin, W. Huang, H. Li, J. Lu, T. Cui, Boron doped diamond electrodes based on porous Ti substrates, Mater. Lett. 83 (2012) 112-114. doi:10.1016/j.matlet.2012.05.044.

[202] Y. He, W. Huang, R. Chen, W. Zhang, H. Lin, H. Li, Anodic oxidation of aspirin on PbO2, BDD and porous Ti/BDD electrodes: Mechanism, kinetics and utilization rate, Sep. Purif. Technol. 156 (2015) 124-131. doi:10.1016/j.seppur.2015.09.036.

[203] Y. He, W. Huang, R. Chen, W. Zhang, H. Lin, Enhanced electrochemical oxidation of organic pollutants by boron-doped diamond based on porous titanium, Sep. Purif. Technol. 149 (2015) 124-131. doi:10.1016/j.seppur.2015.05.008.

[204] Y. He, X. Wang, W. Huang, R. Chen, H. Lin, H. Li, Application of porous boron-doped diamond electrode towards electrochemical mineralization of triphenylmethane dye, J. Electroanal. Chem. 775 (2016) 292-298. doi:10.1016/j.jelechem.2016.06.023.

[205] J. Sun, H. Lu, L. Du, H. Lin, H. Li, Anodic oxidation of anthraquinone dye Alizarin Red S at Ti/BDD $\begin{array}{llllll}\text { electrodes, } & \text { Appl. } & \text { Surf. } & \text { Sci. } & 257 & \text { (2011) }\end{array}$ http://www.sciencedirect.com/science/article/pii/S0169433211003072 (accessed June 1, 2013).

[206] C.H. Lee, E.S. Lee, Y.K. Lim, K.H. Park, H.D. Park, D.S. Lim, Enhanced electrochemical oxidation of phenol by boron-doped diamond nanowire electrode, RSC Adv. 7 (2017) 6229-6235. doi:10.1039/c6ra26287b.

[207] X. Tong, G. Zhao, M. Liu, T. Cao, L. Liu, P. Li, Fabrication and high electrocatalytic activity of threedimensional porous nanosheet Pt/Boron-doped diamond hybrid film, J. Phys. Chem. C. 113 (2009) 1378713792. doi:10.1021/jp9029503. 
[208] R. Mei, Q. Wei, C. Zhu, W. Ye, B. Zhou, L. Ma, Z. Yu, K. Zhou, 3D macroporous boron-doped diamond electrode with interconnected liquid flow channels: A high-efficiency electrochemical degradation of RB-19 dye wastewater under low current, Appl. Catal. B Environ. 245 (2019) 420-427. doi:10.1016/j.apcatb.2018.12.074.

[209] Q. Wei, G. Liu, C. Zhu, B. Zhou, R. Mei, L. Ma, L. Zhang, W. Yang, W. Ye, K. Zhou, Z. Yu, Ordered structures with functional units (OSFU) enabled highly robust diamond anode for electrochemical decomposing of organic pollutants, Chem. Eng. J. 397 (2020). doi:10.1016/j.cej.2020.125465.

[210] M. Behúl, M. Vojs, M. Marton, P. Michniak, M. Mikolášek, M. Kurniawan, H.L. Honig, D. V. Zyabkin, M.O. Ramirez, L. Spieß, D. Flock, A. Bund, M. Papula, R. Redhammer, Nanostructured boron doped diamond enhancing the photoelectrochemical performance of TiO2/BDD heterojunction anodes, Vacuum. 171 (2020) 109006. doi:10.1016/j.vacuum.2019.109006.

[211] Y. Han, X. Ruan, J. Chen, H. Zhang, H. Zhao, S. Zhang, Photoelectrochemical properties and its application of nano-tio 2/boron-doped diamond heterojunction electrode material, Asian J. Chem. 25 (2013) 6167-6172. doi:10.14233/ajchem.2013.14299.

[212] F. Espinola-Portilla, R. Navarro-Mendoza, S. Gutiérrez-Granados, U. Morales-Muñoz, E. Brillas-Coso, J.M. Peralta-Hernández, A simple process for the deposition of $\mathrm{TiO} 2$ onto BDD by electrophoresis and its application to the photoelectrocatalysis of Acid Blue 80 dye, J. Electroanal. Chem. 802 (2017) 57-63. doi:10.1016/j.jelechem.2017.08.041.

[213] S. Chai, Y. Wang, Y. nan Zhang, H. Zhao, M. Liu, G. Zhao, Construction of a bifunctional electrode interface for efficient electrochemical mineralization of recalcitrant pollutants, Appl. Catal. B Environ. 237 (2018) $473-$ 481. doi:10.1016/j.apcatb.2018.06.023.

[214] X. Li, H. Li, M. Li, C. Li, D. Sun, Y. Lei, B. Yang, Preparation of a porous boron-doped diamond/Ta electrode for the electrocatalytic degradation of organic pollutants, Carbon N. Y. 129 (2018) 543-551. doi:10.1016/j.carbon.2017.12.052.

[215] S. Chai, Y. Wang, Y.N. Zhang, M. Liu, Y. Wang, G. Zhao, Selective electrocatalytic degradation of odorous mercaptans derived from S-Au bond recongnition on a dendritic gold/boron-doped diamond composite electrode, Environ. Sci. Technol. 51 (2017) 8067-8076. doi:10.1021/acs.est.7b00393. 
[216] A. El Ruby Mohamed, S. Rohani, Modified TiO2 nanotube arrays (TNTAs): Progressive strategies towards visible light responsive photoanode, a review, Energy Environ. Sci. 4 (2011) 1065-1086. doi:10.1039/c0ee00488j.

[217] R. Amadelli, L. Armelao, A.B. Velichenko, N. V. Nikolenko, D. V. Girenko, S. V. Kovalyov, F.I. Danilov, Oxygen and ozone evolution at fluoride modified lead dioxide electrodes, Electrochim. Acta. 45 (1999) $713-$ 720. doi:10.1016/S0013-4686(99)00250-9.

[218] H. Kong, W. Li, H. Lin, Z. Shi, H. Lu, Y. Dan, W. Huang, Influence of F- doping on the microstructure, surface morphology and electrochemical properties of the lead dioxide electrode, Surf. Interface Anal. 45 (2013) 715-721. doi:10.1002/sia.5146.

[219] J. Cao, H. Zhao, F. Cao, J. Zhang, The influence of F- doping on the activity of PbO2 film electrodes in oxygen evolution reaction, Electrochim. Acta. 52 (2007) 7870-7876. doi:10.1016/j.electacta.2007.06.038.

[220] J. Cao, H. Zhao, F. Cao, J. Zhang, C. Cao, Electrocatalytic degradation of 4-chlorophenol on F-doped PbO2 anodes, Electrochim. Acta. 54 (2009) 2595-2602. doi:10.1016/j.electacta.2008.10.049.

[221] G.G. Bessegato, J.C. Cardoso, M.V.B. Zanoni, Enhanced photoelectrocatalytic degradation of an acid dye with boron-doped TiO2 nanotube anodes, Catal. Today. 240 (2015) 100-106. doi:10.1016/j.cattod.2014.03.073.

[222] R. Amadelli, L. Armelao, E. Tondello, S. Daolio, M. Fabrizio, C. Pagura, A. Velichenko, SIMS and XPS study about ions influence on electrodeposited PbO2 films, Appl. Surf. Sci. 142 (1999) 200-203. doi:10.1016/S0169-4332(98)00707-7.

[223] L.S. Andrade, R.C. Rocha-Filho, N. Bocchi, S.R. Biaggio, J. Iniesta, V. García-Garcia, V. Montiel, Degradation of phenol using Co- and Co, F-doped $\mathrm{PbO} 2$ anodes in electrochemical filter-press cells, J. Hazard. Mater. 153 (2008) 252-260. doi:10.1016/j.jhazmat.2007.08.046.

[224] L.S. Andrade, L.A.M. Ruotolo, R.C. Rocha-Filho, N. Bocchi, S.R. Biaggio, J. Iniesta, V. García-Garcia, V. Montiel, On the performance of Fe and Fe, F doped Ti-Pt/PbO2 electrodes in the electrooxidation of the Blue Reactive 19 dye in simulated textile wastewater, Chemosphere. 66 (2007) 2035-2043. doi:10.1016/j.chemosphere.2006.10.028.

[225] P. Hasin, M.A. Alpuche-Aviles, Y. Wu, Electrocatalytic activity of graphene multilayers toward I -/I3-: Effect of preparation conditions and polyelectrolyte modification, J. Phys. Chem. C. 114 (2010) 15857-15861. 
doi:10.1021/jp106130v.

[226] S. Yang, Y. Huang, W. Zhu, B. Deng, H. Wang, Z. Zhang, P. Bao, G. Wang, Pt/3D-graphene/FTO electrodes: Electrochemical preparation and their enhanced electrocatalytic activity, Int. J. Hydrogen Energy. 39 (2014) 15063-15071. doi:10.1016/j.ijhydene.2014.07.036.

[227] E. Mousset, V. Huang Weiqi, B. Foong Yang Kai, J.S. Koh, J.W. Tng, Z. Wang, O. Lefebvre, A new 3Dprinted photoelectrocatalytic reactor combining the benefits of a transparent electrode and the Fenton reaction for advanced wastewater treatment, J. Mater. Chem. A. 5 (2017) 24951-24964. doi:10.1039/C7TA08182K.

[228] J.S. Yang, W.W.P. Lai, S.C. Panchangam, A.Y.C. Lin, Photoelectrochemical degradation of perfluorooctanoic acid (PFOA) with GOP25/FTO anodes: Intermediates and reaction pathways, J. Hazard. Mater. 391 (2020). doi:10.1016/j.jhazmat.2020.122247.

[229] B. Yang, C. Jiang, G. Yu, Q. Zhuo, S. Deng, J. Wu, H. Zhang, Highly efficient electrochemical degradation of perfluorooctanoic acid (PFOA) by F-doped Ti/SnO2 electrode, J. Hazard. Mater. 299 (2015) 417-424. doi:10.1016/j.jhazmat.2015.06.033.

[230] M. Chen, B. Li, X. Liu, L. Zhou, L. Yao, J. Zai, X. Qian, X. Yu, Boron-doped porous Si anode materials with high initial coulombic efficiency and long cycling stability, J. Mater. Chem. A. 6 (2018) 3022-3027. doi:10.1039/c7ta10153h.

[231] Y.K. Kim, S.K. Lim, H. Park, M.R. Hoffmann, S. Kim, Trilayer CdS/carbon nanofiber (CNF) mat/Pt-TiO2 composite structures for solar hydrogen production: Effects of CNF mat thickness, Appl. Catal. B Environ. 196 (2016) 216-222. doi:10.1016/j.apcatb.2016.05.045.

[232] J.H. Yoon, Y.B. Shim, B.S. Lee, S.Y. Choi, M.S. Won, Electrochemical degradation of phenol and 2chlorophenol using Pt/Ti and boron-doped diamond electrodes, Bull. Korean Chem. Soc. 33 (2012) 22742278. doi:10.5012/bkcs.2012.33.7.2274.

[233] Z. Chen, J. Mao, R. Zhou, Preparation of size-controlled Pt supported on Al2O3 nanocatalysts for deep catalytic oxidation of benzene at lower temperature, Appl. Surf. Sci. 465 (2019) 15-22. doi:10.1016/j.apsusc.2018.09.138.

[234] Y. Chen, Y. Tu, Y. Bai, J. Li, J. Lu, Electrosorption enhanced electrooxidation of a model organic pollutant at 3D SnO2-Sb electrode in superimposed pulse current mode, Chemosphere. 195 (2018) 63-69. 
doi:10.1016/j.chemosphere.2017.12.074.

[235] L. Huang, D. Li, J. Liu, L. Yang, C. Dai, N. Ren, Y. Feng, Construction of TiO2 nanotube clusters on Ti mesh for immobilizing Sb-SnO2 to boost electrocatalytic phenol degradation, J. Hazard. Mater. 393 (2020). doi:10.1016/j.jhazmat.2020.122329.

[236] S. Begum, M. Ahmaruzzaman, CTAB and SDS assisted facile fabrication of $\mathrm{SnO} 2$ nanoparticles for effective degradation of carbamazepine from aqueous phase: A systematic and comparative study of their degradation performance, Water Res. 129 (2018) 470-485. doi:10.1016/j.watres.2017.11.031.

[237] C. Zhou, Y. Wang, J. Chen, L. Xu, H. Huang, J. Niu, High-efficiency electrochemical degradation of antiviral drug abacavir using a penetration flux porous Ti/SnO2-Sb anode, Chemosphere. 225 (2019) 304-310. doi:10.1016/j.chemosphere.2019.03.036.

[238] Y. Wang, H. Duan, Z. Pei, L. Xu, Hydrothermal synthesis of 3D hierarchically flower-like structure Ti/SnO2$\mathrm{Sb}$ electrode with long service life and high electrocatalytic performance, 2019. doi:10.1016/j.jelechem.2019.113635.

[239] J. Wu, K. Zhu, H. Xu, W. Yan, Electrochemical oxidation of rhodamine B by PbO2/Sb-SnO2/TiO2 nanotube arrays electrode, Chinese J. Catal. 40 (2019) 917-927. doi:10.1016/S1872-2067(19)63342-5.

[240] B. Yang, J. Wang, C. Jiang, J. Li, G. Yu, S. Deng, S. Lu, P. Zhang, C. Zhu, Q. Zhuo, Electrochemical mineralization of perfluorooctane sulfonate by novel $\mathrm{F}$ and $\mathrm{Sb}$ co-doped $\mathrm{Ti} / \mathrm{SnO} 2$ electrode containing $\mathrm{Sn}-\mathrm{Sb}$ interlayer, Chem. Eng. J. 316 (2017) 296-304. doi:10.1016/j.cej.2017.01.105.

[241] L. Zhang, L. Xu, J. He, J. Zhang, Preparation of Ti/SnO2-Sb electrodes modified by carbon nanotube for anodic oxidation of dye wastewater and combination with nanofiltration, Electrochim. Acta. 117 (2014) 192201. doi:10.1016/j.electacta.2013.11.117.

[242] W. Wang, X. Duan, X. Sui, Q. Wang, F. Xu, L. Chang, Surface characterization and electrochemical properties of $\mathrm{PbO} 2 / \mathrm{SnO} 2$ composite anodes for electrocatalytic oxidation of m-nitrophenol, Electrochim. Acta. 335 (2020) 135649. doi:10.1016/j.electacta.2020.135649.

[243] X. Duan, X. Sui, W. Wang, W. Bai, L. Chang, Fabrication of PbO2/SnO2 composite anode for electrochemical degradation of 3-chlorophenol in aqueous solution, Appl. Surf. Sci. 494 (2019) 211-222. doi:10.1016/j.apsusc.2019.07.161. 
[244] Q. Wang, T. Jin, Z. Hu, L. Zhou, M. Zhou, TiO2-NTs/SnO2-Sb anode for efficient electrocatalytic degradation of organic pollutants: Effect of TiO2-NTs architecture, Sep. Purif. Technol. 102 (2013) 180-186. doi:10.1016/j.seppur.2012.10.006.

[245] X. Zhou, S. Liu, H. Yu, A. Xu, J. Li, X. Sun, J. Shen, W. Han, L. Wang, Electrochemical oxidation of pyrrole, pyrazole and tetrazole using a $\mathrm{TiO} 2$ nanotubes based $\mathrm{SnO} 2-\mathrm{Sb} / 3 \mathrm{D}$ highly ordered macro-porous $\mathrm{PbO} 2$ electrode, J. Electroanal. Chem. 826 (2018) 181-190. doi:10.1016/j.jelechem.2018.08.039.

[246] Q. Dai, J. Zhou, X. Meng, D. Feng, C. Wu, J. Chen, Electrochemical oxidation of cinnamic acid with Mo modified $\mathrm{PbO} 2$ electrode: Electrode characterization, kinetics and degradation pathway, Chem. Eng. J. 289 (2016) 239-246. doi:10.1016/j.cej.2015.12.054.

[247] C. Tan, B. Xiang, Y. Li, J. Fang, M. Huang, Preparation and characteristics of a nano-PbO2 anode for organic wastewater treatment, Chem. Eng. J. 166 (2011) 15-21. doi:10.1016/j.cej.2010.08.018.

[248] F. Sopaj, N. Oturan, J. Pinson, F. Podvorica, M.A. Oturan, Effect of the anode materials on the efficiency of the electro-Fenton process for the mineralization of the antibiotic sulfamethazine, Appl. Catal. B Environ. 199 (2016) 331-341. doi:10.1016/j.apcatb.2016.06.035.

[249] S. El-Kacemi, H. Zazou, N. Oturan, M. Dietze, M. Hamdani, M. Es-Souni, M.A. Oturan, Nanostructured ZnO$\mathrm{TiO} 2$ thin film oxide as anode material in electrooxidation of organic pollutants. Application to the removal of dye Amido black 10B from water, Environ. Sci. Pollut. Res. 24 (2017) 1442-1449. doi:10.1007/s11356016-7920-6.

[250] J. Wang, D. Zhi, H. Zhou, X. He, D. Zhang, Evaluating tetracycline degradation pathway and intermediate toxicity during the electrochemical oxidation over a Ti/Ti4O7 anode, Water Res. 137 (2018) 324-334. doi:10.1016/j.watres.2018.03.030.

[251] L. Guo, Y. Jing, B.P. Chaplin, Development and characterization of ultrafiltration TiO2 magnéli phase reactive electrochemical membranes, Environ. Sci. Technol. 50 (2016) 1428-1436. doi:10.1021/acs.est.5b04366.

[252] S.O. Ganiyu, N. Oturan, S. Raffy, M. Cretin, R. Esmilaire, E. van Hullebusch, G. Esposito, M.A. Oturan, Substoichiometric titanium oxide (Ti407) as a suitable ceramic anode for electrooxidation of organic pollutants: A case study of kinetics, mineralization and toxicity assessment of amoxicillin, Water Res. 106 (2016) 171182. doi:10.1016/j.watres.2016.09.056. 
[253] S.O. Ganiyu, N. Oturan, S. Raffy, M. Cretin, C. Causserand, M.A. Oturan, Efficiency of plasma elaborated sub-stoichiometric titanium oxide (Ti4O7) ceramic electrode for advanced electrochemical degradation of paracetamol in different electrolyte media, Sep. Purif. Technol. 208 (2019) 142-152. doi:10.1016/j.seppur.2018.03.076.

[254] W. Yang, N. Oturan, S. Raffy, M. Zhou, M.A. Oturan, Electrocatalytic generation of homogeneous and heterogeneous hydroxyl radicals for cold mineralization of anti-cancer drug Imatinib, Chem. Eng. J. 383 (2020) 123155. doi:10.1016/j.cej.2019.123155.

[255] L. Gan, Y. Wu, H. Song, C. Lu, S. Zhang, A. Li, Self-doped TiO2 nanotube arrays for electrochemical mineralization of phenols, Chemosphere. 226 (2019) 329-339. doi:10.1016/j.chemosphere.2019.03.135.

[256] G.G. Bessegato, F.F. Hudari, M.V.B. Zanoni, Self-doped TiO2 nanotube electrodes: A powerful tool as a sensor platform for electroanalytical applications, Electrochim. Acta. 235 (2017) 527-533. doi:10.1016/j.electacta.2017.03.141.

[257] J. Han, H. Choi, G. Lee, Y. Tak, J. Yoon, Electrochemical activity of a blue anatase TiO2 nanotube array for the oxygen evolution reaction in alkaline water electrolysis, J. Electrochem. Sci. Technol. 7 (2016) 76-81. doi:10.5229/JECST.2016.7.1.76.

[258] W.D. Zhu, C.W. Wang, J.B. Chen, Y. Li, J. Wang, Enhanced field emission from Ti 3+ self-doped TiO 2 nanotube arrays synthesized by a facile cathodic reduction process, Appl. Surf. Sci. 301 (2014) 525-529. doi:10.1016/j.apsusc.2014.02.116.

[259] C. Kim, S. Lee, S. Kim, J. Yoon, Effect of Annealing Temperature on the Capacitive and Oxidant-generating Properties of an Electrochemically Reduced TiO2 Nanotube Array, Electrochim. Acta. 222 (2016) 1578-1584. doi:10.1016/j.electacta.2016.11.143.

[260] A. Zhang, F. Gong, Y. Xiao, X. Guo, F. Li, L. Wang, Y. Zhang, L. Zhang, Electrochemical Reductive Doping and Interfacial Impedance of TiO 2 Nanotube Arrays in Aqueous and Aprotic Solvents, J. Electrochem. Soc. 164 (2017) H91-H96. doi:10.1149/2.1231702jes.

[261] C. Kim, S. Kim, J. Choi, J. Lee, J.S. Kang, Y.E. Sung, J. Lee, W. Choi, J. Yoon, Blue TiO2 nanotube array as an oxidant generating novel anode material fabricated by simple cathodic polarization, Electrochim. Acta. 141 (2014) 113-119. doi:10.1016/j.electacta.2014.07.062. 
[262] X. Chang, S.S. Thind, A. Chen, Electrocatalytic enhancement of salicylic acid oxidation at electrochemically reduced TiO2 nanotubes, ACS Catal. 4 (2014) 2616-2622. doi:10.1021/cs500487a.

[263] S.H. Li, Y. Zhao, J. Chu, W.W. Li, H.Q. Yu, G. Liu, Electrochemical degradation of methyl orange on PtBi/C nanostructured electrode by a square-wave potential method, Electrochim. Acta. 92 (2013) 93-101. doi:10.1016/j.electacta.2013.01.012.

[264] Y. Chen, G. Zhang, J. Ma, Y. Zhou, Y. Tang, T. Lu, Electro-oxidation of methanol at the different carbon materials supported Pt nano-particles, Int. J. Hydrogen Energy. 35 (2010) 10109-10117. doi:10.1016/j.jhydene.2010.07.170.

[265] T.P. Tsele, A.S. Adekunle, O.E. Fayemi, E.E. Ebenso, Electrochemical detection of epinephrine using polyaniline nanocomposite films doped with $\mathrm{TiO} 2$ and $\mathrm{RuO} 2$ nanoparticles on multi-walled carbon nanotube, Electrochim. Acta. 243 (2017) 331-348. doi:10.1016/j.electacta.2017.05.031.

[266] D. Li, X. Guo, H. Song, T. Sun, J. Wan, Preparation of RuO2-TiO2/Nano-graphite composite anode for electrochemical degradation of ceftriaxone sodium, J. Hazard. Mater. 351 (2018) 250-259. doi:10.1016/j.jhazmat.2018.03.007.

[267] M.A. Oturan, J.-J. Aaron, Advanced oxidation processes in water/wastewater treatment: principles and applications. A review, Crit. Rev. Environ. Sci. Technol. 44 (2014) 2577-2641. doi:10.1080/10643389.2013.829765.

[268] S.O. Ganiyu, M. Zhou, C.A. Martínez-huitle, Heterogeneous electro-Fenton and photoelectro-Fenton processes : A critical review of fundamental principles and application for water / wastewater treatment, Appl. Catal. B Environ. 235 (2018) 103-129. doi:10.1016/j.apcatb.2018.04.044.

[269] H. Monteil, Y. Péchaud, N. Oturan, M.A. Oturan, A review on efficiency and cost effectiveness of electroand bio-electro-Fenton processes: Application to the treatment of pharmaceutical pollutants in water, Chem. Eng. J. 376 (2019) 119577. doi:10.1016/j.cej.2018.07.179.

[270] M.A. Oturan, P. V. Nidheesh, M. Zhou, Electrochemical advanced oxidation processes for the abatement of persistent organic pollutants, Chemosphere. 209 (2018) 17-19. doi:10.1016/j.chemosphere.2018.06.049.

[271] W.H. Glaze, J. Kang, D.H. Chapin, The chemistry of water treatment processes involving ozone, hydrogen peroxide and ultraviolet radiation, Ozone Sci. Eng. 9 (1987) 335-352. doi:10.1080/01919518708552148. 
[272] N. Oturan, M.A. Oturan, Electro-Fenton Process: Background, New Developments, and Applications, Electrochem. Water Wastewater Treat. (2018) 193-221. doi:10.1016/B978-0-12-813160-2.00008-0.

[273] M. Zhou, M.A. Oturan, I. Sirés, Electro-fenton process : new trends and scale-up, in: Handb. Environ. Chem., Springer Singapore, 2018: p. 430.

[274] H.J.H. Fenton, Oxidation of tartatic acid in presence of iron, J. Chem. Soc. Trans. 65 (1894) 899-910.

[275] F. Haber, J. Weiss, P.R.S.L. A, The catalytic decomposition of hydrogen peroxide by iron salts, Proc. R. Soc. London. Ser. A - Math. Phys. Sci. 147 (1934) 332-351. doi:10.1098/rspa.1934.0221.

[276] J.J. Pignatello, E. Oliveros, A. MacKay, Advanced oxidation processes for organic contaminant destruction based on the fenton reaction and related chemistry, Crit. Rev. Environ. Sci. Technol. 36 (2006) 1-84. doi:10.1080/10643380500326564.

[277] B. Jain, A. Kumar, S. Hyunook, K. Eric, L. Virender, Treatment of organic pollutants by homogeneous and heterogeneous Fenton reaction processes, Environ. Chem. Lett. (2018). doi:10.1007/s10311-018-0738-3.

[278] E. Brillas, R.M. Bastida, E. Llosa, J. Casado, Electrochemical destruction of aniline and 4-chloroaniline for wastewater treatment using a carbon-PTFE O2-Fed cathode, J. Electrochem. Soc. 142 (1995) 1733-1741. doi:10.1149/1.2044186.

[279] M.A. Oturan, J. Pinson, Hydroxylation by electrochemically generated $\mathrm{OH} \bullet$ radicals. Mono- and polyhydroxylation of benzoic acid: Products and isomers' distribution, J. Phys. Chem. 99 (1995) 1394813954. doi:10.1021/j100038a029.

[280] M.A. Oturan, An ecologically effective water treatment technique using electrochemically generated hydroxyl radicals for in situ destruction of organic pollutants : Application to herbicide 2, 4-D, (2000) 475-482.

[281] P.V. Nidheesh, R. Gandhimathi, Trends in electro-Fenton process for water and wastewater treatment: An overview, Desalination. 299 (2012) 1-15. doi:10.1016/j.desal.2012.05.011.

[282] M.A. Oturan, J. Pinson, J. Bizot, D. Deprez, B. Terlain, Reaction of inflammation inhibitors with chemically and electrochemically generated hydroxyl radicals, J. Electroanal. Chem. 334 (1992) 103-109. doi:10.1016/0022-0728(92)80563-J.

[283] A. Özcan, Y. Şahin, A. Savaş Koparal, M.A. Oturan, Carbon sponge as a new cathode material for the electroFenton process: Comparison with carbon felt cathode and application to degradation of synthetic dye basic 
blue 3 in aqueous medium, J. Electroanal. Chem. 616 (2008) 71-78. doi:10.1016/j.jelechem.2008.01.002.

[284] A. Wang, J. Qu, J. Ru, H. Liu, J. Ge, Mineralization of an azo dye Acid Red 14 by electro-Fenton's reagent using an activated carbon fiber cathode, Dye. Pigment. 65 (2005) 227-233. doi:10.1016/j.dyepig.2004.07.019.

[285] A. da Pozzo, L. di Palma, C. Merli, E. Petrucci, An experimental comparison of a graphite electrode and a gas diffusion electrode for the cathodic production of hydrogen peroxide, J. Appl. Electrochem. 35 (2005) 413419. doi:10.1007/s10800-005-0800-2.

[286] P.V. Nidheesh, R. Gandhimathi, N.S. Sanjini, NaHCO3 enhanced Rhodamine B removal from aqueous solution by graphite-graphite electro Fenton system, Sep. Purif. Technol. 132 (2014) 568-576. doi:10.1016/j.seppur.2014.06.009.

[287] J. Fu, X. Zhang, L. Lei, Fe-modified multi-walled carbon nanotube electrode for production of hydrogen peroxide, Acta Phys. - Chim. Sin. 23 (2007) 1157-1162. doi:10.1016/S1872-1508(07)60060-6.

[288] Y. Wang, H. Zhao, G. Zhao, Highly ordered mesoporous Fe3O4@Carbon embedded composite: High catalytic activity, wide pH range and stability for heterogeneous electro-Fenton, Electroanalysis. 28 (2016) 169-176. doi:10.1002/elan.201500488.

[289] E. Rosales, G. Buftia, M. Pazos, G. Lazar, M.A. Sanromán, Highly active based iron-carbonaceous cathodes for heterogeneous electro-Fenton process: Application to degradation of parabens, Process Saf. Environ. Prot. 117 (2018) 363-371. doi:10.1016/j.psep.2018.05.014.

[290] S.O. Ganiyu, T.X. Huong Le, M. Bechelany, N. Oturan, S. Papirio, G. Esposito, E. van Hullebusch, M. Cretin, M.A. Oturan, Electrochemical mineralization of sulfamethoxazole over wide $\mathrm{pH}$ range using FeIIFeIII LDH modified carbon felt cathode: Degradation pathway, toxicity and reusability of the modified cathode, Chem. Eng. J. 350 (2018) 844-855. doi:10.1016/j.cej.2018.04.141.

[291] W. Yang, M. Zhou, N. Oturan, M. Bechelany, M. Cretin, M.A. Oturan, Highly efficient and stable FeIIFeIII LDH carbon felt cathode for removal of pharmaceutical ofloxacin at neutral pH, J. Hazard. Mater. 393 (2020) 122513. doi:10.1016/j.jhazmat.2020.122513.

[292] M. Ghasemi, A. Khataee, P. Gholami, R.D.C. Soltani, A. Hassani, Y. Orooji, In-situ electro-generation and activation of hydrogen peroxide using a CuFeNLDH-CNTs modified graphite cathode for degradation of cefazolin, J. Environ. Manage. 267 (2020) 110629. doi:10.1016/j.jenvman.2020.110629. 
[293] M. Ranjbar, N. Majidian, M. Samipourgiri, Heterogeneous electro-Fenton process by MWCNT-Ce/WO3 nanocomposite modified GF cathode for catalytic degradation of BTEX: Process optimization using response surface methodology, Electrocatalysis. 10 (2019) 628-642. doi:10.1007/s12678-019-00550-5.

[294] X. Mi, J. Han, Y. Sun, Y. Li, W. Hu, S. Zhan, Enhanced catalytic degradation by using RGO-Ce/WO3 nanosheets modified CF as electro-Fenton cathode: Influence factors, reaction mechanism and pathways, J. Hazard. Mater. 367 (2019) 365-374. doi:10.1016/j.jhazmat.2018.12.074.

[295] A. Thiam, M. Zhou, E. Brillas, I. Sirés, Two-step mineralization of Tartrazine solutions: Study of parameters and by-products during the coupling of electrocoagulation with electrochemical advanced oxidation processes, Appl. Catal. B Environ. 150-151 (2014) 116-125. doi:10.1016/j.apcatb.2013.12.011.

[296] E. Brillas, C.A. Martínez-Huitle, Decontamination of wastewaters containing synthetic organic dyes by electrochemical methods. An updated review, Appl. Catal. B Environ. 166-167 (2015) 603-643. doi:10.1016/j.apcatb.2014.11.016.

[297] A. Kraft, Doped diamond: A compact review on a new, versatile electrode material, Int. J. Electrochem. Sci. 2 (2007) 355-385.

[298] A. Kapalka, H. Baltruschat, C. Comninellis, Electrochemical oxidation of organic compounds induced by electro-generated free hydroxyl radicals on BDD electrodes, in: E. Brillas, C.A. Martinez-Huitle (Eds.), Synth. Diam. Film. Prep. Electrochem. Charact. Appl., Wiley, Hoboken/New Jersey, 2011.

[299] E. Guivarch, N. Oturan, M.A. Oturan, Removal of organophosphorus pesticides from water by electrogenerated Fenton's reagent, Environ. Chem. Lett. 1 (2003) 165-168. doi:10.1007/s10311-003-0029-4.

[300] N. Oturan, E.D. Van Hullebusch, H. Zhang, L. Mazeas, H. Budzinski, K. Le Menach, M.A. Oturan, Occurrence and removal of organic micropollutants in landfill leachates treated by electrochemical advanced oxidation processes, Environ. Sci. Technol. 49 (2015) 12187-12196. doi:10.1021/acs.est.5b02809.

[301] L. Labiadh, M.A. Oturan, M. Panizza, N. Ben Hamadi, S. Ammar, Complete removal of AHPS synthetic dye from water using new electro-fenton oxidation catalyzed by natural pyrite as heterogeneous catalyst, J. Hazard. Mater. 297 (2015) 34-41. doi:10.1016/j.jhazmat.2015.04.062.

[302] P. V. Nidheesh, Heterogeneous Fenton catalysts for the abatement of organic pollutants from aqueous solution: A review, RSC Adv. 5 (2015) 40552-40577. doi:10.1039/c5ra02023a. 
[303] N. Barhoumi, N. Oturan, H. Olvera-Vargas, E. Brillas, A. Gadri, S. Ammar, M.A. Oturan, Pyrite as a sustainable catalyst in electro-Fenton process for improving oxidation of sulfamethazine. Kinetics, mechanism and toxicity assessment, Water Res. 94 (2016) 52-61. doi:10.1016/j.watres.2016.02.042.

[304] H. Jiang, Y. Sun, J. Feng, J. Wang, Heterogeneous electro-Fenton oxidation of azo dye methyl orange catalyzed by magnetic Fe3O4 nanoparticles, Water Sci. Technol. 74 (2016) 1116-1126. doi:10.2166/wst.2016.300.

[305] Z. Ye, E. Brillas, F. Centellas, P.L. Cabot, I. Sirés, Expanding the application of photoelectro-Fenton treatment to urban wastewater using the Fe(III)-EDDS complex, Water Res. 169 (2020) 115219. doi:10.1016/j.watres.2019.115219.

[306] A. Lahkimi, M.A. Oturan, N. Oturan, M. Chaouch, Removal of textile dyes from water by the electro-Fenton process, Environ. Chem. Lett. 5 (2007) 35-39. doi:10.1007/s10311-006-0058-x.

[307] O. Iglesias, J. Gómez, M. Pazos, M.Á. Sanromán, Electro-Fenton oxidation of imidacloprid by Fe alginate gel beads, Appl. Catal. B Environ. 144 (2014) 416-424. doi:10.1016/j.apcatb.2013.07.046.

[308] M. Panizza, M.A. Oturan, Degradation of Alizarin Red by electro-Fenton process using a graphite-felt cathode, Electrochim. Acta. 56 (2011) 7084-7087. doi:10.1016/j.electacta.2011.05.105.

[309] M. Diagne, V.K. Sharma, N. Oturan, M.A. Oturan, Depollution of indigo dye by anodic oxidation and electroFenton using B-doped diamond anode, Environ. Chem. Lett. 12 (2014) 219-224. doi:10.1007/s10311-0130437-z.

[310] E. Brillas, S. Garcia-Segura, Benchmarking recent advances and innovative technology approaches of Fenton, photo-Fenton, electro-Fenton, and related processes: A review on the relevance of phenol as model molecule, Sep. Purif. Technol. 237 (2020) 116337. doi:10.1016/j.seppur.2019.116337.

[311] S. Garcia-Segura, J. a Garrido, R.M. Rodríguez, P.L. Cabot, F. Centellas, C. Arias, E. Brillas, Mineralization of flumequine in acidic medium by electro-Fenton and photoelectro-Fenton processes., Water Res. 46 (2012) 2067-76. doi:10.1016/j.watres.2012.01.019.

[312] H. Zazou, N. Oturan, M. Sönmez-Çelebi, M. Hamdani, M.A. Oturan, Mineralization of chlorobenzene in aqueous medium by anodic oxidation and electro-Fenton processes using Pt or BDD anode and carbon felt cathode, J. Electroanal. Chem. 774 (2016) 22-30. doi:10.1016/j.jelechem.2016.04.051. 
[313] H. Monteil, Y. Pechaud, N. Oturan, C. Trellu, M.A. Oturan, Pilot scale continuous reactor for water treatment by electrochemical advanced oxidation processes: Development of a new hydrodynamic / reactive combined model, Chem. Eng. J. 404 (2020) 127048. doi:10.1016/j.cej.2020.127048.

[314] N. Oturan, J. Wu, H. Zhang, V.K. Sharma, M.A. Oturan, Electrocatalytic destruction of the antibiotic tetracycline in aqueous medium by electrochemical advanced oxidation processes: Effect of electrode materials, Appl. Catal. B Environ. 140-141 $\quad$ (2013) 92-97. doi:http://dx.doi.org/doi:10.1016/j.apcatb.2013.03.035.

[315] E. Mousset, S. Pontvianne, M.-N. Pons, Fate of inorganic nitrogen species under homogeneous Fenton combined with electro-oxidation/reduction treatments in synthetic solutions and reclaimed municipal wastewater, Chemosphere. 201 (2018) 6-12. doi:10.1016/j.chemosphere.2018.02.142.

[316] E. Mousset, L. Quackenbush, C. Schondek, A. Gerardin-Vergne, S. Pontvianne, S. Kmiotek, M.N. Pons, Effect of homogeneous Fenton combined with electron transfer on the fate of inorganic chlorinated species in synthetic and reclaimed municipal wastewater, Electrochim. Acta. $334 \quad$ (2020) 135608. doi:10.1016/j.electacta.2019.135608.

[317] E. Mousset, L. Frunzo, G. Esposito, E.D. V Hullebusch, N. Oturan, M.A. Oturan, A complete phenol oxidation pathway obtained during electro-Fenton treatment and validated by a kinetic model study, Appl. Catal. B Environ. (2016). doi:10.1016/j.apcatb.2015.06.014.

[318] A. Kapałka, G. Fóti, C. Comninellis, The importance of electrode material in environmental electrochemistry Formation and reactivity of free hydroxyl radicals on boron-doped diamond electrodes, Electrochim. Acta. 54 (2009) 2018-2023. doi:10.1016/j.electacta.2008.06.045.

[319] J. Radjenovic, D.L. Sedlak, Challenges and opportunities for electrochemical processes as next-generation technologies for the treatment of contaminated water, Environ. Sci. Technol. 49 (2015) 11292-11302. doi:10.1021/acs.est.5b02414.

[320] P. Cañizares, I.F. De Marcos, M.A. Rodrigo, J. Lobato, Measurement of Mass-Transfer Coefficients by an Electrochemical Technique, J. Chem. Educ. 83 (2006) 1204-1207. doi:10.1021/ed083p1204.

[321] E. Mousset, M. Puce, M.N. Pons, Advanced electro-oxidation with boron-doped diamond for acetaminophen removal from real wastewater in a microfluidic reactor: Kinetics and mass-transfer studies, 
ChemElectroChem. 6 (2019) 2908-2916. doi:10.1002/celc.201900182.

[322] C. Trellu, C. Coetsier, J.-C. Rouch, R. Esmilaire, M. Rivallin, M. Cretin, C. Causserand, Mineralization of organic pollutants by anodic oxidation using reactive electrochemical membrane synthesized from carbothermal reduction of TiO 2, Water Res. 131 (2018) 310-319. doi:10.1016/j.watres.2017.12.070.

[323] H. Liu, C.D. Vecitis, Reactive transport mechanism for organic oxidation during electrochemical filtration: Mass-transfer, physical adsorption, and electron-transfer, J. Phys. Chem. C. 116 (2012) 374-383. doi:10.1021/jp209390b.

[324] J. Yang, J. Wang, J. Jia, Improvement of electrochemical wastewater treatment through mass transfer in a seepage carbon nanotube electrode reactor, Environ. Sci. Technol. 43 (2009) 3796-3802. doi:10.1021/es8034285.

[325] A.R. Bakr, M.S. Rahaman, Electrochemical efficacy of a carboxylated multiwalled carbon nanotube filter for the removal of ibuprofen from aqueous solutions under acidic conditions, Chemosphere. 153 (2016) 508-520. doi:10.1016/j.chemosphere.2016.03.078.

[326] W. Duan, A. Ronen, S. Walker, D. Jassby, Polyaniline-coated carbon nanotube ultrafiltration membranes: Enhanced anodic stability for in situ cleaning and electro-oxidation processes, ACS Appl. Mater. Interfaces. 8 (2016) 22574-22584. doi:10.1021/acsami.6b07196.

[327] G. Zhao, P. Li, F. Nong, M. Li, J. Gao, D. Li, Construction and high performance of a novel modified borondoped diamond film electrode endowed with superior electrocatalysis, J. Phys. Chem. C. 114 (2010) 59065913. doi:10.1021/jp909248w.

[328] Y. Jiang, Z. Hu, M. Zhou, L. Zhou, B. Xi, Efficient degradation of p-nitrophenol by electro-oxidation on Fe doped $\mathrm{Ti} / \mathrm{TiO} 2$ nanotube/PbO2 anode, $\quad$ Sep. Purif. $\quad$ Technol. 128 (2014) 67-71. doi:10.1016/j.seppur.2014.03.015.

[329] Z. Hu, M. Zhou, L. Zhou, Y. Li, C. Zhang, Effect of matrix on the electrochemical characteristics of $\mathrm{TiO}_{2}$ nanotube array-based $\mathrm{PbO}_{2}$ electrode for pollutant degradation., Environ. Sci. Pollut. Res. Int. 21 (2014) 847684. doi:10.1007/s11356-014-2792-0.

[330] X. Guo, D. Li, J. Wan, X. Yu, Preparation and electrochemical property of TiO2/Nano-graphite composite anode for electro-catalytic degradation of ceftriaxone sodium, Electrochim. Acta. 180 (2015) 957-964. 
doi:10.1016/j.electacta.2015.09.055.

[331] Y. Yang, M.R. Hoffmann, Synthesis and stabilization of blue-black TiO2 nanotube arrays for electrochemical oxidant generation and wastewater treatment, Environ. Sci. Technol. 50 (2016) 11888-11894. doi:10.1021/acs.est.6b03540.

[332] S. Nayak, B.P. Chaplin, Fabrication and characterization of porous, conductive, monolithic Ti4O7 electrodes, Electrochim. Acta. 263 (2018) 299-310. doi:10.1016/j.electacta.2018.01.034.

[333] A.M. Zaky, B.P. Chaplin, Porous substoichiometric TiO2 anodes as reactive electrochemical membranes for water treatment, Environ. Sci. Technol. 47 (2013) 6554-6563. doi:10.1021/es401287e.

[334] Y. Jing, S. Almassi, S. Mehraeen, R.J. LeSuer, B.P. Chaplin, The roles of oxygen vacancies, electrolyte composition, lattice structure, and doping density on the electrochemical reactivity of Magnéli phase TiO2 anodes, J. Mater. Chem. A. 6 (2018) 23828-23839. doi:10.1039/c8ta03719a.

[335] R. Salazar, E. Brillas, I. Sirés, Finding the best Fe2+/Cu2+ combination for the solar photoelectro-Fenton treatment of simulated wastewater containing the industrial textile dye Disperse Blue 3, Appl. Catal. B Environ. 115-116 (2012) 107-116. doi:10.1016/j.apcatb.2011.12.026.

[336] S. Garcia-Segura, R. Salazar, E. Brillas, Mineralization of phthalic acid by solar photoelectro-Fenton with a stirred boron-doped diamond/air-diffusion tank reactor: Influence of $\mathrm{Fe} 3+$ and $\mathrm{Cu} 2+$ catalysts and identification of oxidation products, Electrochim. Acta. $113 \quad$ (2013) 609-619. doi:10.1016/j.electacta.2013.09.097.

[337] S. Garcia-Segura, E. Brillas, Mineralization of the recalcitrant oxalic and oxamic acids by electrochemical advanced oxidation processes using a boron-doped diamond anode., Water Res. 45 (2011) 2975-2984. doi:10.1016/j.watres.2011.03.017.

[338] S. Garcia-Segura, S. Dosta, J.M. Guilemany, E. Brillas, Solar photoelectrocatalytic degradation of Acid Orange 7 azo dye using a highly stable $\mathrm{TiO} 2$ photoanode synthesized by atmospheric plasma spray, Appl. Catal. B Environ. 132-133 (2013) 142-150. doi:10.1016/j.apcatb.2012.11.037.

[339] E. Mousset, D.D. Dionysiou, Photoelectrochemical reactors for treatment of water and wastewater: a review, Environ. Chem. Lett. 18 (2020) 1301-1318. doi:10.1007/s10311-020-01014-9.

[340] R. Oriol, I. Sirés, E. Brillas, A.R. De Andrade, A hybrid photoelectrocatalytic/photoelectro-Fenton treatment 
of Indigo Carmine in acidic aqueous solution using $\mathrm{TiO} 2$ nanotube arrays as photoanode, J. Electroanal. Chem. 847 (2019) 113088. doi:10.1016/j.jelechem.2019.04.048.

[341] B.O. Orimolade, B.N. Zwane, B.A. Koiki, L. Tshwenya, G.M. Peleyeju, N. Mabuba, M. Zhou, O.A. Arotiba, Solar photoelectrocatalytic degradation of ciprofloxacin at a FTO/BiVO4/MnO2 anode: Kinetics, intermediate products and degradation pathway studies, J. Environ. Chem. Eng. 8 (2020) 103607. doi:10.1016/j.jece.2019.103607.

[342] S. Garcia-Segura, E.B. Cavalcanti, E. Brillas, Mineralization of the antibiotic chloramphenicol by solar photoelectro-Fenton. From stirred tank reactor to solar pre-pilot plant., Appl. Catal. B Environ. 144 (2014) 588-598. doi:10.1016/j.apcatb.2013.07.071.

[343] C. Espinoza, J. Romero, L. Villegas, L. Cornejo-Ponce, R. Salazar, Mineralization of the textile dye acid yellow 42 by solar photoelectro-Fenton in a lab-pilot plant, J. Hazard. Mater. 319 (2016) 24-33. doi:10.1016/j.jhazmat.2016.03.003.

[344] K. Barbari, R. Delimi, Z. Benredjem, S. Saaidia, A. Djemel, T. Chouchane, N. Oturan, M.A. Oturan, Photocatalytically-assisted electrooxidation of herbicide fenuron using a new bifunctional electrode PbO2/SnO2-Sb2O3/Ti//Ti/TiO2, Chemosphere. 203 (2018) 1-10. doi:10.1016/j.chemosphere.2018.03.126.

[345] I. Sirés, E. Brillas, The use of nanomaterials in electro-Fenton and photoelectro-Fenton processes, in: J. Filip, T. Cajthaml, P. Najmanová, M. Černík, R. Zbořil (Eds.), Adv. Nano-Bio Technol. Water Soil Treat., Springer International Publishing, 2020: pp. 257-288. doi:https://doi.org/10.1007/978-3-030-29840-1_11.

[346] M.S. Koo, K. Cho, J. Yoon, W. Choi, Photoelectrochemical degradation of organic compounds coupled with molecular hydrogen generation using electrochromic TiO2 nanotube arrays, Environ. Sci. Technol. 51 (2017) 6590-6598. doi:10.1021/acs.est.7b00774.

[347] W. Cui, J. He, H. Wang, J. Hu, L. Liu, Y. Liang, Polyaniline hybridization promotes photo-electro-catalytic removal of organic contaminants over 3D network structure of rGH-PANI/TiO2 hydrogel, Appl. Catal. B Environ. 232 (2018) 232-245. doi:10.1016/j.apcatb.2018.03.069.

[348] X. Ding, Z. Ai, L. Zhang, A dual-cell wastewater treatment system with combining anodic visible light driven photoelectro-catalytic oxidation and cathodic electro-Fenton oxidation, Sep. Purif. Technol. 125 (2014) 103110. doi:10.1016/j.seppur.2014.01.046. 
[349] R. Hernández, I. Olvera-Rodríguez, C. Guzmán, A. Medel, L. Escobar-Alarcón, E. Brillas, I. Sirés, K. Esquivel, Microwave-assisted sol-gel synthesis of an Au-TiO2 photoanode for the advanced oxidation of paracetamol as model pharmaceutical pollutant, Electrochem. Commun. 96 (2018) 42-46. doi:10.1016/j.elecom.2018.09.009.

[350] M.H. Habibi, N. Talebian, J.H. Choi, Characterization and photocatalytic activity of nanostructured indium tin oxide thin-film electrode for azo-dye degradation, Thin Solid Films. 515 (2006) 1461-1469. doi:10.1016/j.tsf.2006.04.037.

[351] B. Gao, C. Peng, G.Z. Chen, G. Li Puma, Photo-electro-catalysis enhancement on carbon nanotubes/titanium dioxide (CNTs/TiO2) composite prepared by a novel surfactant wrapping sol-gel method, Appl. Catal. B Environ. 85 (2008) 17-23. doi:10.1016/j.apcatb.2008.06.027.

[352] Y. Liu, X. Gan, B. Zhou, B. Xiong, J. Li, C. Dong, J. Bai, W. Cai, Photoelectrocatalytic degradation of tetracycline by highly effective TiO2 nanopore arrays electrode, J. Hazard. Mater. 171 (2009) 678-683. doi:10.1016/j.jhazmat.2009.06.054.

[353] X. Zhao, J. Qu, H. Liu, Z. Qiang, R. Liu, C. Hu, Photoelectrochemical degradation of anti-inflammatory pharmaceuticals at Bi2MoO6-boron-doped diamond hybrid electrode under visible light irradiation, Appl. Catal. B Environ. 91 (2009) 539-545. doi:10.1016/j.apcatb.2009.06.025.

[354] X. Zhao, H. Liu, J. Qu, Photoelectrocatalytic degradation of organic contaminant at hybrid BDD-ZnWO4 electrode, Catal. Commun. 12 (2010) 76-79. doi:10.1016/j.catcom.2010.08.013.

[355] T.T. Guaraldo, S.H. Pulcinelli, M.V.B. Zanoni, Influence of particle size on the photoactivity of Ti/TiO2 thin film electrodes, and enhanced photoelectrocatalytic degradation of indigo carmine dye, J. Photochem. Photobiol. A Chem. 217 (2011) 259-266. doi:10.1016/j.jphotochem.2010.10.019.

[356] L. Li, Z. Zhou, J. Lei, J. He, S. Zhang, F. Pan, Highly ordered anodic TiO 2 nanotube arrays and their stabilities as photo(electro)catalysts, Appl. Surf. Sci. 258 (2012) 3647-3651. doi:10.1016/j.apsusc.2011.11.131.

[357] T.T. Guaraldo, T.B. Zanoni, S.I.C. de Torresi, V.R. Gonçales, G.J. Zocolo, D.P. Oliveira, M.V.B. Zanoni, On the application of nanostructured electrodes prepared by $\mathrm{Ti} / \mathrm{TiO} 2 / \mathrm{WO} 3$ " template" : A case study of removing toxicity of indigo using visible irradiation, Chemosphere. 91 (2013) 586-593. doi:10.1016/j.chemosphere.2012.12.027. 
[358] X. Cheng, Q. Cheng, X. Deng, P. Wang, H. Liu, A facile and novel strategy to synthesize reduced TiO2 nanotubes photoelectrode for photoelectrocatalytic degradation of diclofenac, Chemosphere. 144 (2016) 888894. doi:10.1016/j.chemosphere.2015.09.070.

[359] C. Fu, M. Li, H. Li, C. Li, X. guo Wu, B. Yang, Fabrication of Au nanoparticle/TiO2hybrid films for photoelectrocatalytic degradation of methyl orange, J. Alloys Compd. 692 (2017) 727-733. doi:10.1016/j.jallcom.2016.09.119.

[360] E.H. Umukoro, M.G. Peleyeju, J.C. Ngila, O.A. Arotiba, Towards wastewater treatment: Photo-assisted electrochemical degradation of 2-nitrophenol and orange II dye at a tungsten trioxide-exfoliated graphite composite electrode, Chem. Eng. J. 317 (2017) 290-301. doi:10.1016/j.cej.2017.02.084.

[361] B.A. Koiki, O.A. Arotiba, $\mathrm{Cu} 2 \mathrm{O}$ as an emerging semiconductor in photocatalytic and photoelectrocatalytic treatment of water contaminated with organic substances: A review, RSC Adv. 10 (2020) 36514-36525. doi:10.1039/d0ra06858f.

[362] G.M. Peleyeju, E.H. Umukoro, J.O. Babalola, O.A. Arotiba, Solar-light-responsive titanium-sheet-based carbon nanoparticles/B-BiVO4/WO3 photoanode for the photoelectrocatalytic degradation of Orange II dye water pollutant, ACS Omega. 5 (2020) 4743-4750. doi:10.1021/acsomega.9b02148.

[363] K. Changanaqui, E. Brillas, H. Alarcón, I. Sirés, ZnO/TiO2/Ag2Se nanostructures as photoelectrocatalysts for the degradation of oxytetracycline in water, Electrochim. Acta. 331 (2020) 135194. doi:10.1016/j.electacta.2019.135194.

[364] B.O. Orimolade, O.A. Arotiba, Towards visible light driven photoelectrocatalysis for water treatment: Application of a FTO/BiVO4/Ag2S heterojunction anode for the removal of emerging pharmaceutical pollutants, Sci. Rep. 10 (2020) 1-13. doi:10.1038/s41598-020-62425-w.

[365] X. Xu, J. Cai, M. Zhou, X. Du, Y. Zhang, Photoelectrochemical degradation of 2,4-dichlorophenoxyacetic acid using electrochemically self-doped Blue $\mathrm{TiO} 2$ nanotube arrays with formic acid as electrolyte, J. Hazard. Mater. 382 (2020) 121096. doi:10.1016/j.jhazmat.2019.121096.

[366] J.M. Peralta-Hernández, Y. Meas-Vong, F.J. Rodríguez, T.W. Chapman, M.I. Maldonado, L.A. Godínez, In situ electrochemical and photo-electrochemical generation of the fenton reagent: A potentially important new water treatment technology, Water Res. 40 (2006) 1754-1762. doi:10.1016/j.watres.2006.03.004. 
[367] L.C. Almeida, B.F. Silva, M.V.B. Zanoni, Photoelectrocatalytic/photoelectro-Fenton coupling system using a nanostructured photoanode for the oxidation of a textile dye: Kinetics study and oxidation pathway, Chemosphere. 136 (2015) 63-71. doi:10.1016/j.chemosphere.2015.04.042.

[368] Q. Zhou, A. Xing, J. Li, D. Zhao, K. Zhao, M. Lei, Synergistic enhancement in photoelectrocatalytic degradation of bisphenol A by $\mathrm{CeO} 2$ and reduced graphene oxide co-modified $\mathrm{TiO} 2$ nanotube arrays in combination with Fenton oxidation, Electrochim. Acta. $209 \quad$ (2016) 379-388. doi:10.1016/j.electacta.2016.05.094.

[369] B.O. Orimolade, B.N. Zwane, B.A. Koiki, M. Rivallin, M. Bechelany, N. Mabuba, G. Lesage, M. Cretin, O.A. Arotiba, Coupling cathodic electro-fenton with anodic photo-electrochemical oxidation: A feasibility study on the mineralization of paracetamol, J. Environ. Chem. Eng. 8 (2020) 104394. doi:10.1016/j.jece.2020.104394.

[370] X. Zhu, J. Ni, Simultaneous processes of electricity generation and p-nitrophenol degradation in a microbial fuel cell, Electrochem. Commun. 11 (2009) 274-277. doi:10.1016/j.elecom.2008.11.023.

[371] C.-H. Feng, F. Li, H.-J. Mai, X. Li, Bio-electro-Fenton process driven by microbial fuel cell for wastewater treatment, Environ. Sci. Technol. 44 (2010) 1875-1880. doi:10.1021/es9032925.

[372] C. Feng, F. Li, H. Liu, X. Lang, S. Fan, A dual-chamber microbial fuel cell with conductive film-modified anode and cathode and its application for the neutral electro-Fenton process, Electrochim. Acta. 55 (2010) 2048-2054. doi:10.1016/j.electacta.2009.11.033.

[373] N. Oturan, S. Trajkovska, M.A. Oturan, M. Couderchet, J.-J. Aaron, Study of the toxicity of diuron and its metabolites formed in aqueous medium during application of the electrochemical advanced oxidation process “electro-Fenton,” Chemosphere. 73 (2008) 1550-1556. doi:10.1016/j.chemosphere.2008.07.082.

[374] O. Ganzenko, D. Huguenot, E.D. van Hullebusch, G. Esposito, M.A. Oturan, Electrochemical advanced oxidation and biological processes for wastewater treatment: a review of the combined approaches., Environ. Sci. Pollut. Res. Int. 21 (2014) 8493-524. doi:10.1007/s11356-014-2770-6.

[375] H. Olvera-Vargas, N. Oturan, D. Buisson, M.A. Oturan, A coupled Bio-EF process for mineralization of the pharmaceuticals furosemide and ranitidine: Feasibility assessment, Chemosphere. 155 (2016) 606-613. doi:10.1016/j.chemosphere.2016.04.091.

[376] H. Olvera-Vargas, T. Cocerva, N. Oturan, D. Buisson, M.A. Oturan, Bioelectro-Fenton: A sustainable 
integrated process for removal of organic pollutants from water: Application to mineralization of metoprolol, J. Hazard. Mater. 319 (2016) 13-23. doi:10.1016/j.jhazmat.2015.12.010.

[377] I. Oller, S. Malato, J.A. Sánchez-Pérez, Combination of advanced oxidation processes and biological treatments for wastewater decontamination-A review., Sci. Total Environ. 409 (2011) 4141-4166. doi:10.1016/j.scitotenv.2010.08.061.

[378] F. Ferrag-Siagh, F. Fourcade, I. Soutrel, H. Aït-Amar, H. Djelal, A. Amrane, Electro-Fenton pretreatment for the improvement of tylosin biodegradability., Environ. Sci. Pollut. Res. Int. 21 (2014) 8534-42. doi:10.1007/s11356-014-2771-5.

[379] C. Trellu, O. Ganzenko, S. Papirio, Y. Pechaud, N. Oturan, D. Huguenot, E.D. van Hullebusch, G. Esposito, M.A. Oturan, Combination of anodic oxidation and biological treatment for the removal of phenanthrene and Tween 80 from soil washing solution, Chem. Eng. J. 306 (2016) 588-596. doi:10.1016/j.cej.2016.07.108.

[380] O. Ganzenko, C. Trellu, S. Papirio, N. Oturan, D. Huguenot, E.D. van Hullebusch, G. Esposito, M.A. Oturan, Bioelectro-Fenton: evaluation of a combined biological — advanced oxidation treatment for pharmaceutical wastewater, Environ. Sci. Pollut. Res. 25 (2018) 20283-20292. doi:10.1007/s11356-017-8450-6.

[381] A. Dirany, I. Sirés, N. Oturan, A. Özcan, M.A. Oturan, Electrochemical treatment of the antibiotic sulfachloropyridazine: Kinetics, reaction pathways, and toxicity evolution, Environ. Sci. Technol. 46 (2012) 4074-4082. doi:10.1021/es204621q.

[382] E. Mousset, Z. Wang, H. Olvera-Vargas, O. Lefebvre, Advanced electrocatalytic pre-treatment to improve the biodegradability of real wastewater from the electronics industry — A detailed investigation study, J. Hazard. Mater. 360 (2018) 552-559. doi:10.1016/j.jhazmat.2018.08.023.

[383] D. Mansour, F. Fourcade, I. Soutrel, D. Hauchard, N. Bellakhal, A. Amrane, Mineralization of synthetic and industrial pharmaceutical effluent containing trimethoprim by combining electro-Fenton and activated sludge treatment, J. Taiwan Inst. Chem. Eng. 53 (2015) 58-67. doi:10.1016/j.jtice.2015.02.022.

[384] M. Arellano, N. Oturan, M. Pazos, M. Ángeles Sanromán, M.A. Oturan, Coupling electro-Fenton process to a biological treatment, a new methodology for the removal of ionic liquids?, Sep. Purif. Technol. 233 (2020) 115990. doi:10.1016/j.seppur.2019.115990.

[385] M.A. Oturan, I. Sirés, N. Oturan, S. Pérocheau, J.-L. Laborde, S. Trévin, Sonoelectro-Fenton process: A novel 
hybrid technique for the destruction of organic pollutants in water, J. Electroanal. Chem. (2008) 329-332.

[386] H. Li, H. Lei, Q. Yu, Z. Li, X. Feng, B. Yang, Effect of low frequency ultrasonic irradiation on the sonoelectroFenton degradation of cationic red X-GRL, Chem. Eng. J. 160 (2010) 417-422. doi:10.1016/j.cej.2010.03.027.

[387] A. Babuponnusami, K. Muthukumar, Advanced oxidation of phenol: A comparison between Fenton, electroFenton, sono-electro-Fenton and photo-electro-Fenton processes, Chem. Eng. J. 183 (2012) 1-9. doi:10.1016/j.cej.2011.12.010.

[388] P. V. Nidheesh, M. Zhou, M.A. Oturan, An overview on the removal of synthetic dyes from water by electrochemical advanced oxidation processes, Chemosphere. $197 \quad$ (2018) 210-227. doi:10.1016/j.chemosphere.2017.12.195.

[389] J. Casado, Towards industrial implementation of electro-Fenton and derived technologies for wastewater treatment: A review, J. Environ. Chem. Eng. 7 (2019) 102823. doi:10.1016/j.jece.2018.102823.

[390] S.S. Martínez, E.V. Uribe, Enhanced sonochemical degradation of azure B dye by the electro-Fenton process, Ultrason. Sonochem. 19 (2012) 174-178. doi:10.1016/j.ultsonch.2011.05.013.

[391] M. Lounis, M.E. Samar, O. Hamdaoui, Sono-electrochemical degradation of Orange G in pure water, natural water, and seawater: effect of operating parameters, Desalin. Water Treat. 57 (2016) 22533-22542. doi:10.1080/19443994.2015.1129513.

[392] W.S. Chen, C.P. Huang, Decomposition of nitrotoluenes in wastewater by sonoelectrochemical and sonoelectro-Fenton oxidation, Ultrason. Sonochem. 21 (2014) 840-845. doi:10.1016/j.ultsonch.2013.10.026.

[393] R. Nazari, L. Rajic, Y. Xue, W. Zhou, A.N. Alshawabkeh, Degradation of 4-chlorophenol in aqueous solution by sono-electro-Fenton process, Int. J. Electrochem. Sci. 13 (2018) 9214-9230. doi:10.20964/2018.09.46.

[394] S. Ammar, M.A. Oturan, L. Labiadh, A. Guersalli, R. Abdelhedi, N. Oturan, E. Brillas, Degradation of tyrosol by a novel electro-Fenton process using pyrite as heterogeneous source of iron catalyst, Water Res. 74 (2015) 77-87. doi:10.1016/j.watres.2015.02.006.

[395] N. Barhoumi, L. Labiadh, M.A. Oturan, N. Oturan, A. Gadri, S. Ammar, E. Brillas, Electrochemical mineralization of the antibiotic levofloxacin by electro-Fenton-pyrite process, Chemosphere. 141 (2015) 250257. doi:10.1016/j.chemosphere.2015.08.003.

[396] N. Barhoumi, H. Olvera-Vargas, N. Oturan, D. Huguenot, A. Gadri, S. Ammar, E. Brillas, M.A. Oturan, 
Kinetics of oxidative degradation/mineralization pathways of the antibiotic tetracycline by the novel heterogeneous electro-Fenton process with solid catalyst chalcopyrite, Appl. Catal. B Environ. 209 (2017) 637-647. doi:10.1016/j.apcatb.2017.03.034.

[397] N. Barhoumi, N. Oturan, S. Ammar, A. Gadri, M.A. Oturan, E. Brillas, Enhanced degradation of the antibiotic tetracycline by heterogeneous electro-Fenton with pyrite catalysis, Environ. Chem. Lett. 15 (2017) 689-693. doi:10.1007/s10311-017-0638-y.

[398] I. Ouiriemmi, A. Karrab, N. Oturan, M. Pazos, E. Rozales, A. Gadri, M.Á. Sanromán, S. Ammar, M.A. Oturan, Heterogeneous electro-Fenton using natural pyrite as solid catalyst for oxidative degradation of vanillic acid, J. Electroanal. Chem. 797 (2017) 69-77. doi:10.1016/j.jelechem.2017.05.028.

[399] E. Brillas, R. Sauleda, J. Casado, Peroxi-coagulation of Aniline in Acidic Medium Using an Oxygen Diffusion Cathode, J. Electrochem. Soc. 144 (1997) 2374. doi:10.1149/1.1837821.

[400] E. Brillas, J. Casado, Aniline degradation by electro-Fenton ${ }^{\circledR}$ and peroxi-coagulation processes using a flow reactor for wastewater treatment, Chemosphere. 47 (2002) 241-248. doi:10.1016/S0045-6535(01)00221-1.

[401] E. Brillas, B. Boye, M.M. Dieng, Peroxi-coagulation and photoperoxi-coagulation treatments of the herbicide 4-chlorophenoxyacetic acid in aqueous medium using an oxygen-diffusion cathode, J. Electrochem. Soc. 150 (2003) E148-E154. doi:10.1149/1.1543950.

[402] M. Zarei, D. Salari, A. Niaei, A. Khataee, Peroxi-coagulation degradation of C.I. Basic Yellow 2 based on carbon-PTFE and carbon nanotube-PTFE electrodes as cathode, Electrochim. Acta. 54 (2009) 6651-6660. doi:10.1016/j.electacta.2009.06.060.

[403] S. Vasudevan, An efficient removal of phenol from water by peroxi-electrocoagulation processes, J. Water Process Eng. 2 (2014) 53-57. doi:10.1016/j.jwpe.2014.05.002.

[404] I.K. Paton, M. Lemon, B. Freeman, J.D. Newman, Electrochemical peroxidation of contaminated aqueous leachate, J. Appl. Electrochem. 39 (2009) 2593-2596. doi:10.1007/s10800-009-9935-x.

[405] B. Boye, E. Brillas, M.M. Dieng, Electrochemical degradation of the herbicide 4-chloro-2methylphenoxyacetic acid in aqueous medium by peroxi-coagulation and photoperoxi-coagulation, J. Electroanal. Chem. 540 (2003) 25-34. doi:10.1016/S0022-0728(02)01271-8.

[406] B. Boye, M. Marième Dieng, E. Brillas, Electrochemical degradation of 2,4,5-trichlorophenoxyacetic acid in 
aqueous medium by peroxi-coagulation. Effect of pH and UV light, Electrochim. Acta. 48 (2003) 781-790. doi:10.1016/S0013-4686(02)00747-8.

[407] L.M. Ortega, R. Lebrun, J.F. Blais, R. Hausler, P. Drogui, Effectiveness of soil washing, nanofiltration and electrochemical treatment for the recovery of metal ions coming from a contaminated soil, Water Res. 42 (2008) 1943-1952. doi:10.1016/j.watres.2007.11.025.

[408] P. V. Nidheesh, R. Gandhimathi, Effect of solution $\mathrm{pH}$ on the performance of three electrolytic advanced oxidation processes for the treatment of textile wastewater and sludge characteristics, RSC Adv. 4 (2014) 27946-27954. doi:10.1039/c4ra02958e.

[409] D. Venu, R. Gandhimathi, P. V. Nidheesh, S.T. Ramesh, Effect of solution pH on leachate treatment mechanism of peroxicoagulation process, J. Hazardous, Toxic, Radioact. Waste. 20 (2016) 06016001. doi:10.1061/(asce)hz.2153-5515.0000315.

[410] C. Lizama-Bahena, A. Álvarez-Gallegos, J.A. Hernandez, S. Silva-Martinez, Elimination of bio-refractory chlorinated herbicides like atrazine, alachlor, and chlorbromuron from aqueous effluents by Fenton, electroFenton, and peroxi-coagulation methods, Desalin. Water Treat. 55 (2015) 3683-3693. doi:10.1080/19443994.2014.939858.

[411] A. Kumar, P. V. Nidheesh, M. Suresh Kumar, Composite wastewater treatment by aerated electrocoagulation and modified peroxi-coagulation processes, Chemosphere. 205 (2018) 587-593. doi:10.1016/j.chemosphere.2018.04.141.

[412] G. Ren, M. Zhou, Q. Zhang, X. Xu, Y. Li, P. Su, M. Paidar, K. Bouzek, Cost-efficient improvement of coking wastewater biodegradability by multi-stages flow through peroxi-coagulation under low current load, Water Res. 154 (2019) 336-348. doi:10.1016/j.watres.2019.02.013.

[413] X. Zhou, Z. Hou, L. Lv, J. Song, Z. Yin, Electro-Fenton with peroxi-coagulation as a feasible pre-treatment for high-strength refractory coke plant wastewater: Parameters optimization, removal behavior and kinetics analysis, Chemosphere. 238 (2020) 124649. doi:10.1016/j.chemosphere.2019.124649.

[414] T.Y. Nayir, O. Dinc, S. Kara, A. Akyol, A. Dimoglo, Laundry wastewater treatment by peroxi-coagulation, Desalin. Water Treat. 182 (2020) 98-108. doi:10.5004/dwt.2020.25188.

[415] C. Trellu, N. Oturan, F.K. Keita, C. Fourdrin, Y. Pechaud, M.A. Oturan, Regeneration of activated carbon 
fiber by the electro-Fenton process, Environ. Sci. Technol. 52 (2018) 7450-7457. doi:10.1021/acs.est.8b01554.

[416] J. a Bañuelos, F.J. Rodríguez, J. Manríquez Rocha, E. Bustos, A. Rodríguez, J.C. Cruz, L.G. Arriaga, L. a Godínez, Novel electro-Fenton approach for regeneration of activated carbon, Environ. Sci. Technol. 47 (2013) 7927-7933. doi:10.1021/es401320e.

[417] I. Bouaziz, C. Chiron, R. Abdelhedi, A. Savall, K. Groenen Serrano, Treatment of dilute methylene bluecontaining wastewater by coupling sawdust adsorption and electrochemical regeneration, Environ. Sci. Pollut. Res. 21 (2014) 8565-8572. doi:10.1007/s11356-014-2785-z.

[418] M. Muñoz-Morales, C. Sáez, P. Cañizares, M.A. Rodrigo, Improvement of electrochemical oxidation efficiency through combination with adsorption processes, J. Environ. Manage. 262 (2020). doi:10.1016/j.jenvman.2020.110364.

[419] Y. Lan, C. Coetsier, C. Causserand, K.G. Serrano, Feasibility of micropollutants treatment by coupling nanofiltration and electrochemical oxidation: Case of hospital wastewater, Int. J. Chem. React. Eng. 13 (2015) 153-159. doi:10.1515/ijcre-2014-0136.

[420] C. von Sonntag, U. von Gunten, Chemistry of ozone in water and wastewater treatment: From basic principles to applications, IWA Publishing, London, 2012. doi:10.2166/9781780400839.

[421] C. Qu, S. Lu, D. Liang, S. Chen, Y. Xiang, S. Zhang, Simultaneous electro-oxidation and in situ electroperoxone process for the degradation of refractory organics in wastewater, J. Hazard. Mater. 364 (2019) 468474. doi:10.1016/j.jhazmat.2018.10.073.

[422] Y. Wang, G. Yu, S. Deng, J. Huang, B. Wang, The electro-peroxone process for the abatement of emerging contaminants: Mechanisms, recent advances, and prospects, Chemosphere. 208 (2018) 640-654. doi:10.1016/j.chemosphere.2018.05.095.

[423] H. Wang, J. Zhan, W. Yao, B. Wang, S. Deng, J. Huang, G. Yu, Y. Wang, Comparison of pharmaceutical abatement in various water matrices by conventional ozonation, peroxone $(\mathrm{O} 3 / \mathrm{H} 2 \mathrm{O} 2)$, and an electroperoxone process, Water Res. 130 (2018) 127-138. doi:10.1016/j.watres.2017.11.054.

[424] S. Yuan, Z. Li, Y. Wang, Effective degradation of methylene blue by a novel electrochemically driven process, Electrochem. Commun. 29 (2013) 48-51. doi:10.1016/j.elecom.2013.01.012. 
[425] Y.J. Wang, The electro-peroxone technology as a promising advanced oxidation process for water and wastewater, in: M. Zhou, M.A. Oturan, I. Sirés (Eds.), Electro-Fent. Process New Trends Scale-Up, Springer, 2018.

[426] N. Kishimoto, Y. Morita, H. Tsuno, T. Oomura, H. Mizutani, Advanced oxidation effect of ozonation combined with electrolysis, Water Res. 39 (2005) 4661-4672. doi:10.1016/j.watres.2005.09.001.

[427] B. Yang, J. Deng, G. Yu, S. Deng, J. Li, C. Zhu, Q. Zhuo, H. Duan, T. Guo, Effective degradation of carbamazepine using a novel electro-peroxone process involving simultaneous electrochemical generation of ozone and hydrogen peroxide, Electrochem. Commun. 86 (2018) 26-29. doi:10.1016/j.elecom.2017.11.003.

[428] H.S. Zheng, W.Q. Guo, Q.L. Wu, N.Q. Ren, J.S. Chang, Electro-peroxone pretreatment for enhanced simulated hospital wastewater treatment and antibiotic resistance genes reduction, Environ. Int. 115 (2018) 70-78. doi:10.1016/j.envint.2018.02.043.

[429] M. Ghalebizade, B. Ayati, Acid Orange 7 treatment and fate by electro-peroxone process using novel electrode arrangement, Chemosphere. 235 (2019) 1007-1014. doi:10.1016/j.chemosphere.2019.06.211.

[430] O.M. Cornejo, J.L. Nava, Mineralization of the antibiotic levofloxacin by the electro-peroxone process using a filter-press flow cell with a 3D air-diffusion electrode, Sep. Purif. Technol. 254 (2021) 117661. doi:10.1016/j.seppur.2020.117661.

[431] Y. Zhang, S. Zuo, Y. Zhang, M. Li, J. Cai, M. Zhou, Disinfection of simulated ballast water by a flow-through electro-peroxone process, Chem. Eng. J. 348 (2018) 485-493. doi:10.1016/j.cej.2018.04.123.

[432] Y. Zhang, S. Zuo, Y. Zhang, G. Ren, Y. Pan, Q. Zhang, M. Zhou, Simultaneous removal of tetracycline and disinfection by a flow-through electro-peroxone process for reclamation from municipal secondary effluent, J. Hazard. Mater. 368 (2019) 771-777. doi:10.1016/j.jhazmat.2019.02.005.

[433] H.W. Kim, V.J. Bukas, H. Park, S. Park, K.M. Diederichsen, J. Lim, Y.H. Cho, J. Kim, W. Kim, T.H. Han, J. Voss, A.C. Luntz, B.D. McCloskey, Mechanisms of two-electron and four-electron electrochemical oxygen reduction reactions at nitrogen-doped reduced graphene oxide, ACS Catal. 10 (2020) 852-863. doi:10.1021/acscatal.9b04106.

[434] J. Cai, M. Zhou, W. Yang, Y. Pan, X. Lu, K.G. Serrano, Degradation and mechanism of 2,4dichlorophenoxyacetic acid (2,4-D) by thermally activated persulfate oxidation, Chemosphere. 212 (2018) 
784-793. doi:10.1016/j.chemosphere.2018.08.127.

[435] Y.F. Rao, W. Chu, Y.R. Wang, Photocatalytic oxidation of carbamazepine in triclinic-WO3 suspension: Role of alcohol and sulfate radicals in the degradation pathway, Appl. Catal. A Gen. 468 (2013) 240-249. doi:10.1016/j.apcata.2013.08.050.

[436] Z. Liu, S. Yang, Y. Yuan, J. Xu, Y. Zhu, J. Li, F. Wu, A novel heterogeneous system for sulfate radical generation through sulfite activation on a CoFe2O4 nanocatalyst surface, J. Hazard. Mater. 324 (2017) 583592. doi:10.1016/j.jhazmat.2016.11.029.

[437] H. Song, L. Yan, J. Ma, J. Jiang, G. Cai, W. Zhang, Z. Zhang, J. Zhang, T. Yang, Nonradical oxidation from electrochemical activation of peroxydisulfate at Ti/Pt anode: Efficiency, mechanism and influencing factors, Water Res. 116 (2017) 182-193. doi:10.1016/j.watres.2017.03.035.

[438] L. Liang, M. Zhou, X. Lu, P. Su, J. Sun, High-efficiency electrogeneration of hydrogen peroxide from oxygen reduction by carbon xerogels derived from glucose, Electrochim. Acta. 320 (2019) 134569. doi:10.1016/j.electacta.2019.134569.

[439] L. Xu, G. Liang, M. Yin, A promising electrode material modified by Nb-doped TiO2 nanotubes for electrochemical degradation of AR 73, Chemosphere. $173 \quad$ (2017) 425-434. doi:10.1016/j.chemosphere.2017.01.077.

[440] X. Li, H. Xu, W. Yan, Effects of twelve sodium dodecyl sulfate (SDS) on electro-catalytic performance and stability of PbO2 electrode, J. Alloys Compd. 718 (2017) 386-395. doi:10.1016/j.jallcom.2017.05.147.

[441] Y. Yang, L.C. Kao, Y. Liu, K. Sun, H. Yu, J. Guo, S.Y.H. Liou, M.R. Hoffmann, Cobalt-doped black TiO2 nanotube array as a stable anode for oxygen evolution and electrochemical wastewater treatment, ACS Catal. 8 (2018) 4278-4287. doi:10.1021/acscatal.7b04340. 